BNL-52558

PROCEEDINGS OF THE 1999 OIL HEAT TECHNOLOGY CONFERENCE AND WORKSHOP

Held at

BROOKHAVEN NATIONAL LABORATORY UPTON, NEW YORK 11973

April 15-16, 1999

April 1999

Editor

Roger J. McDonald

Sponsored by the

OFFICE OF BUILDING TECHNOLOGY, STATE AND COMMUNITY PROGRAMS UNITED STATES DEPARTMENT OF ENERGY

And co-sponsored by the PETROLEUM MARKETERS ASSOCIATION OF AMERICA, NEW ENGLAND FUEL INSTITUTE, OILHEAT MANUFACTURERS ASSOCIATION, NATIONAL ASSOCIATION Of OIL HEAT SERVICE MANAGERS, NY STATE ENERGY RESEARCH \& DEVELOPMENT AUTHORITY, EMPIRE STATE PETROLEUM ASSOCIATION, NEW YORK OIL HEATING ASSOCIATION, OIL HEAT INSTITUTE OF LONG ISLAND, and PENNSYLVANIA PETROLEUM ASSOCIATION

Under Contract No. DE-AC02-98CH10886 with the UNITED STATES DEPARTMENT OF ENERGY 


\title{
PROCEEDINGS OF THE 1999 OIL HEAT TECHNOLOGY CONFERENCE and WORKSHOP
}

\author{
Held at \\ BROOKHAVEN NATIONAL LABORATORY \\ UPTON, NEW YORK 11973 \\ APRIL 15-16
}

April 1999

Editor

Roger J. McDonald

Sponsored by the

OFFICE OF BUILDING TECHNOLOGY, STATE AND COMMUNITY PROGRAMS UNITED STATES DEPARTMENT OF ENERGY

WASHINGTON, DC 20555

\author{
And co-sponsored by the \\ PETROLEUM MARKETERS ASSOCIATION OF AMERICA, \\ NEW ENGLAND FUEL INSTITUTE, \\ OILHEAT MANUFACTURERS ASSOCIATION, \\ NATIONAL ASSOCIATION Of OIL HEAT SERVICE MANAGERS, \\ NY STATE ENERGY RESEARCH \& DEVELOPMENT AUTHORITY, \\ EMPIRE STATE PETROLEUM ASSOCIATION, \\ NEW YORK OIL HEATING ASSOCIATION, \\ OIL HEAT INSTITUTE of LONG ISLAND, and \\ PENNSYLVANIA PETROLEUM ASSOCIATION
}

ENERGY EFFICIENCY AND CONSERVATION DIVISION DEPARTMENT OF APPLIED SCIENCE BROOKHAVEN NATIONAL LABORATORY BROOKHAVEN SCIENCE ASSOCIATES UPTON, LONG ISLAND, NEW YORK 11973 UNDER CONTRACT NO. DE-AC02-98CH10886 WITH THE UNITED STATES DEPARTMENT OF ENERGY 
Note: The timeliness of the material in this conference proceedings requires prompt publication. Therefore, to expedite publication, these papers have been reproduced directly from the author's manuscripts. The conference sponsors, organizing committee, and staff disclaim any and all responsibilities for the contents of individual papers and abstracts.

\section{DISCLAIMER}

This report was prepared as an account of work sponsored by an agency of the United States Government. Neither the United States Government nor any agency thereof, nor any of their employees, nor any of their contractors, subcontractors, or their employees makes any warranty, express or implied, or assumes any legal liability or responsibility for the accuracy, completeness, or usefulness of any information, apparatus, product, or process disclosed, or represents that its use would not infringe privately owned rights. Reference herein to any specific commercial product, process, or service by trade name, trademark, manufacturer, or otherwise, does not necessarily constitute or imply its endorsement, recommendation, or favoring by the United States Government or any agency, contractor or subcontractor thereof. The views and opinions of authors expressed herein do not necessarily state or reflect those of the United States Government or any agency, contractor, or subcontractor thereof. 
CONFERENCE DEDICATION $\ldots \ldots \ldots \ldots \ldots \ldots \ldots \ldots$ iv 1999 ACKNOWLEDGMENTS $\ldots \ldots \ldots \ldots \ldots \ldots \ldots \ldots \ldots$ v

I. INTRODUCTION $\ldots \ldots \ldots \ldots \ldots \ldots \ldots \ldots \ldots \ldots \ldots \ldots \ldots$

II. TECHNICAL PRESENTATIONS $\ldots \ldots \ldots \ldots \ldots \ldots \ldots \ldots$

Paper No. 99-1 INTEGRATION AND ADVANCED CONTROLS - MEANS TO OPTIMIZE PERFORMANCE AND INCREASE EFFICIENCY OF COMBINED OIL-FIRED HEATING SYSTEMS $\ldots \ldots \ldots \ldots \ldots \ldots \ldots \ldots \ldots \ldots \ldots, 7$

Paper No. $99-2$ THE EUROPEAN BURNER $\ldots \ldots \ldots \ldots \ldots \ldots \ldots \ldots \ldots$

Paper No. 99-3 HIGH-FLOW FAN ATOMIZED OIL BURNER (HFAB)

DEVELOPMENT AND APPLICATION OF HFAB TO DARPA 500 WATT

THERMOPHOTOVOTAIC (TPV) POWER SYSTEM - UPDATE $\ldots \ldots \ldots \ldots$

29

Paper No. 99-4 FAN ATOMIZED OIL BURNER (PIONEER) AND ITS PERFORMANCE UNDER FIELD CONDITIONS $\ldots \ldots \ldots \ldots \ldots \ldots \ldots$

Paper No. 99-5 USE OF NO-DRIP NOZZLE FOR REDUCING EMISSIONS DURING BURNER START-UP AND SHUTDOWN $\ldots \ldots \ldots \ldots \ldots \ldots \ldots$

Paper No. 99-6 FOULING OF HEAT TRANSFER SURFACES IN DOMESTIC OIL FIRED HEATING BOILERS - - PROS AND CONS OF LOWER FUEL SULFUR SPECIFICATIONS IN ASTM NO.2 FUEL OIL $\ldots \ldots \ldots \ldots \ldots \ldots$

Paper No. 99-7 REVIEW OF RECENT TECHNICÁL ACCOMPLISHMENTS BY THE OILHEAT MANUFACTURERS ASSOCIATION $\ldots \ldots \ldots \ldots \ldots$

Paper No. 99-8 ELECTRONIC OPERATIONS MANUAL (EOM) FOR THE OILHEAT/ENERGY SERVICES INDUSTRY $\ldots \ldots \ldots \ldots \ldots \ldots \ldots \ldots \ldots$

Paper No. 99-9 ADVANCED RESIDENTIAL OIL BURNER CONTROL FUNCTIONALITY AND HOW IT EFFECTS OVERALL PERFORMANCE $\ldots \ldots 103$

Paper No. 99-10 ALTERNATE VENTING FOR FOSSIL FUEL FIRED EQUIPMENT

Paper No. 99-11 REPEATABILITY AND REPRODUCIBILITY ERROR IN SMOKE MEASUREMENT: DEVELOPMENT OF A NEW SCALE .........

Paper No. 99-12 OILHEAT TECHNOLOGY EDUCATION NEEDS ANALYSIS, WHERE WE ARE NOW, AND WHERE WE SHOULD BE HEADED ........ 163 


\title{
CONFERENCE DEDICATION
}

\author{
The 1999 Oil Heat Technology Conference and Workshop \\ Is Dedicated In Memory \\ of \\ David Nelsen
}

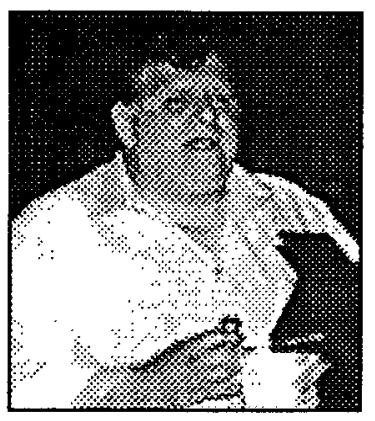

"So many of us who knew Dave Nelsen held a great respect for his commitment to the industry and feel his loss on both a personal and professional level. He was an uncommonly dedicated person who truly loved his work. This quality touched all those who were fortunate enough to come in contact with him and has ensured that he will not be forgotten.

It is the wish of Dave's family and colleagues that his good works for the industry not come to an end because of his passing. Therefore, the "Dave Nelsen Scholarship Fund" is being created and it had already accrued $\$ 6,000.00$ in contributions, even before its official announcement. The scholarship will be an annual endowment, bestowed upon a college or a trade school student who is involved in the Oilheat industry. Each year a new recipient will be chosen based upon review of an essay $\mathrm{s} / \mathrm{he}$ has written, that will detail the way in which the scholarship funds are intended to be used. The best essay will be determined by a consensus among authorized members of the trade magazines, Oilheating, Fuel Oil News and Oil \& Energy (formerly known as Yankee Oil Man)."

Quoted from Bob Boltz (NAOHSM's current president) in a message to members of the National Association of Oil Heat Service Managers which can be found on the NAOHSM web-page at http://www.naohsm.org. If you wish to make a donation see the web-page or contact NAOHSM directly.

Brookhaven National Laboratory had the pleasure of working with Dave Nelson on the PMAA Education Committee where he was a driving force in helping to get the PMAA National Oil Heat Service Technicians's Program started by committing his time and talent to the effort. Two years ago he was an author at the conference and presented a paper about NAOSHM, the Internet and Education within the industry. In Dave was also a member of BNL's Technical Advisory Group which annually reviews the recent progress and future plans for our oil heat research and development program. He was a real contributor to, a supporter of our work and helped in its success and we miss his talent greatly. Dave was a gentleman, a class act all the way and we will not forget him! 


\section{ACKNOWLEDGMENTS}

The 1999 Oil-Heat Technology Conference and Workshop required the dedicated effort of many people to make it successful. The editor of this report would like first to thank the authors for their efforts and splendid cooperation in submitting papers promptly. Secondly, the high quality of the 1999 Oil Heat Technology Conference and Workshop advanced preparations are thanks due to the professional efforts of the BNL conference coordinator: Gail Brown. The BNL staff also wishes to recognize the contributions to our work by our U.S.DoE program manager Esher Kweller and thank him for his leadership. The editor also greatly acknowledges the hard work and effort required by the entire BNL program staff to make this meeting a success. Most of all the staff at BNL wish to thank all of our 1999 Oil Heat Technology Conference and Workshop co-sponsors.

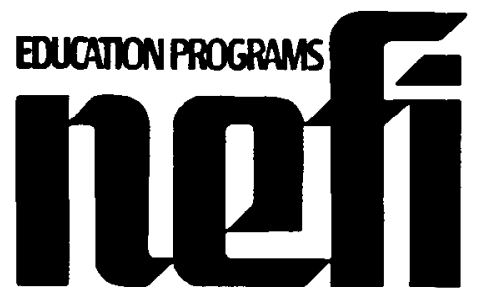

SERVING THE OIL HEAT INDUSTRY
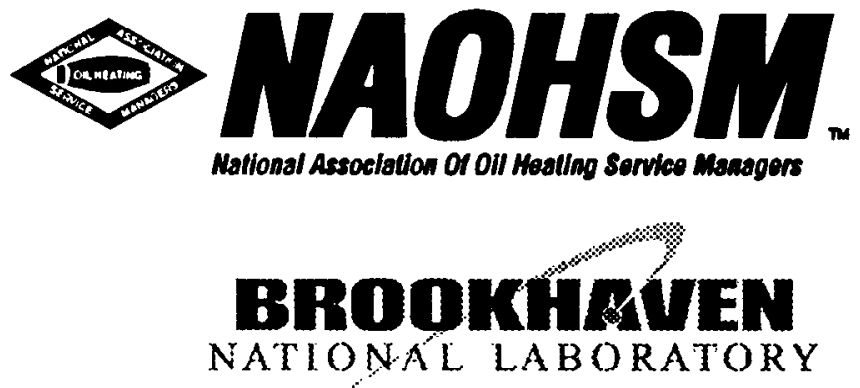
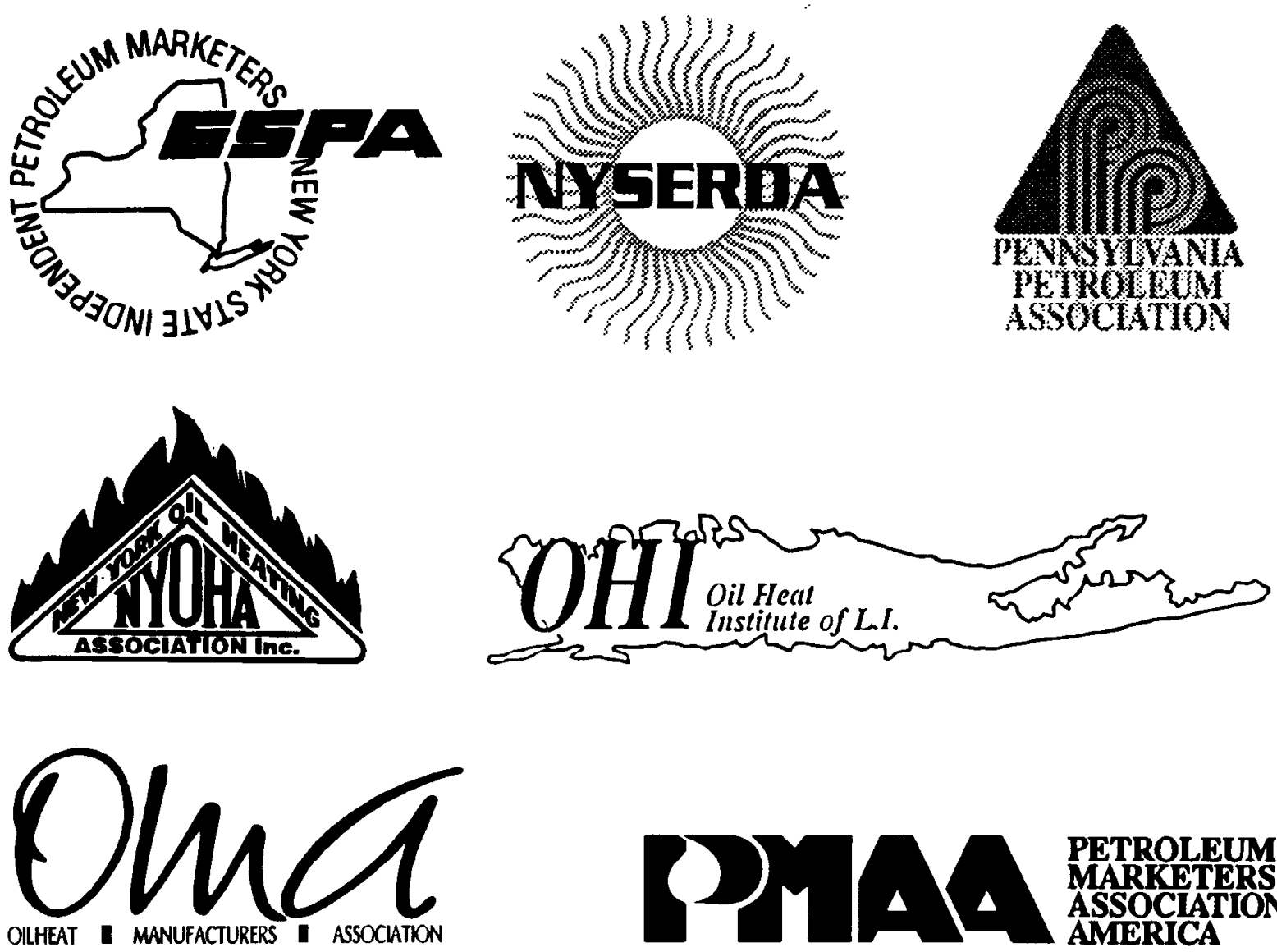

PETROLEUM MARKETERS ASSOCIATION or AMERICA 


\title{
I. INTRODUCTION
}

The 1999 Oil Heat Technology Conference and Workshop, April 15-16 at Brookhaven National Laboratory (BNL) is sponsored by the U.S. Department of Energy, Office of Building Technology, State and Community Programs (DOE/BTS). The meeting is also co-sponsored by the:

\author{
Petroleum Marketers Association of America, \\ New England Fuel Institute, \\ Oilheat Manufacturers Association, \\ National Association of Oil Heat Service Managers, \\ New York State Energy Research \& Development Authority, \\ Empire State Petroleum Association, \\ New York Oil Heating Association, \\ Oil Heat Institute of Long Island, and the \\ Pennsylvania Petroleum Association
}

BNL is proud to acknowledge all of our 1999 co-sponsors, without their help and support the conference would have been canceled due to budget restrictions. It is quite gratifying to see an industry come together to help support an activity like the technology conference, for the benefit of the industry as a whole.

The 1999 Oil Heat Technology Conference and Workshop, will be the thirteenth since 1984, is a very valuable technology transfer activity supported by the ongoing Combustion Equipment Technology (Oilheat R\&D) program at BNL. The foremost reason for the conference is to provide a platform for the exchange of information and perspectives among international researchers, engineers, manufacturers, service technicians, and marketers of oil-fired space-conditioning equipment. They will provide a conduit by which information and ideas can be exchanged to examine present technologies, as well as helping to develop the future course for oil heating advancement. These conferences also serve as a stage for unifying government representatives, researchers, fuel oil marketers, and other members of the oil-heat industry in addressing technology advancements in this important energy use sector. The specific objectives of the Conference/Workshop are to:

o Identify and evaluate the current state-of-the-art and recommend new initiatives for higher efficiency, a cleaner environment, and to satisfy consumer needs cost-effectively, reliably, and safely;

o Foster cooperative interactions among federal and industrial representatives for the common goal of sustained economic growth and energy security via energy conservation.

Introductory remarks will be provided by James Davenport, Ph.D. Chairman, Department of Applied Science, BNL, who will welcome the assembly on behalf of Brookhaven National Laboratory. Dr. Davenport will emphasize BNL's continued commitment to advancing oil heat technology and effecting technology transfer to the private sector. John Huber, Vice President \& Chief Counsel, of the Petroleum Marketers Association of America (PMAA), will follow by welcoming the participants on behalf of PMAA and presenting his views on the subject and then he 
will introduce the Master of Ceremonies, James Buhrmaster, current Chairman of the PMAA Heating Fuels Committee. Mr. Buhrmaster will introduce the Keynote Address which will be given by Mr. Robert V. Boltz, current President of the National Association of Oil Heat Service Managers Association and Chairman of the PMAA Oil Heat Certification Program and President of Vincent R. Boltz, Inc., PA.

Twelve technical presentations will be made during the two-day program, all related to oilheat technology and equipment, these will cover a range of research, developmental, and demonstration activities being conducted within the United States and Canada, including:

- Integration and Advanced Controls - Means to Optimize Performance and Increase Efficiency of Combined Oil-Fired heating Systems

- The European Burner

- High-flow Fan Atomized Oil Burner (HFAB) Development and Application of HFAB to DARPA 500 Watt Thermophotovotaic (TPV) Power System - Update

- $\quad$ Fan Atomized Oil Burner (Pioneer) and its Performance Under Field Conditions

- Use of No-Drip Nozzle for Reducing Emissions During Bumer Start-up and Shutdown

- $\quad$ Fouling of Heat Transfer Surfaces In Domestic Oil Fired heating Boilers Pros and Cons of Lower Fuel Sulfur Specifications in ASTM No.2 Fuel Oil

- Review of Recent Technical Accomplishments by the Oilheat Manufacturers Association

- Electronic Operations Manual (EOM) for the Oilheat/Energy Services Industry

- Advanced Residential Oil Burner Control Functionality and How It Effects Overall Performance

- $\quad$ Alternate Venting for Fossil Fuel Fired Equipment

- Repeatability and Reproducibility Error in Smoke Measurement: Development of a New Scale - Oilheat Technology Education Needs Analysis, Where We Are Now, and Where We Should Be Headed

Panel Discussion

Subject Topic: Status of the Current Oilheat Educational Programs and Future Needs

On the morning of the second day following the technical presentations a panel discussion will be held on the subject topic. The panel discussion will be lead by a moderator, Mr. Paul Geiger of Oil Heating magazine. The seven member panel will address education within the industry as it has been and as it might be provided NORA is approved and it appears to be very likely that it will and quite soon. The panel discussion is a introduction to the topic and it will be followed by further discussions during a workshop session in the afternoon.

Workshop Topics

This year these are three workshop sessions planned including the first, an Oilheat Education Summit dealing with education programs and possible developments under NORA, one on DoE/NYSERDA Oilheat Research Planning where research plans will be discussed, and one on No. 2 Heating Fuel Quality related to future actions being planned by ASTM committee member 
regarding fuel oil enhanced sulfur specification changes.

Adjournment

Following the afternoon workshop sessions the Oil Heat Technology Conference will be concluded with brief summary presentations as to the findings of the workshop sessions and closing remarks by Roger McDonald, editor, conference organizer and senior program manger for the Combustion Equipment Technology (Oilheat R\&D) program.

Combustion Equipment Technology Laboratory

During the scheduled open house time periods, before and after the formal conference sessions, conference participants will be welcome to visit the BNL combustion research facilities located in Building 526 and witness equipment demonstrations of some of the advanced oil-fired heating systems under development at BNL. The equipment to be demonstrated include the HeatWise Inc. Pioneer oil burner based on the BNL High (atomizing air flow) Fan-Atomized (low-firing-rate, low-emission) oil Burner (HFAB). Insight Technologies will display its Advanced Flame Quality Indicator (FQI) which is based on the FQI concept developed by BNL and licensed to Insight Technologies Inc. BNL will also provide numerous visual displays based on prior and ongoing research related to Oil Heat R\&D. 
II. TECHNICAL PRESENTATIONS 
Paper No. 99-1

Integration and Advanced Controls - Means to Optimize Performance and Increase Efficiency of Combined Oil-Fired Heating Systems

Evgueniy Entchev and A.C.S. Hayden

Natural Resources Canada

Advanced Combustion Laboratory

1 Haanel Drive, Ottawa, Ontario

Canada, K1A 1M1

Telephone: 613-992-2516

Fax: 613-992-9335

E-mail: eentchev@nrcan.gc.ca

shayden@nrcan.gc.ca 


\title{
Integration and Advanced Controls - Means to Optimize Performance and Increase Efficiency of Combined Oil-Fired Heating Systems
}

\author{
Evgueniy Entchev
}

\author{
A.C.S. Hayden
}

\author{
Natural Resources Canada \\ Advanced Combustion Laboratory \\ 1 Haanel Drive, Ottawa, Ontario \\ Canada, KlA IMl \\ tel. $+613-992-2516$ \\ fax. $+613-992-9335$ \\ E-mail: eentchev@nrcan.gc.ca \\ shayden@nrcan.gc.ca
}

\begin{abstract}
Combined hot water / space heating systems are a relatively new approach to heating in Canada but have started to gain acceptance in the market. The dual function capability, small footprint and potential for economy are the main driving forces for their success. Builders and contractors have installed the combined systems in different applications. from forced air to hydronic and radiant floor heating. Recent technology development is towards further integration of the ventilation mode within the combined system design, as well as using the same single energy generator in multi air-handler applications. The complexity of the novel integrated combined system designs require a new control strategy that will not oppose the system functions while, at the same time will provide high efficiency, low emissions and optimal system performance.

This paper will present the experience of the Advanced Combustion Laboratory/ CETC with combined heating system applications development. The results from field trials with combined system in multi air handlers application and integration with a new developed waste water reclaimed system for remote communities will be discussed. The development of the advanced controls, based on artificial intelligence to manage in an optimal and efficient way the performance will be presented.
\end{abstract}

\section{Introduction}

Advances in building technology are challenging the heating industry to develop more efficient and sophisticated heating and cooling systems to meet the lower heating loads and an increased demand for improved comfort. Combined heating systems potentially fit these requirements with a small footprint, low output and design mobility. Such systems incorporate at least two energy generators in one, usually to satisfy space and water heating demands. These additional requirements of the energy generator tend to make operation more complex, requiring a novel control strategy to guarantee optimal efficiency and low emissions performance. 
The research in Advanced Combustion Laboratory has been directed both towards the development of new systems and towards new control strategies.

There have been a number of reasons for carrying out this activity, all of which are related. The first reason is to improve the energy efficiency of the applications and to reduce pollutant emissions, including $\mathrm{CO}_{2}$. By improving the energy efficiency of the building envelope of new Canadian housing, it is becoming less cost-effective to justify the incremental expense of a high efficiency space heating system. Thus, much energy efficient housing envelopes are often being left with a less-than-optimum efficiency central furnace. By combining space and water heating into one high efficiency energy generator, there is the possibility of achieving major efficiency gains and pollutant reductions in a costeffective fashion.

However, if the integration is not done carefully, emissions can actually be increased with integrated systems. A significant proportion of the emissions of incomplete combustion products - carbon monoxide, hydrocarbons and particulates - are produced during the transient combustion conditions at startup and shutdown. There are no effective transient increments to the emissions of carbon dioxide and nitrogen oxides. Combined oil-fired space and tap water heating systems can change significantly the number of on-off cycles of an oil burner. At the same time, overall efficiencies can be raised $20-30 \%$, with a commensurate reduction in $\mathrm{NOx}$ and $\mathrm{CO}_{2}$ emissions, and an additional reduction of incomplete combustion products.

Further performance improvements can be achieved by developing appropriate control strategies for system operations, using learning-based systems, based on fuzzy logic and neural networks. Such strategies, combined with intelligent installation, can reduce the number of burner and air handler cycles, lower the emissions and maximize the comfort level in the house.

\section{Integration and Advanced Controls}

\section{Combined heating system in multi air-handler applications}

A consortium led by NRCan-CMHC and including utilities, builder and equipment manufacturers renovated the Ottawa Reno-Demo house in the spring of 1997, as a part of the Renovation-Demonstration Program, features extensive measures for energy efficiency and healthy housing. Initially a two storey duplex, it was converted into three separate apartment units, one per floor and the envelope was upgraded with improved levels of air 'sealing, high levels of insulation and new low "e" windows. As part of the renovation, an old draft hood boiler and hot water tank were replaced with a combined heating system. The domestic hot water demands are met by the 30 US gal storage capacity of the heat generator. The old hydronic/radiator distribution system was dissolved and the new forced warm air ducts system put in place. Separate air handlers located in each 
apartment, with hydronic distribution from the heat generator to each of the air handlers provide the space heating loads. Heat recovery ventilators were also installed in each unit providing fresh air to the living spaces and heat recovery from the exhaust air. Preliminary tests in the spring of 1997 indicated that hot water supply and space heating output would be insufficient during combined space/hot water draws, depending upon the occupants use patterns. Tests of the air flows through the forced air distribution systems indicated high levels of air leakage and insufficient delivery of warm air to the furthest rooms from the air handler.

Several actions were taken to improve the situation. An additional 30gal converted electrical hot water storage tank was connected to the heat generator to increase the domestic hot water availability on demand. Two booster fans were installed on the supply and return trunks to improve the supply and air circulation in the problem rooms.

A data acquisition system with modem for remote data retrieval was installed to monitor the mechanical systems activities, hot water draws and air/water temperatures in the units and inside/outside the building. The house was operated throughout the winter with various combinations of the improvements in effect to determine the occurrence and duration of any problems and to determine the effectiveness of each of the improvements. The operational time and cycling of the generator, the water pump, and input/output water temperatures were subject of monitoring and analysis. During the baseline period, the burner cycles on/off for an average of 100 cycles per day with maximum of 140 and minimum of 60 cycles. The average operational on-time of the burner was four hours per day with a maximum of seven hours and minimum of three hours per day (Figure 1). The water pump responsible for moving the water between the generator and external water storage tank was on an average of one hour per day, with average cycling of 20 cycles. The cycling and on-time operation (Figure 2) of the generator have a strong correlation giving the average burner operational time of $\sim 3-4 \mathrm{~min}$ per cycle. The external water tank is acting as a sump by increasing the available hot water storage capacity and almost eliminating the influence of small domestic hot water draws on the burner operational frequency, thus lowering the emissions produced during burner start-up and shut down. At the same time, the burner is able to restore the temperature status in both the generator and the external water tank in a short time interval satisfying both aquastats. Domestic hot water used per day varies depending on the weekday from $400 \mathrm{~L} /$ day to $1200 \mathrm{~L} /$ day. The water temperature into the generator was maintained at $60{ }^{\circ} \mathrm{C}$ with $+/-3{ }^{\circ} \mathrm{C}$ variation. The tank water temperature and length of burner operation greatly depend on showers taken and appliances - dishwashers, washers-in use (each of the apartments is equipped with both appliances). The priority control strategy (Figure 3), in case of storage water tank bypass, cuts off the air handlers operation until the temperature status into the generator is restored. The air-handlers' operations are strongly dependable on correct sizing, occupants' habits and input water temperature and flow. The sensitivity to all these factors led to large diversification in operational time and correlated cycling of the blower motors and associated water pumps. The air handlers operated with operational cycles of five to ten per day and operational time between two to four hours, with an average of $\sim 20 \mathrm{~min} /$ cycle. 
Combined heating system integration with reclaimed water system for application in remote communities

The extreme outdoor environment and lack of suitable building technologies and equipment were for a long time the main barriers preventing applications of heating sources other than electricity in remote northern communities. Just as in the rest of Canada, new building technologies lowered the design heating loads allowing new approaches for heating to be applied. Recently, Northwest Territories Housing Corporation has initiated a program for electricity replacement with alternative less expensive energy resources. Combined oil-fired heating systems qualified, due to their wide applicability. However, if the heat generator and/or the heat distribution system is not sized properly, problems can result in the adequacy of the domestic hot water supply and with the heating comfort conditions. In addition, each new product needs to be tested to function in the rigorous of the North.

The two demonstration houses in Yellowknife, NWT are build with high levels of insulation and air tightness, and high efficiency oil-fired combined heating systems provide both space and water heating. Initially designed as a non-segregated system, the hot water and space heating needs were met by the 32 US gal storage capacity of the heat generator. The space heating loads were provided by fan-coils hydronically connected to the heat generator tank. Prior to the installation, modifications in the initial design were anticipated and both systems were converted to segregated units to facilitate the installation of a reclaimed waste water system. Most of the domestic hot water and all of the space heating needs are met by the existing water storage of the heat generator connected to the reclaiming water system. The hot water for special domestic needs is heated through an added counter-flow heat exchanger connected to the fresh water supply to the house. A new control strategy was developed to accommodate these functions.

During the systems installation in winter 1998, modifications were made to the unit, installed in house No2, to reduce the electricity consumption/operational cycles of the main system electrical devices: blower motor, water circulation pump and motorized three way valve.

Due to the new control strategy, a significant decrease in cycling of the air handler in house No 2 (Figure 4) was observed compared to the one in house No1. The burner cycles and operational time was reduced as well (Figure 5) due to optimal utilization of the stored heat in the generator. The new control strategy and combined system integration with the reclaiming waste water system significantly reduced the operational cost of the house, leading to significant savings ( $\$ 2,000$ year/per unit) both in terms of electricity and water bills. 


\section{Combined heating system with advanced control strategy}

Most of the combined heating systems are equipped with powerful burners able to restore the system status in a very short time interval. Due to the new functions appointed to the energy generator, it tends to cycle more frequently with short on-time cycles; these cycles significantly decrease the overall system efficiency and produce unfriendly environmental pollutants. Presently, a large portion of the current combined heating/cooling appliances on the market incorporate the old control strategies designed for single function generators. This strategy usually leads to keeping the storage-heating medium at an unnecessary high temperature, causing increased stand-by heat losses. To avoid any complaints, the manufacturers usually oversized their equipment; thus in turn leads to frequent burner cycles lowering the efficiency and increasing the pollutants. This design also fails to satisfy combined heating demands when they occur simultaneously on cold winter days. Functional analysis showed that to improve the system efficiency and performance, a new innovative control strategy should be developed. The strategy should be able to control the system modes of operation in conjunction with system heating capacity and external/internal conditions and influences. The system should be able to adjust its space heating output depending on the current status of room temperatures and ambient weather conditions. The domestic hot water availability should be a function of the homeowner usage pattern - both in magnitude and in time of day. The storage watertank temperature settings should be continuously adjusted according to internal and external factors, so as to lower the stand-by heat losses, improve efficiencies and availability to satisfy all demands. Recently, some manufacturers have introduced a priority control strategy that does not solve the above problems, but instead sacrifices one or more of the requirements.

Detailed examination of the design and operating environment define that a new control strategy should be able to explore the capabilities of new system devices such as modulating burners, variable speed blower motors, variable speed water pumps, etc.. Such strategy should work towards improving the efficiency of energy use, reducing drafts and thermal stratification, while enhancing the thermal comfort and satisfying space and water heating demands throughout the house at all times.

Functional analysis for the new control strategy showed that: a) the system should be able to adjust its space heating output depending on the current status of room temperature and weather conditions; that $b$ ) the domestic hot water availability should be a function of the homeowner's usage patterns, both in magnitude and in time of day; c) the tank aquastat setting should be capable of being continuously adjusted according to internal and external factors.

The developed fuzzy logic control strategy targets three of the heating systems' devices: the variable burner energy input rate, the air handler blower operation and the water storage tank aquastat settings. The fuzzy logic burner strategy controls the energy input in conjunction with the current-storage-tank water temperature and room thermostat temperature differential. It minimizes the cycling and extends the operation length of each 
cycle and as a result increases the overall efficiency while dramatically lowering the emissions. The air-handler blower operation determines the heat utilization across the heating coil and heat distribution rate around the house. Variable blower motor speed is controlled in relation with the external and internal environment conditions. By taking advantage of knowledge of the status of the other system devices and the heating load, the optimal blower motor operation is set to enhance comfort and reduce temperature level required, further increasing the efficiency. The variable water storage tank aquastat settings improve the system performance by lowering the stand-by heat losses and adjusting the aquastat settings according to the outdoor conditions and the occupants' usage pattern.

Subject to the environment and the occupant's habits, the developed overall fuzzy logic control strategy is able to set the system at optimal efficiency mode, thus increasing its ability to satisfy the demands under a range of loads and requirements. The developed fuzzy logic approach to control the overall operation of the integrated heating system would result in improving system efficiency in order of $8-10 \%$ and reduce pollutants for oil-fired systems by $25-30 \%$.

Knowledge of the upcoming hot water usage pattern of the dwelling offers the opportunity to prepare the heating/cooling system mechanical systems in an optimal structural and operational way to successfully meet the demand. Most of the current prediction techniques are based on the "black box" approach. In most cases, the predictive models are steady-state linear approximations, based on selected number of variables. The result is a coarse approximation of the system performance and can result in inaccurate predictions or less-than-optimal performance. Presently, predictive modelling is applied mainly to district heating systems. Predictive water supply temperature levels are based on weather files processing, compiled with the short-term predictive algorithms.

The applications of neural networks are possible in this part of the heating system where there is an established pattern for a certain period of time and the on-going processes have long-time constants. The prediction of the domestic hot water draw load would increase the comfort in the dwellings and would avoid the undesirable shortage of hot water during baths and/or other domestic activities. At the same time, it can optimize the mechanical system performance by preparing it in advance to meet the upcoming loads. Usually, every building has its own hot water draw schedule based on the occupants' water usage patterns. They vary, but could be differentiated by the type of the building (hotels, motels, hospitals, residential, commercial, etc.), time of day, day of the week and the season.

A neural net has been trained with hot water draw data files representing hot water draws of a three-bedroom house. The inputs were defined by month, day and hour. The output was the accumulative amount of hot water drawn every hour. The amount drawn has been presented as one following in the categories described by these linguistic terms: SDRAW draw less than 15L, DRAW - draw between 16 - 40L and LDRAW - draw over 40L. The neural net has been trained and after 140 epochs, the net was able to repeat the test draw values with RMS error of 0.0012 . 


\section{Conclusions}

The long term monitoring of the demonstration houses provided valuable information for the real life performance of the combined hot water/space heating system. The novel applications of the combined heating systems both in terms of providing domestic hot water and space heating to three separate apartments and in integration with reclaimed waste water system showed their advantages. The data pointed out the importance of sizing for the proper operation and comfort heat delivery. Balancing the water flow through the coils and blowers speed adjustment in case of multi-AH applications, hot water storage capacity and warm air duct balancing are of great importance for proper and efficient operation of the heat generator and satisfied delivery of heat. If the hot water storage capacity is incorrectly sized and depending upon the water draw for domestic activities in all the apartments, it is possible that the water priority control may leave the apartments with insufficient space heating for an unacceptable time interval.

The applications of oil-fired heating systems for Northern and remote communities in conjunction with additional systems as reclaimed water system definitely pushed the technology towards self sufficient housing able to satisfy its own needs.

The AI learning- based control strategy would enable an optimal performance of the integrated systems and would avoid the undesirable discomfort in the buildings. Based on the advanced knowledge of the upcoming loads using historical data from the occupants usage pattern and building thermal performance, the control will be able to operate, distribute and further optimize the operating conditions in single and combined modes of operation.

\section{Acknowledgments}

The authors would like to acknowledge the contribution of D. MacKenzie for his strong technical support and the Northwest Territories Housing Corporation, and the Canadian Program for Energy R\&D (PERD) for their financial support of the work presented in this paper. 


\section{Selected Bibliography}

1. E. Entchev, Fuzzy Logic and Neural Network Approach a Way to Increase Efficiency and Improve Overall Performance of Intergated Heating Systems in New and Renovated Housing Stock, 5-th International Conference on Soft Computing and Intelligent Systems, Fukuoka, Japan, October 1998.

2. E. Entchev, B. Gough, F.Shadkowski, Combined Heating Systems in New and Renovated Housing - Problems and Solutions, Energy Efficient Building Association Conference, Washington, October 1998.

3. E. Entchev, A.C.S. Hayden, B. Fandrick, F. Szadkowski, Combined Heating Systems Performance under Harsh Northern Climate, Circumpolar Conference'98, Yellowknife, September 1998.

4. E. Entchev, B. Gough. Performance Evaluation of Mechanical Heating and Distribution System in Reno-DemoHouse, Natural Resources Canada, Interim report, March, 1998.

5. E. Entchev, K. Lee, F. Szadkovski, G. Prockiw, The Manitoba Advanced House Mechanical Systems: Reconciling Prototypical Concepts with Final Performance Needs, Natural Resources Canada, Final report, May, 1997.

6. A.C.S. Hayden, E. Entchev, Optimizing Integrated Systems with Fuzzy Logic and Neural Networks to Reduce Emissions and Increase Efficiency in Residential Buildings, Air \& Waste Management Association's $90^{\text {th }}$ Annual Meeting and Exhibition, Toronto, June, 1997.

7. E. Entchev, Heating Systems Performance Predictions Using Neural Networks Approach, Combustion Canada'96, Ottawa, 1996.

8. E. Entchev, A.C.S. Hayden, Fuzzy Logic for Efficient Systems, Combustion Canada'96, Ottawa, 1996. 

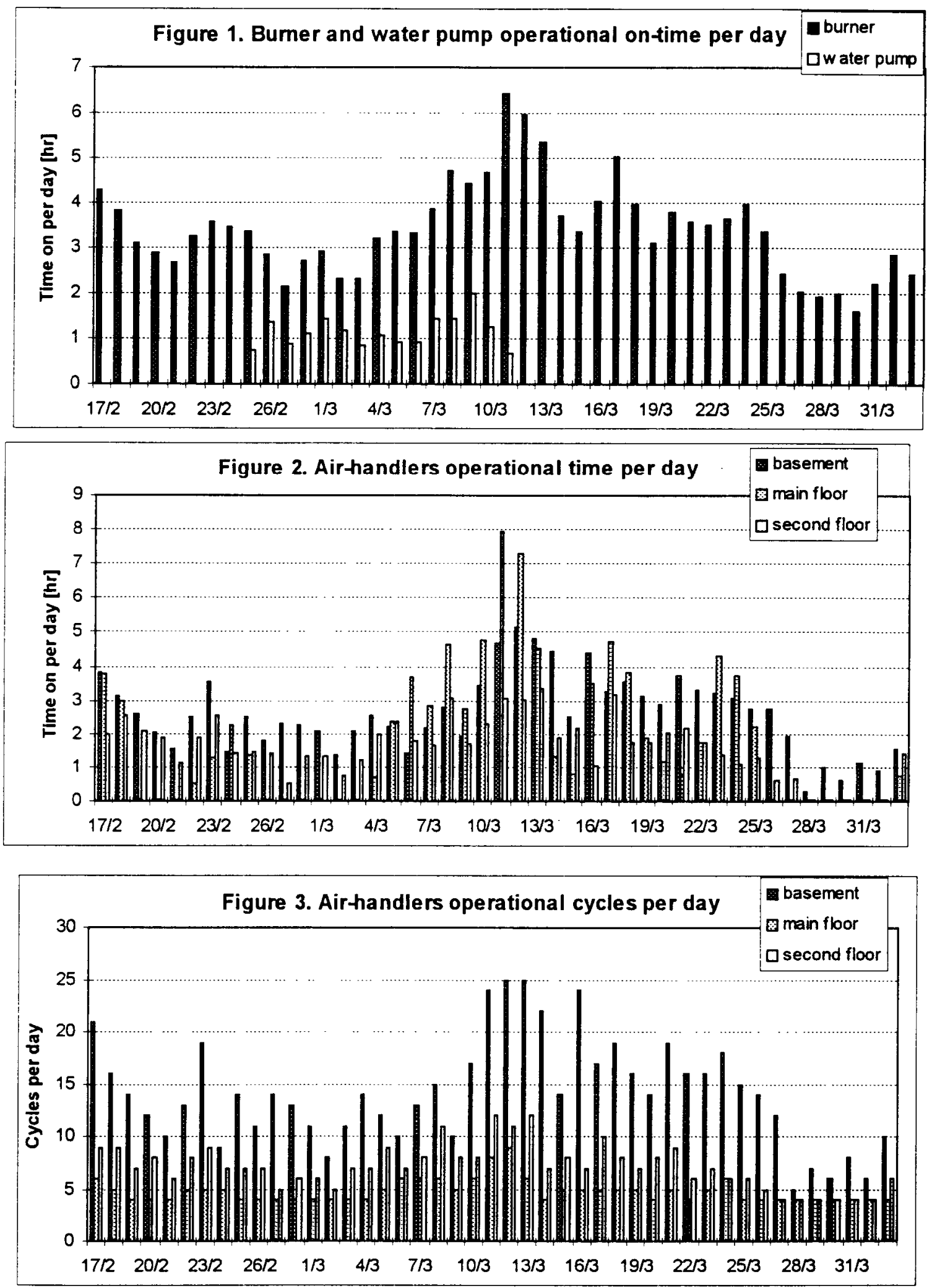

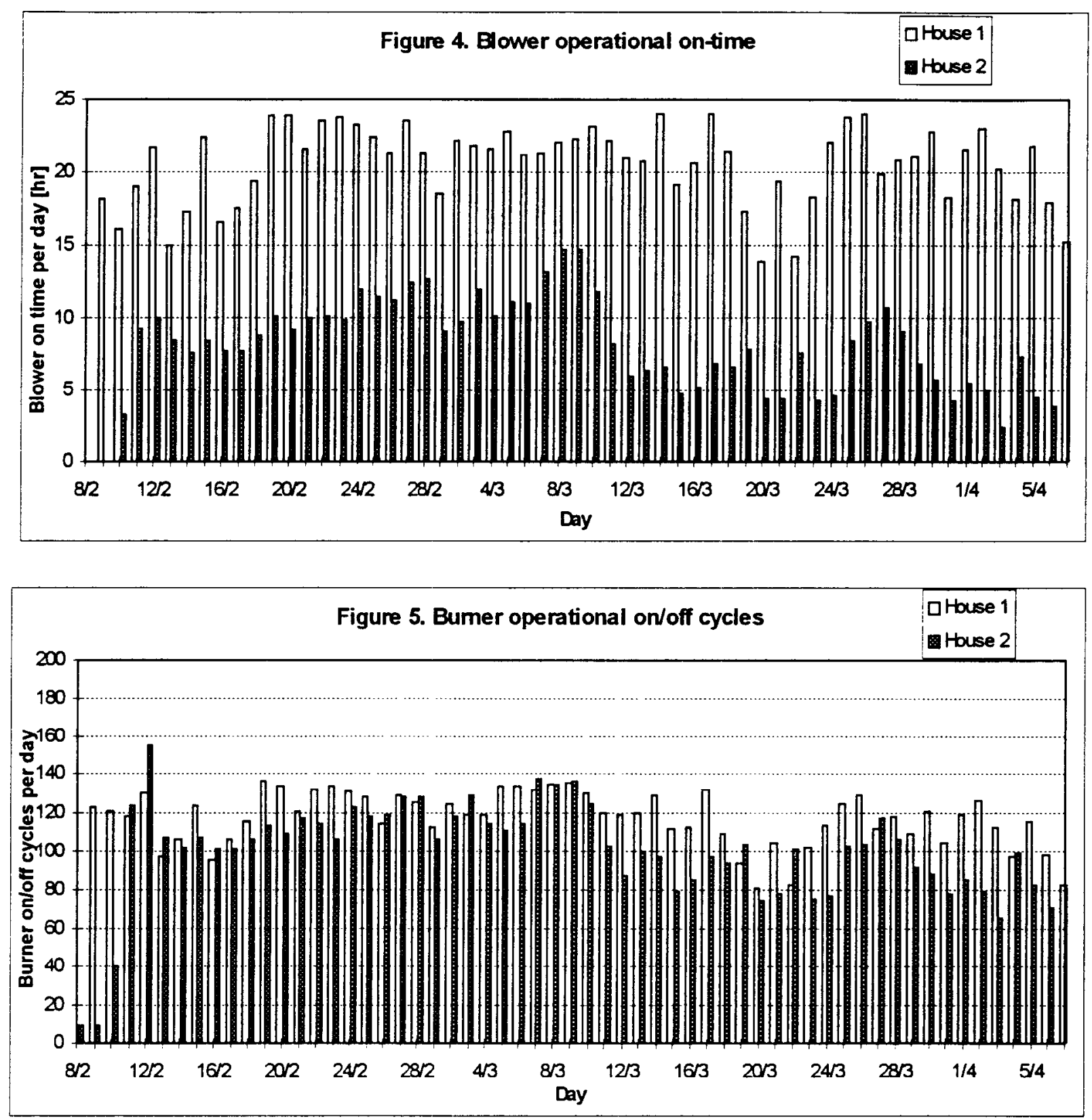
Paper No. 99-2

The European Burner

Poul Kirkelund, M. Sc. Mechanical Engineering

Burner Components Division

Danfoss, Denmark 


\title{
The European Burner
}

\begin{abstract}
In Europe we have taken the position that we want to create the best possible conditions for the nozzle in order to minimise the environmental emissions from the oil burner. That means first selecting an adequately high, constant pump pressure. Second, we want to eliminate the influence from variations in viscosity. These variations can stem from temperature variations and/or variations in the oil supplied from oil companies. Information concerning oil preheaters for domestic burners, including start temperature, temperature in the running period and power consumption will be presented. Finally, we have considered the problems of oil dripping during both burner start-up and stopping. In Europe there are basically three different systems on the market that address this concern. Why is a stop drip mechanism necessary when using a pre-heater? The three types of stop drip mechanisms are the valve in the nozzle, valve in the pre-heater and electrical cut-off in the pre-heater. The nozzle definition point is the European nozzle standard EN293. The paper includes a short review of the existing European legislation on environmental emissions including; EN 267, Blue Angel, and 1 . BImSchV.
\end{abstract}

Another area we have started to look at in Europe is the power consumption of the burner in relation to the heat output of the burner.

Typical electric power consumption values for a standard oil burner in Europe are:

Motor: $180 \mathrm{~W}$,

Pre-heater: 50W,

Solenoid valve: $9 \mathrm{~W}$,

Ignition: $40 \mathrm{~W}$ for traditional transformer, $20 \mathrm{~W}$ for electronic device.

The largest electric power consuming unit on the burner is clearly the motor due to the fact that the pump is far too big, there has never been an interest in reducing amount of the friction in the pump, and partly because the oil flow is far too high. An oil burner runs 1000 to 1500 hours per year and consumes an average of $290 \mathrm{kWh}$. If that could be reduced by $25 \%$ down to approximately $200 \mathrm{kWh}$ it would mean a total reduction of $1260 \mathrm{GWh}$. alone in Europe and globally probably twice as much. We will consider friction in the pump and pre-heater temperature. I know that BNL has been working on its Fan Atomized Burner, but I think that BNL should also consider what could be done on existing burner systems.

In Europe there is a tremendous amount of work being done by the German organisation, IWO. They initiate new developments at the Institutes and Universities. The Surface burner and the Pre-evaporation burner are examples of their work. Especially the Surface burner which has a potential for use in a small wall hung oil burner. Briefly the paper will also address the function of these burners. 


\section{Introduction}

In spite of the fact that the oil burner originally came to Europe from the USA, today a European burner differs much from an American burner. I should rather say, two European burner types. Besides the yellow flame burner, we have in Europe an increasing share of blue flame burners, also. In brief, one can say that the fundamental difference between the two types is that in a yellow flame burner, small oil droplets are burnt while they are moving ahead in the flame, whereas in a blue flame burner, the oil droplets are evaporated and transformed into gas phase before the combustion takes place. This causes the characteristic blue colour of the flame. Later I will show you some examples of new developments in the blue flame area and go into details about this point. In all cases, as with the American burners, pressure atomization of the oil is used to produce an oil/air mixture which can be ignited and burned.

\section{Pump pressure, preheating, the definition point of the nozzle and stop drip mechanisms}

Originally, the nozzle was defined at $100 \mathrm{psi}$, but in Europe we have diverged from this definition point. Indeed, we now have a standard in Europe, EN 293, laying down the definition of the nozzle.

Definition point EN 293: $\quad 1000$ kPa (10 bar) 145 psi

\section{$3.4 \mathrm{cSt}$.}

\section{$840 \mathrm{~kg} / \mathrm{m}^{3}$}

The vast majority of the burners operates at an atomizing pressure between 130 and 175 psi. Besides the higher atomizing pressure, the oil is heated by means of a pre-heater to approximately $50-60^{\circ} \mathrm{C}$ corresponding to $122-140^{\circ} \mathrm{F}$. We want the droplets to be as small as possible because of the very severe emission requirements. Moreover, the droplets have a higher average speed, partly due to a higher pressure and partly due to a lower viscosity. As preheating was introduced at the beginning of the 1980s, the burner manufacturers had to change the air pattern in the burner to profit from the more stable conditions of the nozzle. Even with preheating, the European burners are operating at pump pressures higher than 100 psi.

\section{The pre-heater has several functions}

It ensures that the oil has a reasonably high temperature at start-up. This facilitates ignition of the burner during starting conditions. It lowers the oil viscosity. It ensures a sufficiently high operating temperature to minimize variations in the oil viscosity. It contains a valve that prevents pre and after dripping from the nozzle, minimizing start/stop emissions. In the European countries where heavy demands on emissions are made, Germany, Switzerland, 
Denmark, Sweden, almost $100 \%$ of the new burners are equipped with pre-heater. The percentage is somewhat lower in the other countries. In the UK they do not use pre-heaters because they are using a kerosene with a viscosity of less than $2 \mathrm{cSt}$. The pump pressure, as mentioned before, is about 145 psi, except in UK where a pressure of typically 100 to 115 psi. is sufficient.

For the UK market we have a nozzle series defined at:

\section{6 psi (8 bar)}

\section{$1.65 \mathrm{cSt}$.}

\section{$790 \mathrm{~kg} / \mathrm{m} 3$}

In this way we tailor the definition point to the needs of the countries in question. We produce nozzles for Japan and North America, each of them having their special definition points. The debate about pump pressure brought up by George Lanthier in Fuel Oil and Oil Heat is very relevant. In some cases, 100 psi. is a rather low pressure, especially if the oil is cold.

We can make a calculation with $\mathrm{Re}$, but to have a simple view, we usually use a formula that will do very well:

$$
\frac{\sqrt{Q \cdot[L / h] * P \cdot[b a r]}}{v \cdot[c S t]} \geq 0.7
$$

With $\mathrm{Q}=1.5 \mathrm{~L} / \mathrm{h}$ and $\mathrm{P}=6.9 \mathrm{bar}$, oil viscosity must be below $4.6 \mathrm{cSt}$.

As regards small nozzles and cold oil, we are close to the limit to an optimum atomization. If you, in North America, in general decide on a higher pressure. The definition point of the nozzle should be changed because the tolerances of the nozzle have been established based on this definition point. If this point is deviated from, the tolerance limits will change as well.

\section{The pump pressure}

All domestic burners in Europe are using pumps with solenoid valve and control boxes with combustion air pre-purge. In North America you normally use pumps with a hydraulic cutoff. We also make this type of pump. The European pumps normally have a maximum pressure of $15 \mathrm{bar}$, but is available with a maximum pressure of $20 \mathrm{bar}$. The pumps have a 
theoretical displacement of $50 \mathrm{l} / \mathrm{h}$ and an increase of the pump pressure does only mean an increase of power consumption of approximately 1.4 Watt / bar. So there are no obstructions for the suppliers of components in terms of increasing the pump pressure on burners in North America. Of course, one could be "content" with preheating of the oil, which according to the formula will be highly effective. Besides a constant atomization, a more constant combustion is obtained by this and thus a higher efficiency. The burner can be adjusted to a higher $\mathrm{CO}_{2} \%$.

\section{Drip-stop mechanisms}

There is no doubt that a closing device placed as closed at the nozzle as possible has very great influence on the start and stop emission with pre-heater. A look at the curve of unburnt hydro-carbon quite clearly shows the effect. Unfortunately, there is no norm or standard making demands on start/stop. In Europe, a few burner manufacturers keep the flag flying and have built-in a drip-stop mechanism, but in general, these systems were not a great success because they cost extra. In the burner trade competition is ruthless and that is why these mechanisms are less widespread, even if all agree on the effect.

In Europe, several different types are available:

closing valve in the nozzle,

built-in or screwed on,

ball check valve or diaphragm valve,

closing valve in pre-heater or in nozzle holder, and

solenoid valve built into the pre-heater instead of solenoid valve in the pump.

The different systems are not equally effective and the solenoid valve solution is not as one should believe the most effective valve. The ball check valve in our LE-nozzles has turned out to be highly effective, but the nozzle is expensive and as it is a replacement part, it has been difficult to sell this nozzle.

We are producing 3 different system solutions:

LE-pump + LE-nozzle + standard. pre-heater (ball check valve),

LE-pump + LE-pre-heater + standard nozzle (diaphragm valve), and

LE-S pump + LE-pre-heater + standard nozzle (diaphragm valve).

We have tested these systems on American burners, where the number of revolutions of the pump controls the opening/closing function. Unfortunately, the effect was minimal, which could be due to the fact that two hydraulic valves in series cannot normally be recommended. In UK, where the pre-heater is not used, the closing function is used as an extra safety valve when they are operating with a positive pressure on the suction line. 
Legislation on emission

\begin{tabular}{|l|l|l|l|}
\hline Norm & NOx mg/kWh & $\mathrm{CO} \quad \mathrm{mg} / \mathrm{kWh}$ & $\mathrm{CxHy} \mathrm{mg} / \mathrm{kWh}$ \\
\hline Blue Angel & $<120$ & $<60 \quad$ & $<15$ \\
\hline EN 267 & $<250$ & $<110$ & $<15$ \\
\hline 1. BImSchV & $<120$ & $-\cdots-\cdots---$ & $-\cdots$ \\
\hline
\end{tabular}

\section{Power consumption}

In addition to our being very conscious of burner emissions and boiler efficiency, we have in Europe begun to specify how great the power consumption on the burner may be, seen in relation to the heat output.

The power consuming products:

motor Pump and fan,

pre-heater,

ignitor, and

solenoid valve.

The most greedy power consumer by far is the motor. If the motor power is to be reduced, an alteration of the pump is required, so that the friction is reduced, as well as a reduction of the theoretical pump displacement.

Other possibilities for changing motor/pump are:

reduce the friction using ball bearings for the shaft bearing for example, reduce the theoretical displacement (this may involve alterations of the tank installation), split the double function of the motor, one motor for the pump and one motor for the fan, and use more effective motors.

We are looking at the friction in the pump and expect to be able to reduce the power consumption of the pump by at least $25 \%$.

For some sorts of installations, especially one-pipe installations, displacement of the pump can be reduced without causing any problems. The main part of the domestic burners that are for sale are using 0.5 gallon nozzles, but the pump typically delivers $15 \mathrm{gal} / \mathrm{h}$. The whole issue of theoretical displacement is put to question. Power consumption is: $0.027 \mathrm{~W} / / \mathrm{bar}$. In Europe, several countries have passed a Bill that installations must be one-pipe only. This necessitates the use of a device called a tigerloop, or some other form of de-aerator device because of the air/gas formation from the oil under vacuum.

Another idea would be to let the fan have its own motor and then build the pump together with a motor. The problem to be solved is to find a motor that is cheap enough and has a long life. 
Energy consumption of the pre-heater is 60-70 Watt depending on nozzle capacity. In some cases this may be more capacity (fuel preheating) than actually required. This is particularly true with blue flame burners, which have a hot burner tube. In the cases where the fuel preheat requirement is not as great some electric power could probably be saved.

As to the electric power used for ignition and solenoid valve operation, there is almost nothing to gain. We are by and large using electronic ignition device and the ignition is only operating during the short period which includes; pre-ignition, burner ignition, and a short post ignition time period. Once the flame is established the ignition turns off. Constant ignition only disturbs the flame and combustion.

All things considered, we expect to be able to reduce the power consumption on domestic burners by $30 \%$ from approximately. 300 Watts to approx. 225 Watts.

\section{Burner development}

In Europe, blue flame burners are used more and more, because evaporated oil has a cleaner combustion than oil droplets. The development on blue burners has resulted in an essential lowering of the noise level compared to the first types. The rocket burner from the beginning of the 1980s did live up to its name, but the burners marketed today are much more cultivated.

I will show you a few examples of the new development which has taken place at the Technical University in Aachen, Germany, with the financial support of IWO, the Institute of Economical Oil Heating. This institute is financed by oil companies in Germany with roughly 30 mio. DEM or 17 mio. \$ US.

\section{Surface burner}

Inside the porous surface, which because of the mass is now made of a mesh, there is in principle a quite ordinary blue burner with flue gas re-circulation. The nozzle is a normal simplex nozzle. When this starting burner has stabilised after 10-15 seconds, the hot flue gasses have heated the mesh to operating temperature and oil supply is interrupted. When oil supply is started again, the oil will evaporate, because the air is heated by the heat exchanger tubes, which are between the mesh and the burner tube. Now, combustion takes place from the mesh surface and the burner is in a stable phase.

This burner can modulate without problems with the use of, for example, a spill back nozzle, or an air atomizing or pulse atomizing nozzle. Also ultrasonic atomization has been tested with a good results. The burner is not critical of the atomizing pattern of the nozzle. 
Such a surface burner or radiation burner could be used to make the burner/boiler construction more compact. Those of you who were at the ISH have probably seen the system in operation.

\section{Pre-evaporation Burner}

This burner type has also two-stage starting. In the starting phase, the quantity of the recirculation is reduced by means of a blocking air stream. After a heating phase, depending on nozzle capacity, the blocking air is stopped and the total re-circulation is released. What happens in the burner tube is mostly a pre-evaporation and the final combustion takes place at the end of the burner tube. Because of the large increase of the area, air velocity falls heavily and noise emission from this burner will be approx. $87 \mathrm{~dB}(\mathrm{~A})$ in the starting phase and fall to approx. $77 \mathrm{~dB}(\mathrm{~A})$ in the stationary operating phase. A normal yellow burner will be somewhat higher. Flame monitoring of this burner is problematic, but acoustic flame monitoring has been a possible solution. This burner can be made to modulate thermal output by pressure variation alone. Changes in pressure from 4 to 20 bar produces a thermal output modulation ratio larger than $1: 2$.

\section{Conclusion}

I have tried to give you an impression of why we in Europe are operating with pre-heaters and with a higher atomizing pressure than you do in North America. As we are very much aware of the environmental problems and would prefer to avoid unnecessary waste of energy, a lot of development is done in improving combustion and minimising emissions. Both the surface burner and the pre-mix burner are examples of that development. I believe that in a very near future our oil boilers are small wall hung maybe even condensing devices, modulating from 6 to $20 \mathrm{~kW}$, with very reduced power consumption. The atomizing of oil could still be done by simplex-nozzles but other ways are possible. Therefore we have with interest followed the development of the fan atomized burner, as an alternative to the pressure jet burner. I hope that our planet can benefit from the development that takes place both here and in Europe.

\section{References:}

1. Emissionsarmer Vorverdampfungsbrenner mit Stabilisierung im Umkehreinsatz. RWTH Aachen, Dipl.-ing. Christoph Dötsch, Prof. Dr.-ing. Heinrich Köhne.

2. Oberflächenverbrennung für flüssige Brennstoffe.

RWTH, Aachen. Dipl.-ing. H.-P. Gitzinger, Dipl.-ing. F. von Issendorff, Prof. Dr.-ing. H. Köhne.

3. IWO, Institut für Wiertschaftliche Oelheizung. Various publications, $\mathrm{O}-\mathrm{H}$ films.

4. Danfoss nozzle department. M. Sc. Mech. Eng. Prcben Nørskov

5. The European norms EN 293, EN 299, EN 267

6. Blue Angel. RAL UZ 9, 1. BImSchV. Germany 
28 


\section{Paper No. 99-3}

High-flow Fan Atomized Burner (HFAB) Development and Application of HFAB Technology to DARPA 500 Watt Thermophotovotaic (TPV) Power System- Update

Thomas A. Butcher, Ph.D., Yusuf Celebi, \& Gang Wei Brookhaven National Laboratory 


\section{Introduction}

The Oil Heat Research Program at BNL has an on-going interest in the development of practical options for improved oil burners. Improved in this instance can be defined as capable of operating at lower firing rates to provide new application options while providing clean combustion at low excess air levels. Low emission of $\mathrm{NO}_{\mathrm{x}}$, while not a primary driver, is certainly an important feature sought in any new burner concept. Following from this on-going interest in advanced burners, BNL has been developing the Fan - Atomized Burner (FAB) concept. This is a low pressure, air atomizing burner concept. Unlike conventional, pressure atomized burners, fuel flow passage sizes do not provide a lower limit on achievable firing rates. Unlike prior air atomization concepts which need higher air pressure to achieve fuel atomization, an air compressor is not a required component of this burner package. Atomization is achieved using air from the burner combustion air fan at a pressure of about 6 inches of water. The development of the Fan Atomized Burner has been described in two BNL reports and several technical papers [1-4].

Heat Wise Inc., is commercializing one burner concept based on this approach and current status is reviewed in another paper at this conference. This burner has been termed the "Pioneer". Beyond providing technical support for the Heat Wise efforts with the Pioneer, BNL is developing advanced burner head designs, which can lead to lower cost. This approach generally involves using a higher fraction of the total burner head airflow through the atomizer than in the case of the Pioneer. Simplicity is a key advantage although a limitation to the firing rate range over which each specific head can operate is a possible disadvantage. This approach has been termed the High-flow Fan Atomized Burner or HFAB. Here high flow refers to high atomizer airflow not high total airflow. BNL is currently developing several configuration options for this and the current status is reviewed here. BNL is also currently applying the HFAB burner approach to the development of a small, oil-fired thermophotovoltaic power generation system and this was introduced at last year's conference [5]. Current status of this development effort is also presented.

\section{$\underline{\text { HFAB Burner Development }}$}

Figure 1 shows the configuration of a burner head which uses the HFAB concept. In this configuration all of the combustion air enters the air tube through a side feed connection at a pressure of about 6 inches of water. The air then enters the back of the nozzle, and atomizes the fuel. There is no retention head on this system, simply a disk that defines the start of the combustion zone. All of the combustion air enters the flame zone along the central axis of the burner and this provides a strong central jet surrounded by a recirculation zone, which stabilizes the flame. Most of the flame is contained within the flame tube. In this concept service of the burner head components is relatively easy. The fuel line, flame shield, electrodes, nozzle, and cad cell are all withdrawn as an assembly from the back end. During the 1998 Oil Heat Conference this system was demonstrated operating at a firing rate of $0.25 \mathrm{gph}$. This has since been scaled-up to $0.4 \mathrm{gph}$, simply using a larger nozzle. 


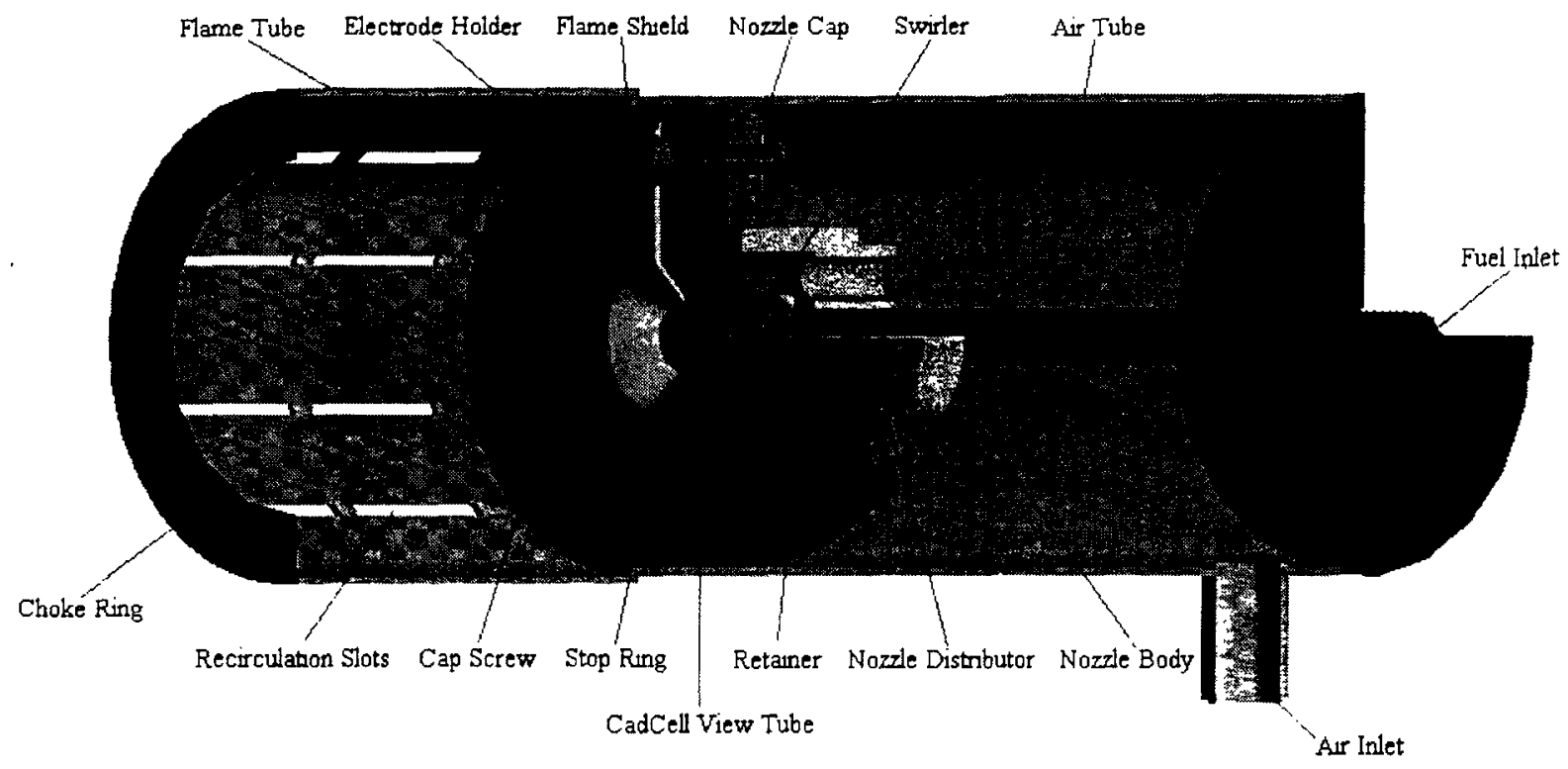

Figure 1. Illustration of a burner head with HFAB concept.

A fully functional burner system prototype has been built using a brushless DC blower / fan set, a pulsed solenoid fuel pump, interrupted ignition, and a conventional cad cell primary control. The system has undergone limited field testing during this past winter. Table 1 provides a summary of the performance of this system, fired into a steel boiler with a horizontal combustion chamber.

Table 1. Performance of the HFAB burner head in a steel boiler at $0.4 \mathrm{gph}$.

\begin{tabular}{|c|c|c|c|c|}
\hline Excess air (\%) & $\mathrm{CO}_{2}(\%)$ & Smoke number & $\begin{array}{l}\mathrm{CO} \\
\left(\mathrm{ppm} @ 3 \% \mathrm{O}_{2}\right)\end{array}$ & $\begin{array}{l}\mathrm{NO}_{\mathrm{x}} \\
\left(\mathrm{ppm} @ 3 \% \mathrm{O}_{2}\right)\end{array}$ \\
\hline 29.2 & 11.9 & 0 & 45 & 74 \\
\hline 22.1 & 12.5 & 0 & 45 & 72 \\
\hline 18.7 & 13.0 & 0 & 43 & 71 \\
\hline 12.6 & 13.7 & 0 & 42 & 73 \\
\hline 9.3 & 14.2 & 0 & 42 & 71 \\
\hline 6.7 & 14.5 & 0 & 40 & 69 \\
\hline 3.7 & 15.0 & 0 & 45 & 70 \\
\hline
\end{tabular}

The airflow in this HFAB configuration can be varied over a limited range by adjusting the air pressure. If the air pressure is reduced below about 4 inches of water the atomization quality can be expected to degrade. The highest air pressure available really depends upon the characteristics of the fan used. A change in air pressure from 4 to 8 
inches yields a change in airflow of $22 \%$. At constant excess air the firing rate could be changed by about the same amount, leading to a fairly limited turndown capability.

In more recent work at BNL effort has been placed on another approach to the head design. The new approach may provide even greater simplification and might also allow at least a limited range of firing rates to be achieved with a single head. The system is illustrated in Figure 2. Here, combustion air is delivered to the nozzle through a small tube, which surrounds the fuel line. Some additional air for combustion is drawn from the room, through the air tube and into the low-pressure zone created by the nozzle airflow. The increase in simplicity with this configuration results largely from the flame shield arrangement. In this case the flame shield is not removed with the nozzle and fuel line assembly. The need for a seal between the flame shield and nozzle face and between the flame shield and the air tube is eliminated. The openings in the back plate can be adjusted to provide some firing rate range. To date tests have been done at a firing rate of 0.33 gph. At $13.2 \% \mathrm{CO}_{2}$ (15\% excess air) smoke number is $0, \mathrm{CO}$ is $26 \mathrm{ppm}$, and $\mathrm{NO}_{\mathrm{X}}$ is $50 \mathrm{ppm}$. Development of this concept is continuing.

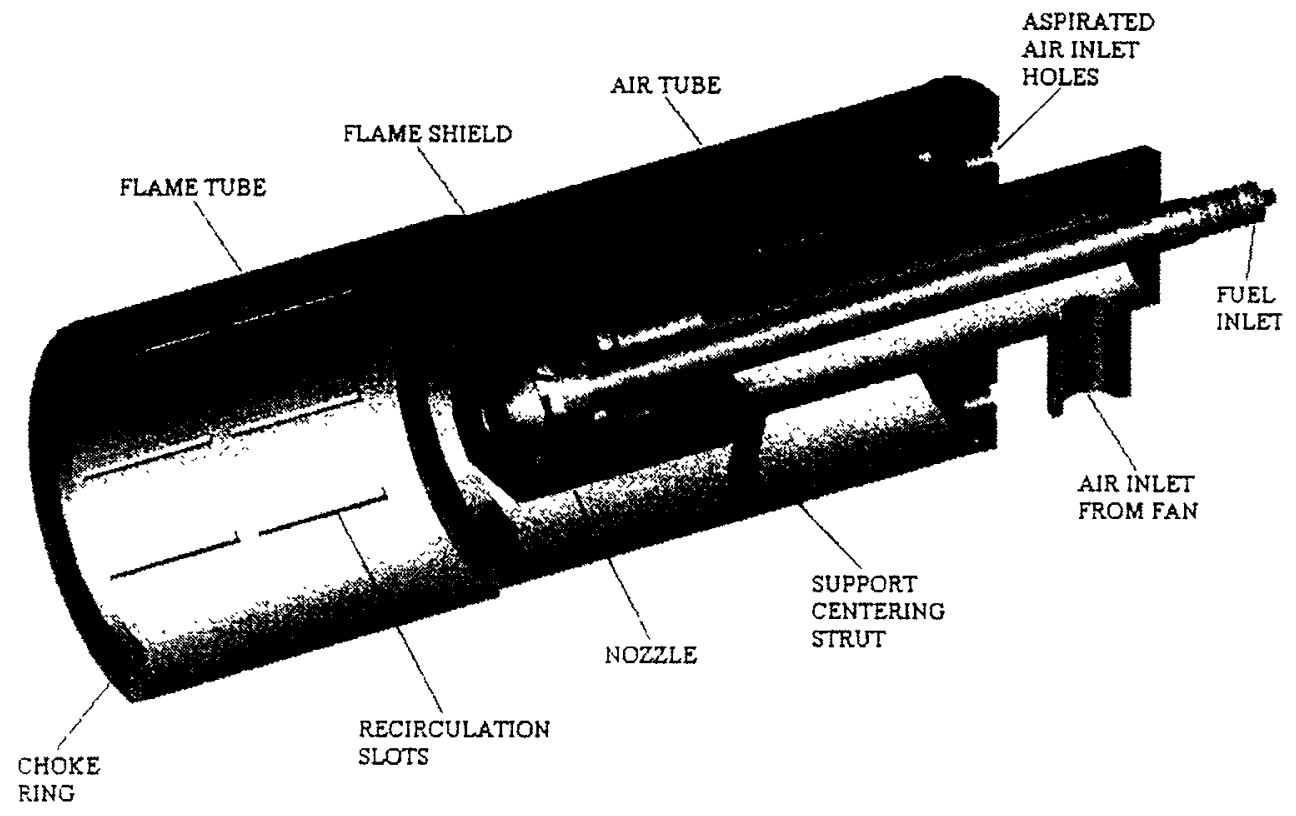

Figure 2. Illustration of simpler concept for HFAB burner head.

\section{$\triangle$ pplication of the HF $\triangle B$ Concept to Thermophotovoltaic Power Generator System}

Thermophotovoltaics (TPV) is a technology for generating electric power directly from a high temperature source such as a flame. Principal components include a light emission source, such as the flame itself or a solid emitting surface heated directly by the flame, and optical filter, and photocells. BNL is currently participating on a team developing a 500 watt TPV power generation system for the U.S. Army. The system will be used in the field for battery charging. For this application the burner requirements are challenging. It must use liquid fuel (diesel or JP-8), run at a nominal rate of $0.07 \mathrm{gph}$, 
and operate with combustion air preheated to $2100^{\circ} \mathrm{F}$. BNL has responsibility for development of the burner, the ignition system, and the combustion air pre-heater. The BNL parts of the overall system are illustrated in Figure 3. In the top half of the system combustion air is preheated by hot exhaust gas leaving the combustion chamber area. Preheated combustion air is directed into the nozzle where it atomizes the fuel. As in the HFAB oil burner arrangement, $100 \%$ of the combustion air is used for atomization. The recuperator and nozzle parts are made of Inconel alloy for high temperature durability. Within the flame zone the flame is contained in a flame tube made of sintered silicon carbide. This is contained inside of a cylinder with one end closed, also made of silicon carbide. This cylinder is the emitter, which is heated by the combustion and emits light that generates electric power in the surrounding photocells (not shown).

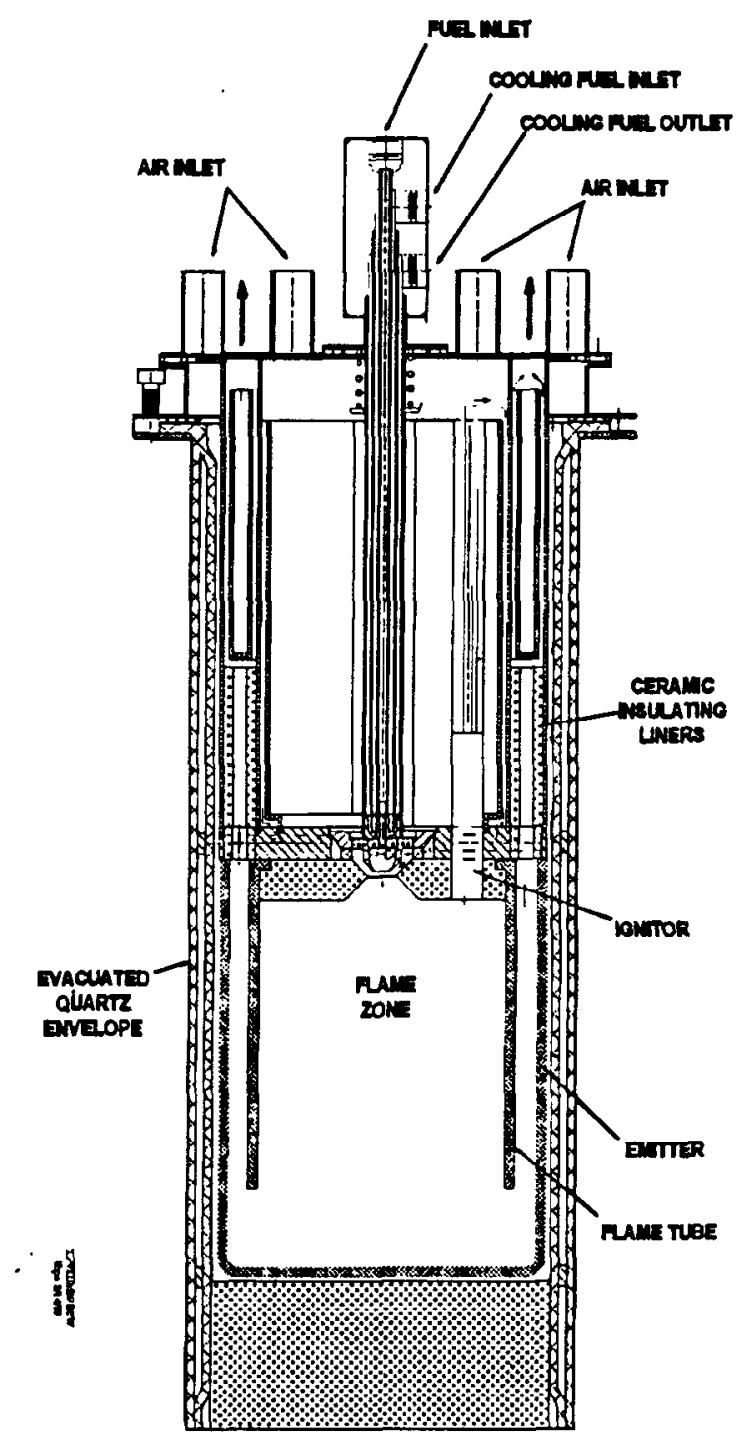

Figure 3. Illustration of part of the TPV Power Generation System Including the Burner, Combustion Chamber and Air Pre-heater. 
Because of the very high temperatures the atomizing nozzle is subjected to, the fuel line must be cooled nearly to the tip. This is accomplished by jacketing the fuel injection line with a fuel-cooling loop. The bypass on the fuel system pressure regulator provides fuel for this loop. Ignition is accomplished using an oil-fueled torch, started with a ceramic hot surface ignitor. This was selected over spark ignition for several reasons, the primary one being reduced overall system weight. In addition, with this approach, the ignitor is completely removed from the combustion chamber where temperatures well over $3000^{\circ} \mathrm{F}$ are expected.

At the present time the optical part of the TPV system is still under development. System integration (see Figure 4) and the first complete system tests are expected by summer, 1999. The burner has been tested for extended periods however. At the design rate $\mathrm{CO}$ in the range of $40 \mathrm{ppm}$ with zero smoke have been measured at $20 \%$ excess air. No coke formation has been observed in the nozzle or chamber area. With high levels of air preheat the $\mathrm{NO}_{\mathrm{x}}$ emissions are high $-350 \mathrm{ppm}$. Such high $\mathrm{NO}_{\mathrm{x}}$ levels are to be expected with highly preheated combustion air. The higher temperatures enhance the conditions for the formation of thermal $\mathrm{NO}_{\mathrm{x}}$ which is the largest single contributor to the total $\mathrm{NO}_{\mathrm{x}}$ levels formed during the combustion process.

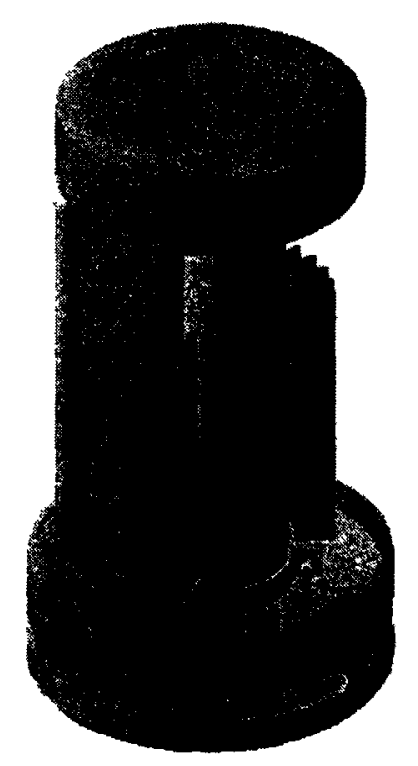

Figure 4. Cut-A-Way Illustration of Integrated Army 500 Watt TPV Power Generator

\section{Computational Fluid Dynamics (CFD) and Burner Design}

To assist in the development of the HFAB, the TPV system, and other combustion concepts BNL is currently using a commercial computational fluid dynamics code. Important features which are calculated using this code include: fuel oil droplet motion and evaporation, combustion of evaporated fuel, $\mathrm{CO}, \mathrm{NO}_{\mathrm{x}}$, soot production, turbulent 
flow, temperature fields in the burner, exchange of heat between surfaces and between surfaces and the flame, and heat transfer within solid members in the flame zone (for example the retention head or flame tube). BNL is planning to conduct some validation tests of the predictions made of temperature and oxygen fields in a practical burner configuration.

\section{$\underline{\text { Conclusions }}$}

The low pressure, air atomizing nozzle burner approach remains under active development at BNL and is seen as an enabling technology for the development of new applications of oil heat.

\section{$\underline{\text { References }}$}

1. Butcher, T. Development of a low pressure, air atomized oil burner with high atomizer air flow - Progress Report FY 1997, BNL Informal Report 66160, January 1998.

2. Butcher, T. Advanced oil burner for residential heating - development report, BNL Informal Report BNL-62077 (July 1995).

3. Krajewski, R., Butcher, T., Celebi, Y., and Wei, G. High-flow fan-atomized burner (HFAB) development. Proceedings of the 1998 Oil Heat Technology Conference, Upton, N.Y. April 7-8, 1998. BNL Report - 52544, April 1998.

4. Butcher, T., Celebi, Y., and Fisher, L. The BNL Fan Atomized Burner System Prototype, Proceedings of the 1995 Oil Heat Technology Conference, Upton. N.Y. March 22-23, 1995. BNL Report -52475, April 1995.

5. Butcher, T. Application of HFAB technology to the development of a 500 watt thermophotovoltaic (TPV) power system, Proceedings of the 1998 Oil Heat Technology Conference, Upton, N.Y. April 7-8, 1998. BNL Report - 52544, April 1998.

6. Butcher, T., Krishna, C.R., Horne, W.E., Mogan, M., Sundaram, and Charters, R. Small-scale power production with oil-fired thermophotovoltaic system, to be presented at Combustion Canada 99, Calgary, Alberta, Canada, May 26-28, 1999. 


\section{Paper No. 99-4}

\section{Fan Atomized Burner (Pioneer) and Its Performance Under Field Conditions}

Bola R. Kamath and Manjunath Kamath

Heat Wise, Inc.

PO Box 662

Ridge, NY 11961

Telephone: 516-345-0447 


\section{Fan Atomized Burner (Pioneer) and Its Performance Under Field Conditions}

Bola R. Kamath and Manjunath Kamath, Heat Wise Inc.

Performance data recorded during the first two years of operation and field experience with the pre-production Pioneer (FAB) burner has been very good and quite comparable to that of more conventional flame retention burners. When poorly adjusted, sooting of the heat exchangers in the absence of adequate combustion air occurred at similar levels with both burner types. When the Pioneer burner was starved for air and there was excess fuel spray, the heat exchangers became fouled and plugged with soot just like with the flame retention burner under comparable conditions. When the fuel spray was limited, it created nuisance flame detection (primary safety lockout) problems. Heat Wise read with great interest, during the last year, several oil heat trade journal articles about "wetting of boilers, dry base or wet base type" and how to handle the associated problems created for the serviceman in the field. These authors discussed only the effects the problem can cause and provided their own suggested solutions to resolve them by cleaning the oil soaked "wet" combustion chambers and restarting the units. Heat Wise studied the problem to find out why this happens.

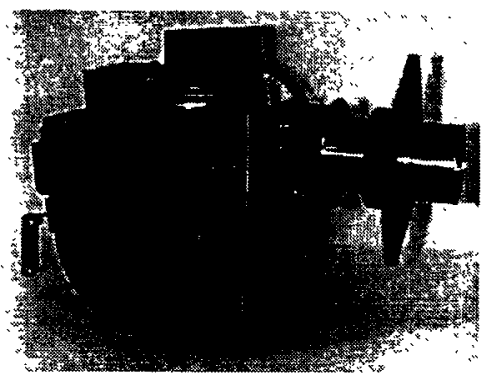

Figure 1. Pioneer Burner Manufactured by Heat Wise Inc.

Heat Wise studied the effect of draft ( 0 to .06 " water column) for flame retention burners and the Pioneer. The study also examined concurrently the effect of varying oil temperature from $30^{\circ} \mathrm{F}$ to $65{ }^{\circ} \mathrm{F}$. Changing combustion air to vary the flame, resulting in $\mathrm{CO}_{2}$ varying from of $9 \%$ to $14 \%$, the "U" shaped curves shown in Figures $2 \mathrm{a}$ and $2 \mathrm{~b}$ were obtained for study regarding the "wetting" (oil soaking) problem. The "U" curves were typical for flame retention burners, with the expected Bacharach smoke numbers and $\mathrm{CO}$ formation. When the percent $\mathrm{CO}_{2}$ became lower due to dilution (due to the increase of excess air), the smoke paper occasionally had a yellow tinge ${ }^{1}$. A corresponding decrease in percent $\mathrm{CO}_{2}$ now showed a higher amount of $\mathrm{CO}$. When the yellow tinge was detected on the smoke paper, the burner was cycled for a day to see the effect. The boiler and stack started to pick up an oil residue and there was a pungent smell within a day. CO numbers were 600 to 800 PPM and the oil stain on the smoke paper had increased.

The "wetting" of boilers could happen if: (1) the burner is initially installed with too much excess air and no adjustment procedure is performed, (2) the initial burner air/fuel adjustment is set at too much excess air because of improper use of the smoke gun (the hand pump used for smoke spot determination), which can lead to a false reading by drawing the pump strokes too rapidly; (3) there is partial plugging of the nozzle which can reduce the fuel flow rate significantly, skewing the air/fuel ratio; and (4) there is partial plugging of the oil filter which increases vacuum on the pump suction and reduces the flow rate. All these lead to significant dilution of the flame, which could cause "wetting" of the boilers.

\footnotetext{
${ }^{1}$ It was noted that the smoke recording varied, depending on the brand of smoke paper. Therefore we took care to take smoke readings using a steady well maintained smoke gun and used only Bacharach brand smoke paper which conforms to ASTM standards.
} 


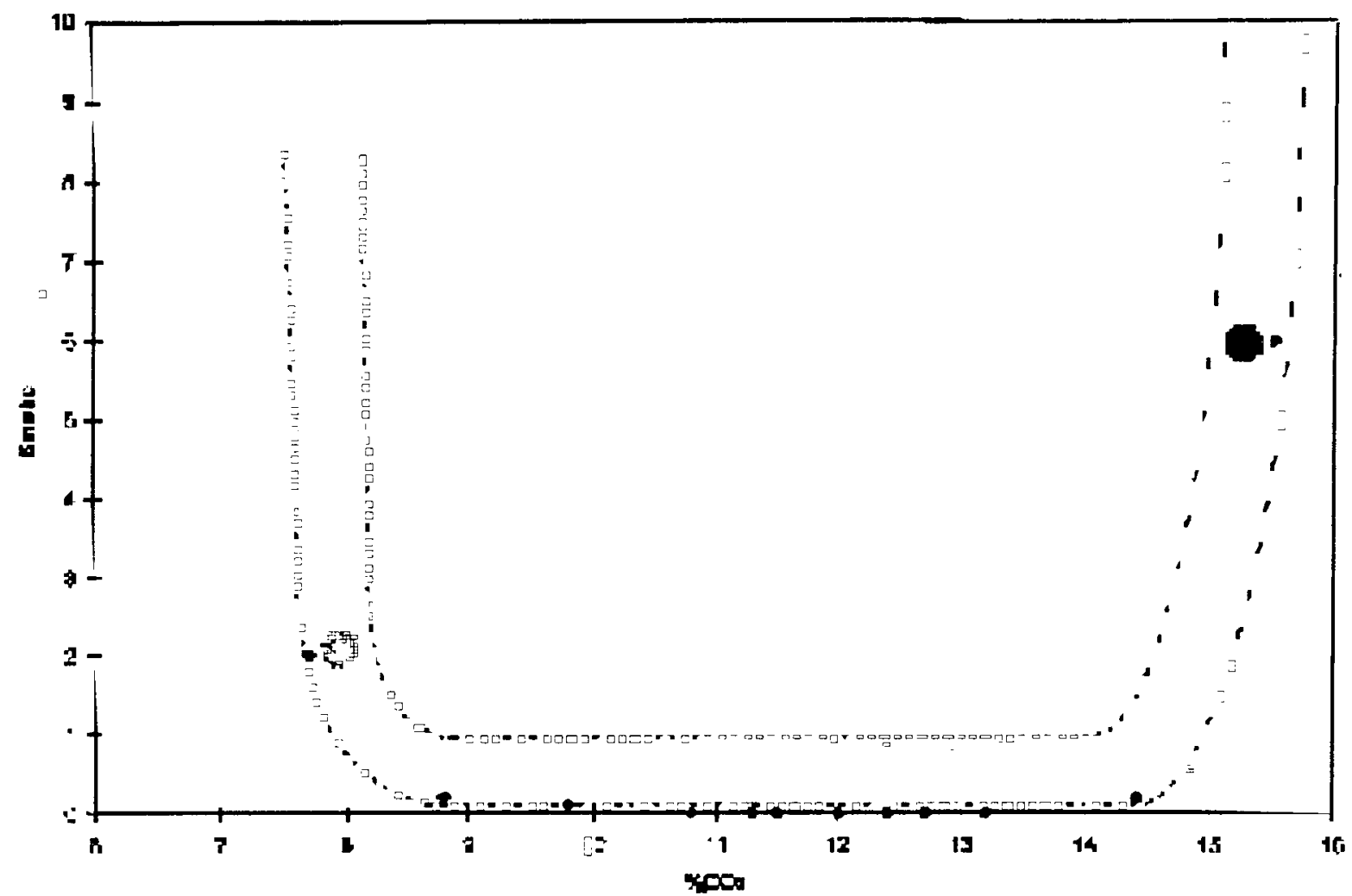

- EIT me

Figure 2a.

Bmole and cor

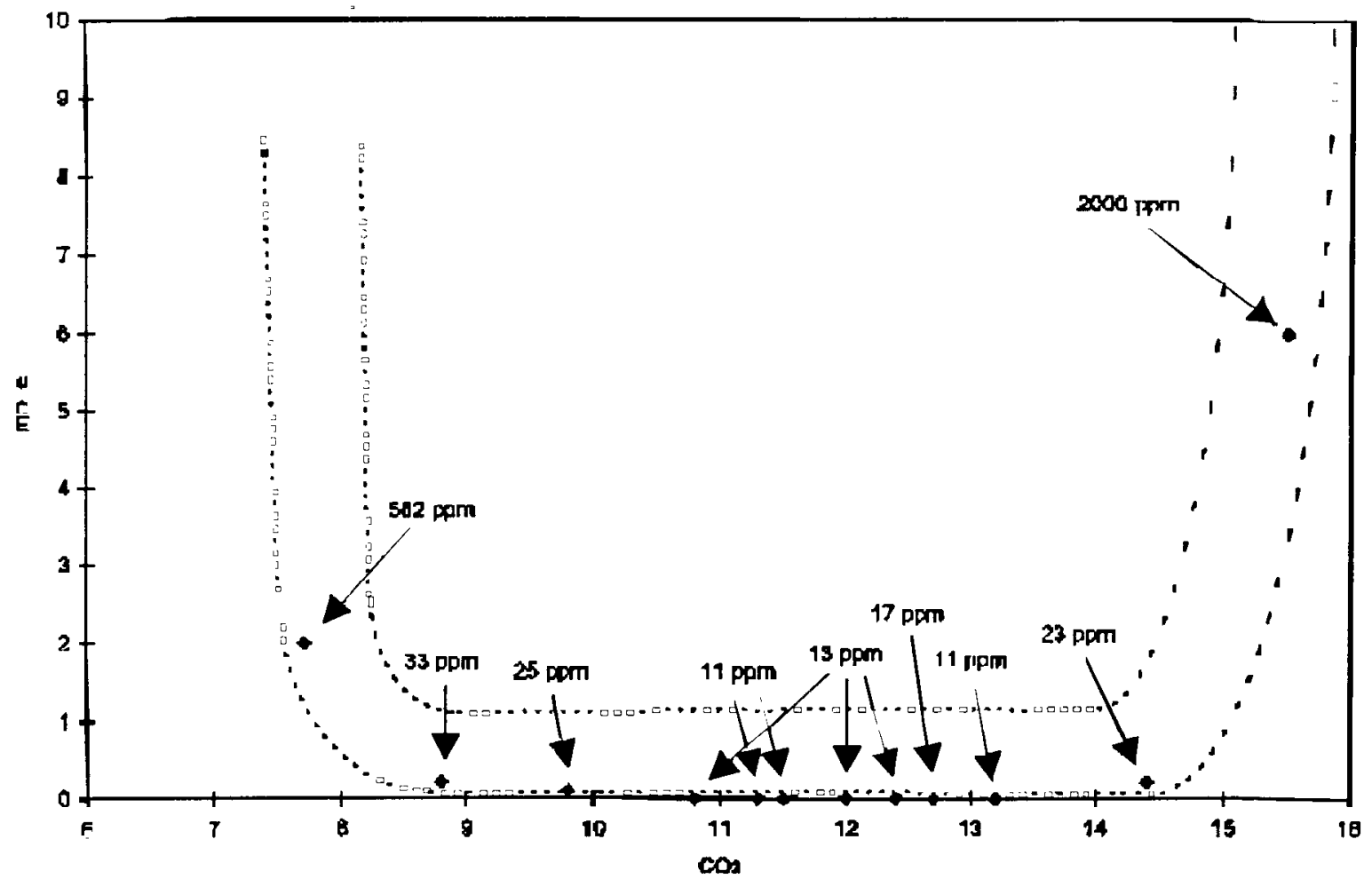

Figure $2 b$. 
Another field installed boiler, rated at $1.5 \mathrm{GPH}$ was equipped with a flame retention burner and was operating with a $0.75 \mathrm{GPH}$ nozzle to heat six different zones in the building! There was also a separate fifty-gallon water heater using the same flue. The boiler had white scale all over. Under firing is another problem that could cause problems at any time.

Figure 3 shows an entirely different situation where the boiler flue passages were not vacuumed and created a significant level of back pressure in the heat exchanger. There was no smoke, but the burner was venting $\mathrm{CO}$ in excess of 600 PPM into the house. By opening the air shutter slightly, the CO level was reduced to 35 PPM and yet the boiler still had a positive pressure of 0.02 " water column (draft measurement) over the fire. After the cleaning of the boiler passages, the same burner after cleaning showed a higher stack temperature along with a four percentage point increase in excess air, but a lower N0x PPM level, 91 PPM before versus 125 PPM after cleaning. The draft was now -0.02 " of water column, an acceptable and normal level. As a result of these measurements we decided to concentrate our efforts on N0x levels. We believe that the flame residence time was significantly longer when the pressure (draft measurement) was positive. This would explain the notably higher NOx level that existed.

\section{Boiler with white scale} and fire box pressure $+\mathbf{0 . 0 2 "}$ ". TIME: 13:06:35

DATE: 01/06/99

FUEL \#2 OIL: COMBUSTION EFFICIENCY: AMBIENT TEMPERATURE:

STACK TDTFRATIURF: OXYGEN:

$\%$ CARBON MONOXIDE:

CARBON DIOXIDE: COMBUSTIBLE GASES:

$\%$ EXCESS AIR:

NITRIC OXIDE:

NITROGEN DIOXIDE:

NOX ( NO + N02):

SULFUR DIOXIDE:

CARBON MONOXIDE ALARM: 50 PI

\section{After cleaning -0.02"Draft over fire}

TIME: 19:23:01

DATE: $01 / 24 / 9$

19360 BTU/LB FUEL \#2 OIL: $83.9 \% \quad$ COMBUSTION EFFICIENCY: $\quad 82.5 \%$ $64 \mathrm{~F}$ $467 \mathrm{~F}$ $04.0 \%$ 35 PPM $12.7 \%$ $0.05 \%$ $22 \%$ $125 \mathrm{PPM}$ 00 PPM $125 \mathrm{PPM}$ 224 PPM

\section{Figure 3. NOx - Wet base boiler with flame retention burner}

Figure 4 shows the results for a Pioneer burner, which has been operating for one year in a dry base boiler. At the same site, there was a similar dry base boiler with a flame retention burner. Identical readings were obtained for excess air in both boilers. The boiler cquipped with the Pioneer burner had an average of 80 PPM N0x, while the boiler with the flame retention burner produced a much higher level of 141 PPM N0x, a 75\% increase of this undesired air emission. 
Pioneer Burner

TIME: 09:27:51

DATE: $12 / 24 / 98$

FUEL \#2 OIL:

COMBUSTION EFFICIENCY:

AMBIENT TEMPERATURE:

STACK TDTERATURE:

OXYGEN:

$\%$ CARBON MONOXIDE:

CARBON DIOXIDE:

COMBUSTIBLE GASES:

\% EXCESS AIR:

NITRIC OXIDE:

NITROGEN DIOXIDE:

NOX ( NO + N02):

SULFUR DIOXIDE:

CARBON MONOXIDE ALARM: 50 PPM

$81.5 \%$

$60 \mathrm{~F}$

$414 \mathrm{~F}$

$08.4 \%$

09 PPM

$09.4 \%$

$0.09 \%$

$62 \%$

80 PPM

00 PPM

80 PPM

40 PPM

\section{Flame Retention Head Burner}

TIME: 11:29:27

DATE: $12 / 24 / 98$

$19360 \mathrm{BTU} / \mathrm{LB}$ FUEL \#2 OIL: $19360 \mathrm{BTL} / \mathrm{LB}$

COMBUSTION EFFICIENCY:

AMBIENT TEMPERATURE:

$84.8 \%$

STACK TEMPERATURE:

TERATURE:

CARBON MONOXIDE: 00 PPM

CARBON DIOXIDE: $\quad 09.2 \%$

COMBUSTIBLE GASES: $0.05 \%$

EXCESS AIR:

$65 \%$

NITRIC OXIDE: $\quad 141 \mathrm{PPM}$

NITROGEN DIOXIDE: .00 PPM

NOX $(\mathrm{NC})+\mathrm{NC}) 2$ ). $141 \mathrm{PPM}$

SULFUR DIOXIDE: $\quad 050$ PPM

CARBON MONOXIDE ALARM: 50 PPM

Figure 4.

Figure 5 compares the performance of the Pioneer (FAB) burner and a flame retention burner, both fired into a wet base hydronic boiler equipped with a target wall and having no refractory chamber. This boiler installed in the field with the flame retention burner had an old oil tank that was recently changed to a new one. Tests conducted before and after indicated that significantly less $\mathrm{SO}_{2}$ was produced with the new tank in place. This suggests that the old tank was badly contaminated with fuel and sludge with high levels of sulfur. The test results (Figure 5) indicate that the same high levels of N0x were present with the flame retention head burner before ( 113 PPM) and after (117 PPM) the tank replacement. This can be compared to the 69 PPM NOx level measured when the Pioneer burner was installed after the fuel tank replacement.

Flame Retention Head /
TIME: $11: 57: 08$
DATE: 01/27/99
FUEL \#2 OIL:
COMBUSTION EFFICIENC)
AMBIENT TEMPERATURE:
STACK TEMPERATURE:
OXYGEN:
CARBON MONOXIDE:
CARBON DIOXIDE:
COMBUSTIBLE GASES:
EXCESS AIR:
NITRIC OXIDE:
NITROGEN DIOXIDE:
NOX ( NO + NO2):
$\quad$ 69 PPM
SULFUR DIOXIDE:

TIME: 11:57:08

DATE: $01 / 27 / 99$

$19360 \mathrm{BTU} / \mathrm{LB}$

STACK TEMPERATURE: $\quad 441 \mathrm{~F}$

OXYGEN

CARBON DIOXIDE:

COMBUSTIBLE GASES:

EXCESS AIR:

NITRIC OXIDE

NITROGEN DIOXIDE:

SULFUR DIOXIDE:

$12.0 \%$

$0.05 \%$

$29 \%$
Flame Retention Head / New Tank

TIME: 11:29:27

DATE: $02 / 25 / 99$

FUEL \#2 OIL:

COMBUSTION EFFICIENCY: $80.7 \%$

AMBIENT TEMPERATURE: $\quad 46 \mathrm{~F}$

STACK TEMPERATURE:

OXYGEN:

22 PPM

$113 P P M$

00 PPM

CARBON MONOXIDE:

CARBON DIOXIDE:

COMBUSTIBLE GASES:

EXCESS AIR:

NITRIC OXIDE:

NITROGEN DIOXIDE:

$\operatorname{NOX}(\mathrm{NC})+\mathrm{NC}) 2)$

202 PPM SULFUR DIOXIDE:
Pioneer Burner in Same Boiler

TIME: $11 \cdot 21: 45$

DATE: $02 / 20 / 99$

FUEL \#2 OIL:

$19360 \mathrm{BTU} / \mathrm{LB}$

COMBUSTION EFFICIENCY: $82.8 \%$ AMBIENT TEMPERATURE: $\quad 71 \mathrm{~F}$

STACK TEMPERATURE: $\quad 464 \mathrm{~F}$

OXYGEN:

$06.0 \%$

15 PPM CARBON MONOXIDE: 30 PPM

$11.1 \% \quad$ CARBON DIOXIDE: $\quad 11.2 \%$

$0.05 \%$ COMBUSTIBLE GASES: $\quad 0.05 \%$

$39 \%$ EXCESS AIR: $\quad 37 \%$

117 PPM NITRIC OXIDE: $\quad 69$ PPM

00 PPM NITROGEN DIOXIDE: O0 PPM

117 PPM NOX ( NO + N02):

058 PPM SULFUR DIOXIDE:

94 PPM

Figure 5. 
Heat Wise staff started taking combustion readings as shown in figure 6. These were for 17 brand new, recently installed boilers. In general the wet-base boilers produced lower N0x levels then the dry base boilers. These are typical readings in the field, but $\mathrm{CO}_{2} \%$ was anywhere from $8.4 \%$ to $12.4 \%$ !

\begin{tabular}{|c|c|c|c|c|c|c|c|c|c|}
\hline \multirow{2}{*}{$\begin{array}{l}\text { Field } \\
\text { Test } \\
\text { Reports }\end{array}$} & \multicolumn{2}{|c|}{ Boiler Type } & \multirow[b]{2}{*}{$\begin{array}{l}\text { Firing } \\
\text { rate(Nozzle) }\end{array}$} & \multirow[b]{2}{*}{ Smoke } & \multirow[b]{2}{*}{$\mathrm{O} 2(\%)$} & \multirow[b]{2}{*}{$\mathrm{CO} 2(\%)$} & \multirow[b]{2}{*}{$\mathrm{CO}(\mathrm{PPM})$} & \multirow[b]{2}{*}{$\mathrm{SO}_{2}^{(\mathrm{PPM})}$} & \multirow[b]{2}{*}{$\mathbf{N O}_{\mathbf{x}} \mathbf{P P M}$} \\
\hline & $\overline{\text { Wet }}$ & Dry & & & & & & & \\
\hline 1 & & $x$ & 1.0 & 0 & 9.6 & 8.4 & $\mathbf{0}$ & - & 191 \\
\hline 2 & & 2 & $1.0 \quad 80^{0} \mathrm{~A}$ & 0 & 5.2 & 11.7 & 22 & - & 105 \\
\hline 3 & & $\infty$ & $0.8580^{\circ} \mathrm{A}$ & 0 & 5.0 & 11.9 & 12 & - & 108 \\
\hline 4 & 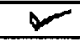 & & $1.580^{0} \mathrm{~B}$ & 0 & 5.8 & 11.3 & 0 & - & 99 \\
\hline 5 & & $x$ & $0.8580^{\circ} \mathrm{A}$ & 0 & 7.8 & 9.8 & 4 & - & 106 \\
\hline 6 & $r$ & & $1.2580^{\circ} \mathrm{B}$ & 0 & 4.2 & 12.4 & 0 & - & 107 \\
\hline 7 & & & $1.0 \mathrm{H}$ & 0 & 9.0 & 8.8 & 12 & - & 103 \\
\hline 8 & & r & $0.7580^{\circ} \mathrm{A}$ & 0 & 7.6 & 10.0 & 0 & - & 103 \\
\hline 9 & & $\Delta<$ & $1.080^{\circ} \mathrm{B}$ & 0 & 6.7 & 10.6 & 1 & - & 131 \\
\hline 10 & $\mu$ & & $1.060^{\circ} \mathrm{A}$ & 0 & 4.6 & 12.2 & $\overline{0}$ & - & 121 \\
\hline 11 & 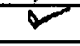 & & $1.060^{\circ} \mathrm{A}$ & 0 & 7.2 & 10.2 & 0 & - & 102 \\
\hline 12 & $N$ & & $1.080^{\circ} \mathrm{A}$ & 0 & 6.2 & 11.0 & 0 & - & 111 \\
\hline 13 & 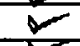 & & $1.580^{\circ} \mathrm{B}$ & 0 & 5.7 & 11.3 & 9 & - & 110 \\
\hline 14 & 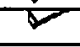 & & $1.2570^{0} \mathrm{~B}$ & 0 & 7.5 & 10.0 & 4 & - & 117 \\
\hline 15 & $N$ & & $0.7570^{0} \mathrm{~A}$ & 0 & 8.3 & 9.5 & 7 & 84 & 103 \\
\hline 16 & 2 & & $1.070^{\circ} \mathrm{A}$ & 0 & 6.1 & 11.1 & 14 & 96 & 126 \\
\hline 17 & & & $0.7570^{\circ} \mathrm{A}$ & 0 & 5.8 & 11.3 & 1 & - & 124 \\
\hline
\end{tabular}

Figure 6.

We have distributed several Pioneer burners after last year's conference. All Pioneer burners were accompanied by combustion data sheets showing the settings (air, pump pressure, etc) for various firing rates. A typical sheet is shown in figure 7. Among the Pioneer burners that were distributed, only one unit was actually installed by service personnel. Without any assistance from the staff at Heat Wise, and this burner is still cycling. The others units have not been installed. Since the nozzle, pump and fuel-supply system are unique to this new burner, we wrote the Pioneer manual, which contains two parts. Part I was like most other oil burner manuals; Part II provides a great level of detail (specifics) on the Pioneer and its parts and provides recommendations addressing potential concerns when installing the unit in the field.

\section{Conclusions}

NOx levels produced in oil flames are not just related to the burner design features. The presence of a chamber plays a major role as well. The PPM NO $\mathrm{N}_{\mathrm{X}}$ level, as measured in a wet based boiler equipped with only a target wall is significantly lower when compared to the same boiler using a full combustion chamber. A completely wet base boiler without a target wall should reduce this level further. The Pioneer is distinctly a low NOx burner when compared to any other flame retention burner in use today.

As a result of the experience gained from field practice and operational situations encountered over the last two years we have decided to make this burner simpler with no special pump, no solenoid valve, no pressure regulator and with a simpler burner head. In the mean time, several units are still performing in the field, but they don't release unburned fuel that can "wet" the boilers and they continue to produce only very low levels of $\mathrm{NO}_{\mathrm{X}}$. The newer version of the burner has already been designed and is cycling under test conditions at our facility. We should be able to bring this version to the market place soon after it is listed with U.L. 
The physical effects of $\mathrm{NO}_{\mathrm{X}}$ and $\mathrm{SO}_{2}$ are well known. The Pioneer burner can operate at very low excess air levels. Avoiding the unnecessary levels of excess air required with other oil burner designs is very beneficial. Operation at low excess air levels reduces the amount of $\mathrm{SO}_{3}$ that is formed during combustion. Reduced $\mathrm{SO}_{3}$ formation leads to lower corrosion rates and reduced scaling of the metals used in the heat exchanger. This is important in both maintaining efficiency and avoiding unnecessary maintenance calls to clean fouled heat exchangers

PIONEER AD 276689

7" Pitch End Cone, Std. 3 Hule Fuel Distributur with pre-post(2minutes) Control

Draft 0.28 " w.c. with inducer Fan On.

HEAD SETTING

22

20

18

17
FLOW RATE PRESSURE(GPH)

0.33

0.38

0.43

0.51
PUMP PRESSURE(psi)

10

11

12

13
Time: 09:51:18

Date: 04/30/98

Fuel \#2 OIL:

AMBIENT TEMPERATURE: $\quad 71 \mathrm{~F}$

STACK TEMPERATURE: $\quad 202 \mathrm{~F}$

OXYGEN:

CARBON MONOXIDE: $\quad 48 \mathrm{PPM}$

CARBON DIOXIDE:

COMBUSTIBLE GASES: $\quad 0.33 \%$

EXCESS AIR:

NITRIC OXIDE:

NITROGEN DIOXIDE:

$\mathrm{NO} \times(\mathrm{NO}+\mathrm{N} 02):$

SULFUR DIOXIDE:

Time: 10:04:37

Date: $04 / 30 / 98$

COMBUSTION EFFICIENCY: $\quad 84.2 \%$

AMBIENT TEMPERATURE: $\quad 75 \mathrm{~F}$

STACK TEMPERATURE: $\quad 248 \mathrm{~F}$

OXYGEN:

CARBON MONOXIDE: $\quad 41$ PPM

CARBON DIOXIDE: $\quad 10.0 \%$

COMBUSTIBLE GASES: $\quad 0.33 \%$

EXCESS AIR:

NITRIC OXIDE:

NITROGEN DIOXIDE:

$\mathrm{NO} \times(\mathrm{NO}+\mathrm{N} 02)$ :

SULFUR DIOXIDE:
$53 \%$

98 PPM

0 PPM

98 PPM

$116 \mathrm{PPM}$
Time: 09:12.00 Flow Rate 0.38 GPH

Date: $04 / 30 / 98$

Fuel \#2 OIL: $\quad 19360 \mathrm{BTU} / \mathrm{LB}$

COMBUSTION EFFICIENCY: $\quad 84.3 \%$

AMBIENT TEMPERATURE: $\quad 71 \mathrm{~F}$

STACK TEMPERATURE: $\quad 251 \mathrm{~F}$

OXYGEN:

CARBON MONOXIDE: $\quad 54$ PPM

CARBON DIOXIDE: $\quad 9.7 \%$

COMBUSTIBLE GASES: $\quad 0.26 \%$

EXCESS AIR: $\quad 57 \%$

NITRIC OXIDE: $\quad 85$ PPM

NITROGEN DIOXIDE: $\quad 0$ PPM

$\mathrm{NO} \times(\mathrm{NO}+\mathrm{N} 02): \quad 85 \mathrm{PPM}$

SULFUR DIOXIDE: $\quad 107 \mathrm{PPM}$
Time:10:18:43 Flow Rate $0.51 \mathrm{GPH}$

Date: $04 / 30 / 98$

COMBUSTION EFFICIENCY: $\quad 81.8 \%$

AMBIENT TEMPERATURE: $\quad 76 \mathrm{~F}$

STACK TEMPERATURE: $\quad 306 \mathrm{~F}$

OXYGEN: $\quad 7.7 \%$

CARBON MONOXIDE: $\quad 26 \mathrm{PPM}$

CARBON DIOXIDE: $\quad 9.9 \%$

COMBUSTIBLE GASES: $\quad 0.34 \%$

EXCESS AIR: $\quad 55 \%$

NITRIC OXIDE: $\quad 98$ PPM

NITROGEN DIOXIDE: 0 PPM

$\mathrm{NO} \times(\mathrm{NO}+\mathrm{N} 02): \quad 98 \mathrm{PPM}$

SULFUR DIOXIDE: $\quad 124$ PPM

Figure 7. 


\section{Paper No. 99-5}

Use of No-Drip Nozzle Valves for Reducing Emissions During Burner Start-up and Shutdown

Richard Theurer and Bart Frame

Hago Mfg. Co., Inc.

1120 Globe Ave.

Mountainside, N.J. 07092 


\title{
Use of No-Drip Nozzle Valves for Reducing Emissions During Burner Start-up and Shutdown
}

\author{
Richard Theurer and Bart Frame \\ Hago Mfg. Co., Inc. \\ 1120 Globe Ave. \\ Mountainside, N.J. 07092
}

\section{Introduction}

For as long as homes have been heated with oil burners using direct pressure atomizing nozzles, there have been many technical problems associated with fuel oil after-drip from the nozzles, after burner shutdown.

Among these problems are customer complaints resulting from odor, drippage of oil on the floor outside the burner, fouling of the burner's combustion head/air swirler, fouling of electrodes, excessive sooting, rumbling shutdowns and of course, wasted energy.

A simple, cost effective solution to this problem is currently available to the market in the form of a new generation of no-drip nozzle shut-off valve.

\section{Background}

Burner start-up is a critical period in the efficient operation of an oil burner. The oil in the supply pipe leading to the nozzle is typically pressurized to 100 PSI or greater during burner operation. When the burner gets a signal to start operation, the pump builds it's pressure from zero to the full operating pressure. During this very short period of pressure build-up, the atomization begins very coarsely and rapidly changes into a very fine mist. During this period of incomplete atomization, there is, of course, a period of incomplete combustion and therefore, sooting. This production of soot eventually results in the reduction of heat transfer thus, reducing the operating efficiency of the unit.

Conversely, at shut-down, when the burner ceases operation, the pump cutoff closes the oil flow and the pressure between the pump and the nozzle drops to atmospheric pressure because the nozzle orifice is open to the atmosphere. This occurs even if the unit is equipped with a solenoid valve because it is located 6" or so away from the nozzle. As the pressure gradually diminishes over 2 to 3 seconds, the force to atomize the oil into fine droplets diminishes. The droplets become larger and larger until all atomization completely ceases. During this transition, the spray collapses momentarily into a spray "bubble" and then very quickly changes into a straight stream. This un-atomized stream of oil can often continue for an additional 1 to 2 seconds. You have seen the same thing happen when you turn off your garden hose. It is conceptually the same with an oil nozzle, but on a much smaller scale.

The chart and graph of drop size distribution on the following page demonstrate the degree to which atomization deteriorates as pressure declines. It is these increasingly larger droplets that create incomplete combustion. 


\section{Spray Droplet Distribution of a Typical Oil Burner Nozzle}

Calculation method: Rosin-Rammler modeled Fraunhofer diffraction theory

Verification:

Nozzle Type:

$\mathrm{Xbar}:$

D-32:

D-90:
ASTM Test Reticle

Hago $1.0080^{\circ} \mathrm{H}$ oil burner nozzle

Rosin-Rammler mean diameter.

Sauter mean diameter. The diameter of the drop whose ratio of volume to surface area is the same as that of the entire spray.

The diameter at which $90 \%$ of the total volume is in droplets of smaller diameter.

\begin{tabular}{|c|c|c|c|c|c|c|}
\hline Pressure & Pressure & Flow Rate & Flow Rate & X-bar & D-32 & D-90 \\
\hline (psi) & (bar) & (gph) & (Iph) & (um) & (um) & (um) \\
\hline 15 & 1.03 & 0.39 & 1.47 & 185.9 & 106.4 & 298.1 \\
\hline 20 & 1.38 & 0.45 & 1.69 & 112.2 & 67.3 & 168.9 \\
\hline 30 & 2.07 & 0.55 & 2.07 & 73.5 & 45.5 & 108.2 \\
\hline 40 & 2.76 & 0.63 & 2.39 & 59.1 & 37.6 & 85.4 \\
\hline 50 & 3.45 & 0.71 & 2.68 & 51.8 & 32.9 & 74.9 \\
\hline 60 & 4.14 & 0.77 & 2.93 & 49.3 & 31.3 & 71.5 \\
\hline 70 & 4.82 & 0.84 & 3.17 & 46.0 & 28.6 & 67.7 \\
\hline 80 & 5.51 & 0.89 & 3.39 & 43.5 & 27.1 & 63.5 \\
\hline 90 & 6.20 & 0.95 & 3.59 & 41.2 & 25.9 & 60.2 \\
\hline 100 & 6.89 & 1.00 & 3.79 & 40.4 & 25.0 & 59.7 \\
\hline 110 & 7.58 & 1.05 & 3.97 & 37.2 & 23.0 & 54.7 \\
\hline 120 & 8.27 & 1.10 & 4.15 & 37.2 & 22.6 & 55.3 \\
\hline 130 & 8.96 & 1.14 & 4.32 & 36.7 & 22.5 & 54.5 \\
\hline 140 & 9.65 & 1.18 & 4.48 & 35.6 & 21.8 & 52.7 \\
\hline 150 & 10.34 & 1.22 & 4.64 & 34.2 & 20.8 & 50.7 \\
\hline
\end{tabular}

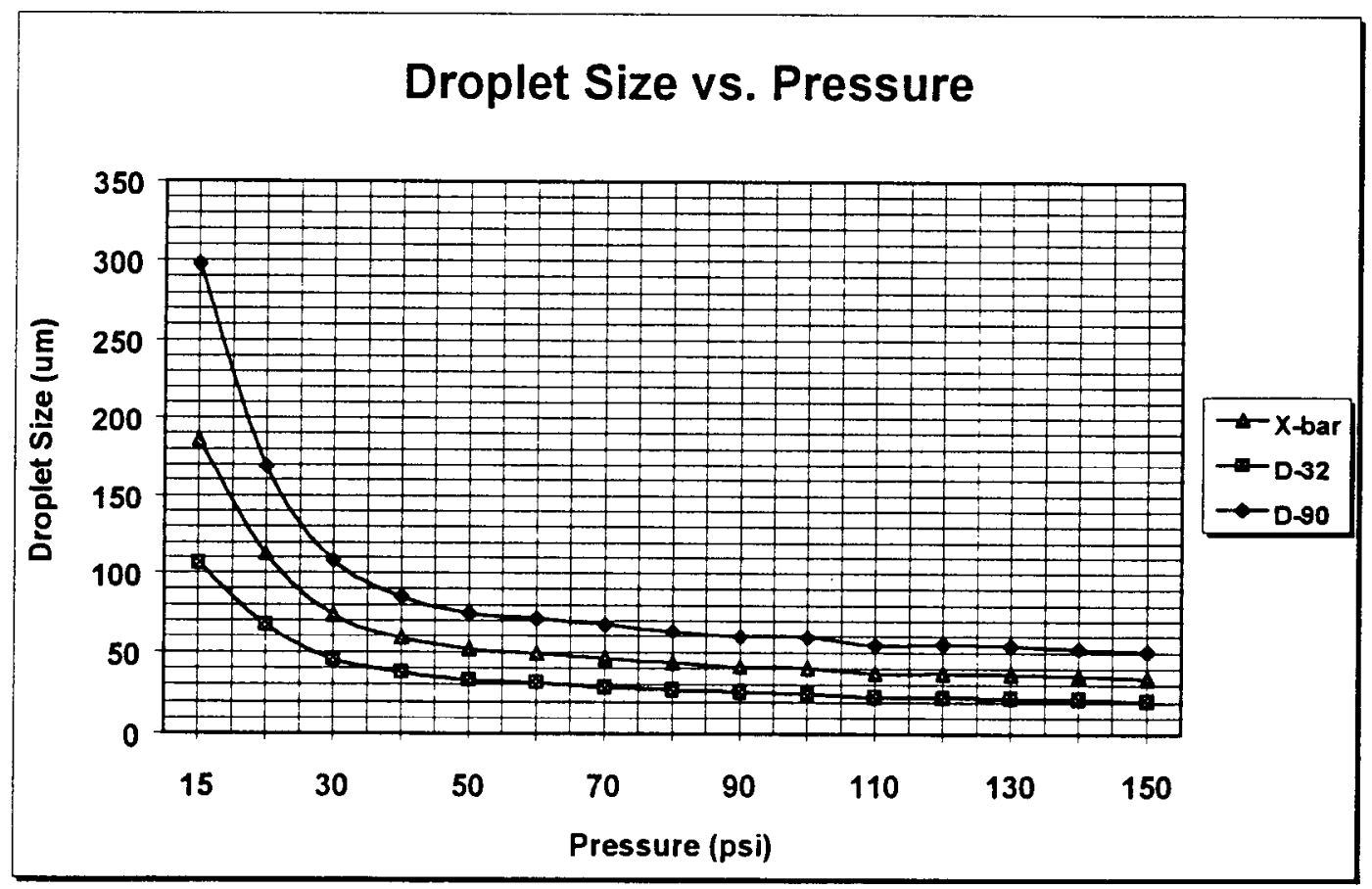




\section{Discussion}

Any unburned oil that comes to rest in the bottom of the combustion chamber has a foul odor that must be vented out the chimney or it may creep into the occupied part of the residence. If there is enough to form a puddle, it can re-ignite and give a smokey after-burn that contributes greatly to sooting of heat transfer surfaces. This process of venting the fumes is now regularly achieved with a continuation of the burner blower fan for a period after shutdown and is commonly referred to as the "post purge". Unfortunately, the post purge requirement is also recognized as a major contributor to the lowering of burner efficiencies.

Post purge time duration varies. It is estimated that only about a one minute post purge time is actually needed to clear the combustion chamber and exhaust ducts of smoke and combustion by-products. However, if the post purge is lengthened to allow complete clearance of the odors resulting from nozzle after-drip, the duration can reach up to 5 minutes. In general, the longer the duration of post purge cycles, the greater the reduction in AFUE efficiencies. With power vented systems the loss of efficiency is even greater than for non-power vented systems because more heated air is purged than with a natural draft system. In non-power vented systems the post purge is a natural phenomenon in which the flue gases and odors rise up the chimney by naturally existing forces. Additionally, the natural nozzle cooling provided under sustained offcycle draft flows in a chimney vented system results in less after-drip.

Aside from the transient changes in start-up and shut-off pressures, the phenomenon of after-drip is also caused at least by two other factors. Most important is the presence of air in the oil line, nozzle adapter and/or nozzle. During burner operation, any air present is under high pressure and is compressed. When the pressure is relieved during the pump's "Off" cycle this air expands, resulting in some oil droplets being forced out through the end of the nozzle. Because it has no other place to go, it naturally follows the path of least resistance. The second major factor causing after-drip is heat that is reflected back onto the nozzle and oil line after burner shutdown. This heat, which can raise the temperature of the nozzle to $350^{\circ} \mathrm{F}$., causes the oil in the nozzle and oil line to become warmer, which expands it's volume. Similar to the air problem cited above, this expansion forces some oil droplets out the nozzle's orifice. In some instances, nozzle preheating devices also can cause this phenomenon as an unintended side effect.

As we all know, soot build-up on any surfaces in the furnace or boiler causes a greatly reduced operating efficiency. Today's modern burners have been so well engineered that it is fair to say that they create very little or no smoke or soot while they are burning. In a properly tuned system it is primarily at start-up and shutdown that smoke and soot are created.

In a report entitled "Expanded Use of Residential Oil Burners to Reduce Ambient Ozone and Particulate Levels, Dated Oct., 1997, the author, Mr. John Batey, President of Energy Research Center, Inc. says "research suggests that during normal cyclic operation as much as two-thirds of the total smoke produced occurs during these starting and stopping transients. During start-up, a transient pressure pulse affects the fuel air ratio, and during burner shutdown lower oil pressure reduces fuel atomization quality as the burner stops and can cause after-drip. Both of these contribute to higher smoke as the burner starts and stops." It therefore stands to reason that if the 
creation of smoke and soot can be nearly eliminated at these points of the cycle, the total amount created over the course of a heating season will be very greatly reduced. This means that the ease and costs of Spring tune-ups will also be reduced considerably and service calls during the season should also be reduced.

Soot and the necessity for post purge cycles, are major contributors to inefficient burner operation. Tests conducted a few years ago by ETL labs for Brookhaven National Laboratories showed substantial furnace and boiler efficiency reductions due to post purging. Their tests showed Annual Fuel Utilization Efficiency (AFUE) drops of $8 \%$ for boilers and $14 \%$ for furnaces by increasing post purge times from 1 minute to 5 minutes. There was some debate about the magnitude of these losses, but the significant fact is that eliminating nozzle after-drip can either eliminate or substantially reduce post purge time and sooting.

In summary, the principal energy losses attributed to start-up and shutdown cycles in residential burners generally break down into three categories:

1) During initial start-up, low oil pressures create poorly atomized fuel, thereby causing a short period of unclean burning until full operating pressure is reached. This cycle repeats itself, startup after start-up, and ultimately contributes to sooting and reduced heat transfer.

2) At shut-down, the residual fuel in the line and nozzle continues to drip into the combustion chamber, again causing incomplete burning, sooting of the chamber and heat transfer surfaces, coking of the burner's air turbulator and the creation of foul smelling fumes.

3) Heat loss up the chimney or out the vent during the off cycle, including powered post purge periods.

It should not be overlooked that a reduction or elimination in the purging of unburned or partially burned hydrocarbons in the form of soot can have an important benefit in improving our air quality. New regulations from the Environmental Protection Agency requiring improvements in ambient air quality call for a reduction in ozone and fine airborne particulate at the local level.

Oil fired equipment produces nitrogen oxide, (a precursor to ozone), and particulate emissions, so there is justifiable concern that steps will be taken that may negatively impact the oil heat market. The particulate emissions that are produced by residential oil burners tend to be generally less than 1 micron in size. Studies have shown that it is the very small particles in the air of 2.5 microns or less that are most damaging to people's health. This means the particulate produced by our industry are those especially targeted for reduction by the EPA. Individual states are left to create their own regulations to achieve the mandated reductions. This makes it clear that, sooner or later it is very likely that the government (local, state or federal) will be after the oil heat industry to help achieve these goals. An obvious first step is the expanded use of inexpensive and effective anti-drip valves on all residential burner installations. 
In recent years various innovations have been developed to reduce these transient-sooting effects. Among these are the addition of solenoid valves, vent dampers, reduction of the internal diameter of oil lines, special internal geometry nozzle adapters, devices to be placed inside the adapter to break up and disburse air, and nozzle ball-spring check valves. All of these have had positive, but less than optimal, benefits and the problems of after-drip have continued. It is clear that to eliminate after-drip to the maximum extent possible, the closer a shutoff device can be located to the nozzle orifice, the better.

The problem with the original ball-spring type nozzle shutoff valves installed inside the nozzle's strainer was that they acted relatively slowly and also that they had a considerable pressure drop through them; often 30 - 35 PSI. This required that the installing service man had to increase the burner's pump pressure by 30 - 35 PSI to compensate for this pressure loss and to assure sufficient atomizing pressure would remain at the nozzle and that nozzle flow rates would thereby remain reasonably accurate. This was not always possible and often servicemen did not understand this and valves were installed without increasing the pressure sufficiently or not at all. Additionally, future servicemen were not always aware of the presence of the valve and did not realize that the pump's pressure had been increased. When they removed the nozzle and installed a new one, if the pressure was not checked and reset accurately, over firing resulted.

The good news is that patented nozzle anti-drip check valves are now available from two different manufacturers that give a positive cutoff right at the nozzle and are designed in such a way as to have virtually no pressure drop through them when the burner is firing. At Hago we call our valves by the registered trade name "EcoValve". In September of 1998 it was granted U.S. Patent \#5799871. Due to the lack of a pressure drop associated with the new generation valves, the negative aspects of prior valves has been overcome. As a result, energy losses due to soot generation as well as fouling in combustion chambers and complaints of odors in residential oil fired heating systems can be significantly reduced, effortlessly, and at a very low cost with the use of these valves. The small extra cost of these valves can be expected to be repaid many times over by the savings they will create.

EcoValve

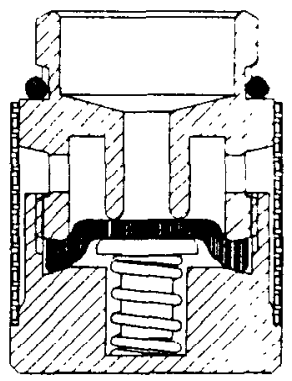

EcoValve Assembled to a Nozzle

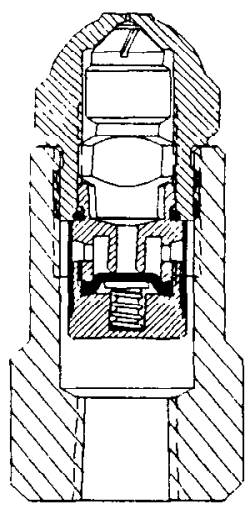


The valves are designed inside a nozzle strainer of standard dimensions so installation consists of simply unscrewing the nozzle's original strainer/filter and screwing the EcoValve in it's place. There are no adjustments necessary to the pump, no re-wiring or re-piping necessary.

The valves function as follows: As the pump at start-up pressurizes, the fuel is forced into the valve cavity. The oil exerts force against the opposing forces of the diaphragm and coil spring. When the force of the oil exceeds that of the opposing forces, the diaphragm/spring snaps open, thereby assuming the open position and permitting oil to flow at full pressure to the nozzle's orifice. It is precisely because of these counter acting forces within the valve that we have been able to achieve a valve that operates with no measurable pressure drop. The point at which the valve is calibrated to open is typically only $10-15$ PSI below the nozzle's full normal operating pressure, assuring full atomization from the instant the spray commences. Very important is the fact that the valve causes absolutely no change in the normal operation of the nozzle other than the elimination of the after-drip. Flow rate, spray angle, spray pattern and spray quality remains unchanged.

At the end of the burner's operating cycle the power is cut to the motor and so it begins a period of gradually decreasing rotational speed and this causes the oil pump to begin a period of corresponding declining pressure to the nozzle. In a normal nozzle, this creates oil droplets that are gradually increasing in size until they finally turn into a sputter and an ongoing dribble for a short period. If the new style anti-drip valve is installed, however, the reducing oil pressure reverses the process described above and the diaphragm/spring snaps closed at a point about 20 to 30 PSI below the snap-open point. The pressure in the oil line and nozzle is then held at this pressure, with no further pressure loss, until the subsequent burner start-up cycle. The following page demonstrates the complete cycle of a model LC EcoValve. 

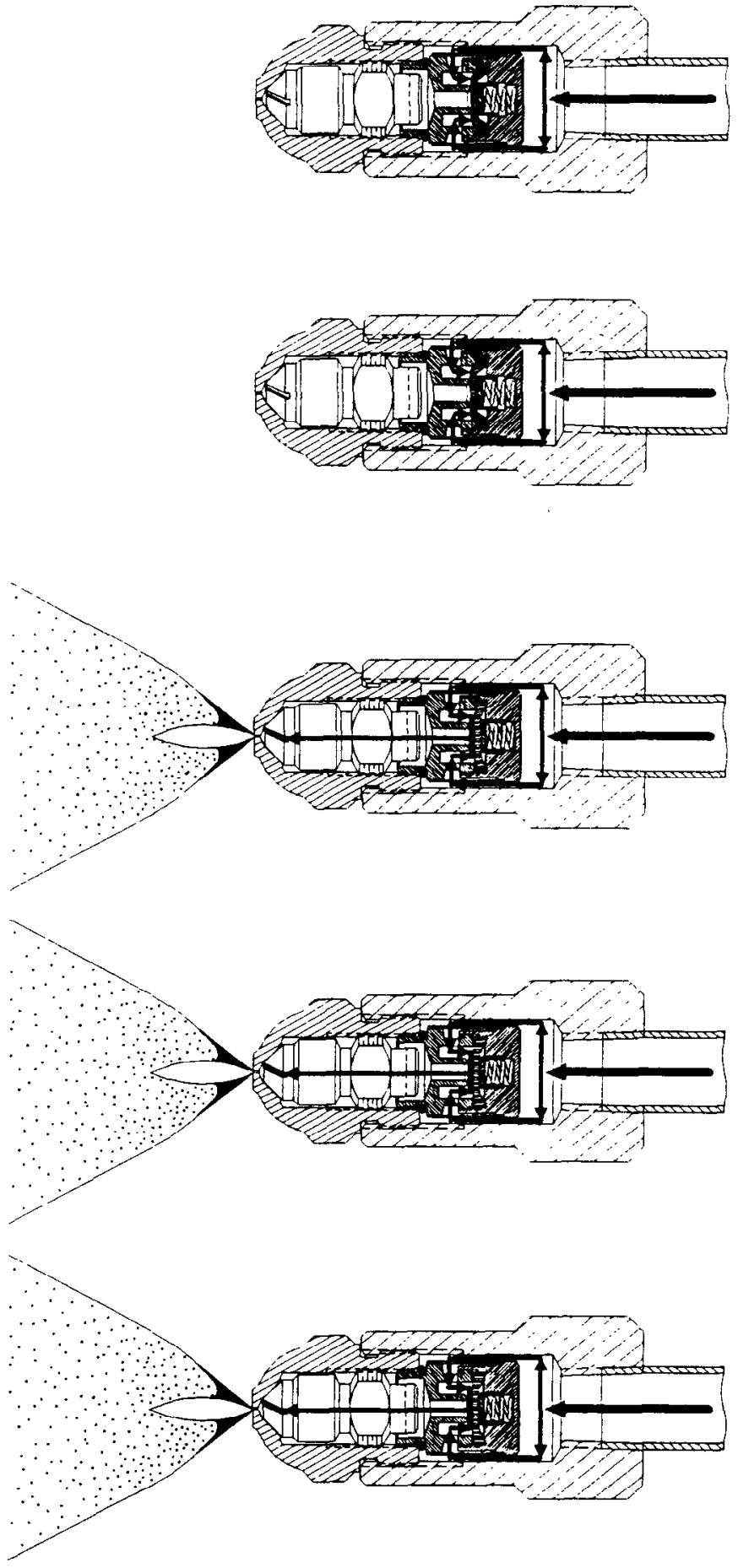

Line Pressure: 55 psi

\section{Cycle Off}

Flow Rate: $\quad 0$ gph

During burner off cycle there is no drip due to reflected heat from the combustion chamber. Note that during burner off cycle, the line pressure will be determined by the lesser of the ECoVALVE closing pressure and the pump cut-off pressure.

Line Pressure: 80 psi

Flow rate: $\quad 0$ gph

During burner cycle start the valve remains totally closed, with no flow and no drip until within 2 psi of the calibrated opening pressure.

Line Pressure: 90 psi

\section{Cycle Start}

Flow rate: $0.95 \mathrm{gph}$

During burner cycle start the EcoVALVE completely opens at the calibrated opening pressure. There is a fully developed spray with complete atomization and flow rate that is typical of 90 psi line pressure. Therefore, the flow rate at that instant is $0.95 \mathrm{gph}$. The valve reacts to pressure change instantaneously. Therefore, the duration of cycle start is dependent upon the burner system.

Line Pressure: 100 psi

\section{Steady State}

Flow rate: $\quad 1.00 \mathrm{gph}$

During burner steady state operation the EcoVALVE remains completely open with no effect on flow rate, spray angle or spray pattern.

\section{Cycle Stop}

Line Pressure: 56 psi

Flow Rate: $0.75 \mathrm{gph}$

During burner cycle stop the EcoVALVE remains completely open until within I psi of the calibrated closing pressure. There is a fully developed spray with complete atomization and flow rate that is typical of $56 \mathrm{psi}$ line pressure. Therefore, the flow rate at that instant is $0.75 \mathrm{gph}$. The valve reacts to pressure change instantaneously. Therefore, the duration of cycle stop is dependent upon the burner system.

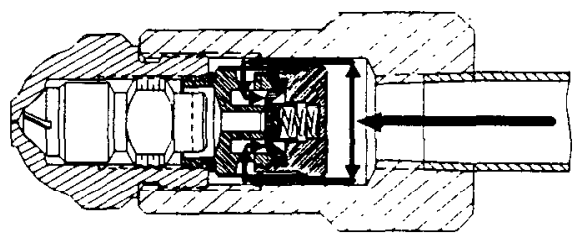

Line Pressure: 55 psi

Flow Rate: $\quad 0$ gph

The instant the line pressure drops to the calibrated closing pressure the ECOVALVE closes completely, thus eliminating after-drip and incomplete atomization. The ECoVALVE remains completely sealed until the calibrated opening pressure is reached again. 


\section{Combustion Results}

The following chart shown depicts the typical performance of a residential oil burner in a wet based boiler using a standard nozzle with and without an anti-drip valve. The dotted line shows a burner start-up with a newly installed nozzle without an EcoValve generating a short spike of Carbon Monoxide, (CO) with a value of about 30 PPM that gradually diminishes and lasts for roughly one minute. The $\mathrm{CO}$ emissions cease during the running cycle but at shutdown begins to climb again. The CO spike recommences, climbing to about 75 PPM and then diminishing back to zero over a period of about $2 \frac{1 / 2}{2}$ minutes. Subsequent cycles reproduce these spikes, albeit at slightly lower values, again and again continuing endlessly for the life of the installation. $\mathrm{CO}$ production, it can be said, parallels soot production, and so periods of escalated $\mathrm{CO}$ production equate directly to periods of elevated soot production.

The solid line shows the same unit with an EcoValve installed on the same nozzle. Beginning with the first start-up cycle you will note there was no $\mathrm{CO}$ spike and the first shut-down spike reached a peak of only about 45 PPM of $\mathrm{CO}$ and lasting for only about one minute. Most importantly, the second shutdown cycle produced a CO spike of only about 3 PPM and thereafter there was no CO spikes whatever at shutdown. The complete elimination of both start-up and shutdown CO spikes then continued on for the rest of the burner's cycles. It is the elimination of these $\mathrm{CO}$ spikes that led John Batey to state in his previously referenced report "The new fuel nozzle cut-off valves offer an effective and low cost option for substantially lowering oil burner smoke during start-up and shut-down which can reduce total smoke and soot emissions by as much as two-thirds".

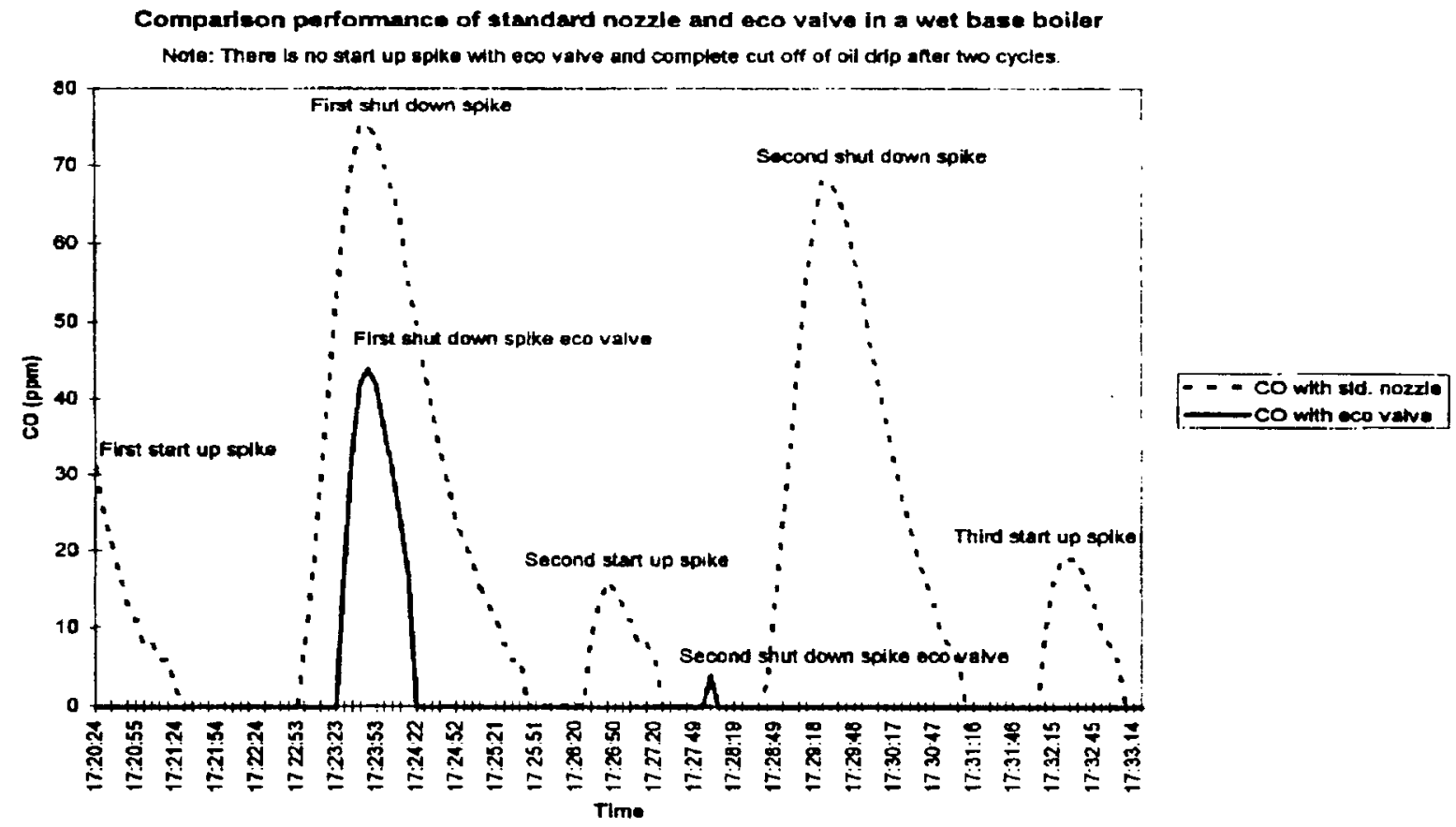

Tests performed by Dr. Bola Kamath, Heatwise inc.

The apparent reason for the slightly higher readings on first start-up after installation is due to air in the nozzle and oil line that is gradually purged during the first few minutes of continual operation and, possibly, the start-up in a cold combustion chamber. 


\section{Reliability}

The mechanical life of these devices is, of course, important. At Hago, we set up a test bench of about 50 of our EcoValve anti-drip devices installed on nozzles and continually cycled them on and off at two second intervals at a pressure of 145 PSI, night and day, until we had concluded well over one million complete cycles. Throughout the tests, the oil temperature remained at approximately $120^{\circ} \mathrm{F}$. as a result of the warming effect of the pump's operation. During the period of the test we experienced absolutely no valve failures. The valves were then individually re-tested. It was found that most had experienced a decline of about 10 PSI in both their opening and closing points, but that the opening and closing remained positive and complete with afterdrip remaining eliminated. One million burner cycles would be greater than 80 years of actual cycles in a residential burner, so we feel the EcoValves are a totally and reliable long term accessory to be used with oil nozzles. Since the lab tests, performed in 1996, these valves have been widely used in the field worldwide and actual operating results have confirmed our test conclusions.

\section{Further Improvement}

One remaining problem is that a small after-drip can occur if the reflected heat on the nozzle is exceedingly high. This would be more likely with certain very hot chamber furnace applications. Our tests have shown that at temperatures of around $350^{\circ} \mathrm{F}$. the temperature-induced expansion of the oil volume in the nozzle can create a pressure which is sufficient to force open the valve's diaphragm momentarily and allow a tiny drip of oil to weep out of the nozzle orifice until the pressure has been relieved. As the oil expands it cannot be compressed and so it must go somewhere to escape and the nozzle orifice is currently the only possible place. This is still a significantly less volume than if a valve were not installed.

A solution to this problem would be to somehow relieve this pressure back to the suction side of the pump. Attempts have been made in the past to develop such a system. These systems have required specially calibrated pump and nozzle combinations. This is an area we are considering for further research and development.

\section{Summary}

The problems caused by after-drip of oil from oil burner nozzles are varied and problematic. After-drip causes loss of unit efficiency, wasted oil and many service problems. The resulting soot is a factor that contributes to the incorrect unfortunate image of oil as being a dirty means of residential heating. With a very low price in the range of $\$ 3.00$ to $\$ 4.00$, the new nozzle antidrip valves offer the industry an extremely simple and cost effective means of solving these many problems. Regretfully, thus far, in the field, many have insisted on installing them only on "trouble Jobs", or on taking a "wait and see" attitude for a few years. We suggest that the manufacturers of oil burners and appliances take a more serious study of the benefits of these devices for their equipment and our industry. Utilizing these valves as standard OEM equipment will demonstrate their effectiveness to the field. Proven technologies such as these valves are here and ready today and progressive members of the oil heat industry need to learn more about them and start utilizing them. 
Paper No. 99-6

\section{Fouling of Heat Transfer Surfaces in Domestic, Oil-Fired Heating Boilers}

T. Butcher, Ph.D., BNL, S. Win Lee, CANMET-CETC, Y. Celebi, BNL, and W. Litzke

Report Reprint of BNL-64833, Previously Published for Limited Distribution

Presentation: Pros and Cons of Lower Sulfur level Specification in ASTM No. 2 Fuel Oil

Victor Turk, R.W., Beckett Corporation, \&

Roger McDonald, Brookhaven National Laboratory 


\title{
Fouling of heat transfer surfaces in domestic, oil-fired heating boiiers
}

\author{
T BUTCHER* S W LEE**, Y CELEBI*, W LITZKE*
}

Domestic heating boilers fired with distillate oil are subject to fouling of the convective section gas-side surfaces. This fouling leads to a reduction in efficiency and increased maintenance requirements. A rapid test to enable fouling deposit composition and fouling rates to be studied has been developed and used at two laboratory sites. The test involves special fouling surfaces which can be removed for deposit analysis. It is shown that fouling rates are directly related to fuel sulfur content. Also, operation with reduced excess air in these boilers can reduce fouling rates by reducing the conversion of fuel sulfur to sulfuric acid. Results are compared with full size boiler tests.

\section{Introduction}

This work has addressed the fouling of the convective heat exchanger surfaces of small, oil-fired domestic heating boilers. These boilers are commonly either steel, firetube type or cast iron with pin or fin type convective sections. These are hot water boilers with outlet water temperatures of $75-95^{\circ} \mathrm{C}$ and return water temperatures typically $55-65^{\circ} \mathrm{C}$. Oil bumers used in these boilers are of the pressure atomized, retention head type and typically operate with $20-50 \%$ excess air. These burners are installed with firing rates higher than required and an oversize factor of $70 \%$ is considered typical. The burners effectively modulate input by operating in an on-off mode. For efficiency labeling purposes ${ }^{1}$ a typical cycling pattern of 9.68 minutes on and 33.6 minutes off has been adopted in the U.S.

In this paper "oil" alwavs refers to distillate oil commonly used for home heating applications. In the U.S. and Canada this is referred to as Number 2 heating oil and is similar to diesel fuel. Typically in the U.S. these fuels have a sulfur content of $2000 \mathrm{mg} \mathrm{kg}^{-1}$, a $50 \%$ distillation temperature of $260^{\circ} \mathrm{C}$, and an API gravity of 35 . Oil heating values, where used here, are gross or higher heating values and boiler thermal efficiencies are based on these.

During normal operation, fouling deposits accumulate on the gas-side of convective section surfaces, leading to efficiency degradation and a requirement for seasonal cleanings. The average rate of efficiency degradation of these systems has been estimated at about $2 \%$ per year ${ }^{2}$. In severe cases, the fouling leads to near-complete blockage of the convective sections, increased pressure of combustion products in the combustion chamber, and spilling of combustion products into the home. Factors which may contribute to the fouling of these heat exchangers include: the deposition of carbonaceous soot from incomplete combustion of the fuel oil, oxygen corrosion of metal on the boiler surface and the formation of metal oxides, and attack on the boiler metal by sulfates formed during combustion and the formation of metal sulfates.

\footnotetext{
* Department of Applied Science, Brookhaven National Laboratory, Upton, N.Y., U.S.A.

** CANMET Energy Technology Center, Natural Resources Canada, Ottawa, Canada
} 
Consideration of the possible role of soot in the fouling process can begin with a review of available information on particulate emissions from oil-fired boilers. In the early 1970's a study was done of particulate emissions from oil-fired boilers operating in the field ${ }^{3}$. Based on the results of this study the authors recommended an average emission factor of $7.7 \mathrm{ng} \mathrm{J}^{-1}$ of heat input. Assuming a typical excess air level of $40 \%$, this is equivalent to a particulate concentration in the flue gas of $22 \mathrm{mg} \mathrm{m}^{-3}$. This study inciuded a total of 31 oil-fired units. Over half of these units were "non-retention head" burners. Currently, burners of this type are no longer used and have been replaced by retention head bumers. In a follow-up study in the laboratory ${ }^{4}$, with a modern retention head burner, lower average emission factors were found - on the order of 1.7 $\mathrm{ng} \mathrm{J}^{-1}\left(4.9 \mathrm{mg} \mathrm{m}^{-3}\right)$. During installation and service, the smoke emissions from residential burners are often measured using a simple smoke test ${ }^{5}$. In the laboratory study attempts were made to correlate the results of this test with particulate concentrations. In steady state operation a simple correlation may be made between smoke number and flue gas particulate concentration. Typically, burner excess air levels are adjusted for a smoke number of "trace" to 1 . At this level the particulate concentration varies from 2 to $10 \mathrm{mg} \mathrm{m}^{-3}$. A poorly operating burner might have a smoke number of 4 and at this level the soot concentration is about $13 \mathrm{mg} \mathrm{m}^{-3}$. Under extremely severe conditions the smoke number may be as high as 6 , where particulate concentration can be $25 \mathrm{mg} \mathrm{m}^{-3}$. In cyclic operation, correlations between measured particulate concentrations and smoke number are less consistent due to transients which result in high particulate emissions during startup. Smoke numbers used in the correlations are typically measured under steady conditions. In cyclic operation particulate concentration is, of course, greater than that under steady operation but with a properiy operating retention head burner still under $15 \mathrm{mg} \mathrm{m}^{-3}$.

In a more recent study with several types of modern retention head burners, Butcher et. al ${ }^{6}$ found emission factors for normal, cyclic operation to be about $1.2 \mathrm{ng} \mathrm{J}^{-1}$ which is equivalent to an average flue gas concentration of $3.5 \mathrm{mg} \mathrm{m}^{-3}$. If a burner is operating in steady state only, particulate emissions are lower by about a factor of 3 , indicating that startup and shutdown transients contribute greatly to the total particulate emissions. Similar particulate emission rates have also been measured in the lab by others ${ }^{7,8}$.

In a boiler, most of the fuel sulfur is converted to $\mathrm{SO}_{2}$ and emitted but a small fraction is converted to $\mathrm{SO}_{3}$ and then to $\mathrm{H}_{2} \mathrm{SO}_{4}$. This acid combines with water vapor to form a dewpoint considerably higher than the dewpoint resulting from water vapor alone. The amount of $\mathrm{SO}_{3}$ formed in a boiler is dependent upon burner excess air level. The operation of large power boilers with minimum excess air is a common approach to reducing flue gas acid concentration and minimizing "cold end corrosion". With residual oil, catalytic components in the fuel such as vanadium can enhance the conversion of $\mathrm{SO}_{2}$ to $\mathrm{SO}_{3}$ and increase acid concentration ${ }^{9,10}$.

As part of a 30 unit field study, Koebel and Elsener ${ }^{11}$ reported results of $\mathrm{SO}_{3}$ measurements at the exit of the combustion chamber (heat exchanger inlet) and at the boiler exit. This involved all small heating boilers, fired with distillate oil. The average $\mathrm{SO}_{3}$ concentration at the combustion chamber exit was $2.53 \mathrm{ppm}$ which is equivalent to a sufuric acid concentration of $11.1 \mathrm{mg} \mathrm{m}^{-3}$. At the boiler exit average $\mathrm{SO}_{3}$ concentration was $2.13 \mathrm{ppm}$, equivalent to $9.4 \mathrm{mg} \mathrm{m}^{-3}$ of sulfuric acid. For boilers which operate with water temperatures above the dew point of water vapor alone 
(about $50{ }^{\circ} \mathrm{C}$ - the usual case) these authors concluded that the primary mechanism of boiler gasside corrosion attack is by sulfuric acid. In this case the corrosion rate is limited by the rate of diffusion of acid to the surface and iron sulfate is the primary corrosion product. If the boiler surface temperature drops below the water vapor dewpoint, a water film forms on the surface, allowing oxygen corrosion. In this case the authors report a dramatic increase in corrosion rate.

Until 1993, the sulfur content of distillate fuels used for diesel engines and as heating oil was relativeiy constant. Average industry values have stayed within the range of 2200 to $2700 \mathrm{mg} \mathrm{kg}^{-1}$ sulfur ${ }^{2}$ although local regulations often permit the use of higher sulfur content fuels. Recent regulations in the U.S. and Canada now limit the maximum allowable sulfur content of diesel fuel for transportation vehicles to $500 \mathrm{mg} \mathrm{kg}^{-1}$. In 1994, the average suifur level of No. 2 heating oil dropped to about $1700 \mathrm{mg} \mathrm{kg}^{-1}$, however, the long term implications of this for the sulfur content in heating fuels are unclear. There is a need for the heating boiler industry to understand the implications of higher or lower average sulfur contents on the appliances.

The objectives of the work described here were: 1) to develop a test method which can be used to rapidly evaluate the relative importance of soot and corrosion and effects of fuel and operational parameters on the rate of fouling of boilers and 2) to study the effects of fuel sulfur content and excess air on the rate of fouling and boiler efficiency degradation.

\section{Experimental}

Experimental work described here was conducted at two facilities, Brookhaven National Laboratory (BNL) in Upton. N.Y. and CANMET Energy Technology Center (CETC) in Ottawa, Canada. At both locations the same basic rapid fouling test system was used, although the construction details, deposit analysis procedures, and measurements were different at each site as described below. Some additional studies including a full-scale laboratory study and a field study were also done at BNL and are described below.

\subsection{BNL rapid fouling test arrangement}

Figure 1 illustrates the arrangement used at BNL for rapid studies of gas-side fouling. A conventional steel heating boiler has been modified to allow extraction of a part of the combustion products from the back end of the combustion chamber. The boiler has a horizontal combustion chamber, lined with a cylindrical refractory insert for about half of the length. The normal arrangement is "horizontal return tube" - at the end of the combustion chamber the gas passes back through the convective section tubes. In the test arrangement about $10 \%$ of the combustion products are drawn from the end of the combustion chamber through the fouling test section. The test section includes four water-cooled boxes, arranged in pairs. Each of the test boxes has a face $(.102 \mathrm{~m} \mathrm{X} .102 \mathrm{~m})$ which is exposed to the hot gas. The spacing between the test surfaces on opposing boxes can be adjusted. Test sections can be maintained at constant temperature by circulating water from an external water bath. Alternatively, the test sections can be cooled with water circulating from the boiler and, in this case, the surface temperature cycles in a representative way along with the boiler water temperature. This second approach was used in all 
tests included here. Gas flow rate through the test section was adjusted to produce a gas temperature at the exit from the test section similar to the gas temperature leaving the convective section of the boiler. Typically, the entering, mid-section, and exit gas temperatures were 550, 400 , and $275^{\circ} \mathrm{C}$ respectively. Flue gas Reynolds number through the sections typically varied from 737 to 942 . Two types of boiler surfaces were included in separate tests at BNL: a flat steel surface and a cast iron surface with pins. In both cases the test surfaces were provided by boiler manufacturers. When normalized to surface area similar fouling rates were observed in both cases and, in this paper, only results with the cast iron surfaces are included. Each cast iron plate had 44 pins with a height of $12.7 \mathrm{~mm}$. The pins are truncated cones with a base diameter of $5.6 \mathrm{~mm}$ and a tip diameter of $4.8 \mathrm{~mm}$. The distance between pin tips on opposing plates was $7.14 \mathrm{~mm}$.

Prior to each test the plates were cleaned with a steel brush and washed with water and acetone. After the boiler was warmed to the planned test condition the plates were inserted into the test section and gas flow through the test section was adjusted. After the test period, typically 24 hours, the test sections were removed. Deposits were removed from the surfaces through a water rinse and light brushing. This was followed by an acetone rinse which generally did not produce any significant residue. The rinsate was collected and allowed to dry at $50^{\circ} \mathrm{C}$ to determine the mass of residual deposit. After this mass was determined, distilled water was added and the concentration of sulfate and soluble iron in solution was measured by spectrophotometry. The water of crystallization associated with soluble iron sulfate was then caiculated by assuming that the iron sulfate is monohydrate. The total deposit mass was then calculated as the sum of the water of crystallization and the mass of the initial dried residue.

For most tests a conventional, pressure-atomized retention head oil burner was used. Some testing, however, was also done using a novel, air-atomized burner capable of operating at very low excess air levels without smoke.

During tests of the effects of excess air level some measurements were made of tlue gas sulfuric acid content. These were done using a controlled condensation technique ${ }^{13}$.

\subsection{CETC rapid fouling test arrangement}

The fouling test system used at CETC was similar to the system at BNL and is illustrated in Figure 2. The boiler is steel, horizontal return tube rated for a fuel input rate of $102.5 \mathrm{~kW}$. At the entrance to the heat exchanger convective section a portion of the hot combustion gas is extracted and directed through the test section. In the CETC system six test sections are installed each with a test face area of $.114 \mathrm{mX} .114 \mathrm{~m}$. The total surface area of the 6 cell faces is about $.0784 \mathrm{~m}^{2}$ and this is approximately $5 \%$ of the area of the boiler heat exchanger surface. The water circuit in the boiler has been modified to allow circulation through the test sections. Internal baffles were installed to provide a well defined water flow pattern within the test sections and this is illustrated in Figure 3.

As in the BNL test, flue gas was not introduced into the test section until after the boiler had reached the planned temperature condition and was cycling steadily. Prior to each test the test 
surfaces were carefully cleaned. All tests were done with the burner operating under cyclic conditions and total test time was 48 hours with 11.14 hours of burner "on" time.

In the CETC tests the following procedure was used in the analysis of deposits collected on the test plates:

1. Test sections were removed at the end of the test and cleaned in water in an ultrasonic bath for 20 minutes. Total contents from the cleaning of the surfaces were quantitatively transferred and filtered through a pre-weighed filter with an average pore size of $1.2 \mu \mathrm{m}$. Total volume of collected washing liquid and $\mathrm{pH}$ were determined.

2. A $50 \mathrm{ml}$ portion of the soluble deposit solution was analyzed for sulfate and sulfite ions using ion chromatography. The ion chromatographic analysis utilizes a Dionex DX 500 Gradient system equipped with an Ion Pac ASI2A analytical column and a Ion Pac AG12A guard column. The ions are separated selectively from the column using a 2.7 $\mathrm{mM}$ sodium carbonate, $0.3 \mathrm{mM}$ sodium bicarbonate eluent mixture. The rest of the solution was acidified with a mixture of nitric and hydrochloric acids to solubilize the metals and the resulting solution was analyzed for metals using inductively coupled plasma emission spectroscopy (ICP). A total of 36 metals are determined including Fe, $\mathrm{S}, \mathrm{Al}, \mathrm{P}$, $\mathrm{Mg}, \mathrm{Ca}, \mathrm{Na}, \mathrm{Ba}, \mathrm{Co}, \mathrm{Cr}, \mathrm{Cu}, \mathrm{Mn}, \mathrm{V}, \mathrm{Zn}, \mathrm{Ni}, \mathrm{Pb}$, and $\mathrm{Si}$.

3. Solids on the filter were dried overnight and weighed to examine the total weight of water insoluble deposits. About 15\% of the solids were accurately weighed, acid-digested and filtered again to determine the concentrations of acid insoluble deposits such as carbon. The dissolved solids in acid solution were then analyzed for metals using ICP as for the liquid portion.

4. Total deposit weight was determined by adding the weight of soluble materials in the soluble deposit solution and the weight of insoluble deposits. The soluble deposits weight was obtained by summation of amounts of soluble iron, sulfate and water of crystallization associated with soluble iron sulfate. As in the BNL analysis, this is equivalent to the weight of one molecule of water for each iron molecule, assuming that the iron sulfate is monohydrate.

In the work at CETC, the primary emphasis was placed on isolating the effects of fuel sulfur. For these tests a specially formulated distillate fuel containing only $99 \mathrm{mg} \mathrm{kg}^{-1}$ sulfur was obtained with the cooperation of a refiner. Table 1 lists the properties of this fuel. Fuels with varied sulfur content were then prepared by adding ditertiary butyl disulfide (DTBDS) to the ultra low sulfur base line fuel. Fouling tests were done with nominal fuel sulfur contents of 100, 500, 2000, 5000, 7000 , and $10,000 \mathrm{mg} \mathrm{kg}^{-1}$. Actual sulfur levels varied slightly from these target values. 
Table 1. Analysis of baseline ultrajow sulfur content distillate oil used in CETC tests

\begin{tabular}{|c|c|c|}
\hline Property & \multicolumn{2}{|c|}{ Value } \\
\hline Density at $15^{\circ} \mathrm{C}$ & \multicolumn{2}{|c|}{.836} \\
\hline Distillation & IB O & 174.0 \\
\hline & $10 \%$ & 200.5 \\
\cline { 2 - 3 } & $50 \%$ & 258.0 \\
\cline { 2 - 3 } & $90 \%$ & 317.0 \\
\cline { 2 - 3 } & FB & 337.5 \\
\hline Carbon $(\mathrm{wt} \%)$ & \multicolumn{2}{|c|}{86.3} \\
\hline Hydrogen $\left(\mathrm{wt}^{\circ}\right)$ & \multicolumn{2}{|c|}{13.6} \\
\hline Nitrogen $\left(\mathrm{mg} \mathrm{kg}^{-1}\right)$ & \multicolumn{2}{|c|}{9.1} \\
\hline Sulfur $\left(\mathrm{mg} \mathrm{kg}{ }^{-1}\right)$ & \multicolumn{2}{|c|}{99.0} \\
\hline Flash Point $\left({ }^{\circ} \mathrm{C}\right)$ & \multicolumn{2}{|c|}{64} \\
\hline Heating Value $\left(\mathrm{kJ} \mathrm{kg}^{-1}\right)$ & \multicolumn{2}{|c|}{45910} \\
\hline Viscosity at $38^{\circ} \mathrm{C}(\mathrm{c} \mathrm{St})$. & \multicolumn{2}{|c|}{2.41} \\
\hline
\end{tabular}

\subsection{Full size boiler tests in the laboratory}

To provide a direct comparison with the results of the fouling test sections, tests were also done in the BNL laboratory with two full size, cast iron boilers. The units tested are two-section with a rated input of $35 \mathrm{~kW}$ and a pin-type heat exchanger. Preliminary triais showed that it is difficult with full scale boiler tests to repeatably remove all of the fouling deposit and to obtain repeatable results. The test procedure finally developed involved sand-blasting heat exchanger surfaces, followed by a water wash prior to the test. The test period was 4 months, during which the burners operated in a 5 minute on, 15 minute off cycling pattern under computer control. Boiler water temperatures were monitored carefully during the test period and ranged from 54 to $71{ }^{\circ} \mathrm{C}$. Gas temperature at the boiler exit was also monitored and used to estimate rate of efficiency degradation. The efficiency in this case was estimated using gas exit temperature, excess air, and a "heat loss" efficiency calculation. Two fuels were tested in the identical side-by-side boilers, operating simultaneously. This included a typical No. 2 heating oil with a fuel sulfur content of $3500 \mathrm{mg} \mathrm{kg}^{-1}$ and a low sulfur oil sold for transportation diesel use with a sulfur content of 400 $\mathrm{mg} \mathrm{kg}^{-1}$. Following the four month test period the heat exchangers were opened for inspection and deposit samples removed for analysis. As a first step, the heat exchangers were brushed and 
the dry deposit carefully collected for weighing and analysis. This was followed by a water washing during which the rinse water was carefully collected. This was allowed to slowly oven iry at $50^{\circ} \mathrm{C}$ and the mass of solid residue weighed. The rinsate was analyzed for total deposit mass, mass of soluble iron, and mass of sulfate. Solid deposits removed from the boiler by simple brushing were analyzed in a similar way.

\subsection{Analysis of deposits removed from boilers in the field}

To compliment the laboratory studies some field studies were also done in ten homes during one full heating season. All of these homes have hydronic, oil-fired heating systems and Table 2 provides a summary. In this table a "wet base" boiler type refers to a unit in which the combustion chamber area is surrounded by cooled surface. A "dry base" boiler, in contrast, has a full refractory combustion chamber. At each home the unit was cleaned by brushing the heat exchanger surface carefully at the start of the heating season. Trends in excess air, and gas temperature at the boiler exit were recorded through the heating season. At the end of the heating season the heat exchangers were exposed for inspection. Deposits were removed for total mass determination and analysis. 
Table 2. Basic description of sites included in field study

\begin{tabular}{|c|c|c|c|c|c|}
\hline Site & Boiler type & \begin{tabular}{|l} 
Heat \\
exchanger \\
type
\end{tabular} & $\begin{array}{l}\text { Firing rate } \\
(\mathrm{kW})\end{array}$ & $\begin{array}{l}\text { Initial excess } \\
\text { air setting } \\
(\%)\end{array}$ & $\begin{array}{l}\text { Gas } \\
\text { temperature } \\
\text { at boiler exit } \\
\text { at test start } \\
\left({ }^{\circ} \mathrm{C}\right)\end{array}$ \\
\hline 1 & $\begin{array}{l}\text { wet base, } \\
\text { steel }\end{array}$ & $\begin{array}{l}\text { horizontal } \\
\text { firetube }\end{array}$ & 30.8 & 38 & 238 \\
\hline 2 & $\begin{array}{l}\text { wet base, } \\
\text { cast iron }\end{array}$ & $\begin{array}{l}\text { pin } \\
\text { construction }\end{array}$ & 34.9 & 56 & 293 \\
\hline 3 & $\begin{array}{l}\text { wet base, } \\
\text { cast iron }\end{array}$ & $\begin{array}{l}\text { pin } \\
\text { construction }\end{array}$ & 41.0 & 29 & 299 \\
\hline 4 & $\begin{array}{l}\text { wet base, } \\
\text { cast iron }\end{array}$ & $\begin{array}{l}\text { pin } \\
\text { construction }\end{array}$ & 30.8 & 29 & 316 \\
\hline 5 & $\begin{array}{l}\text { wet base, } \\
\text { cast iron }\end{array}$ & $\begin{array}{l}\text { pin } \\
\text { construction }\end{array}$ & 34.9 & 54 & 247 \\
\hline 6 & $\begin{array}{l}\text { wet base, } \\
\text { cast iron }\end{array}$ & $\begin{array}{l}\text { pin } \\
\text { construction }\end{array}$ & 34.9 & 49 & 305 \\
\hline 7 & $\begin{array}{l}\text { dry base, } \\
\text { steel }\end{array}$ & $\begin{array}{l}\text { vertical } \\
\text { firetube }\end{array}$ & 26.7 & 61 & 216 \\
\hline 8 & $\begin{array}{l}\text { dry base, } \\
\text { steel }\end{array}$ & $\begin{array}{l}\text { vertical } \\
\text { firenube }\end{array}$ & 36.9 & 46 & 278 \\
\hline 9 & $\begin{array}{l}\text { dry base, } \\
\text { steel }\end{array}$ & $\begin{array}{l}\text { vertical } \\
\text { firetube }\end{array}$ & 26.7 & 64 & 363 \\
\hline 10 & $\begin{array}{l}\text { dry base, } \\
\text { steel }\end{array}$ & $\begin{array}{l}\text { vertical } \\
\text { firetube }\end{array}$ & 34.9 & 35 & 227 \\
\hline
\end{tabular}

a. gas temperature at boiler exit with boiler operating neariy in steady state.

\section{Results}

\subsection{Tests at BNL with rapid fouling test arrangement on sulfur effects}

A series of tests were performed at BNL with fuel sulfur contents ranging from 370 to $7000 \mathrm{mg}$ $\mathrm{kg}^{-1}$. Table 3 provides a summary of the measured deposition rates. Included in this table is the estimated weight of the insoluble deposit. This estimate is presented here for comparison with CETC results in Section 3.3. The insoluble deposit mass is taken as total deposit mass minus soluble iron, sulfate, and water of crystallization of iron sulfate. With increasing fuel sulfur content the total deposition rate increases and the fraction of the total mass which is insoluble decreases. 
Table 3. Tests at BNL. effects of suifur on test surface deposition rates.

\begin{tabular}{|l|l|l|l|l|l|l|l|}
\hline $\begin{array}{l}\text { Fuel sulfur } \\
\text { content } \\
\left(\mathrm{mg} \mathrm{kg}^{-1}\right)\end{array}$ & $\begin{array}{l}\text { Estimated } \\
\text { insoluble } \\
(\mathrm{mg})\end{array}$ & $\begin{array}{l}\text { Sulfate } \\
(\mathrm{mg})\end{array}$ & $\begin{array}{l}\text { Soluble } \\
\text { iron } \\
(\mathrm{mg})\end{array}$ & $\begin{array}{l}\mathrm{H}_{2} \mathrm{O}^{\mathbf{2}} \\
(\mathrm{mg})\end{array}$ & $\begin{array}{l}\text { Total } \\
\text { deposit } \\
(\mathrm{mg})\end{array}$ & $\begin{array}{l}\text { Deposition } \\
\text { rate } \\
\left(\mathrm{mg} \mathrm{h}^{-1} \mathbf{m}^{-2}\right)\end{array}$ & $\begin{array}{l}\text { Portion of } \\
\text { total } \\
\text { deposit } \\
\text { which is } \\
\text { insoiuble } \\
(\%)\end{array}$ \\
\hline 370 & 32.5 & 21.2 & 17.0 & 5.48 & 76.2 & 331.8 & 42.7 \\
\hline 1800 & 41.7 & 100 & 45 & 14.5 & 201.2 & 873.3 & 20.7 \\
\hline 4400 & 115.8 & 204 & 117.5 & 37.9 & 475.2 & 2085.3 & 24.4 \\
\hline 7000 & 9.7 & 415 & 166.3 & 53.6 & 644.6 & 2797.3 & 1.50 \\
\hline
\end{tabular}

a. assumed water of hydration associated with soluble iron sulfate

b. includes insoluble part, soluble iron and sulfate, and water of hydration

\subsection{Tests at BNL on effect of excess air level}

As excess air is decreased, the fraction of the sulfur in the fuel which is converted to sulfur trioxide decreases. Figure 4 shows the results of measurements of sulfuric acid made in a boiler flue. Two different burners were used in these tests, a conventional, pressure atomized retention head burner and an air-atomized bumer. The air-atomized bumer was used to obtain data at very low excess air levels because at these excess air levels the conventional, pressure atomized bumer produced unacceptably high levels of smoke. As discussed in the Introduction, this trend is consistant with reported trends observed in much larger boilers.

Fouling rate measurements were made in the BNL lab with the same pressure-atomized and air atomized burners at different excess air levels. Results are shown in Figure 5. For both types of burners the deposition rate reaches a maximum level at $30 \%$ excess air and remains relatively constant for higher excess air levels. These deposits consist mostly of iron and sulfate.

\subsection{Tests at CETC with rapid fouling test arrangement on sulfur effects}

A similar series of tests were performed at CETC with varied fuel sulfur content. For each level of fuel suifur tested at CETC three or, in some cases four, fouling runs were repeated.

For these tests Table 4 provides a summary of the analysis of the insoluble part of the deposit removed from the test surfaces with varied fuel sulfur content. Among the measured elements iron is dominant and it is expected this is simply in the form of iron oxide. A semiqualitative Xray diffaction analysis of these deposits showed the principle crystalline component to be goethite. Table 5 provides a summary of the insoluble and soluble deposits and estimates of the deposition rates. Clearly as the fuel sulfur content increases the rate of collection of iron sulfate and the total deposit accumulation rate on the surface increases. The rate of collection of insoluble deposit apparently decreases with increasing sulfur content. Certainly the portion of the total collected deposit which is insoluble decreases dramatically with increasing fuel sulfur content. 
Table 4. Tests at CETC. anaiysis of insoluble portion of deposits

\begin{tabular}{|l|l|l|l|l|l|l|l|l|l|}
\hline $\begin{array}{l}\text { Fuet sulfur } \\
\text { content } \\
\left(\mathrm{mg} \mathrm{kg} \mathrm{l}^{-1}\right)\end{array}$ & $\begin{array}{l}\mathrm{Fe} \\
(\%)\end{array}$ & $\begin{array}{l}\mathrm{Al} \\
(\%)\end{array}$ & $\begin{array}{l}\mathrm{S} \\
(\%)\end{array}$ & $\begin{array}{l}\mathrm{Na} \\
(\mathrm{ppm})\end{array}$ & $\begin{array}{l}\mathrm{Ba} \\
(\mathrm{ppm})\end{array}$ & $\begin{array}{l}\mathrm{P} \\
(\mathrm{ppm})\end{array}$ & $\begin{array}{l}\mathrm{Si} \\
(\mathrm{ppm})\end{array}$ & $\begin{array}{l}\text { Acid } \\
\text { in- } \\
\text { soluble } \\
(\%)\end{array}$ & $\begin{array}{l}\text { Combined } \\
\text { trace } \\
\text { elements } \\
(\%)\end{array}$ \\
\hline \hline 100 & 43.2 & 3.06 & 1.82 & 416 & 258 & 0 & 0 & 4.52 & 0.74 \\
\hline$\%$ sd & 12.3 & 33.0 & 40.4 & 76.9 & 112 & 0 & 0 & 14.5 & 100 \\
\hline \hline 500 & 37.2 & 2.62 & 3.72 & 284 & 147 & 0 & 0 & 5.09 & 0.62 \\
\hline$\%$ sd & 2.38 & 17.8 & 22.3 & 70.6 & 67.5 & 0 & 0 & 13.9 & 39.0 \\
\hline \hline 2000 & 35.4 & 3.35 & 4.50 & 61.7 & 232 & 361 & 0 & 6.17 & 0.7 \\
\hline$\%$ sd & 4.59 & 24.1 & 6.01 & 200 & 42.5 & 85 & 0 & 12.3 & 32.3 \\
\hline \hline 5000 & 23.6 & 6.74 & 6.73 & 734 & 638 & 623 & 0 & 14.9 & 1.56 \\
\hline$\%$ sd & 40.5 & 39.8 & 15.7 & 10 & 46.8 & 154 & 0 & 34.4 & 25.0 \\
\hline \hline 7000 & 14.4 & 3.18 & 4.87 & 294 & 213 & 926 & 269 & 14.6 & 3.90 \\
\hline$\%$ sd & 83.9 & 9.58 & 4.36 & 141 & 78.0 & 8 & 141 & 24.3 & 75.8 \\
\hline \hline 12000 & 10.7 & 2.34 & 5.48 & 453 & 287 & 293 & 1314 & 27.0 & 5.86 \\
\hline$\%$ sd & 75.7 & 18.9 & 17.1 & 90.4 & 95.9 & 173 & 90.0 & .320 & 50.7 \\
\hline
\end{tabular}


Table 5. Estimation of test surface deposition rates - tests at CETC

\begin{tabular}{|l|l|l|l|l|l|l|l|}
\hline $\begin{array}{l}\text { Fuel } \\
\text { sulfur } \\
\text { content } \\
\left.(\mathrm{mg} \mathrm{kg})^{1}\right)\end{array}$ & $\begin{array}{l}\text { Insoluble } \\
\text { deposit } \\
(\mathrm{mg})\end{array}$ & $\begin{array}{l}\text { Sulfate } \\
(\mathrm{mg})\end{array}$ & $\begin{array}{l}\text { Soluble } \\
\text { iron } \\
(\mathrm{mg})\end{array}$ & $\begin{array}{l}\mathrm{H}_{2} \mathrm{O}^{2} \\
(\mathrm{mg})\end{array}$ & $\begin{array}{l}\text { Total } \\
\text { deposit } \\
(\mathrm{mg})\end{array}$ & $\begin{array}{l}\text { Deposition } \\
\text { rate } \\
\left(\mathrm{mg} \mathrm{h}^{-1} \mathrm{~m}^{-2}\right)\end{array}$ & $\begin{array}{l}\text { Portion of } \\
\text { total } \\
\text { deposit } \\
\text { which is } \\
\text { insoluble } \\
(\%)\end{array}$ \\
\hline \hline 100 & 175 & 91.0 & 37.8 & 12.2 & 316 & 361 & 55.4 \\
\hline$\%$ sd & 15.5 & 27.9 & 19.9 & 19.8 & 15.3 & 15.3 & - \\
\hline \hline 500 & 201 & 264 & 125 & 40.4 & 630 & 722 & 31.9 \\
\hline$\%$ sd & 5.41 & 5.99 & 24.8 & 24.8 & 10.1 & 10.1 & - \\
\hline \hline 2000 & 209 & 694 & 281 & 90.6 & 1274 & 1459 & 16.4 \\
\hline$\%$ sd & 27.3 & 12.8 & 15.4 & 15.4 & 5.79 & 5.79 & - \\
\hline \hline 5000 & 135 & 1937 & 724 & 233 & 3029 & 3469 & 4.5 \\
\hline$\%$ sd & 49.4 & 6.24 & 2.38 & 2.39 & 3.04 & 3.04 & - \\
\hline \hline 7000 & 104 & 3022 & 111 & 358 & 4595 & 5262 & 2.3 \\
\hline$\%$ sd & 97.8 & 17.2 & 19.0 & 19.0 & 15.2 & 15.2 & - \\
\hline \hline 12000 & 94 & 3643 & 1353 & 436 & 5525 & 6327 & 1.7 \\
\hline$\% s d$ & 50.7 & 13.8 & 14.3 & 14.3 & 13.5 & 13.5 & - \\
\hline
\end{tabular}

a assumed water of hydration associated with soluble iron sulfate

$\mathrm{b}$ includes insoluble part, soluble iron and sulfate, and water of hydration

\subsection{Results of full size boiler tests in the laboratory}

Figure 6 shows the trends in the flue gas temperature during the four month test period with moderate and low sulfur fuels. These temperatures were recorded just before the end of the burner on-period. With the moderate sulfur fuel the average rate of rise in peak flue gas temperature was $0.283{ }^{\circ} \mathrm{C}$ day ${ }^{-1}$ and this translates to a $1.85 \%$ decrease in boiler thermal efficiency over the 120 day test period. With the low sulfur fuel the temperature trend line slope is $0.087^{\circ} \mathrm{C}$ day ${ }^{-1}$ giving a $0.6 \%$ decrease in thermal efficiency over the period. Table 6 provides a summary of the bulk deposit mass from each of the two boilers. Table 7 provides results of the soluble iron and sulfate analysis done on the portions of the deposits brushed and rinsed from the heat exchanger. In general, the test with the higher sulfur fuel produced more total deposit consisting of a higher fraction of sulfate and corresponding lower carbon fraction. 
Table 6 Summary of deposits removed from laboratory boiler tests

\begin{tabular}{|l|c|c|}
\hline Fuel & low sulfur $\left(400 \mathrm{mg} \mathrm{kg}^{-1}\right)$ & moderate sulfur $\left(3500 \mathrm{mg} \mathrm{kg}^{-1}\right)$ \\
\hline $\begin{array}{l}\text { Deposit brushed from heat } \\
\text { exchanger }(\mathrm{g})\end{array}$ & 3.3 & 157.5 \\
\hline $\begin{array}{l}\text { Deposit rinsed from heat } \\
\text { exchanger }(\mathrm{g})\end{array}$ & 31.4 & 228.3 \\
\hline Total deposit $(\mathrm{g})$ & 34.7 & 385.8 \\
\hline
\end{tabular}

Table 7 Iron and sulfate analysis of deposits from laboratory test boilers

\begin{tabular}{|c|c|c|}
\hline Fuel & low sulfur ( $400 \mathrm{mg} \mathrm{kg}^{-1}$ ) & moderate sulfur (3500 $\mathrm{mg} \mathrm{kg}^{-1}$ ) \\
\hline \multicolumn{3}{|c|}{ deposit brushed from heat exchanger } \\
\hline $\begin{array}{l}\text { Soluble iron ( } \% \text { of total } \\
\text { deposit) }\end{array}$ & 10.7 & 17.4 \\
\hline Sulfate ( $\%$ of total deposit) & 33.6 & 73.2 \\
\hline Carbon (\% of total deposit) ${ }^{b}$ & 16.7 & 3.2 \\
\hline \multicolumn{3}{|c|}{ deposit rinsed from heat exchanger } \\
\hline $\begin{array}{l}\text { Soluble iron ( } \% \text { of total } \\
\text { deposit) }\end{array}$ & 21.8 & 20.0 \\
\hline Sulfate $(\%$ of total deposit) & 35.6 & 33.0 \\
\hline \multicolumn{3}{|c|}{ combined deposit } \\
\hline Total deposit (g) & 37 & 409 \\
\hline Soluble iron $(\mathrm{g})$ & 7.2 & 73.1 \\
\hline Sulfate $(g)$ & 12.3 & 191 \\
\hline $\mathrm{H}_{2} \mathrm{O}^{2}(\mathrm{~g})$ & 2.3 & 23.6 \\
\hline Insoluble deposit (g) & 15.2 & 122 \\
\hline Insoluble deposit ( $\%$ of total) & 41.1 & 29.8 \\
\hline
\end{tabular}

a. assumed water of hydration associated with soluble iron sulfate

b. total carbon analysis by ASTM D 3178-89 14

\subsection{Results of field tests}

As discussed in Section 2.4, the field tests were done to provide a comparison with the laboratory test results. Nine of the ten test homes operated without incident over the test period. In one 
home, however (Site 10, Table 2), a severe sooting situation occurred at the end of the heating season. Upon exposing the heat exchanger sections the unit was found to be nearty totally blocked with soot.

To estimate efficiency loss due to fouling for each boiler unit it is most useful to look at the temperature difference before and after cleaning of the heat exchanger sections at the end of the heating season. The reason for this is that operating conditions and other seasonal variations do not change much within the short time span during which monitoring is done. In most cases, temperatures were recorded over a 24 hour period before and after the end of season cleaning. The efficiency degradation due to sooting was then calculated from the change in peak flue gas temperature. Excess air, which also affects efficiency, was also included although in all cases the excess air change was very small. Table 8 provides a summary of the field test results.

Table 8. Summary of field test results

\begin{tabular}{|l|l|l|l|}
\hline Site & $\begin{array}{l}\text { Total soot deposit } \\
\text { collected }{ }^{2}(\mathrm{gms})\end{array}$ & Season oil use $\left(\mathrm{m}^{3}\right)$ & $\begin{array}{l}\text { Efficiency loss due to } \\
\text { fouling }(\%)\end{array}$ \\
\hline 1 & 203 & 1.51 & 1.9 \\
\hline 2 & 240 & 2.97 & 1.0 \\
\hline 3 & 43 & 2.65 & 1.7 \\
\hline 4 & 113 & 1.7 & 1.2 \\
\hline 5 & 122 & 2.34 & 1.1 \\
\hline 6 & 40 & - & 3.0 \\
\hline 7 & 254 & 2.27 & 3.8 \\
\hline 8 & 108 & 1.82 & 3.1 \\
\hline 9 & 80 & 3.03 & - \\
\hline 10 & 813 & 2.08 & - \\
\hline
\end{tabular}

a. dry mass, does not include water of crystallization

At site 10, the efficiency degradation due to fouling could not be determined. When the unit was found to be severely fouled it could not be practically run to obtain the required temperature data. At site 9 the efficiency degradation was not measured.

At three of the test sites, deposits collected from the final cleaning of the boiler convective sections were analyzed to determine soluble iron and sulfate. In addition, at two of the sites analysis of total carbon was done. Results are provided in Table 9. 
Table 9 Composition of deposits removed from three sites.

\begin{tabular}{|l|l|l|l|}
\hline & Site 3 & Site 7 & Site 10 \\
\hline Total deposit $(\mathrm{g})$ & 46.6 & 628.2 & 588 \\
\hline Soluble iron $(\mathrm{g})$ & 11.3 & 87.6 & 117 \\
\hline Sulfate $(\mathrm{g})$ & 18.6 & 300 & 132 \\
\hline $\mathrm{H}_{2} \mathrm{O}(\mathrm{g})$ & 3.63 & 28.2 & 37.6 \\
\hline Insoluble deposit $(\mathrm{g})$ & 13.2 & 212 & 301 \\
\hline $\begin{array}{l}\text { Insoluble deposit }(\% \\
\text { of total) }\end{array}$ & 28.2 & 33.8 & 51.3 \\
\hline Carbon $(\mathrm{g})^{2}$ & 3.2 & NA & 145 \\
\hline
\end{tabular}

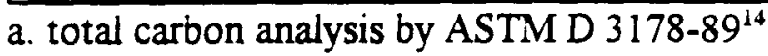

At Site 10, the higher percentage of carbon in the collected deposits is consistent with the severe sooting situation which occurred at the end of the heating season. The other two sites could be considered more typical of correctly operating boilers.

\section{Discussion}

Results of all of the tests done show that, for fuels with sulfur contents currently typical of heating oils, the deposition of sulfuric acid and subsequent formation of iron sulfate contributes most of the mass of the fouling deposits. This implies that the rate of transfer of sulfuric acid from the flue gas to the boiler surfaces is faster than the rate of soot deposition. The relative rates of deposition of soot particles and sulfuric acid on the surface may at least be approximately estimated by comparing concentrations in the flue gas and deposition mechanisms. From the review provided in Section 1, the soot concentration in cyclic operation can be assumed to be in the range of 2 to possibly $10 \mathrm{mg} \mathrm{m}^{-3 .}$. From Figure 4 flue gas sulfuric acid content is typically about $\mathrm{l} \mathrm{ppm}$ or about $4.5 \mathrm{mg} \mathrm{m}^{-3}$, the same order of magnitude as the soot concentration. For soot particles deposition by impaction or interception on the pins or fins of the convective sections of the heat exchangers of cast iron boilers might be considered. The soot particles produced from the combustion of distillate oil have aerodynamic diameters smaller than 0.3 microns, however. For such small particles inertial impaction is insignificant. For both sulfuric acid and soot particles deposition may occur by diffusion generally, or by diffusion enhanced by thermophoresis in the case of cooled boiler surfaces. In this case the deposition rate will depend upon the diffusivity. Certainly the diffusivity (and thermophoresis-enhanced diffusion) of molecular sulfuric acid is much greater than that of the soot particles. Considering only size, the diffusivity of the the acid should be greater than that of the soot particle by several orders of magnitude. Condensation of the acid into an aerosol in the gas phase would, of course, offset this. ${ }^{13}$ Acid aerosol has a size distribution similar to that of the soot particles. Based on the results of measurements presented here the effective diffusion rate of the acid is greater than that of the soot particles. 
The rapid fouling test developed here provides a repeatable method of examining factors which degrade boiler efficiency over time. Beyond the work done here this test method could be use to evaluate impacts of parameters such as: fuel additives, boiler water temperature, burner cycling patterns, and other fuel properties such as aromatics fraction.

\section{Conclusions}

A new method of testing the influence of fuel and operating parameters on heat exchanger fouling mechanisms and rates in residential, oil-fired heating boilers has been developed. This approach has been used at two laboratories to study fouling. Results show that sulfuric acid deposition on heat exchanger surfaces and subsequent formation of iron sulfate contributes most of the mass of the fouling deposits. Generally, the concentration of both sulfuric acid and soot in flue gas are of a similar magnitude. The higher diffusivity of the acid molecules, however, leads to higher deposition rates. Measures which reduce acid formation reduce fouling rates. These mechanisms include use of reduced sulfur content fuel and operation with reduced excess air. The results clearly show that the use of lower sulfur content fuels in domestic boilers will lead to reduced fouling rates.

\section{ACKNOWLEDGEMENT}

The work at Brookhaven National Laboratory, included in this paper, was performed under Contract No. DC-AC02-76CH00016, U.S. Department of Energy, Office of Building Technologies.

\section{References}

1. U.S. DEPARTMENT OF ENERGY. Uniform test method for measuring the energy consumption of furnaces, U.S. Code of Federal Regulations, 10CFR Ch. 11, Pt. 430, Subpt B, App. N, Jan 1, 1995.

2. KELLY G, DIDION DA, QUIGLEY D, and COLLINS B. Potential energy savings in residential oil-fired heating systems in the U.S., U.S. Department of Commerce NBS Building Science Series 163, December 1984.

3 BARRETT R E, MILLER S E, and LOCKLIN D W. Field investigations of emissions from combustion equipment for space heating, U.S. Environmental Protection Agency Report EPAR2-73-084a, NTIS PB 2233 148, 1973.

4 BARRETT R E, LOCKLIN D E, and MILLER S E. Investigation of particulate emissions from oil-fired resdiental heating units, U.S. Environmental Protection Agency Report EPA- 6502-74-026, 1974.

5 AMERICAN SOCIETY FOR TESTING AND MATERIALS. Standard test method for smoke density in flue gases from burning distillate fuels, Standard D 2156-80, 1980. 
6 BUTCHER T A, KRAJEWSKI R F, CELEBI Y, and MCDONALD R J. Prospects for residential oil burners with reduced emissions, Proc. annual meeting of the Air and Waste Management Assoc., Kansas City, June 1992, paper no. 92-110.05 (BNL report no. 47452), 1992.

7 LEARY J A, BIENAM K, LAFLEUR A, KRUZEL E, PRADEO G, LONGWELL J P, and PETERS W. Chemical and toxilogical characterization of residential oil burner emissions, Environmental Health Perspectives, 1987, 72, pp 223-234.

8 MILLER C A, RYAN J V, and LOMBARDO, T. Characterization of air toxics from an oilfired firetube boiler, J. Air and Waste Management Assoc., 46, pp. 742-748, 1996.

9 CARTER N W T, and BROOKS W J D, An engineer's appreciation of the acid smut problem and its solution, J. Inst. Energy, June 1983, pp 100-106.

10 CONNOLLY R and KELSELL P H, A direct assessment in $60 \mathrm{MW(e)} \mathrm{oil-fired} \mathrm{boilers} \mathrm{of} \mathrm{the}$ limitation of good practices in combating acid deposition and associated smut emission and the consequent use of a neutralizing additive, J. Inst. Energy, March, 1992, pp 47-54.

11 KOEBEL $M$ and ELSENER $M$ Corrosion of oil-fired central heating boilers, Werkstoffe und Korrosion, 1989, 40, pp 285-294.

12 DICKSON C L and WOODWARD P W. Heating Oils, 1994, National Institute for Petroleum and Energy Research Report NIPER-186 PPS 94/4.

13 DIETZ R. Brookhaven controlled condensation system for the measurement of combustion flue gas pollutants. Brookhaven National Laboratory Report BNL 27590, March, 1980.

14 AMERICAN SOCIETY FOR TESTING AND MATERIALS. Standard test methods for carbon and hydrogen in the analysis sample of coal and coke, Standard D $3178-89,1989$.

15 LAND T. The theory of acid deposition and its application to the dew-point meter, J. Inst. Fuel, June, 1977, pp 68-75. 


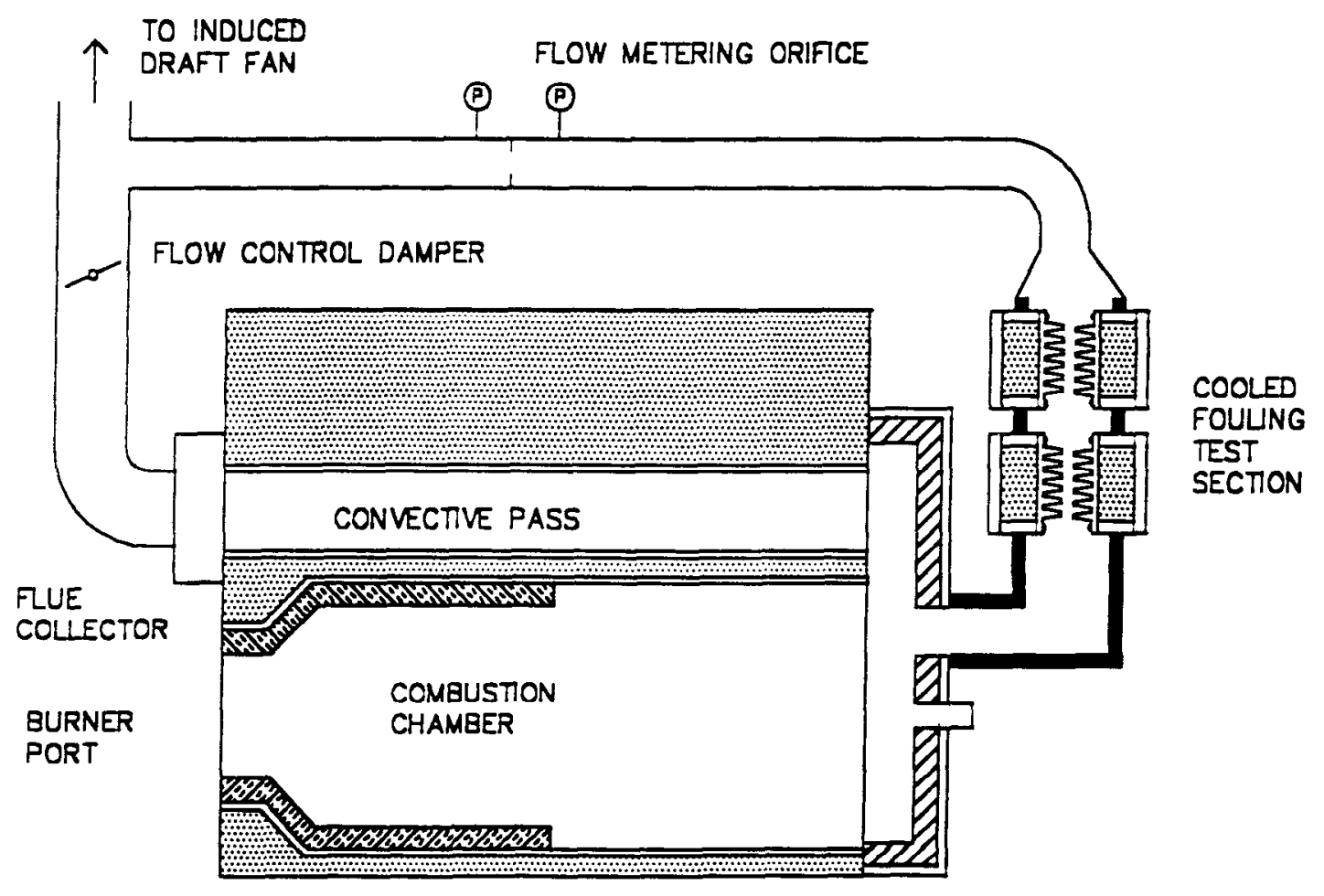

Figure 1. Fouling test arrangement used at BNL 


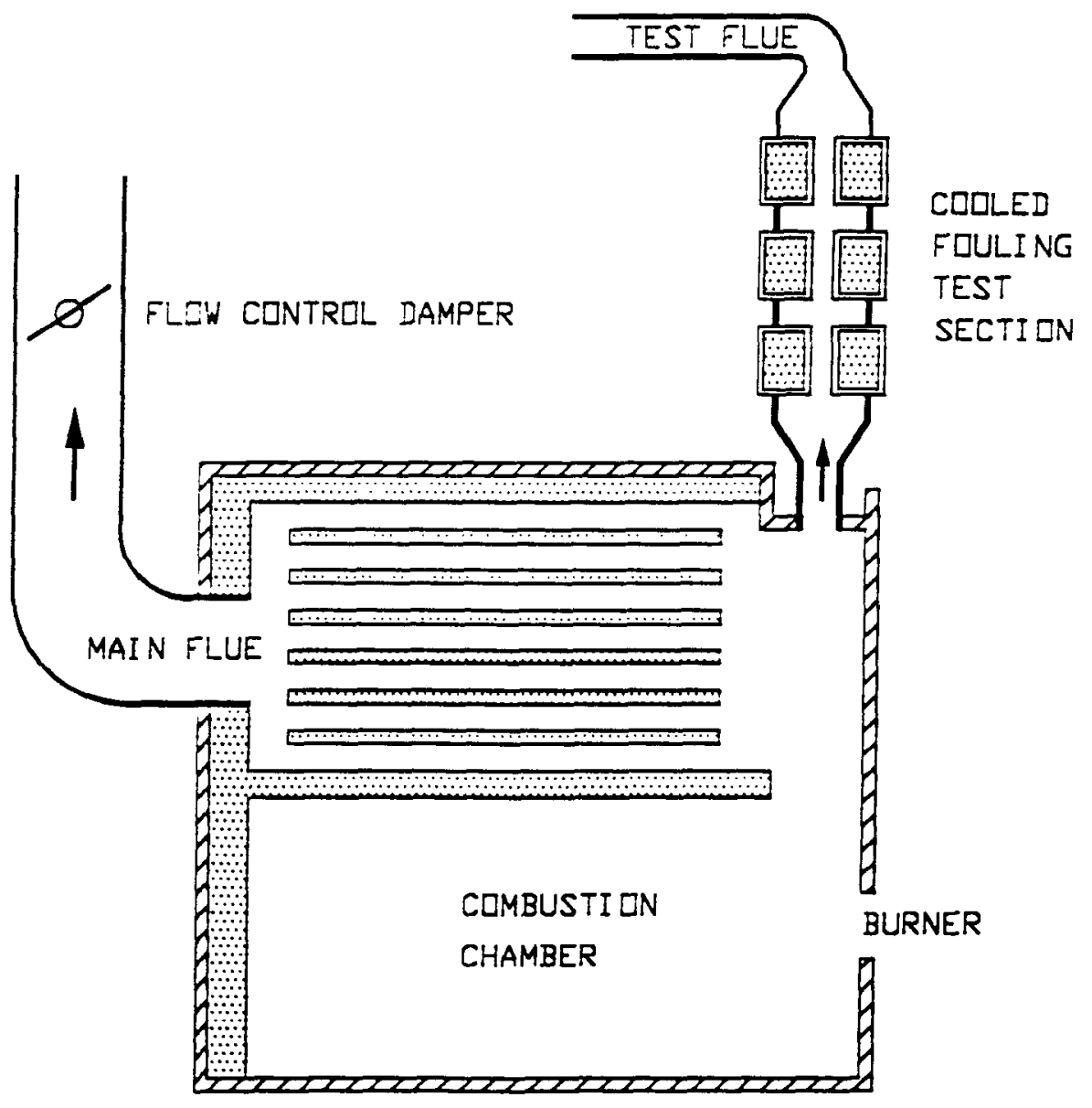

Figure 2. Fouling test arrangement used at CETC 


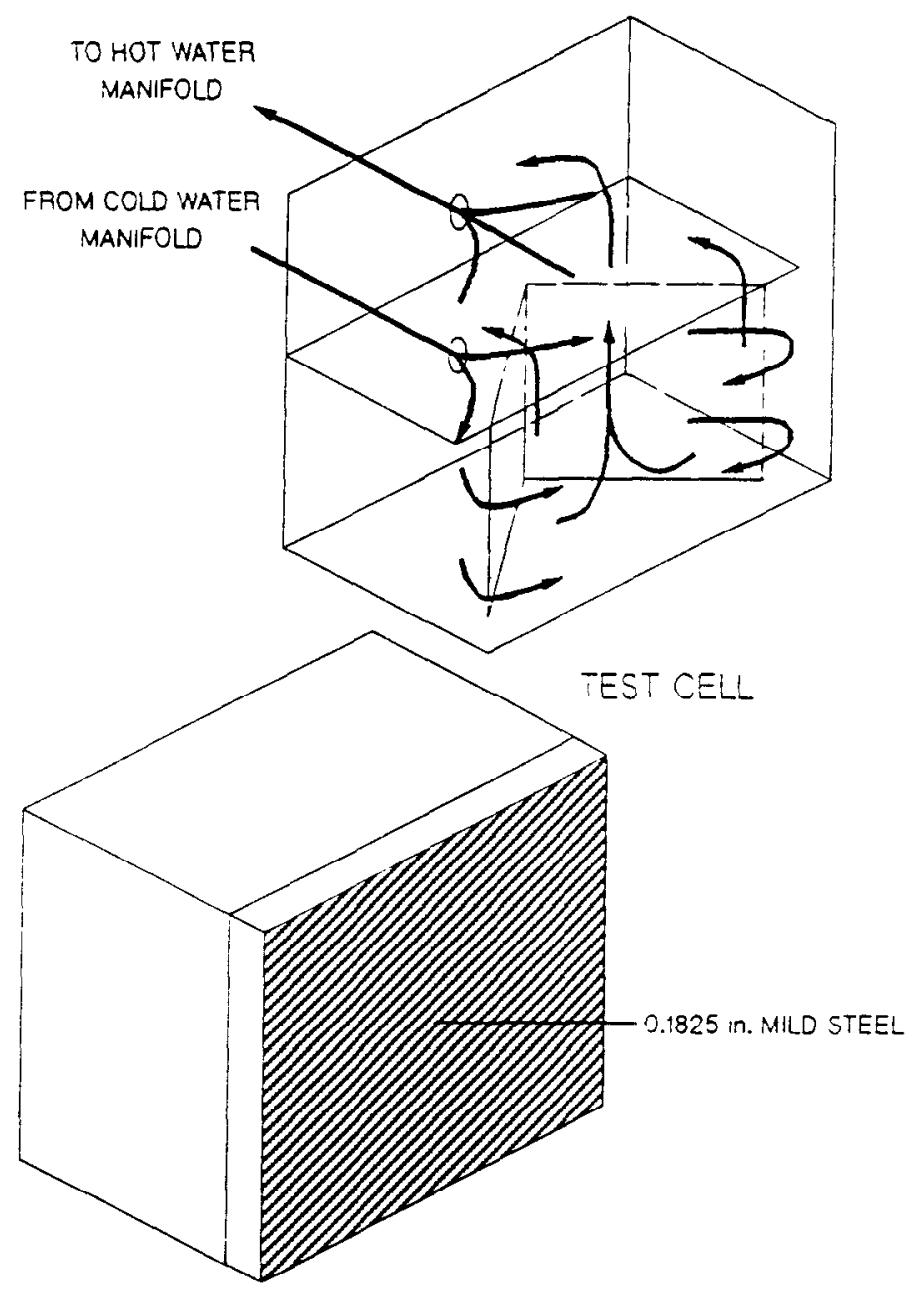

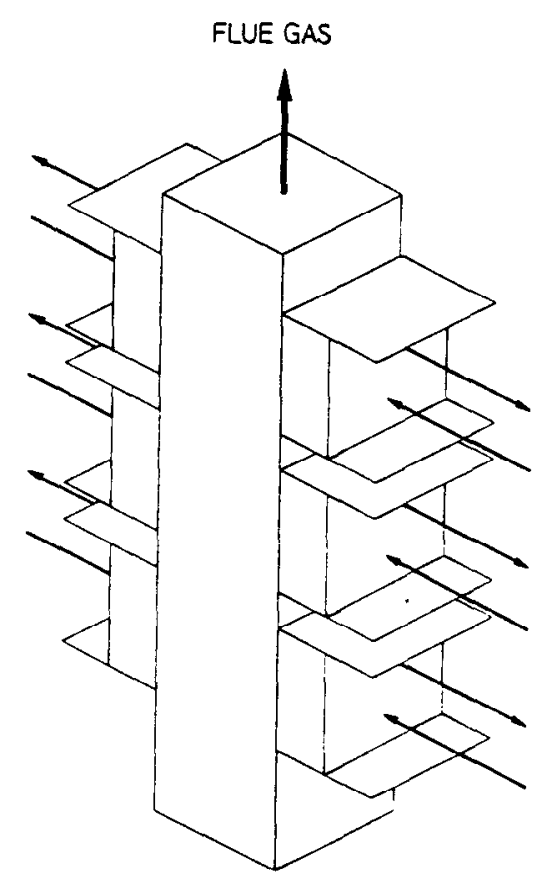

TEST SECTION

Figure 3. Fouling test cell (1 of 6) and test section as used at CETC 


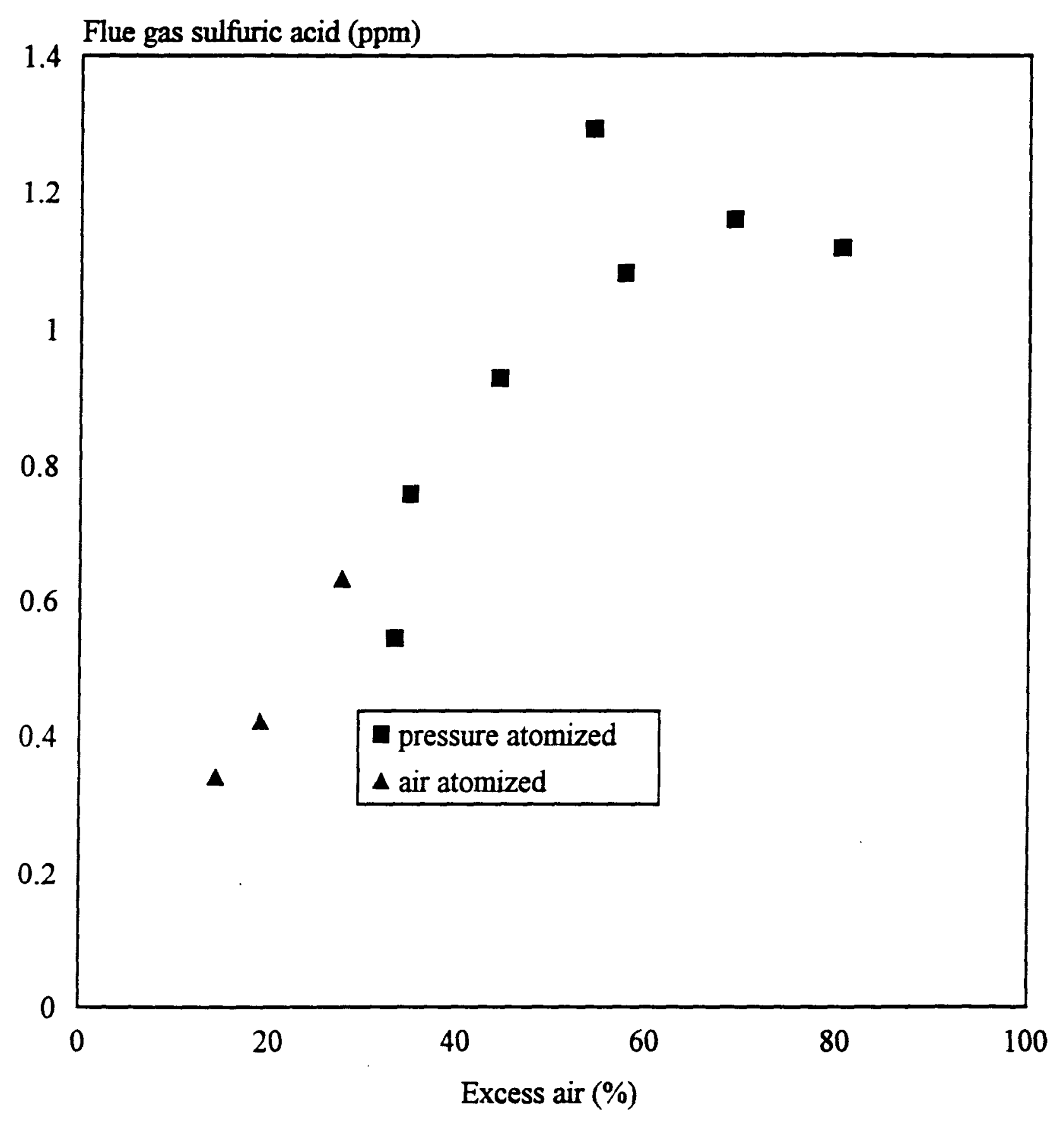

Figure 4. Effect of excess air on acid in flue gas 
Deposition rate $(\mathrm{mg} / \mathrm{m} 2 \mathrm{hr})$

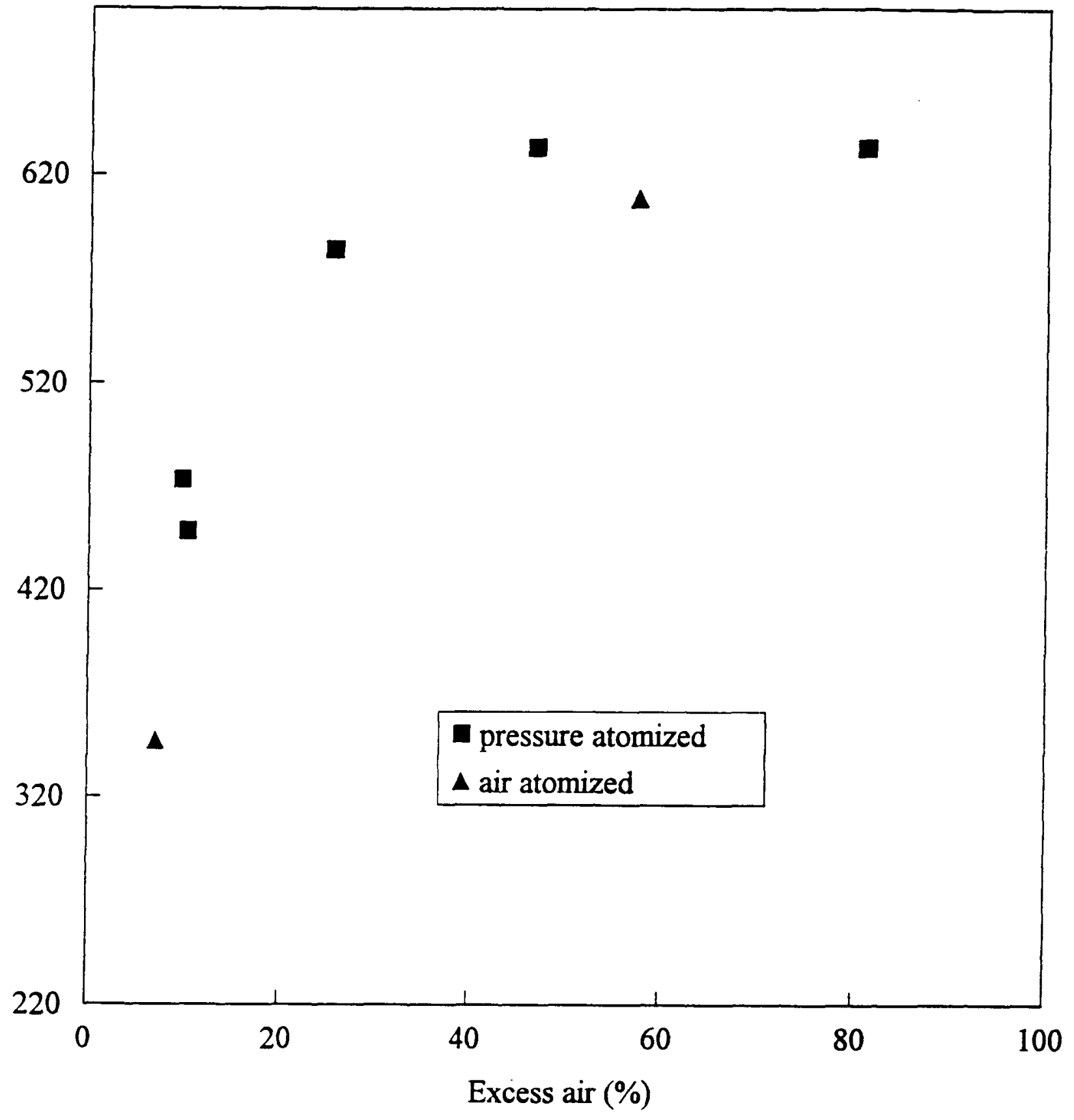

Figure 5. Effect of excess air on fouling rate 


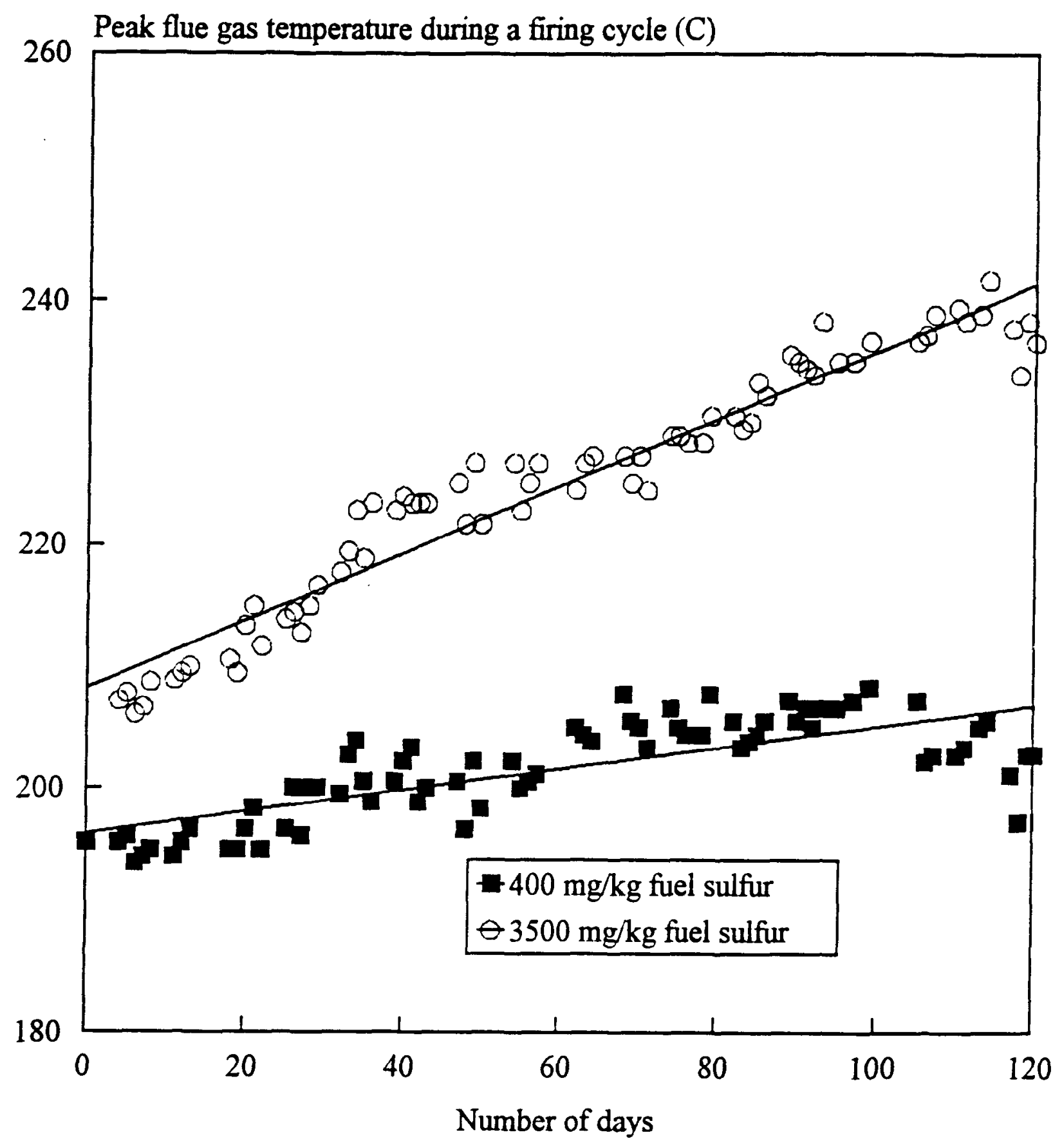

Figure 6. Trends in peak flue gas temperature during full size boiler tests. 
Paper No. 99-7

Review of Recent Technical Accomplishments by the Oilheat Manufacturers' Association (OMA)

By: John E. Batey, PE *

President

Energy Research Center, Inc.

35 Fawn Rd.

Easton, CT 06612

Telephone: $203-459-0282$

Fax: 203-459-0282

* Engineering Consultant to the Oilheat Manufacturer's Association (OMA) 
Review of Recent Technical Accomplishments by the Oilheat Manufacturers' Association (OMA)

By: John E. Batey, PE

\section{Introduction}

The Oilheat Manufacturers Association (OMA) is a not-for-profit corporation that represents oilheat equipment manufacturers to the industry, the government and the public. OMA's primary mission is to "promote the growth and well being of the oilheat industry by providing technical and related marketing support". It conducts engineering and marketing studies and assembles positive well-documented information about oil heating equipment. OMA works with other oilheat industry associations and others to promote and maintain public awareness of the benefits of oil heat products and services. Specific benefits offered by OMA include:

- Serving as the oilheat industry's government "watchdog" - tracking proposed legislation to make sure that industry interests are protected. This includes proposed energy and environmental regulations, and codes and standards.

- Acting as a connection between oilheat equipment manufacturers, PMAA, Oilheat Associations, Brookhaven National Laboratory, and other vital segments of the industry.

- Conducting studies and supplying the technical research data needed to substantiate claims that oilheat systems are efficient, safe, economical, clean-burning and environmentally friendly.

- Supplying information to convince homeowners, realtors, and builders, and the public that oil is the heating fuel of choice.

Over the past five years OMA has successfully completed a number of important projects that include the development of the "Oil heat Advantage Project" which supplies documentation on the many advantages of modern oil heating equipment including its efficiency, cleanliness, safety, economics, and low air emissions. This report gives a brief overview of some recent technical accomplishments in support of the oil heat industry.

\section{Recognition Of Brookhaven National Laboratory's Oil Heat Research Program}

The primary source for oil heat research over the past 24 years has been the oil heat research program at Brookhaven National Laboratory. It has continuously supplied valuable and credible information on the performance of oil heating equipment, and has contributed to the advancement of oil equipment design improvements. Brookhaven's research on efficiency and emissions has identified and quantified many important performance advantages of oil compared to other home heating sources. It has helped to show that modern oil burners are clean burning and produce very low air emissions of air pollutants. In fact, OMA's Oil heat Advantage Project, and many other successful oil heat projects have relied heavily on the BNL research program.

The BNL research formed the technical foundation for many important accomplishment over the past 20 years that have begun to generate a more favorable image toward home heating oil. A 
few examples of ways in which the Brookhaven research program already has helped to improve oilheat's image follow:

- An Engineering Report by the Energy Research Center to WCBS radio regarding oil cquipment efficiency and safety allowed WCBS to run the East Coast Energy Council Advertisements, and this was supported by BNL research.

- "Ten Common Misconceptions About Oil Heat" that presented some of the key technical advantages of oil heating equipment for the first time and began to show oil heat's advantages used research by Brookhaven.

- Engineering Reports Submitted to the New York State Energy Office on behalf of the Empire State Petroleum Association and again in Massachusetts by the Massachusetts Oilheat Council successfully defeated proposed bans on tankless coils. This report relied primarily on BNL research program.

- Expert Testimony Prepared for the Oil Heat Institute of Long Island presented the advantages of oilheat and contributed to a favorable decision from the New York State Public Service Commission concerning conversions from oil to natural gas, and was based on Brookhaven research.

- The USEPA Acknowledged Lower Particulate (Smoke and Soot) Emission Factors for oil burners in 1996 based on actions by OMA using BNL's research reports. This is an important accomplishment especially considering recent reductions (in 1997) in allowable particulate levels by the USEPA.

- Favorable articles in newspapers including the New York Post, the Boston Globe, the Boston Herald, and other publications concerning oil heating equipment relied on research by Brookhaven.

- Technical support to Oil Heat Associations on key issues including conversions from electric heat to oil, and efficiency, cost, and air emissions benefits use BNL data.

- Successful defense of Oil Companies Against Carbon Monoxide claims used test data produced by Brookhaven over the past 10 years.

- Engineering reports submitted to the U.S. Department of Energy for the Petroleum Marketers Association of America that helped produce an unbiased report that compared the relative merits of various home heating energy sources used BNL test data.

- Engineering Reports for the Oil Heat Advantages Project completed by the Oil Heat Manufacturers' Association that document the many advantages of modern oil heating equipment included research conducted by Brookhaven.

These are a few examples of how the Oil heat Research Program at Brookhaven National Lab has been used to document some of the key advantages of oil heating equipment. It has helped to win important victories. These efforts have begun to improve oil heat's image. 
In addition to these important applications on behalf of the oilheat industry, the Brookhaven Oil Heat Program has helped to conserve fuel oil and lower greenhouse gas emissions from oil heating equipment. The net savings in fuel costs to homeowners over the past 15 years is more than $\$ 40$ billion. Greenhouse gas emissions from oil heat were also reduced by more than 470 million tons over the past 15 years, with a value of more than $\$ 10$ billion. Therefore, the total cost benefit of the Brookhaven Oilheat Research Program is more than $\$ 50$ Billion, which is approximately 500 times greater than the total cost of the research program (assuming that the BNL program is credited with only $25 \%$ of the total savings). This means that more than $\$ 500$ was saved for every one dollar spent on oil heat research at Brookhaven.

This excellent benefit-to-cost ratio and the important reductions in greenhouse gas emissions produced by the program, call for continuation and expansion of the Brookhaven Oil heat Program. However, this program is currently scheduled to end in September of this year. I strongly recommend that you call or write your US Representative or Senator immediately to indicate the need for continuing this program that has supplied valuable information in support of the oil heat industry. Your help is needed so that Oil Heat Research Program at BNL can continue.

\section{Recent Technical Accomplishments By Oma}

Over the past five years, I have supplied engineering consulting services to OMA on many key technical issues. During the past year, I have worked several issues that include code and regulations issues that directly impact oil heating equipment and oil marketers. Several projects are briefly presented here, and more detailed information on these issues is presented in the Publications and References List at the end of this report.

\section{Chimney Venting Codes for Oil Heating Equipment}

The National Fire Protection Association standard for "Installation of Oil-Burning Equipment (NFPA-31) was revised in 1997so that all existing chimneys must be brought up to "current standards" before installing new oil fired equipment. These new chimney provisions present serious concerns for oil heat equipment manufacturers and oil heat marketers:

- Many existing chimneys serving oil heating equipment may not comply with all the requirements of NFPA 211 , but are not a hazard.

- The need for upgrading (relining) all oil chimneys to NFPA 211 standards has not been demonstrated factually by a record of documented safety incidents.

- The cost of chimney upgrades and relining is very high (on the order of $\$ 1,000$ to $\$ 5,000$ ) and is not justified in most cases.

- The added cost of mandated chimney upgrades will prevent many homeowners from installing inherently safer new oil heating systems.

At the October 20-22 meeting of the NFPA Technical Committee on Installation of Oil Burning Equipment, I presented a report that summarized oil heat industry concerns about the new provision in NFPA-31. After his presentation, committee members voted to eliminate the objectionable provision of the code. This is an important change because it allows continued installation of new oil heating equipment without costly chimney inspections and upgrades that could severely restrict the use of new equipment. The code revision was initiated by OMA and the 
work was supported by PMAA, NEFI, Massachusetts Oil heat Council, Maine Oil Dealers, and the Oil Heat Institute of Rhode Island. I am now working with a Task Group to modify the code and its appendix and prepare for a letter ballot for all committee members. In addition, a Temporary Interim Amendment (TIA) to the code is needed so that the revision will be effective before the next edition of NFPA 31 is published in the year 2000 .

\section{NFPA Increases in Oil Tank Vent Size are Reversed}

In the 1997 version of NFPA 31, the minimum size for oil tank vents was increased to 2 inches. At the Spring NFPA meeting, I presented the results of engineering calculations showing that this increase is not needed. The NFPA meeting minutes published on September 15, 1998, now show the following minimum tank vents:

Underground tanks less than or equal to 550 gallons Underground tanks greater than 550 gallons

$1-1 / 4$ inches Indoor tanks less than or equal to 660 gallons Indoor tanks greater than 660 gallons

This revision will allow indoor tanks that are less than or equal to 660 gallons to use a 1-1/4 inch vent instead of a 2 inch vent as required in the 1997 standard. A TIA may also be required.

\section{Proposed Restrictions on Oil Water Heaters in Massachusetts were Prevented}

Proposed changes to Massachusetts building codes threatened to restrict the use of tankless coils and other indirect water heaters powered by oil. OMA research on this issue that was based on oil equipment testing at Brookhaven was used in a collaborative effort with the Massachusetts Oilheat Council to prepare an engineering report that compares the relative efficiencies of oil, natural gas, and clcctrically powered equipment. This report demonstrates that oil powered water heaters produce efficiencies that are comparable to or better than gas, and much higher than electric powered units. As a result. the proposed restrictions to indirect oil water heaters were not implemented in Massachusetts. Accurate evaluation of domestic hot water efficiencies is difficult, and the many years of efficiency testing by Brookhaven National Laboratory supplied critically needed data for successfully completing this project.

\section{Greenhouse Gas Emissions in New Jersey and Oil Heat's Role}

New Jersey established a Greenhouse Gas Banking Advisory Committee to investigate ways to lower greenhouse gas emissions. One of the options considered was replacing oil heating equipment with natural gas powered equipment. I worked with the Fuel Merchants' Association of New Jersey to prepare an engineering report that shows the important role that oil heat serves in lowering greenhouse gases and other pollutant emissions. This included past research by OMA and presented the following conclusions:

- Negligible greenhouse gas reductions are produced by replacing oil with gas

- Converting electrically-heated home to oil lowers greenhouse gases by $50 \%$

- Converting electrically-heated home to oil lowers ground-level Ozone 
- Converting electrically-heated home to oil lowers Particulate Emissions by $94 \%$

- Homeowners can lower heating costs by $\$ 70,000$ over 20 years by converting from clcctric heat to oil.

A strong argument was presented for expanded use of oil heat to lower emissions and improve ambient air quality in New Jersey.

\section{Comparisons of Residential Heating Costs with Oil, Gas, and Electricity}

Spreadsheets developed for various OMA projects (including payback period calculations) have been used to compare the relative costs of heating fuels for specific locations. Recently a report was prepared for the Delaware Valley Fuel Oil Dealers that clearly demonstrated the economic advantages of heating oil in homes. This approach can be applied to other specific regions using local gas and electric utility rates to evaluate the economics of oil heat and the benefits of electricto-oil and heat pump-to-oil conversions. This can become a valuable tool for selling conversions to oil heat. The current computer-based programs calculate:

- The average local price of natural gas for heating using monthly Heating Degree Days

- The average local price of electricity for heating using monthly Heating Degree Days

- Payback Periods for Electric-to-Oil conversions for a range of conversion costs

- Payback Periods for Heat Pump-to-Oil conversions for a range of conversion costs

- Payback Periods for Oil-to-Gas conversions (or lack of payback)

- Payback Periods for Gas-to-Oil conversions

These can be performed by computer and summary reports prepared to assist oil heat associations and individual oil marketers across the US in their electric-to-oil and gas-to-oil conversion programs.

\section{Other OMA Activities}

The following list summarizes other recent actions by the Oilheat Manufacturers' Association.

- OMA is organizing input for a complete re-write of NFPA-31 for the year 2000

- OMA research, engineering reports, and technical updates are supplied to oilheat associations to support their on-going activities

- Technical support for Newspaper articles concerning oil heating equipment

- OMA continues to work closely with Brookhaven National laboratory in reviewing recent research, assistance with prioritization research projects, and transferring technical information on recent BNL research to OMA members and others.

- Continuing research and Technical Updates on the environmental advantages of oil heat

- Research on Carbon Monoxide emissions from oil heat and other sources

- Proposed revisions to International Fire Code

- Voting member at NFPA-31 Technical Committee meetings

- Engineering data were sent to the American Council for an Energy-Efficient Economy during the preparation of a report comparing domestic water heater efficiencies

- Reviewed and commented on proposed revisions to ASHRAE Standard 90.2

- Review of US Department of Energy efficiency testing and rating programs 
- Continuing research on Global Warming and potential impacts on oil heating

- Planning for expanded OMA communications and information outreach program

- ACTION PLAN: Electric-to-Oil Conversion Program

- ACTION PLAN: Demonstrating Oil Heat's Environmental Advantages - Ozone/Particulate

- ACTION PLAN: Demonstrating Oil Heat's Global Warming Advantages

OMA continues to address key technical issues to support the growth and well being of the oil heat industry.

7. Publications and References List (November 1998)

Reports: OMA and the Energy Research Center:

Chimney Upgrades Contained in NFPA-31 (1997) and Proposed Changes to the Standard. John E. Batey, submitted to the NFPA 31 Technical Committee on behalf of OMA, PMAA, New England Fuel Institute, Massachusetts Oilheat Council, Maine Oil Dealers Association, Oil Heat Institute of Rhode Island, October 22, 1998.

Comparison of Heating Oil, Natural Gas, and Electricity Costs for Residential Heating, John E. Batey, prepared for the Delaware Valley Fuel Oil Dealers, June 1998.

The Role of Home Heating Oil in Lowering Greenhouse Gases and Other Emissions in New Jersey, for the Fuel Merchants Association of New Jersey, May 1998.

Comparison of Residential Water Heater Efficiencies, John Batey, for OMA and Massachusetts Oilheat Council, February 1998.

Expanded Use of Residential Oil Burners to Reduce Ambient Ozone and Particulate Levels SUMMARY REPORT - presented at Oil Heat Technology Conference at Brookhaven National Laboratory, April 1998.

Expanded Use of Residential Oil Burners to Reduce Ambient Ozone and Particulate Levels Engineering Report and Documentation in Response to Revised USEPA Standards, prepared by John E. Batey, October 1997.

Problems Associated with Natural Gas Conversion Burners, by John Batey, for the Mainc Oil Dealers, November 1997.

An Overview of Proposed Revisions to Ambient Air Quality Standards for Ozone and Particulates - Potential Impacts on Residential Oil Burners, prepared by John E. Batey, February 3, 1997, 15 pages.

An Overview of Carbon Monoxide Generation and Release by Home Appliances, prepared by John E. Batey, April 1997, (Presented at ASHRAE and Brookhaven Conferences), 12 pages.

OMA Oilheat Advantages Project - Engineering Analysis and Documentation, prepared by John E. Batey, and Robert G. Hedden. 1995, 139 pages. 
Engineering Update - Oil and Gas Heating, Energy Research Center, for the Maine Oil Dealers Association, based on OMA publications, October 1997.

OMA Technical Updates:

Oil Heat Engineering Update - January to May 1998, Broadcast FAX to OMA members.

Immediate Action Needed on Proposed Restrictions on Indirect Water Heaters, ASHRAE 90.1 Proposed Revisions, March 1998.

Oil Heat Engineering Update - summary of recent OMA developments - November 1997 (3 pages)

Electric-to-Oil Conversions Reduce Greenhouse Gases by 50\%, DRAFT, October 1997, (3 pages)

Outline for Oil Burning Equipment Maintenance and Service (Preliminary), for NFPA-3 (2000), September 1997 (5 pages)

Oil Burner Advances at Brookhaven National Laboratory, Sept. 1997, John Batey, 1 page.

Oilheat Technical Advisory Group Meeting at Brookhaven National Laboratory, meeting summary and recommended actions, John Batey, September 17, 1997, 3 pages.

New Ozone and Particulate Emission Standards by the USEPA, key concerns and Action Plan, John Batey, July 18, 1997, 2 pages.

US Department of Energy Water Heater Workshop, Report of meeting in Washington, John Batey, July 21, 1997, 3 pages.

US Environmental Protection Agency Recently Acknowledged that Modern Oil Burners are Clcan Burning, John Batey, April 1997, I page.

Direct Comparison of Oil Boiler and Heat Pump Efficiency, by John E. Batey, October 1996, (will be revised as OMA Technical Update), 3 pages.

Oilheat Engineering Update- summary of recent developments and actions, April 1997, 2 pg.

OMA Memos:

ACTION PLAN - Electric-to-Oil Conversion Program, plan for how oil heat associations can use OMA documents to expand the number of oil heat customers by converting electrically-heated homes, John E. Batey, 1998, I page.

ACTION PLAN - Demonstrating Oil Heat's Global Warming Advantages, plan for how oil heat associations can demonstrate lower greenhouse gas emissions with oil heating equipment, John $\mathrm{E}$. Batey, 1998, l page.

OMA Member Comments and Input Needed on Re-Write of NFPA-31 - Installation of Oil Burning Equipment", September 26, 1997 
Technical Information from OMA Members for the Ozone/Particulate Report Now Being

Written", September 26, 1997

Research and Development: The Key to Oilheat's Future, prepared by John E. Batey, May 1997, 4 pages.

ACTION PLAN - Demonstrating Oil Heat's Environmental Advantages - a plan for how oil heat associations can respond to the proposed USEPA Regulations, John E. Batey, May 1997, 1 page.

Article on Carbon Monoxide Hazards, in response to article regarding oil burners in AirConditioning Heating and Refrigeration News, John Batey, April 22, 1997, 2 pages.

Indirect Water Heater Efficiency Test Procedures, July 10, 1996, (a summary and critique of Brookhaven tests), 4 pages.

Update on Greenhouse Gas Emissions by Natural Gas, November 20, 1996, (based on recent Gas Research Institute publication), 2 pages.

Greenhouse Gas Reductions and Oilheat Research at Brookhaven National Laboratory, August 1996, (a brief summary of reduced greenhouse gas emissions by oilheat), 3 pages.

Update on Oil and Gas Furnaces Efficiencies (AFUEs), November 12, 1996, (recent efficiency trends and observations), 5 pages.

Participation in Energy Star Program, July 9, 1996, (review of program requirements and minimum efficiencies), 2 pages.

Revision of NFPA-31 - Installation of Oil Burning Equipment, May 27 1997, (the opportunity for code re-write by OMA members), John Batey, 4 pages.

Mecting Report - NFPA-31 Technical Committee, May 29-30, 1996, 4 pages.

Meeting Report - NFPA-31 Technical Committee, October 5-6, 1995, 2 pages.

Revision of ANSI-A40 - Double Wall Heat Exchangers, April 25, 1996, (letter from John Batey to International Association of Plumbing and mechanical Officials), 3 pages.

Meeting Report - PMAA Research and Development Committee, July 7, 1996, 2 pages.

Meeting Report - Technical Advisorv Group at Brookhaven National Laboratory, August 21, 1996,5 pages.

Comparison of Residential Heating Equipment Performance, November 11, 1996, (an overview letter of key points in OMA's Oil Heat Advantages Project Engineering Document), 5 pages. References:

US CPSC Carbon Monoxide Information and reports on incidents, injuries and deaths - OMA report and Technical Updates in progress. 
California Leaking Underground Fuel Tank (LUFT): Recommendations to Improve the Cleanup Process for California's leaking Underground Fuel Tanks, and Historic Case Studies, (recommends passive remediation), Lawrence Livermore National Laboratory, October 16, 1995 and November 16, 1996, OMA report and Technical Updates in progress.

Role of technology in Reducing Global Warming, White House Conference on Global Climate Change, October 6, 1997, C-Span Videotape.

Science of Global Climate Change, White House Conference on Global Climate Change, October 6, 1997, C-Span Videotape.

Scenarios of U.S. Carbon Reduction - Potential Impacts of Energy Technologies by 2010 and Beyond, Interlaboratory Working group on Energy-Efficient and Low-Carbon Technologies, Oak Ridge National Laboratory, LBNL, PNNL, National Renewable Energy Laboratory, Argonne National Laboratory, September 22, 1997.

Climate Change Policy and Fact Sheet, Global Climate Change Coalition, Washington, DC.

Oilheat Research Agenda - A Ten year Blueprint for Residential Oilheat Research and Development in the Twenty-First Century, R.J. McDonald, and J.E. Batey, Brookhaven National Laboratory, Report 52529, May 1997.

Development and Technology Transfer of the BNL Flame Quality Indicator for Oil-Fired Applications, Brookhaven National Laboratory, Informal Report 61860, September 1994.

Compilation of Air Pollutant Emission Factors, Volume I: Stationary Point and Area Sources, US Environmental Protection Agency, Publication AP-42, Fifth Edition, Supplement B, November 1996.

OMA members can obtain copies of these Technical Updates, Memos, and reports by calling (802)325-3509. For engineering and technical questions concerning these publications, please call John Batey at (203)459-0353, or you can FAX questions to (203)459-0282. 
Paper No. 99-8

Electronic Operations Manual (EOM) for the Oilheat/Energy Services Industry

Richard Rutigliano, President

PriMedia, Inc.

Williston Park, NY 11596

Telephone: 800-796-3342

Fax: 516-741-6502

www.primedia-ny.com

Alan Levi, President

Oil Services, Inc.

Oceanside, NY 11572

Telephone: 516-763-1400

Fax: 516-763-1463

www.osi-ny.com 



\section{Electronic Operations Manual (EOM) for the Oilheat/Energy Services Industry}

\section{Overview of the EOM}

An Electronic Operations Manual (EOM), commonly dubbed a "Policy and Procedures Document" (PPD) is the most advanced, comprehensive business management tool an organization can implement. Simply put, it is the one source every new and veteran employee can use to keep up and keep in contact with his or her company's specific practices. Customized to fit any organization's modus operandi, the EOM acts as a "Living Document" installed on the company's computer network or individual workstations. Employees have access to key information right at their fingertips, and updating or retrieving data is simple and fast. Perhaps best of all, the considerable administrative work associated with a paper manual is eliminated.

Over the last decade consolidation, competition and environmental regulations have profoundly altered the Oilheat/Energy Services industry. Such changes have made it imperative for an organization to maintain clear communications to properly manage the work environment, reduce waste and minimize insurance liability, key factors in competing in today's business climate. Employing an EOM is crucial for companies seeking to keep employees informed, productive and empowered. It is an essential part of a coherent training program for new and veteran employees alike, and provides management with a uniform platform for measuring employee performance. 


\section{Key Benefits of the EOM}

$>$ Ideal for training new hires

$>$ Provides clear guidelines for measuring employee performance

$>$ Builds teamwork and helps make employees more company-oriented

$>$ Streamlines operations and helps company to run more efficiently

$>$ Ensures consistency in performing tasks and serving customers

$>$ Helps mitigate insurance liability claims

\section{History/Background}

The Electronic Operations Manual (EOM), a computerized Policy \& Procedures document that works on a wide variety of computer platforms (Windows ${ }^{\mathrm{m}}$, DOS ${ }^{\mathrm{m}}$, UNIX ${ }^{m}, M^{\prime} C^{m}$ ) has undergone a major transformation over time from simple prototype to its present-day structure. Its foundation can be traced back to OSI (Oil Services, Inc.) the 66 year-old, family-owned and -operated comfort services provider located on Long Island, New York. Recognizing the need to streamline its operations, improve business techniques and offer a broader range of products and services to garner new customers and better retain existing ones, it became apparent that an operations manual was necessary to ensuring that everyone in the company was on the same track to success.

The Long Island Oilheat market is one of fierce competition, both among local Oilheat dealers and from competing energy sources and related service groups and companies. Full-service companies like OSI must work diligently to keep overhead costs down to better withstand pressure on margins from such fierce competition. Having joined the prestigious Contractors 2000, a national association serving the HVAC, electrical and plumbing industries to advance member companies by helping them to improve efficiency and increase market penetration, OSl's owners, the Levi family, became exposed to valuable management philosophies, most notably the novel approaches expounded by Michael Gerber in The E Myth, Why Most Small Businesses Don't Work and What to Do About It (HarperBusiness). An essential tenet of Gerber's business philosophy is that any type of business, even those intensely driven by customer service, can be automated in a way that empowers everyone in the organization to deliver superior service consistently. The role of the entrepreneur, or business owner, is to create that very system. In short, owners should work on their businesses, not in them.

Subsequently, the Levi's developed their "cookbook" approach to running their operations via a complete manual that served as the blueprint for running a successful home comfort services company. They enlisted the aid of industry luminary Dan Holohan. Together, they examined and deciphered every function of OSI, detail by minute detail. They spearheaded meetings, brainstormed with employees and adapted suitable shortcuts to facilitate procedures. After two 
years of dedicated input, they created a document that defined step-by-step procedures for some 300 main tasks, which with spin-offs, added up to more than a thousand.

The result was a newly-developed operations manual, exhaustingly comprehensive, that necessitated frequent revision. In fact, that is a process that continues even today as more modernized and refined procedures are discovered. Still, during its infancy, it became difficult to keep up with all the changes and as the manual grew larger, it became increasingly difficult to find information. The Levi's knew that if the operations manual weren't 'user-friendly,' it would not be the "recipe for success" they'd envisioned.

The next step saw the involvement of PriMedia, the marketing \& communications firm specializing in the Oilheat sector and its related industries. PriMedia's founder, Richard Rutigliano, has an extensive background in Oilheat operations, having served as General Manager of a sizable Oilheat company for many years.

PriMedia set out to transform the operations manual to an electronic document. The advantages were extraordinary. Suggestions for updates could be posted within seconds, information retrieval was simplified and query searches were easily achieved by linking from key words or an index. In addition, photos, artwork and a variety of graphics were now easily accessible. Instantly, the consummate business tool was available at everyone's fingertips.

\section{"Walk-Through" of the EOM - Its Organization and Features}

Customized for every company, the EOM allows personnel to search, classify and categorize key information on every aspect of their organization's operations. By offering clear guidelines, a company ensures consistency, a crucial measure in fostering enhanced overall performance and profitability.

There are three ways to access information in the EOM. Bookmarks act like a running table of contents, or index, that appear in the left-hand margin of the page alongside the active page. Simply mouse-clicking any bookmark allows the user to immediately navigate to the page listed, in much the same way as a text link helps users navigate web sites via a Browser. Bookmarks can be easily customized by the user in a number of ways. For instance, users can categorize information by job description, department, or other designation in a format much like the folders and sub-folders common to most Word Processing programs. Pages can even be duplicated, appearing in two or more bookmarked sections without, as in a paper manual, actually copying or repeating the page or pages themselves which would alter the original document unnecessarily. 


\section{Sample Page indicating Bookmarks}

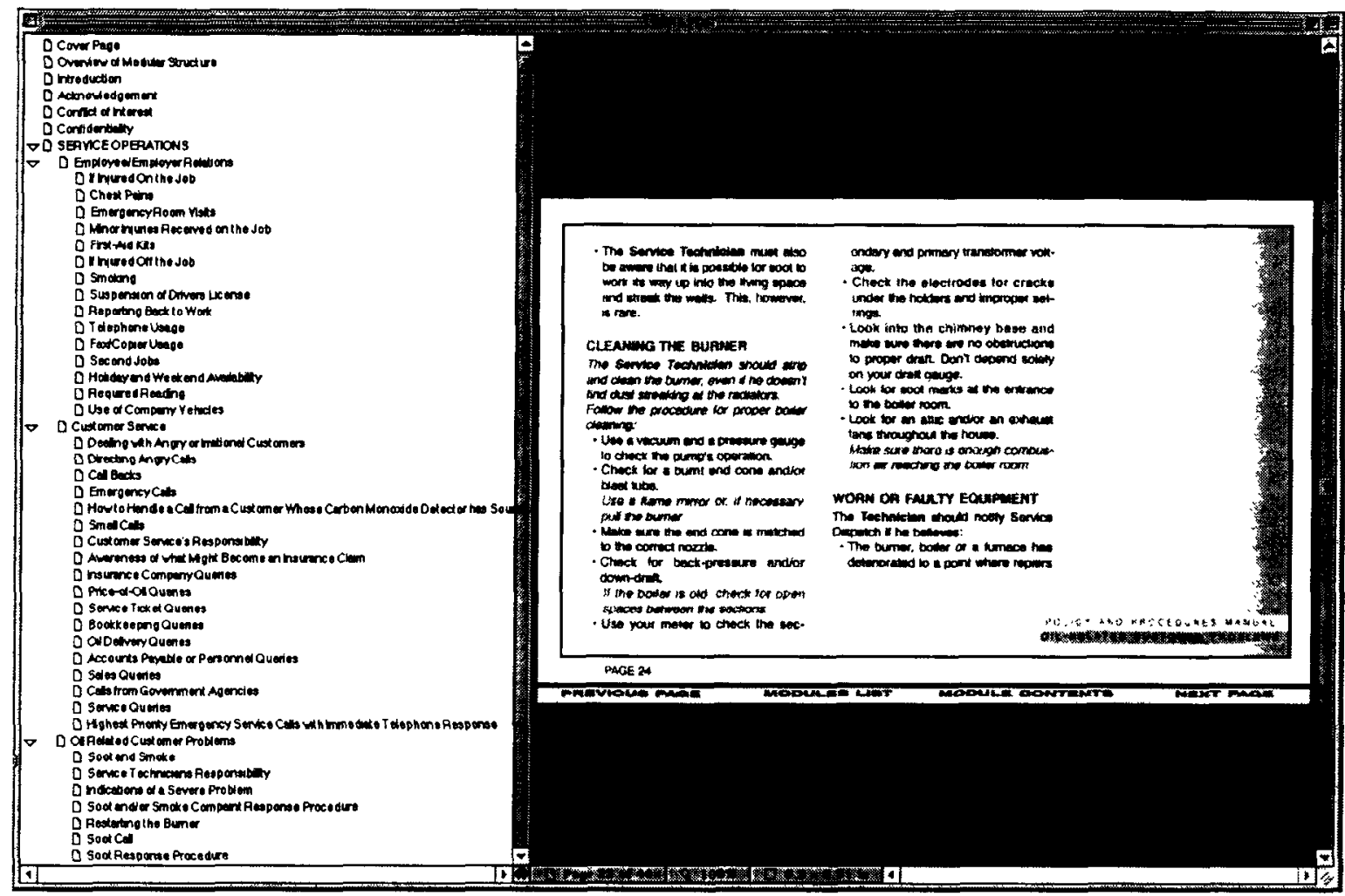

Menu Approach to Accessing Information

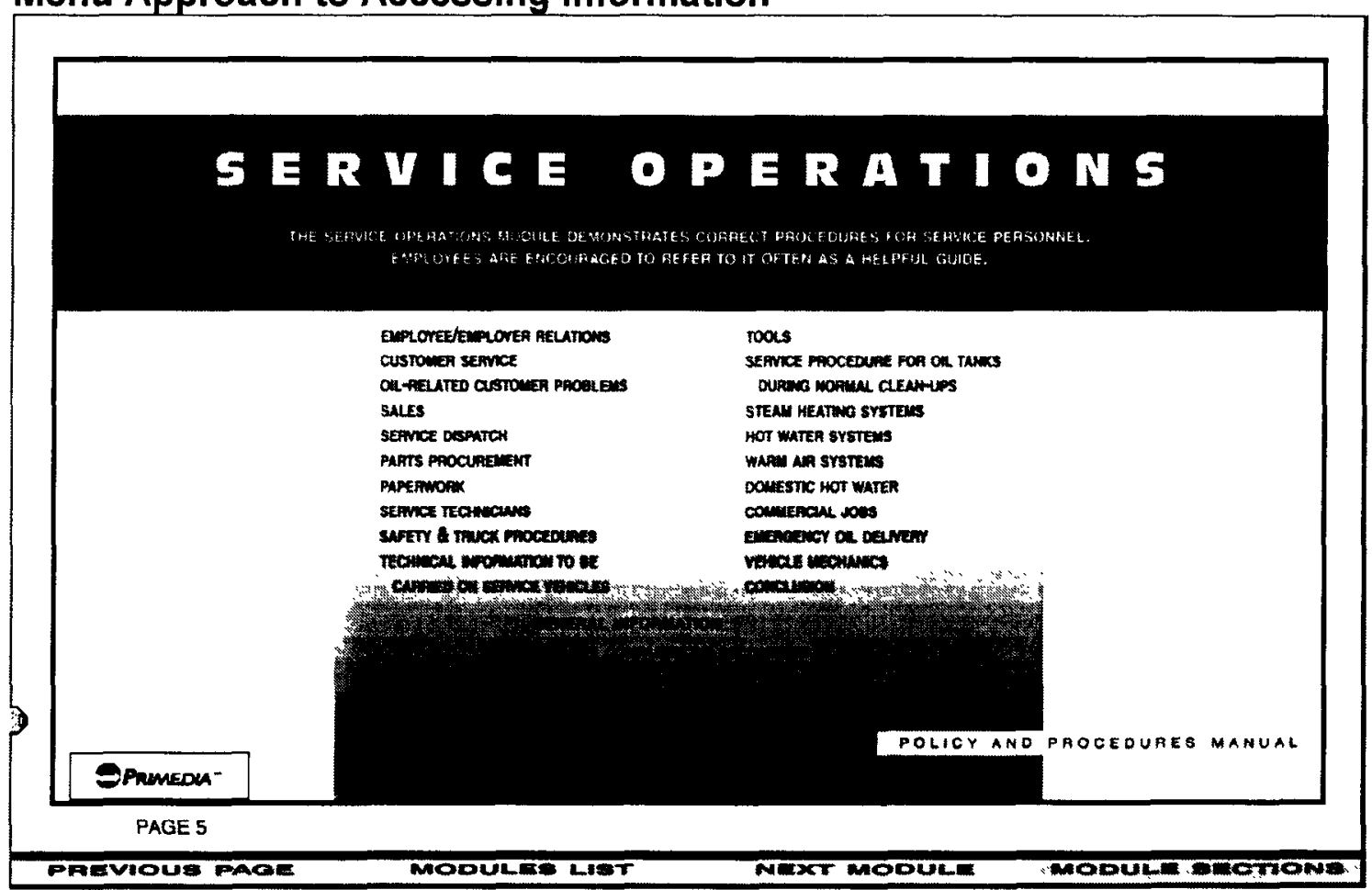


In addition to bookmarks (which can be made viewable or non-viewable at user's option), key information can also be accessed via a more traditional menu or table of contents that can be "popped up" on screen similar to the "help" screen located on common Windows-compatible software. Finally, employees can search for a specific word or topic simply by keying in a word or phrase much like locating information from a search engine on the World Wide Web.

The EOM contains the following eight modules, or main sections of material: Administrative Guidelines; Employee Handbook; Safety Guide; Service Operations; Fuel Operations; Plumbing; Air Conditioning; and Gas Furnace $\&$ Boiler. If we were to "click on" each, we would find a host of sub-categories.

For example, accessing "Administrative Guidelines" brings us to a screen featuring the following subdivisions:

- Employee/Employer Relations

- Customer Service

- Oil-Related Customer Problems

- Sales

- Service Dispatch

- Parts Procurement

- Service Technicians

- Helpers

- Safety \& Truck Problems

- Oil Delivery

- Vehicle Maintenance

- Accounts Receivable

- Conclusion

Within each subdivision there exist step-by-step processes for every conceivable task pertaining to that subdivision.

The EOM serves as a company guideline for policy and procedure on every facet of operation. In order to keep the document current and comprehensive, the EOM enables users to suggest changes and revisions via a "sticky note" icon located on the main tool bar of each page. By simply mouse-clicking the icon the user is able to "drag and drop" the icon anywhere within the page indicating where revision is necessary. The icon itself can handle a virtually unlimited amount of text, typed directly onto the document or imported from another source document or application. Upon closing the window, a blue folder icon appears, symbolizing 'a change' has been made. After the administrator has performed all of the updates, s/he either e-mails or sends the edited version on disk to PriMedia to revamp the PPD. That way the integrity of the document is maintained with no possibility of unauthorized changes occurring. 


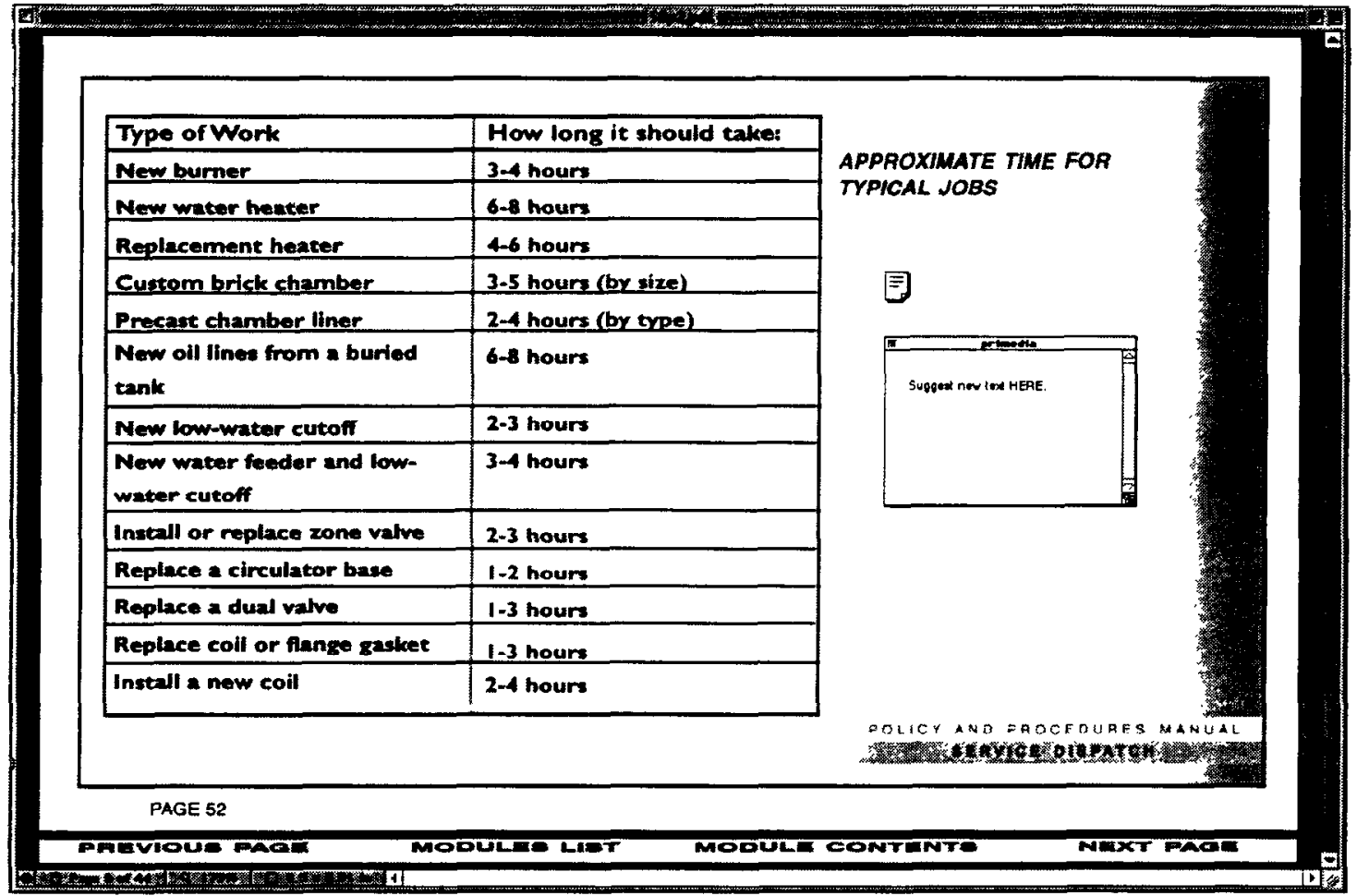

Key features of the EOM "paperless" format include:

- Search - Find subjects by simply typing a key word or phrase.

- Link - Various topics of interest can be accessed with one mouse-click.

- Bookmark - Allows the user to mark and easily return to places of interest.

- Zoom - Magnify sections up to $800 \%$ for clear and easy viewing.

- Security Access - Ensures only your employees have access to sensitive materials.

- Print - Any or all of the document can be printed for in-office use.

- Change - Allows updates to the document, when necessary.

- Distribute - Distribute your documents via your Network, Intranet and the Internet.

\section{Recap/Conclusion}

The PPD is the essential tool for every company to streamline its procedures and reduce inefficiencies. Employees need to know the policies their organization has in place in order to work productively. Consolidating operations helps your company build teamwork, ensure consistency, mitigate insurance liability claims and ultimately boost your bottom line. 
Questions and answers about the Electronic Operations Manual:

Q: How do I benefit by having this Policy and Procedures Document?

A: This program provides...

- a "cookbook approach" to creating a standard company response to routine situations.

- an efficient training tool, decreasing training time and effort.

- improved levels of customer satisfaction.

- better company-wide communication.

- a standardized way to perform, and measure performance.

- a way for management to "release" trained employees, allowing everyone to do their jobs.

- a team building atmosphere where all employees have a voice in developing policies and procedures.

- a flexible format for reviewing, improving and changing policies as needed.

- a way to reduce insurance costs through improved safety programs.

Q: Why isn't a paper version sufficient?

A: $\quad$ As more and more policies are created, the paper version becomes too overwhelming to use effectively. Searching is very cumbersome. The constant updating becomes difficult when the text and pages need to be added, deleted and amended. A paper document exposes a company to having its sensitive document copied.

Also, a paper version can not incorporate forms, photographs and video clips.

Q: What type of computer system do I need?

A: The Document will work on any platform - DOS, Windows, Unix, Macintosh. Basically, you need a PC with a 386 or better processor, and $4 \mathrm{MB}$ Ram. We suggest using a monitor with 256-color capability. Monochrome or 16-color monitors will not perform well. 
Q: How does the standard version become my customized Electronic Operations Manual?

A: By using the "post it" notes that can be sent back to PriMedia via the Internet or by mailing a disk, the document can be customized for each company. The more you use it the more it becomes your company's own document. The process is similar to the improvements made to a Flat Rate document as it gets used and refined.

Q: How does this get supported by PriMedia?

A: PriMedia will provide support via the Internet and by phone. Provisions can be made for on-site training as well. 
Paper No. 99-9

Advanced Residential Oil Burner Control Functionality And How It Effects Overall Performance

(A Study Of Interrupted Duty Ignition)

Charles W. Feldman, Chicf Engineer

Peter J. Cullen, National Service Manager

Carlin Combustion Technology, Inc.

70 Maple Street

East Longmeadow, MA 01028

(800) $989-2275$ 


\section{Advanced Residential Oil Burner Control Functionality And How It Effects Overall Performance}

\section{(A Study Of Interrupted Duty Ignition)}

\section{Introduction}

This paper attempts to define the current state of the art with respect to residential oil burner control functionality and how various optional sequencing strategies influence overall burner performance.

It was our intent to discuss here, in some detail, all new and cutting edge protocols, including: pre-purge, interrupted spark ignition, recycle on flame failure, post-purge and the benefits of microprocessor based control systems. However, as we developed this document, it became quite evident that there was far too much material to cover in one paper. So, we chose to limit the presentation here to the one issue that appears to have the most significant impact on overall performance, that being interrupted ignition.

In general, oil-heating equipment has come a long way in the last thirty (30) to forty (40) years. Technology improvements have made it possible to provide clean, efficient oil burning equipment, while at the same time, dramatically improving heat transfer efficiencies. Lower mass, higher efficiency heat exchanger designs were, of course, central to these efficiency gains; but those gains came, in large part, at the cost of higher combustion chamber pressures and new performance challenges for burner manufacturers. To some degree, the result of higher efficiencies and higher combustion chamber pressures have resulted in certain unexpected, negative side effects that have become problematic to the industry. So, as we examine the benefits of interrupted ignition, we will attempt to identify and examine some of these negative side issues as well.

The data presented here is in large part a confirmation of expected design criterion, confirmed by measured values, lab verification testing and reported field experiences. Some, however, is the result of feedback from the field that was not anticipated. Only phenomena that could be replicated, understood and quantified will be presented here.

For this study, we have examined the operation of oil burners utilizing intermittent and interrupted ignition; and have measured and compared the operational effect in the following areas:

- Electrical Energy Consumption

- Sound Levels

- Electrode Wear

- Interrupted/Intermittent Ignition System Life

- Combustion Efficiency

- Plugged Heat Exchangers \& Running Saturation 


\section{Control History}

In order to appreciate the advantages provided by today's control technology, it is important that we first look at the evolution of residential oil burner controls over the years.

When we look back on the early oil burner primary safety controls, the stack switch clearly stands out. Designed to be installed in the flue pipe connected to an oil heating appliance, the stack switch utilized a bi-metal helix to sense a three hundred $\left(300^{\circ}\right) \mathrm{F}$ to five hundred $\left(500^{\circ}\right) \mathrm{F}$ degree temperature rise in the stack. Provided this increase in stack temperature was detected, the bi-metal helix would expand, make the switch contacts inside the control, and once made, allow the burner to continue to run. The trial for ignition period for stack relays was typically 90 seconds. And while long by today's standards, this timing was quite a reasonable period of time given:

- The design of the heat exchangers of the day

- The flame characteristics of the burner designs typical of that time

- The time necessary for the combustion process to be initiated

- The time necessary for the heat generated by the burner to find it's way through the flue passages of the heat exchanger and reach the control's helix.

In addition to the mounting location, means of sensing flame and trial for ignition period, there is one other significantly noteworthy feature of the old stack controls. They normally provided for interrupted ignition.

The introduction of the Cad Cell Relay brought with it a significant reduction in the trial for ignition timing; reduced from ninety (90) seconds to forty-five (45) seconds. Unfortunately, this improvement brought along with it the elimination of interrupted ignition. And while some will contend that the early flame retention burner designs required constant spark to maintain flame stability, we submit that internupted ignition was eliminated as a matter of cost reduction.

Interrupted Ignition Primary Control Technology can provide enhanced burner performance while providing a stronger, more reliable heating system design to address many issues problematic to the modern day oil heating technician (contractor). Technology that adds safety to the system, operates more quietly, extends component life, reduces energy cost, addresses such system concerns as plugged heat exchangers and running saturation while not sacrificing any performance efficiency, has been proven to be as simple as shutting down the ignition source after combustion is established and proven.

Microprocessor based residential oil burner control technology is today's state-of-the-art. It provides the platform for the addition of many advanced burner control features, such as interrupted duty ignition, purge cycles, recycle on flame failure, etc. It also provides enhanced product safety and reliability while still meeting the cost targets for residential oil burning equipment. We expect this technology to become the industry standard within the next two (2) to five (5) years. 


\section{Electrical Energy Consumption}

There is an electrical energy cost associated with the generation of the spark for ignition. The type of ignition system employed (transformer or electronic ignitor), and the design of the control strategy applied, (intermittent or interrupted duty) have a measurable impact on the quantity of power consumed and therefore overall equipment efficiency. This is notable when A.F.U.E. ratings that incorporate overall efficiency, not just combustion efficiency, are listed.

A residential oil burner with a $1 \mathrm{GPH}$ nozzle, on average, consumes 1000 gallons of oil per year to produce both heat and hot water. This typical system will start and stop 2,300 times during the course of a typical heating season (PMAA statistic). On that basis, we established the following profiles for typical ignition "on-time".

\begin{tabular}{|c|c|c|c|c|}
\hline & \multicolumn{2}{|c|}{ Burner } & Operating & Profile \\
\hline & Burner Hours & Length of & Number of & Ignition System \\
\hline Type of Control System & Per Year & Duty Cycle & Cycles Per Year & Total Hours Per Year \\
\hline & & & & \\
\hline Intermittent Duty & 1000 & Continuous & 2300 & 1000 \\
\hline & & & & 28.75 \\
\hline Interrupted Duty & 1000 & 45 Seconds & 2300 & 19.1 \\
\hline & & 30 Seconds & 2300 & 9.5 \\
\hline & & 15 Seconds & 2300 & 6.4 \\
\hline & & 10 Seconds & 2300 & \\
\hline
\end{tabular}

Figure 1

In an attempt to compare these time "on-time" estimates to energy cost, we have developed the table presented below to quantify the annual energy costs in dollars, at various (KWH) utility rates. As you will note, we have selected a $12 \mathrm{KV}$ transformer rated at $275 \mathrm{VA}$ ( 2.3 amperes at $120 \mathrm{VAC})$, a $10 \mathrm{KV}$ transformer rated at $250 \mathrm{VA}(2.1$ amperes at $120 \mathrm{VAC})$ and a solid state ignitor rated at $42 \mathrm{VA}(.35$ amperes at $120 \mathrm{VAC})$.

\section{Cost of System Operation at Various Utility Rates}

\begin{tabular}{|c|c|c|c|c|c|c|c|c|c|c|c|c|c|}
\hline Type of & Hours & \multicolumn{4}{|c|}{ Solid State Ignitor } & \multicolumn{4}{|c|}{$10 \mathrm{KV}$ Transformer } & \multicolumn{4}{|c|}{$12 \mathrm{KV}$ Transformer } \\
\hline Control & Of & \multicolumn{4}{|c|}{ Cost per Kilowatt Hour } & \multicolumn{4}{|c|}{ Cost per Kilowatt Hour } & \multicolumn{4}{|c|}{ Cost per Kilowatt Hour } \\
\hline System & Operation & $\$ 0.04$ & $\$ 0.08$ & $\$ 0.12$ & $\$ 0.16$ & $\$ 0.04$ & $\$ 0.08$ & $\$ 0.12$ & $\$ 0.16$ & $\$ 0.04$ & $\$ 0.08$ & $\$ 0.12$ & $\$ 0.16$ \\
\hline Intermittent & 1000 & $\$ 1.68$ & $\$ 3.36$ & $\$ 5.04$ & $\$ 6.72$ & $\$ 10.00$ & $\$ 20.00$ & $\$ 30.00$ & $\$ 40.00$ & $\$ 11.00$ & $\$ 22.00$ & $\$ 33.00$ & $\$ 44.00$ \\
\hline & & & & & & & & & & & & & \\
\hline Interrupted & & & & & & & & & & & & & \\
\hline 45 Seconds & 28.8 & $\$ 0.05$ & $\$ 0.10$ & $\$ 0.15$ & $\$ 0.19$ & $\$ 0.29$ & $\$ 0.58$ & $\$ 0.86$ & $\$ 1.15$ & $\$ 0.32$ & $\$ 0.63$ & $\$ 0.95$ & $\$ 1.27$ \\
\hline 30 Seconds & 19.1 & $\$ 0.03$ & $\$ 0.06$ & $\$ 0.10$ & $\$ 0.13$ & $\$ 0.19$ & $\$ 0.38$ & $\$ 0.57$ & $\$ 0.76$ & $\$ 0.21$ & $\$ 0.42$ & $\$ 0.63$ & $\$ 0.84$ \\
\hline 15 Seconds & 9.5 & $\$ 0.02$ & $\$ 0.03$ & $\$ 0.05$ & $\$ 0.06$ & $\$ 0.10$ & $\$ 0.19$ & $\$ 0.29$ & $\$ 0.38$ & $\$ 0.10$ & $\$ 0.21$ & $\$ 0.31$ & $\$ 0.42$ \\
\hline 10 Seconds & 6.4 & $\$ 0.01$ & $\$ 0.02$ & $\$ 0.03$ & $\$ 0.04$ & $\$ 0.06$ & $\$ 0.13$ & $\$ 0.19$ & $\$ 0.26$ & $\$ 0.07$ & $\$ 0.14$ & $\$ 0.21$ & $\$ 0.28$ \\
\hline
\end{tabular}

Figure 2 
While the total annual dollar costs at these rates are quite modest, the magnitude of difference between intermittent and interrupted duty systems is quite significant; as is the difference between the transformer and solid state ignitor.

From our view, we have seen a major shift in trade preference away from the iron core transformer, in favor of the solid state ignitor in the last two (2) to three (3) years. Similarly, we are now seeing a major shift in trade preference away from constant duty controls, in favor of 15 second interrupted duty control sequencing. In addition to several other advantages, as is evident from Figure 2, this shift will provide an average electrical savings of $\$ 29.95$ per year, at an electrical rate of $\$ 0.12$ per kwh.

\section{Burner Operational Noise Levels}

The electrical energy that is created by the Ignitor / Ignition Transformer, transmitted to, and discharged across the tips of the burner electrodes, creates an audible sound that is detectable by the human ear. During the operational cycle of a residential oil burner, there is a noticeable and measurable difference in burner noise levels with the ignition activated and with the ignition deactivated.

Sound levels are measured in terms of decibels $(\mathrm{dB})$. This unit of measure was named in honor of Alexander Graham Bell (bel) in recognition of the work he did in the study of the measure of hearing and deafness. The original decibel scale, developed by Alexander Graham Bell, was modified during the 1930's, to the present day standard, which is ten (10) times it's original scale. This change was made to make the numerical decibel measure easier to work with.

Perceived sound levels vary by individual. A volume level, measured as zero decibels $(0 \mathrm{~dB})$, is the minimum threshold of sound level detectable by the human ear. A whisper is about $10 \mathrm{~dB}$. A typical office environment has a measured sound level of about $45 \mathrm{~dB}$. The full range of frequencies that we, as humans, can hear, extends from around $10 \mathrm{~Hz}$ to more than $10,000 \mathrm{~Hz}$, depending on both the particular individual's hearing sensitivity, and his or her age. The ability to hear frequencies at both ends of this scale diminishes with age.

Years ago, audible frequencies were divided into eight octave bands. These bands have center frequencies from $63 \mathrm{~Hz}$ to $8000 \mathrm{~Hz}$. For purposes of our testing we used bands 3,4 and 5, having center frequencies of 250,500 and $1000 \mathrm{~Hz}$, respectively. These are not only frequency ranges that are easily detected by the human ear, but they are also in the range where, if there is too much noise, speech effectiveness will be limited.

Our readings were taken with a meter that provided an "A-weighted" sound level scale. The "Aweighted" scale is where the common abbreviation dBA comes from.

What does A-weighted mean? In its simplest terms, the sounds that we hear are generated at different frequencies. But in an effort to depict what we hear in a single frequency range, the "A-weighted scale was developed to give a particular "weight" to each of the frequencies, based 
on what the human ear can hear. You might say that the "A-weighted" scale averages all octave bands, but places a weighting on those bands that are most easily detected by the human ear. In actual practice, the A-weighting protocol adds priority to each of the scales, and then, adds each scale together, logarithmically, to provide a single numerical value. In practice, what this means is that two $60 \mathrm{dBA}$ sound sources, when combined, do not equal 120, rather, they equal 63 .

Figure 3 below illustrates how this weighting protocol works. Note that:

- When two sound levels differ by $1 \mathrm{~dB}$ or less, the combined sound level is calculated by adding $3 \mathrm{~dB}$ to the higher of the two values.

- When two sound levels differ by 2 or $3 \mathrm{~dB}$, add $2 \mathrm{~dB}$ to the higher of the two values.

- When two sound levels differ by 4 to $8 \mathrm{~dB}$, add $1 \mathrm{~dB}$ to the higher of the two values.

- When two sound levels differ by $8 \mathrm{~dB}$ or more, use the higher of the two values.

In our testing, we measured a number of different burner sounds. Our dBA figure included sounds from: the blower motor, air movement and the typical resonating sound of combustion. To this combined sound level, we added the noise from an ignition source.

\section{Example Of Combining Sound Levels}

Since decibels are logarithmic values, they cannot be combined by normal algebraic addition. For example, $60 \mathrm{~dB}+60 \mathrm{~dB}=63 \mathrm{~dB}$, not $120 \mathrm{~dB}$.

When two-decibel values differ by: Add the following amount to the higher value

$\begin{array}{ll}0 \text { or } 1 \mathrm{~dB} & 3 \mathrm{~dB} \\ 2 \text { or } 3 \mathrm{~dB} & 2 \mathrm{~dB} \\ 4 \text { to } 8 \mathrm{~dB} & 1 \mathrm{~dB} \\ 9 \mathrm{~dB} \text { or more } & 0 \mathrm{~dB}\end{array}$

For example

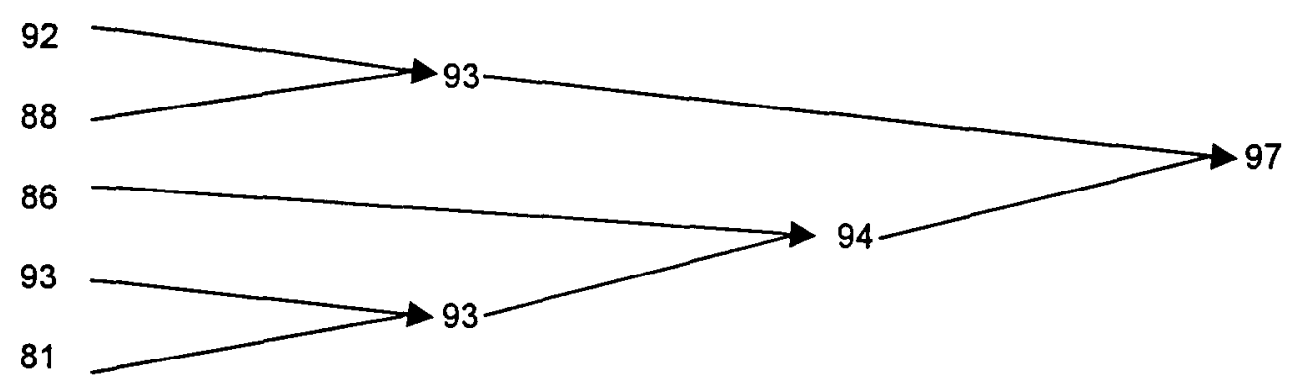

Figure 3

The following graph (see Figure 4) depicts sound level (dBA) readings taken from a variety of appliances during our testing. The " $O N$ " bar represents the A-weighted sound level readings for each appliance with the ignition source activated, wherein spark is energized throughout the burner operating cycle. The "OFF" bar represents the sound level reading for each appliance " with the ignition source deactivated, wherein the spark is de-energized, shut-off, once combustion (flame) has been established. 


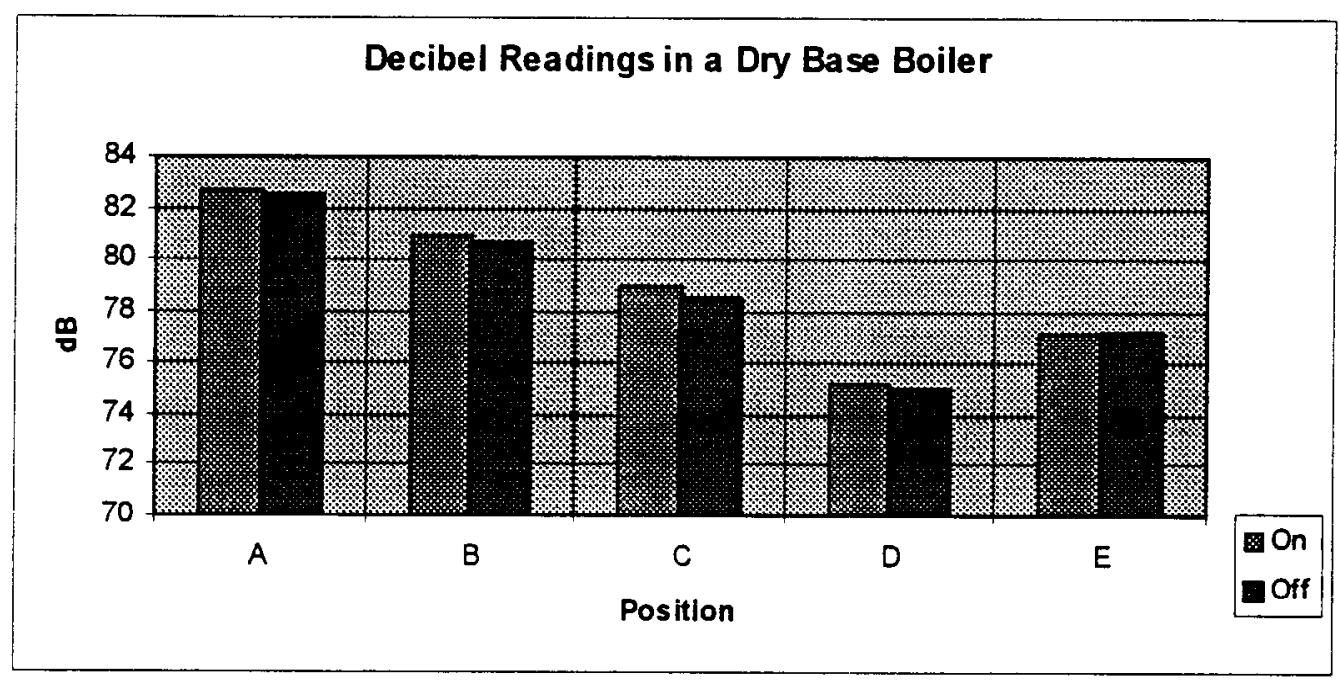

Figure 4

This graph includes sound readings taken from five (5) positions relative to the burner. These positions are labeled $\mathrm{A}$ through $\mathrm{E}$. Position $\mathrm{A}$ is at a point coincident with the motor/oil pump shaft on the oil pump side of the burner. Positions $\mathrm{B}$ through $\mathrm{D}$ are taken from positions $45^{\circ}$ counter-clockwise around the burner, with position $\mathrm{E}$ being coincident with the motor/oil pump shaft on the motor side.

\section{Effect Of Ignition On Combustion Efficiency}

Concerns and questions from the field regarding the effects of intermittent and interrupted ignition systems on combustion efficiency spurred this portion of our research project. The graphs in appendix A, B and C present both interrupted (spark-off) and intermittent (spark-on) ignition systems on a variety of appliance types. The graphs depict $\mathrm{CO}_{2}$, combustion efficiency percentage and $\mathrm{NO}_{\mathrm{x}}$ emissions levels.

As the following graphs demonstrate (see Figures 5 through 13, as contained in Appendices A, B and $\mathrm{C}$ ), there is no measurable effect on either carbon dioxide or combustion efficiency based on the type of ignition system employed. What was evident however, was a measurable reduction in the $\mathrm{NO}_{\mathrm{x}}$ emission levels for interrupted duty ignition systems.

This finding was not expected, but is reasonable considering the known ionization properties of a high voltage electrical arc. Clearly, this data dispels the notion that residential oil burners, somehow, operate less efficiently when operating with interrupted ignition.

\section{Effects Of Interrupted Igniton On Generation Of $\mathrm{NO}_{\mathrm{x}}$}

Perhaps the single most significant finding during the course of our testing for this paper is the revelation that interrupted ignition has a positive environmental impact. The basic underlying engineering principals at work here are well known and well understood, but generally not widely considered in their practical application to residential oil burning equipment. 
It is an axiomatic fact that a high voltage electrical arc produces ozone and oxides of nitrogen. For this reason it was not surprising to discover lower measured $\mathrm{NO}_{\mathrm{x}}$ emissions during the efficiency verification tests. What was surprising however was the magnitude of the reduction, observed here. In a further attempt to verify these results we decided to try to measure the level of $\mathrm{NO}_{\mathrm{x}}$ generated by an oil burner ignition arc outside of the combustion environment.

Using an EZ-1 burner equipped with a standard Carlin 41000 ignitor and standard electrode setting the burner was run (without a pump coupling) in a warm air furnace. The $\mathrm{NO}_{\mathbf{x}}$ measured in the flue pipe with the ignition energized was 13 PPM while the $\mathrm{NO}_{x}$ measured with the ignition de-energized was 0 PPM.

With the growing environmental concern over $\mathrm{NO}_{x}$ emission levels in our industry, and with the current trend toward more tightly regulating these emissions, this level of reduction should not be ignored. With nearly a $10 \%$ reduction in $\mathrm{NO}_{\mathrm{x}}$ levels interrupted ignition will help to address the nagging concerns over the environmentally unfriendly image of Oil Heat.

\section{Electrode Wear}

Again, this analysis is based upon the established annual average operating time for a residential oil burner ( 1,000 hours at $1 \mathrm{GPH}$ firing rate). Using this estimated 1,000 hours of operation as the basis, electrode wear was evaluated. Due to time constraints, the actual testing was limited to a total of 860 running hours, and then, extrapolated out to 1,000 hours. The table below (Figure 14) shows the extrapolated values for electrode wear based upon measured values for electrode wear and final gap setting. Values for both solid state ignitors and transformers are recorded. The initial gap setting was .121" for both; with the wear factors indicated for each in the table below (Figure 14).

Since electrode wear is a function of operating time, interrupted ignition will extend electrode life due to reduced operating time. See Figure 15 for percentages of burner "on" time at various trial for ignition periods.

\begin{tabular}{|l|c|c|c|}
\hline Type of Ignition & Initial Gap Setting & Final Gap Setting & Total Electrode Wear \\
\hline Transformer & $.121^{\prime \prime}$ & $.161^{\prime \prime}$ & $.04^{\prime \prime}$ \\
\hline Solid State Ignitor & $.121^{\prime \prime}$ & $.129^{\prime \prime}$ & $.008^{\prime \prime}$ \\
\hline
\end{tabular}

Figure 14

The results of this testing indicates that a gap can be maintained for a longer period with appreciably less electrode wear using a solid-state ignitor versus an ignition transformer by a factor of five (5) to one (1). 


\section{Intermittent/Interrupted Duty System Life Expectancy}

Again, using the established "1000-hour" average annual burner operating time, we have calculated the length of time a typical ignition system will operate under varying ignition control strategies. The following table (Figure 15) illustrates total annual hours and percentage of burner on time, during which the ignition system is operating. While the number of starts and stops within the period remains the same, the actual operating time is greatly reduced as we move from intermittent to interrupted duty, and then further as we reduce the duty cycle of our interrupted duty ignition system.

\begin{tabular}{|c|c|c|}
\hline \multicolumn{2}{|c|}{} & \multicolumn{2}{|c|}{$\begin{array}{c}\text { Percentage of Burner On-time } \\
\text { When Ignition System } \\
\text { is Operating }\end{array}$} \\
\hline Type of Ignition System & Hours of Operation & \multicolumn{2}{|c|}{} \\
\hline Intermittent & 1000 & $2.87 \%$ \\
\hline Interrupted & & $1.91 \%$ \\
\hline 45 Seconds & 28.75 & $0.95 \%$ \\
\hline 30 Seconds & 19.10 & $0.64 \%$ \\
\hline 15 Seconds & 9.50 & \\
\hline 10 Seconds & 6.40 & \\
\hline
\end{tabular}

Figure 15

Clearly, these reduced operating times realized through the use of interrupted duty ignition control will translate to extended service life for both transformers and ignitors.

We did not make any attempt here to quantify how much the service life of the typical transformer or ignitor would be extended as a result of applying interrupted ignition control. Rather, we simply point out that it will be significant. Since the number of cycles remain unchanged, the greatest impact on component life will result from the greatly shortened operating cycle times. Longer cycle times generate higher internal operating temperatures and higher operating temperatures, along with wider heating and cooling temperature cycles, translate into shortened electronic component life. In fact, many electronic (solid state) component manufacturers publish data on life expectancy vs. operating temperatures. So we see that by minimizing the maximum operating temperature and or by limiting the variations in temperature extremes we can optimize the life expectancy of solid state ignitors and other electronic devices. 


\section{Effects Of Ignition On Plugged Heat Exchangers And Running Saturation}

\section{General}

One of the primary, intended, design benefits of interrupted ignition was to remedy burner operational conditions where combustion quality had degraded to a level where it could only be sustained by the presence of a constant spark (intermittent ignition). Field Reports and our lab testing have confirmed the benefit of interrupted ignition with respect to soot generation and heat exchanger plugging. In addition, we had received field reports describing a running saturation condition. But initially, we felt that because the symptoms were very similar to the fairly well understood sooting condition, certainly there was at least some commonality with respect to what factors caused this condition.

For purposes of this discussion, we would define sooting as the buildup of a black (hydrocarbon) residue in the heat exchanger that takes the form of a fluffy, basically dry substance. Soot is at the opposite end of the combustion quality scale from "zero smoke". When this residue becomes moist and seemingly denser, and the actual presence of (wet) oil is obvious in the flue pipe, then we have the condition commonly known as "running saturation". A heat exchanger that is sooting up may reach a point where, due to increased back-pressure and insufficient combustion air, it will begin to accumulate oil droplets. We are viewing running saturation as a condition unto itself and not the last vestiges of a sooting problem that ultimately results in a plugged boiler and burner lock-out.

To this end, various burner/heat exchanger combinations were tested. As we tested the various appliances, we examined the following factors that we felt might influence these two conditions.

- Running vacuum on the oil system

- Fuel unit pressure

- Air/fuel ratio

- Effect of partially plugged nozzles

\section{Plugged Heat Exchangers}

Our testing in this area yielded rather interesting results. We determined that the variables of vacuum and fuel pump pressure would only create a sooting condition if they were well outside of manufacturers recommended values. As we expected, air/fuel ratio was found to be a key factor in most sooting incidents. Furthermore, we found that three (3) specific factors, usually in some combination with each other or in combination with other conditions are typically common to situations that result in sooting of heat exchangers, they are:

- Insufficient combustion air.

- Incorrect (fixed) combustion head selection.

- Improper (adjustable) combustion head positioning 
In any event, in all cases where the burner operating performance was poor enough to create substantial sooting, interrupted ignition would shut the burner down, while constant ignition, in fact helped to sustain the flame, allowing the burner to continue to run. The benefit of interrupted ignition was expected and confirmed. However, what was not expected was the degree to which the burner must be out of adjustment in order to create a sooting condition.

\section{Running Saturation}

Our examination of running saturation generated at least as many questions as had existed prior to our study. Operating on the premise that, like soot generation, the combustion problems that result in a running saturation condition can be reduced to the basics. We examined the variables of fuel, spark and air in the combustion equation. Tests were conducted with a selection of oil pumps, a variety of nozzle pressures and a variety of nozzles. Nozzles were plugged, known poor quality oil (sludge) was fired, and the fuel systems were subjected to various degrees of vacuum, while spark systems were turned on and off.

Attempts to fully recreate a running saturation condition in a laboratory were largely unsuccessful, except in one specific test set-up. We tested several boiler / burner combinations in an attempt to create the reported running saturation condition. Test units included:

- A Buderus G115-21 Boiler with a Carlin EZ-1 Burner

- A Burnham RSA-135 Boiler with a Carlin EZ-1 Burner

- A Ford CL84/95H Furnace with a Carlin EZ- Burner

- A Smith Series 8-4 Boiler with a Carlin EZ-1HP Burner

- A Therma-Flow S30GL Water Heater with a Carlin EZ-1 Burner

- A Weil McLain Gold GO-9 Boiler with a Carlin 102 CRD Burner

The tests began by considering the effect of spark on the combustion equation. This meant that the variables would be fuel and air. We expected that too much air would result in a condition where unburned fuel would create a "wet tarring" or running saturation condition. Our expectations were correct, however we found that air alone is seldom the culprit. We went on to lower the fuel unit nozzle pressure and realized the same results as we did when we increased the airflow.

The next step was to examine the effects of a plugged nozzle. We learned that as nozzle slots begin to plug, there is a dramatic reduction in the oil flow rate. Our continued testing showed that the combination of excess air and a reduced fuel flow would bring the burner to a running saturation condition more rapidly than either variable by itself.

All attempts to create a running saturation condition with these test unit combinations failed. At this point we were beginning to question whether this phenomena was real or perceived. 
As a last resort, we tested a European cast iron boiler design with a burner that was not of our manufacture or design. That combination did prove successful. During a series of tests, while subjecting the fuel system to between $7 \& 18$ " of vacuum, with intermittent ignition (spark on), we recorded a wet, yellow, trace to \# 1 smoke with continuing burner operation. Shutting off the spark caused the loss of flame within 3 minutes to 6 seconds depending upon the level of vacuum applied. More specifically, test results were as follows:

- A constant spark and 7" WC vacuum produced a trace of smoke that included a wet yellow tinge. When the spark was shut-off (simulated interrupted spark), flame failure occurred within 3 minutes.

- A constant spark and 11 "WC vacuum produced a \#1 smoke that included a wet yellow tinge. When the spark was shut-off (simulated interrupted spark), flame failure occurred within 20 seconds.

- A constant spark and 13" WC vacuum produced a \#1 smoke that included a wet yellow tinge. When the spark was shut-off (simulated interrupted spark), flame failure occurred within 10 seconds.

- A constant spark and 15" WC vacuum produced a \#1 smoke that included a wet yellow tinge. When the spark was shut-off (simulated interrupted spark), flame failure occurred within 6 seconds.

These results suggest that this phenomena is real and can be recreated under laboratory conditions. We are unfortunately unable to draw any definitive conclusions from this study, as we believe that there is a combination of factors that must be present that we do not fully understand. From our observations however, we do believe that this condition is site specific. More study is needed, and we intend to engage further testing.

It is our view that the existence of a cold firing environment, especially on a "cold start", would be very conducive to the build-up or accumulation of unburned oil in the combustion process. Not surprisingly, the addition of a target wall, rug or chamber has an effect on the operation that would indicate that a running saturation condition is less likely to occur with the addition of these accessories. 
We arrived at the following conclusions as to the most likely causes of the running saturation condition:

1. A burner that is set-up, initially with too much excess air

2. A plugged, or partially plugged oil burner nozzle

3. High over-fire furnace pressure

4. Poor oil quality

5. High heat release

6. A high vacuum condition limiting fuel flow rate

7. An improper fixed head selection or adjustable head positioning

8. Oil temperature

9. Combustion air temperature

The plugged nozzle issue is particularly important because it suggests why we believe the problem to be site-related. The issue of fuel oil quality now comes into our equation. Oil quality will vary from house to house depending on, but not limited to, variables such as the condition of the storage tank, the origin of the fuel and the length of time the tank has been in place (age). The oil quality issue makes it difficult to factor-in the nozzle-plugging variable. This also explains why this condition may not limited to any specific OEM package or combination.

The benefits of interrupted duty ignition become more evident when we consider running saturation. With an intermittent system, the flame is more likely to remain on or close to the retention head, allowing the Cad cell to see light and allowing the burner to continue to run. With an interrupted system without benefit of spark, the flame will "walk off" the combustion head long before it will with an intermittent system. For this reason, running saturation is more likely to occur with an intermittent system.

While we learned a great deal from our work on this project, we know that it is unlikely that all of the answers to the running saturation question will be learned in a lab environment. Considering this, we are planning to continue our research for another year and will be selecting companies that we hope will be willing to partner-up with us to participate in our fact-gathering mission. We will attempt to compile a complete and accurate case study of information on this subject. Then, by working closely with Interested Industry Groups we hope to be able to pass this information on to the trade. It is our hope that this approach will lead us to identifying the ultimate cause that results the running saturation condition. 


\section{Conclusions}

Our final conclusions with regard to the question of interrupted duty ignition systems versus intermittent are as follows:

1. Lower electrical consumption, and consequently, higher overall efficiency is obtained using interrupted duty ignition control

2. Lower operational noise levels are realized with interrupted duty ignition systems

3. Electrode wear is significantly less, over time, with interrupted systems

4. Reduced on-time suggests that component life would be enhanced with interrupted duty systems

5. Choice of control strategy has no significant effect on combustion efficiency

6. Interrupted duty ignition systems either had no detrimental effect or actually helped to reduce the operational conditions that lead to both sooted heat exchangers and running saturation conditions. 


\section{APPENDIX A}

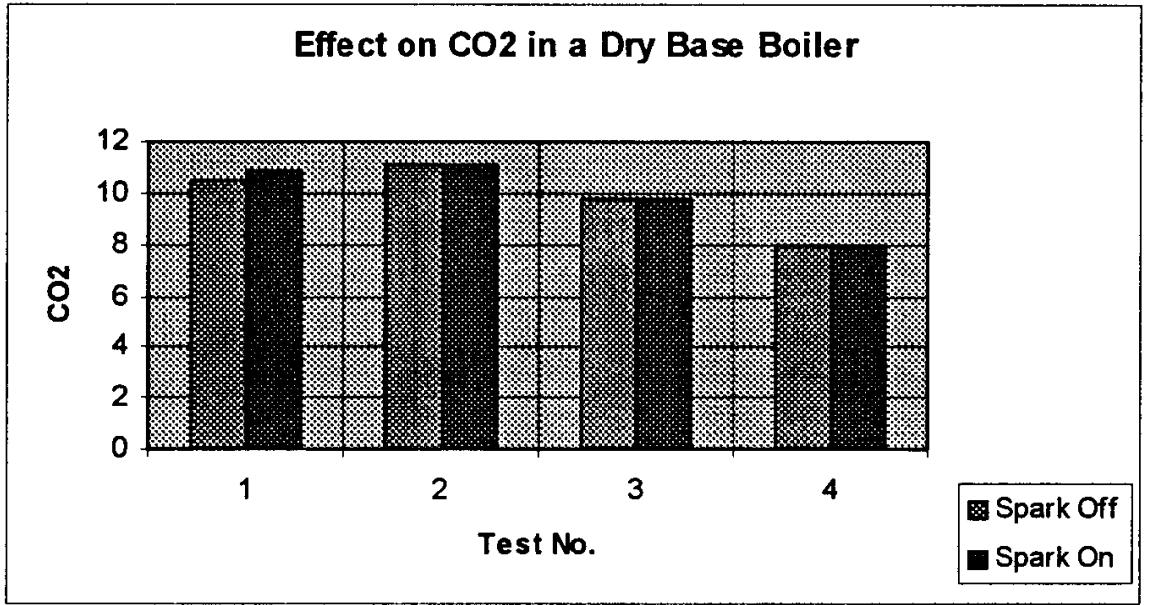

Figure 5

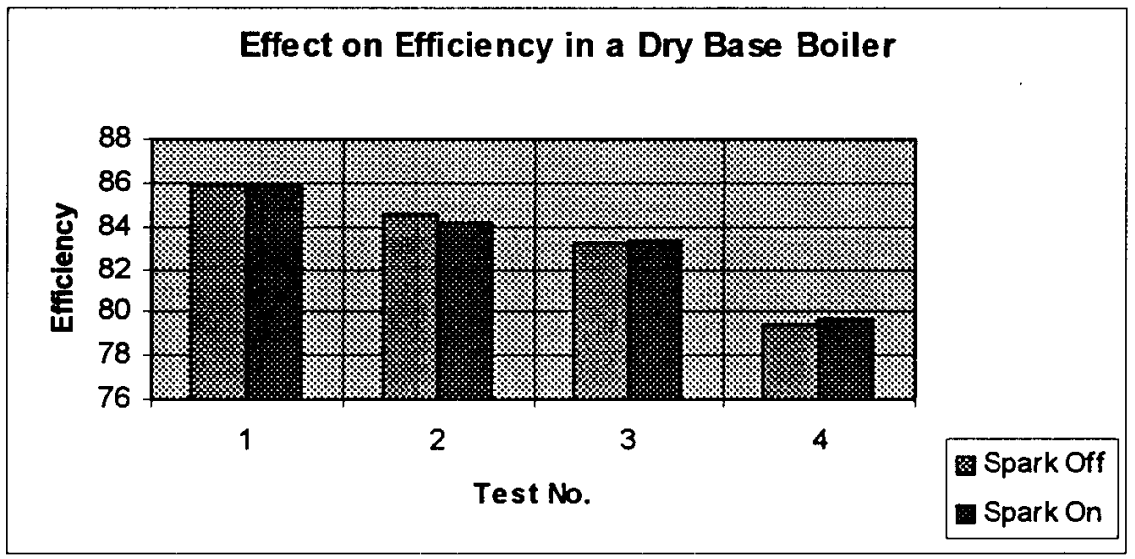

Figure 6

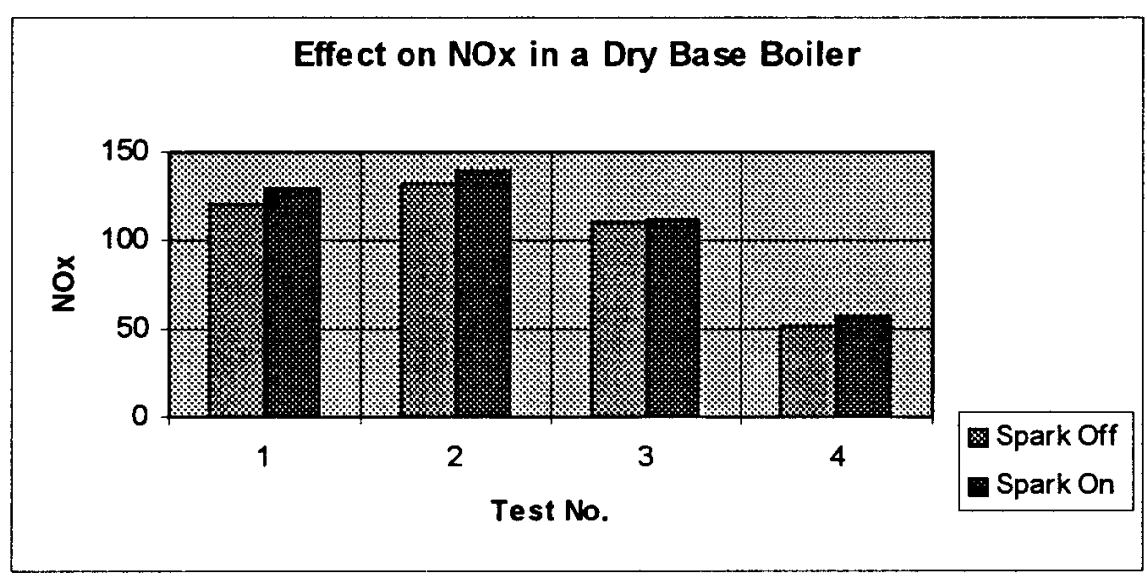

Figure 7 


\section{Appendix B}

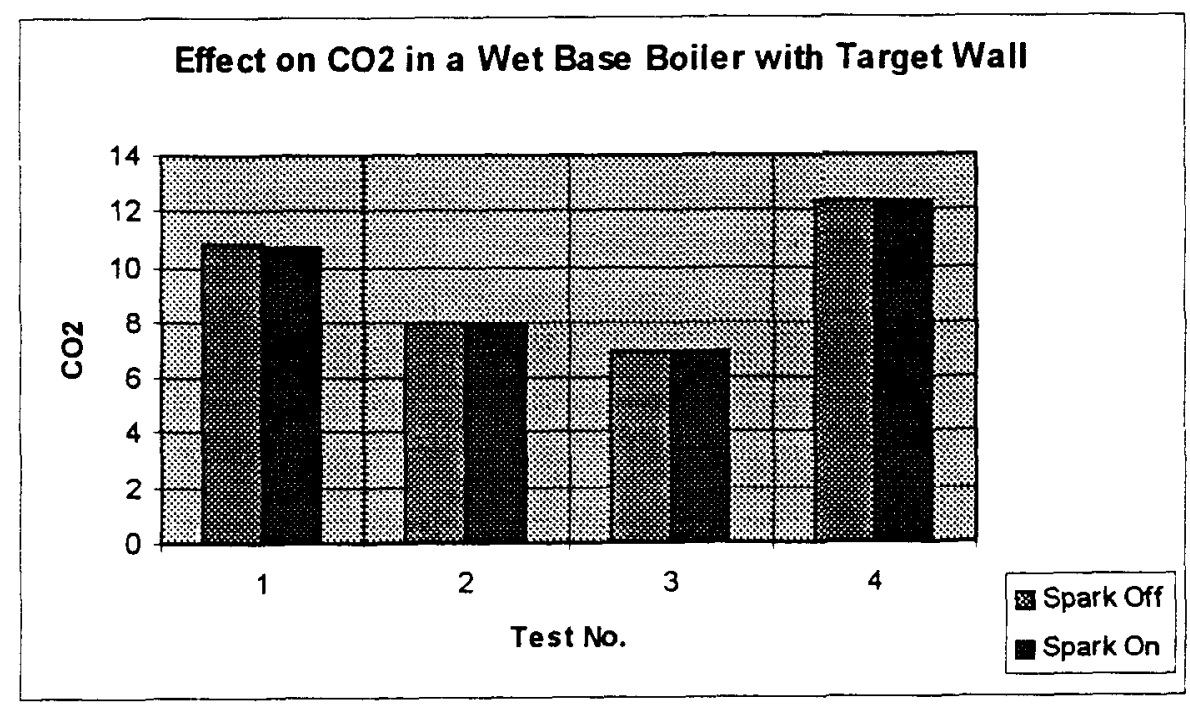

Figure 8

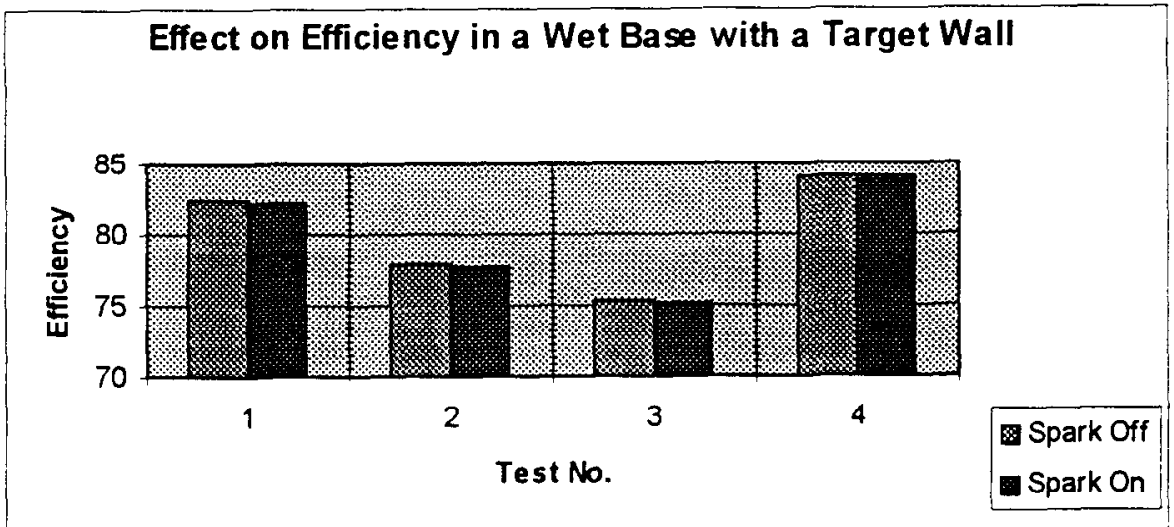

Figure 9

Effect on NOx in a Wet Base Boiler with Target Wall

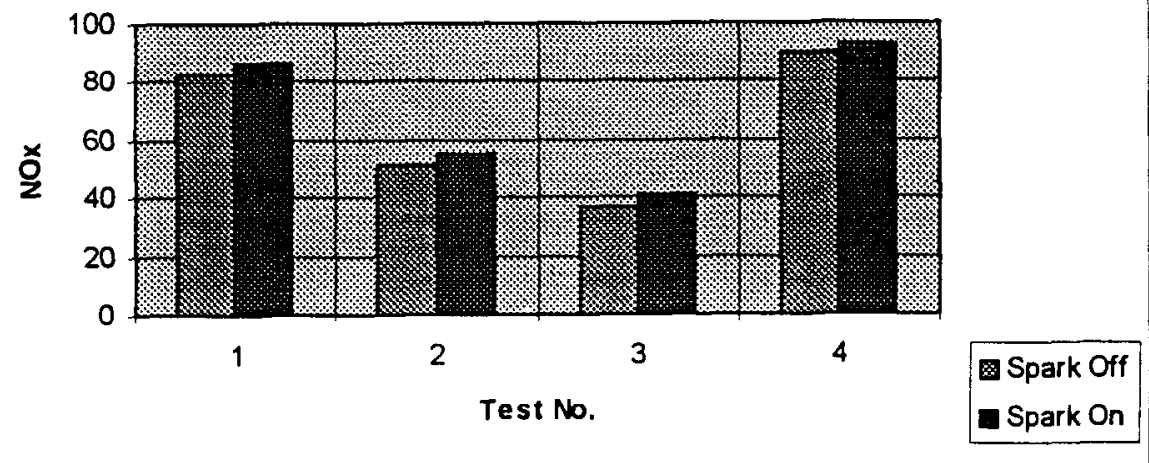

Figure 10 
Appendix C

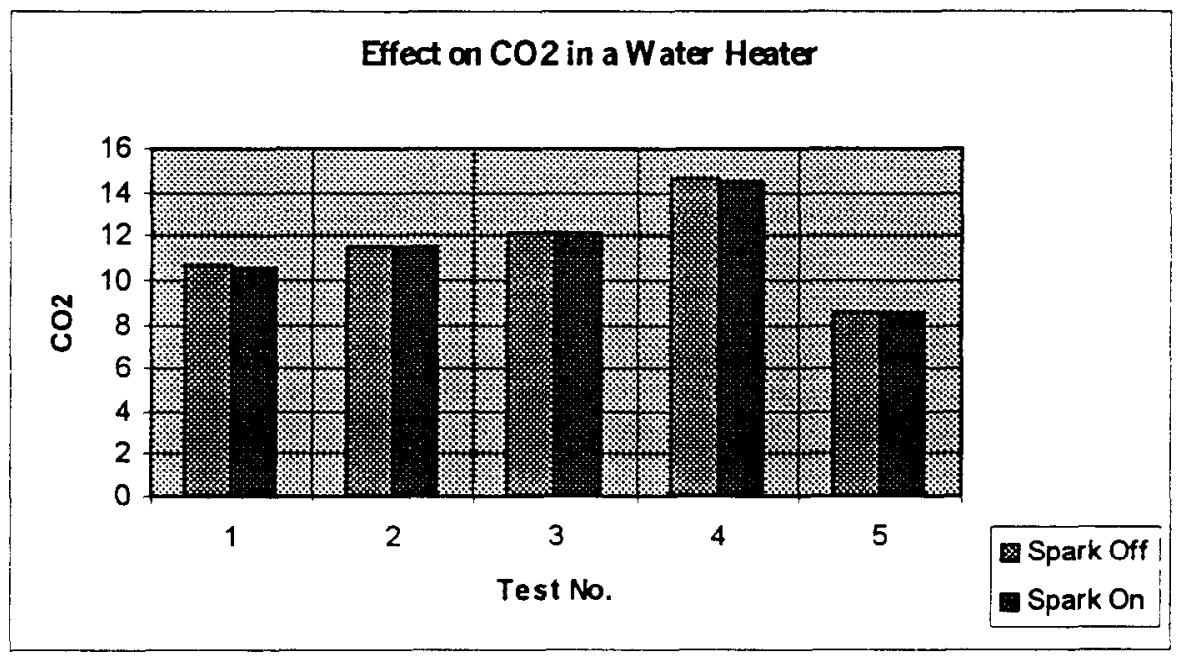

Figure 11

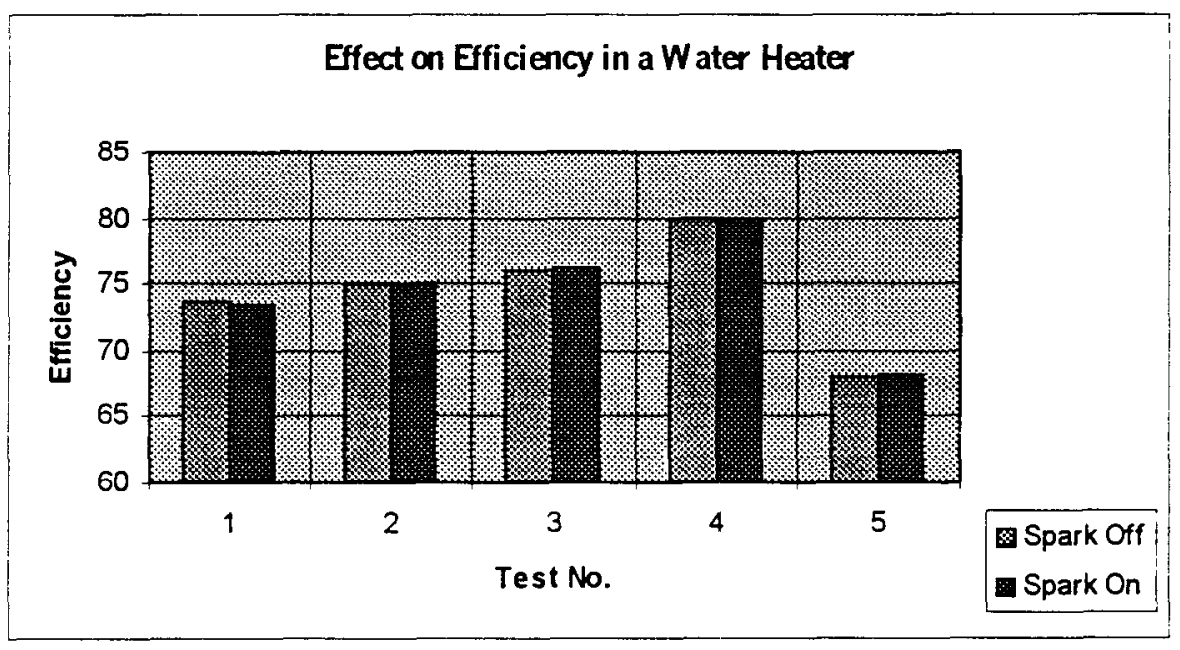

Figure 12

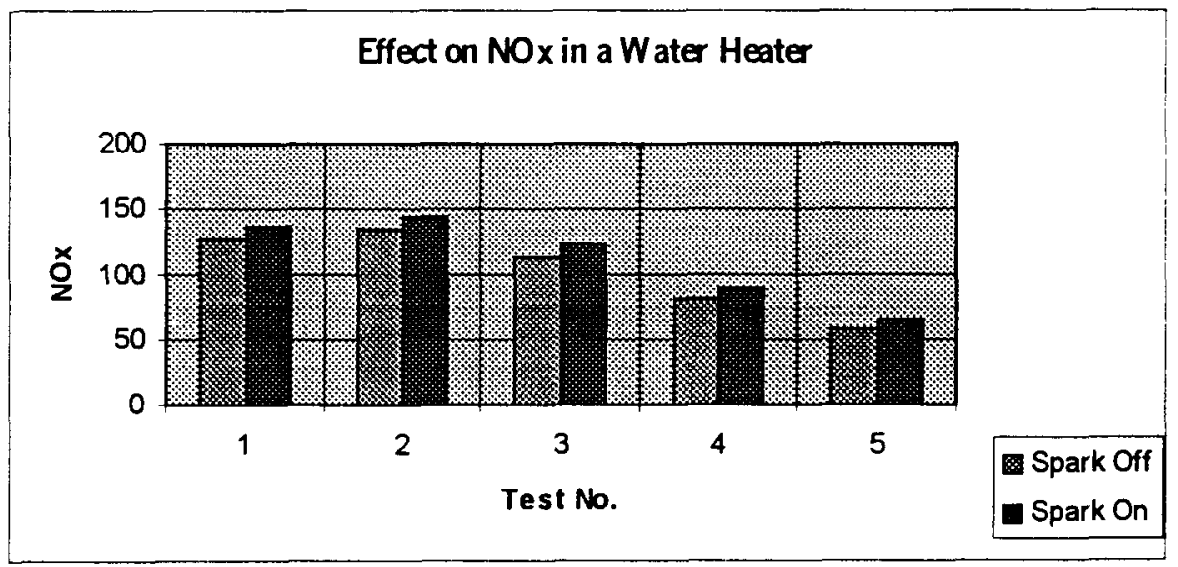

Figure 13 
Paper No. 99-10

\section{Alternate Venting for Fossil Fuel Fired Equipment}

Tests Conducted By:

Harry West

H.R. Holdings

18 Locton Crescent

Brampton, Ontario

L6W 1 C3

George Marlatt

GM Testing

105 Martin Grove

Etobicoke, Ontario

$$
\text { For }
$$

Vebteck Research 30 Riviera Drive

Marham, Ontario 


\section{ALTERNATE VENTING FOR FOSSIL FUEL FIRED EQUIPMENT}

Previously in 1987 I reported on a field service problem that was causing venting problems for oil fired heating appliances. The title of the paper was Safe Venting for Fossil Fuel Fired Equipment. The scenario started in 1982 when a chimney or vent system froze over, dumped products of combustion out of the barometric damper and snuffed out the life of the female resident of the dwelling. The ensuing legal ramifications was that because the company I worked for positioned themselves as experts in the oil heat market the out-of-court settlement was in the range of six figures but not seven.

The subsequent field study of customers with excess service calls for fumes and odours numbered 180 plus and the resultant installation of insulated stainless steel liners of five inch diameter appeared to alleviate all the field service problems.

The next field work that I was involved with was designing oil fired appliances for through the wall vent applications. The first series of vents using the through the wall vent application was the replacement of oil fired condensing furnaces used in conversion of electric heated homes. The through the wall vent connectors were insulated stainless steel with a designed air foil terminal that was over 12 " outside the wall for the exit point of the combustion gases. The next generation of heating appliances designed were vented with a new designed terminal to withstand sixty mile per hour winds without unduly effecting the oil fired appliance performance during start up, cycle run, and shut down. Unless a manufacturer can control the venting parameters during the operation of the equipment installed in the consumer's residence then the service personnel will spend the profit from the sale with service calls. The service department of an oil company is not profitable unless the service call is for a mechanical malfunction.

The next field work that I became involved in was with mechanical flue gas exhausters or in the Venacular power venters.

It was during two years of evaluation of power venters both in the field and in the lab testing for certification of oil burners with equipment that the manufacturers' requested certification with CSA Canada or ULC Canada that a consistent pattern, of in my estimation, unacceptable venting performance under certain operating parameters was noted. Conversely superior performance was noted when the rules were changed to incorporate control of the heating appliance vent system during the complete cycle.

The testing of two appliances on a single venter was where the operating parameters of the heating appliances on the venting system came up short and emphasized the default in the performance of the appliances.

The unacceptable default was that when the heating appliance was operating and when a domestic water call was activating, the heating appliance burner was immediately shut down and the results from not allowing the completion of a normal heating cycle 
prior to changeover led us to complete an indepth analysis of normal heating cycles of oil burners as the heating industry perceived them.

First the use of mechanical flue gas exhausters has not been the salvation of the heating industry gas or oil. The learning curve was very steep and the basic problem was that no one 1 believe in all honesty outlined the basic operating criteria for mechanical flue gas exhausters. The development of mechanical flue gas exhausters was not harmonized with the operating parameters of gas fired and oil fired heating equipment. Standing back and looking at the various configurations and methodology that was used the best that could be said for the whole process was that the marriage was not an overwhelming success. follows:

The proper marriage of a mechanical flue gas exhauster should be defined as

"The use of a mechanical flue gas exhauster must ensure that all the products of combustion must be safely conveyed to the outdoor atmosphere and the combustion process inside the heating appliance must from light off to shutdown have a uniform pressure applied to the process and ensure the burner will not be subjected to combustion zone draft fluctuations. The objective is to optimize the burner performance."

\section{MECHANICAL FLUE GAS EXHAUSTER TEST CRITERIA}

Project:

Appliances:

Burners:

Venter:

Rated Input:

Combustion set up: $\quad$ Maximum $\mathrm{Co}_{2}$ attainable with 0 - trace smoke
Evaluate effects of Shirvent Power Venter on oil fired heating appliances.

Warm air furnace

Oil fired storage water heater

Dual operation

3 conventional North American flame retention head burners

Shirvent MVP 100

.65 USGPH at 100 psi on water heater

.40 USGPH at 100 psi minimum

$.75 \mathrm{USGPH}$ at $100 \mathrm{psi}$ maximum

on warm air furnace 


\section{TEST INSTRUMENTS}

Nova 370 combustion analyzer

Lynn combustion analyzer with smoke tester

United Systems data logger, model $590 \mathrm{JF}$, type J

Range $-320^{\circ} \mathrm{F}-+1400^{\circ} \mathrm{F}, 19$ channels

Dwyer Magnehelic

$0-.20$ " WC

Dwyer Magnehelic

$0-1.0 \mathrm{WC}$

Dwyer Magnehelic

$0-3.0$ "WC

Bacharach standard draft gauge for stack draft

Test Term 9000 thermometer

$-120^{\circ} \mathrm{C}$ to $+1370^{\circ} \mathrm{C}$

$-180^{\circ} \mathrm{F}$ to $+2490^{\circ} \mathrm{F}$

Dwyer water flow meter 0-20GPM

All instrument calibrated and labelled.

All combustion instruments calibrated with test gases.

\section{POWER VENTER/OIL FIRED APPLIANCE OPERATING TESTS}

We completed an analysis of the roll back phenomena that oil burners experienced with power venters on field installations of heating appliances after the burner has ceased operation. Power venters with a post purge option still experienced this phenomena even though the power venters continued operation for periods of five minutes after burner shut down. We will address this as the power venter application varies from heating appliance to heating appliance and the variables provided from the performance of the burners and the heating appliances.

We decided to use the smaller input ratings of the appliances and in the case of the storage water heater we lowered the input from .75 USGPH to .65 USGPH. This was a conscious decision on our part because of the depth and height of the combustion chamber, in the test water heater. Plus the previous tests with warm air furnaces with multi-input firing rates the highest end cone temperatures were recorded with the lowest input nozzles. 


\section{WATER HEATER TEST PROCEDURE}

We prepared three common North American burners for our series of tests. Each burner end cone was thermocoupled at top dead centre and a special nozzle adaptor thermocouple was braised into the three test burner nozzle adaptors allowing us to monitor the oil temperature behind the nozzle from start up, to any time after shut down. We completed all our initial run up direct from the street water temperature in the unit. We wanted to ensure ourselves that the reduced input would not produce domestic water supply shortages. The 32 US gallon tank was filled with water from the street mains. The inlet temperature of the supply water was $42^{\circ} \mathrm{F}$. The water heater was fired first with a .75 USGPH nozzle on a chimney application with a barometric damper in the vent connector system. The vent connector system consisted of $12 \mathrm{ft}$. of pipe and two $45^{\circ}$ elbows. The total time to achieve burner off when the water heater operating limit was satisfied was 17 minutes from start up.

We then repeated this test using Burner $B$ with the reduced firing rate and a Shirvent MVP 100 connected with 20' of insulated $3^{\prime \prime} \theta$ vent connector. The unit was started from cold $42.5^{\circ} \mathrm{F}$ water and the shut down of the burner was realized again in 17 minutes.

The maximum $\mathrm{CO}_{2}$ we could attain on the chimney vented application was $10.5 \%$ with zero to a trace of smoke. The light off on a cold chimney produced a start up pulsation.

The chimney application had variable over fire pressures in the -.03"WC range due to wind and slow barometric damper reaction during the 17 minute test run.

The maximum $\mathrm{CO}_{2}$ we could attain with Burner $\mathrm{B}$ on the power venter application was $13.2 \%$ fired at .65 USGPH with 0 to $A$ trace of smoke.

The power venter test application was set so that the water heater always maintained a slight positive over fire pressure during combustion and the higher the $\mathrm{Co}_{2}$ level attained, the lower the over fire pressure was observed on the draft gauge.

All three North American burners during the power venter tests where we initiated slight positive over fire pressure we achieved superior combustion test results and lower gross stack temperatures. We observed this even on long $21-27$ minute runs draining water at a rate of $1 / 2$ gallon per minute to 1 gallon per minute from the tank, to allow a continuous burner run.

\section{TEST RESULTS FOR DOMESTIC WATER HEATER}

We initiated our tests with a cold tank to verify start up and the time required to produce a tank of hot water for domestic use, both on a natural draft chimney application and with a power venter. 
We then completed a series of test runs that started the burner after domestic water was drawn, thus the operating control activated the burner and the water was drawn for a selected time frame to allow the burner to operate from seven minutes to twenty-one plus minutes. The completion of every burner firing cycle resulted from the operating limit control being satisfied after the water draw was terminated.

The combustion gases were constantly monitored from three minutes after start up to ten minutes after burner off $\mathrm{Co}-\mathrm{CO}_{2}-\mathrm{O}_{2}$ gross stack temperature.

The oil temperature inside the nozzle adaptor was monitored from start up and every minute during the run and for up to 12 minutes after burner shut down. Oil temperatures were also observed for a longer burner time off to measure the effect of the domestic water heater tank temperature on the oil in the adapter.

The burner end cone temperatures were monitored from start up to 12 minutes after cessation of the combustion process.

The power venter was always activated first and air flow proven the draft was established prior to the burner being allowed to light off. No pulsation on light off.

The burner combustion process when shut down on the initial series of tests also had the venter shut down at the same time increment. No post purge was wired into the test.

\section{TEST RESULTS BURNER B}

The burner end cone temperature reached the maximum recorded temperature, between five minutes and a maximum of six minutes. The temperatures ranged from a high of $1059^{\circ} \mathrm{F}$ and low of $1043^{\circ} \mathrm{F}$ on run up.

The recorded oil temperature in the nozzle adaptor reached a high temperature of 113.6 when the end cone temperatures dropped to $1007^{\circ} \mathrm{F}$ and when we measured the oil flow rate it was reduced by $\underline{6.5 \%}$. Every test run showed a slow decrease in input as the end cone temperature decreased and the $\mathrm{CO}_{2}$ also showed a slight decrease. This verified same air flow less oil flow or input.

The burner combustion process was stopped. The air flow was stopped and the oil temperature in the nozzle adaptor increased from $113.6^{\circ}$ to $160.6^{\circ} \mathrm{F}$ in less than 5 minutes.

$\begin{array}{ll}1 \text { minute } & -117.2^{\circ} \mathrm{F} \\ 2 \text { minutes } & -133.5^{\circ} \mathrm{F} \\ 3 \text { minutes } & -138.7^{\circ} \mathrm{F} \\ 4 \text { minutes } & -143.2^{\circ} \mathrm{F} \\ 5 \text { minutes } & -160.6^{\circ} \mathrm{F}\end{array}$


The constant monitoring of the flue gases after burner shut down showed a rapid rise in the production of $\mathrm{Co}$ as recorded over a six minute time frame.

\begin{tabular}{lcl} 
Time & $\begin{array}{l}\text { Temperature } \\
\text { Nozzle Adapter }\end{array}$ & Co \\
\cline { 2 - 3 } Shut down & $113.6^{\circ} \mathrm{F}$ & 17 PPM \\
1 minute & $117.2^{\circ} \mathrm{F}$ & \\
2 minutes & $133.5^{\circ} \mathrm{F}$ & 157 PPM \\
3 minutes & $138.7^{\circ} \mathrm{F}$ & \\
4 minutes & $143.2^{\circ} \mathrm{F}$ & 260 PPM \\
5 minutes & $160.6^{\circ} \mathrm{F}$ & \\
6 minutes & $158.2^{\circ} \mathrm{F}$ & 240 PPM
\end{tabular}

The roll back of fumes from the burner was noticeable in the test lab and the tests when repeated using various time periods produced predictable roll back results. The rapid increase in the adaptor temperatures after burner shut down ejected the oil from the nozzle due to oil expansion producing unburnt oil fumes and odours as verified by the high levels of Co produced. The Co readings on the Nova analyzer verified this phenomena.

The second series of tests with Burner B was completed and the Shirvent MVP 100 venter was allowed to operate after combustion shut down but the appliance damper closed and a small $1 " \theta$ knock out was removed in the damper plate.

These test results showed that the nozzle adaptor oil temperatures again escalated but the maximum temperature reached was $138^{\circ} \mathrm{F}$ on a 9 minute run and $140^{\circ} \mathrm{F}$ on a 17 minute run. No roll out odour was observed but a Co reading, although much lower at $63 \mathrm{ppm}$, was observed. The roll back odour was not observed as the venter exerted slight negative pressure on the water heater combustion zone.

The next test application was to retrofit the burner with a line voltage solenoid on the high pressure line from the oil pump and wire in a pre purge and post purge control package. The pre purge was 30 seconds and the post purge time was 300 seconds and the venter was wired into the circuit. The burner was allowed to operate for 21 minutes using a water draw rate of $1 / 2 \mathrm{gpm}$ to keep the operating control active and the water draw was terminated at 14 minutes and the burner went off at 21 minutes.

When the water draw was activated in a tank that had reached operating limit the oil in the nozzle adaptor was above $90^{\circ} \mathrm{F}$ and the water temperature was $148^{\circ} \mathrm{F}$ inside the tank. After five minutes operating time the oil in the nozzle adaptor was $103.5^{\circ} \mathrm{F}$ and the nose cone on the burner was $1030^{\circ} \mathrm{F} . \mathrm{Co}_{2}$ was $13.2 \%$ Co $11 \mathrm{ppm}$ gross stack $610^{\circ} \mathrm{F}$. The burner end cone temperature attained a high of $1030^{\circ} \mathrm{F}$ at 7 minutes run time and slowly dropped to 1015.8 at 19 minutes of run time. The nozzle adaptor temperature continued to rise and reached $116.3^{\circ} \mathrm{F}$ and $\mathrm{Co}_{2}$ dropped to $12.9 \%$, Co 14 
ppm with a gross stack of $659^{\circ} \mathrm{F}$. The oil flow was reduced because of the increase in oil temperature in the nozzle adaptor.

On this test run, the oil burner flame was cut off at 21 minutes as the solenoid closed and the burner motor/blower continued to run for five minutes, the power venter was also operative.

Against the closed damper with a 1 " 0 knock out the temperature in the nozzle adaptor climbed in one minute to $125.1^{\circ} \mathrm{F}$ and at the end of the five minute post purge had dropped to $104.7^{\circ} \mathrm{F}$ and the end cone temperature had dropped to $198^{\circ} \mathrm{F}$.

The continuous Co read outs slowly rose to $25 \mathrm{ppm}$ after 4 minutes and returned to $16 \mathrm{ppm}$ after five minutes. This change indicates that on shut down even with a solenoid the heat on the nozzle from radiation from the end cone and chamber causes the injection of raw oil into the combustion zone and the resultant levels of Co clearly indicate the amount of oil sprayed into the combustion zone.

When we tested without the post purge but ran the venter to allow negative pressure in the vent system back to the burner tip (no barometric in the system) the temperatures of the oil in the adaptor even on a seven minute run would elevate to $136^{\circ} \mathrm{F}+$ and the Co would reach $72 \mathrm{ppm}$ by test.

When we tested without the post purge and shut the venter off on burner shut down the oil temperature in the nozzle adaptor would reach $150^{\circ} \mathrm{F}$ plus and the Co would reach levels in excess of $200 \mathrm{ppm}$.

The maximum adaptor oil temperatures would be reached in four minutes and the maximum Co would show on the tester in four minutes to six minutes. The nozzle adaptor oil temperature that appears to start evacuating the oil from the nozzle adaptor is around $131^{\circ} \mathrm{F}$. The Co readings start a rapid climb after the $131^{\circ} \mathrm{F}$ temperature is reached. Even at $125^{\circ} \mathrm{F}$ the Co starts to climb but it normally levels out at $30-40 \mathrm{ppm}$. When the post purge runs and the venter continues to run with the post purge of five minutes the amount of Co produced is significantly lower due to the lower nozzle adaptor temperatures reached that reduce the amount of oil injected into the combustion chamber.

We tested three models of North American style flame retention head burners and the amount of oil displaced into the combustion zone upon shut down was not a constant, even though they were operating in the same heating appliance with the same input into the same combustion chamber. Each burner has its own operating characteristics. The end cone temperatures and oil adaptor temperatures at the same input rates may vary in excess of $400^{\circ} \mathrm{F}$ on the end cone and $40^{\circ} \mathrm{F}$ on the adapter.

All three burners were operated with the same nozzle flow rates and the end cone temperature factor during run and then shut down increased the rapid rise in the oil temperature inside the nozzle adaptor. This rapid temperature increase was most 
evident when there was no post purge on the burner and the power venter ceased operation when the burner was shut down.

The longer the burner runs up to 20 plus minutes did not produce the worst case Co test results after shut down. A seven minute run when the burner end cone was at its highest temperature and the nozzle adaptor oil temperatures read less than $112^{\circ} \mathrm{F}$ produced the highest Co numbers. The adaptor temperatures of the oil went up rapidly and the Co went up in direct proportion, as the oil had more weight per volume to expand, after burner shut down.

During the long burner runs up to twenty-seven minutes the oil temperature would reach $121^{\circ} \mathrm{F}+$ but the end cone temperature would slowly drop because of reduced oil flow and the expansion and oil temperature increase did not accelerate at the same rate. Lower Co readings verified this on long runs on all three burners, after shut down.

We completed tests with pre purge and post purge and a Delevan Protek nozzle shut off device. The tests were inconclusive because on short runs we still had Co spikes on shut down but on long runs they were not evident. This lead us to try the same tests with a standard burner, no pre purge or post purge. The burner was allowed to operate for seventeen minutes and on shut down the temperature on the end cone accelerated to $160.6^{\circ} \mathrm{F}$ in less than three minutes plus the Co went off the scale at over $550 \mathrm{ppm}$. This phenomena is no direct reflection on the Protek nozzle shut off device. This is caused by hi end cone temperatures plus the burner delivery tube is excessive in size and the rapid temperature expansion of the oil in the tube and nozzle adaptor raises the pressure above $100 \mathrm{psi}$. This opens the Protek valve and sprays oil into the chamber.

Tests on the warm air furnace produced us similar results and similar Co spikes depending on the burner configuration. The warm air furnace was allowed to cycle as a heating appliance for the lab test area and the burner cycles varied from three minutes to eight minutes depending on the doors opening to outside or windows open. The combustion chamber size was similar to the water heater and end cone temperatures were slightly lower, 50 to 60 degrees: The Co levels were higher during the no pre purge and post purge operation with the warm air furnace. The domestic water heater test data sheets mirror the warm air furnace test data except that the oil temperature in the nozzle adaptor is higher on start with a tank of $148^{\circ}$ water above the combustion zone.

\section{CONCLUSIONS}

The present application of oil burners to today's heating appliances should be redefined to eliminate combustion chamber roll back in air tight homes. This could be accomplished by making the following changes:

1. Reduce the mass of the adaptors and the volume of oil behind the nozzle subject to radiant heat. 
2. Eliminate the present oversized oil tubes and have a capillary tube with the inside diameter of the capillary to \#55 drill size or less. A \#55 drill size should be applicable to firing rates up to $2.25 \mathrm{gph}$. This will reduce the oil volume in the tube by $90 \%$ and control the excess expansion that cannot even be controlled by a 100 psi shut off valve behind the nozzle.

3. Equip the burners with a pre purge and post purge control that will cool the end cones, clear the combustion zone of all shut down by-products, plus cool the nozzle adaptor and the oil inside.

4. Stop putting amulets on oil burners to reduce the end cone temperatures. The temperature only increases on shut down as if the amulet was not in place.

5. Consider operating all burners at $140 \mathrm{psi}$ to $160 \mathrm{psi}$ for better combustion through oil atomization. Droplet size being easier to mix with the air.

6. If you have to put oil drip holes in your air tubes or silicone dams then you have a temperature volume problem that should be addressed.

7. Seal the appliances to operate against positive pressure. Natural draft vent systems produce positive pressure over fire on light off thus you get customer complaints. During our tests of the water heater we were able to achieve $\mathrm{Co}_{2}$ readings of $14 \%$ o smoke and $15 \mathrm{ppm}$ Co with only +.002 positive pressure, but the water heater leaked gases into the insulation above the combustion zone and the burner entry area. The gross stack was reduced by over $100^{\circ} \mathrm{F}$ and the efficiency was increased to $83 \%$. The water heater nozzle size was reduced on all burner tests because at the firing rate shown on the rating plate the burner end cone temperatures could exceed $1200^{\circ} \mathrm{F}$. The reduced input produced a $150^{\circ} \mathrm{F}$ to $200^{\circ} \mathrm{F}$ drop on the end cone temperatures but with the improved efficiency the water volume produced was the same. Flames touching the crown sheet of a water heater is not acceptable for long tank life.

\section{HEATING EQUIPMENT INSTALLERS AND SERVICE TECHNICIANS}

1. The ability to safely vent the bi-products of combustion to the atmosphere is your primary concern to avoid liability and to reduce your service calls.

2. Previously I stated that in the 1980 s we lined masonry chimney with 5 inch diameter stainless steel liners and insulated them. The 5 " diameter stainless steel liners in some installations proved to be oversized and it was determined that $3 " \varnothing$ and $4 " \varnothing$ liners are a better size but if they are not insulated to achieve $200^{\circ} \mathrm{F}$ exit temperatures at the top of the vent then your draft will fluctuate and your vent system may fail.

3. Through the wall forced draft venting was one of my original alternatives to chimney venting and the first certified heating appliances I engineered using this method were listed six years ago. The terminal was designed to protect against 
$60 \mathrm{mph}$ winds and the outlet was set at nine inches from the wall inside the wind foil. Nine inches was selected to be outside the wind screen effect on the walls of the houses. The one consideration that was never factored into the equation was no wind. I have visited four installations installed in excess of four years where part of the aluminum siding is paint free on one installation, the vinyl siding on another has changed colour and two other brick veneer homes have mortar between the bricks so soft that the removal with your fingers is very easy to accomplish.

In every case when there was a still cold night the flue gases from the exhaust terminal migrated back to the wall and condensed on the wall surfaces. The location of the terminal was not a factor as they were on the north side, 2 on the west side and one on the south side. The common denominator was not wind but lack of wind. A gentle breeze carried the exhaust gases away and diluted them adequately. The home owners confirmed that they only noticed the migration to the wall with a no wind environment.

Other through the wall vent applications also came up short during a period when we experienced high winds. They dumped fumes inside the residence when we experienced high winds. The flue gases were forced back into air intake on coaxial vents and dumped into the basements.

4. The Shirvent MVP 100 Mechanical Flue Gas Exhauster was designed and patented by an oil heat serviceman who worked 30 years in the burner service trade. George Marlatt had above average knowledge of how an oil fired heating appliance should perform. His design of the flue gas exhauster covered off and eliminated the problems of bad draft with masonry chimneys or the ability to produce draft when the outdoor temperature was higher than the indoor temperature.

\section{SHIRVENT MVP $100^{\mathrm{TM}}$}

The SHIRVENT power venter generates a high speed air loop which provides "CONTROLLED" removal of the by-products of combustion from the heating appliance. This is accomplished in the following manner:

A "T" connector, or stub, is mounted at a right angle from the wall of the 6" diameter air intake tube, and is located between the outdoor air intake holes and the compartmented enclosure containing the blower. Outdoor air is drawn into and mixed with the by-products of combustion, then propelled out from the venter nose at a speed of about 30 feet per second.

The heating appliance is connected to this stub WITHOUT THE USE OF A BAROMETRIC DAMPER OR ANY DILUTION DEVICE IN THE VENT CONNECTOR. The venter air loop generates a venturi flow which is impressed throughout the venter, connectors, flue passes and combustion zone of the heating appliance. 
When a call for heat is initiated, the venter motor starts, proves adequate air flow and permits the burner to start. When flame is established, the oil burner fan moves the expanding combustion gases through the flue passes and connectors to the venter " $T$ " stub where they now encounter the high speed outdoor air being drawn into the venter through the 6" diameter air intake tube. The 4" diameter venter discharge tube is located co-axially within the 6 " diameter intake tube, the cylindrical cavity remaining in the outer tube through which the gases and outdoor air must flow, is now able to by venturi action, make this area a controlled restriction.

The flue gases, which have been moving at about $11 / 2 \mathrm{fps}$ through the vent connector, are now mixed into the incoming air stream and their velocity abruptly increases to about 30 feet per second. This combination of velocity, turbulence and the VERY short residence time in the venter, (0.02 seconds), tend to prevent any condensing of combustion products in any part of the SHIRVENT exhaust system.

The oil burner is not subject to combustion zone draft fluctuations. The flame front is therefore permitted to "HUG" the end cone of the burner allowing the oil droplets to retain their proper position within the air pattern generated by the oil burner. A clean burn will now result due to adequate oxygen availability which virtually eliminates smoke spikes on start-up and shut-down when using the SHIRVENT System.

Studies have shown that any high draft swings as found in most chimneys, affects oil droplet mixability with primary air by disturbing them from the position they would occupy were draft non-existent. This variable flow of air in the combustion zone tends to destabilize combustion. It is therefore no surprise to find starting smoke and pulsation when a furnace is subjected to all the variables of combustion zone "draft changes."

The Shirvent MVP 100 Power Venter can eliminate the barometric damper, maintain uniform over fire pressure under all indoor/outdoor conditions, follow in sync with the burner and eliminate roll backs into the residences when the burner ceases operation while allowing higher levels of efficiencies on the heating appliances that we have tested, during dual operation with a single venter.

The use of lower input burner applications can be justified and practical when you stabilize the combustion process and improve the $\mathrm{Co}_{2}$ production level then reduce the gross stack temperature. The use of lower input burner application to achieve the equivalent heating appliance input output relationship has a high factor in the reduction of harmful flue gas products expelled to the atmosphere. 


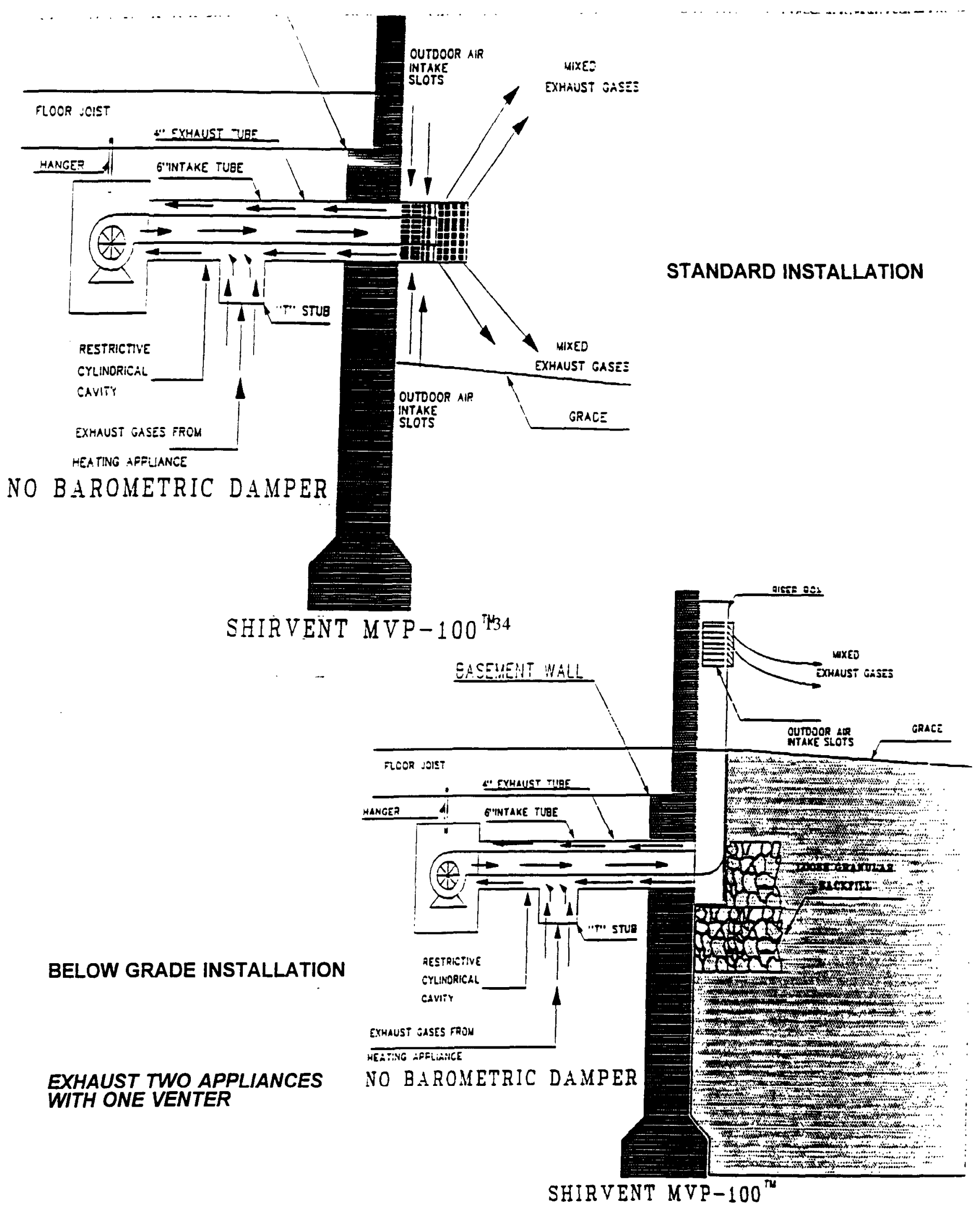

VEBTECK RESEARCH 
SAFE VENTING FOR FOSSIL FUEL

FIRED RESIDENTIAL HEATING EQUIPMENT

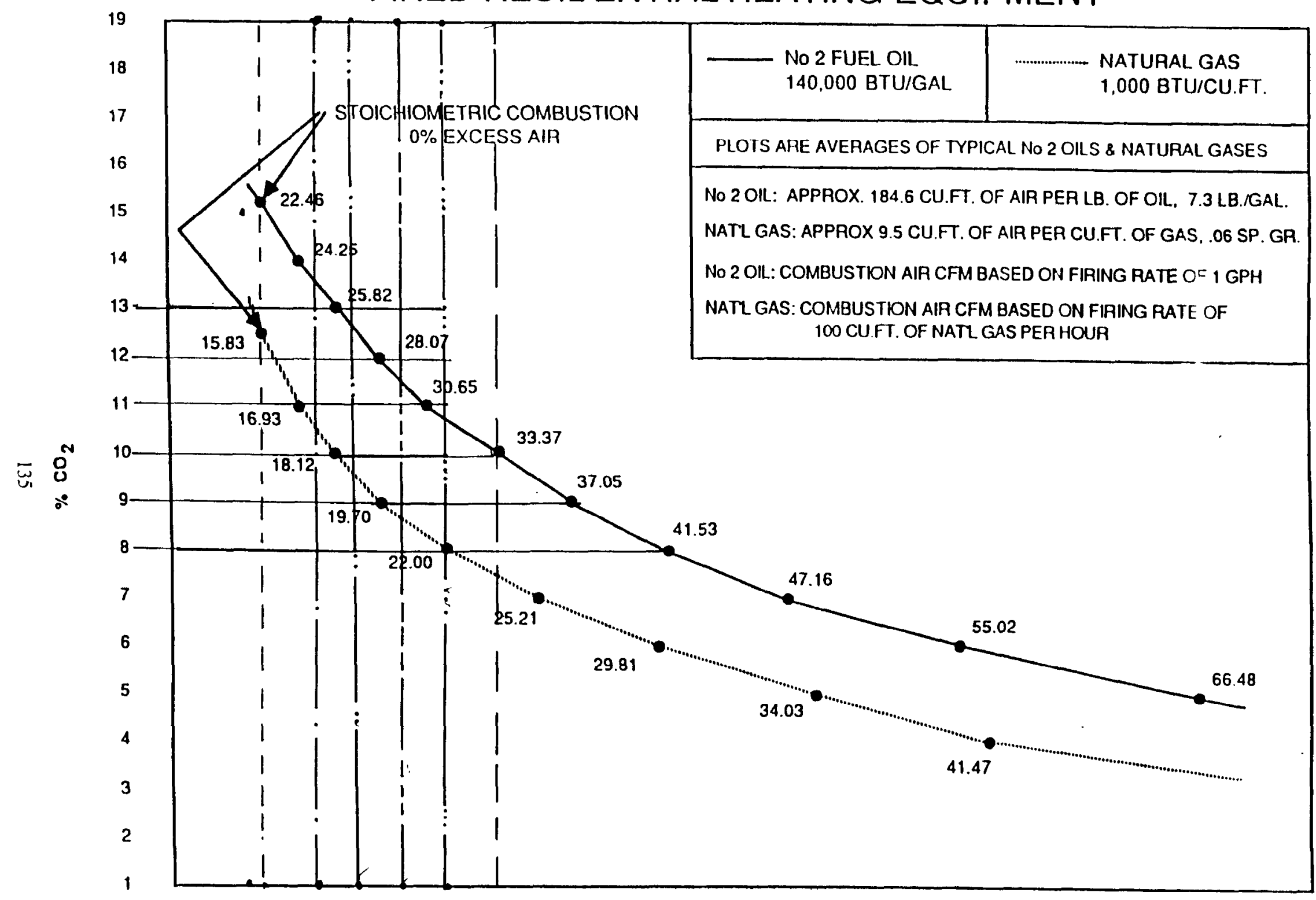

$\begin{array}{llllllllllllllllllllll}0 & 10 & 20 & 30 & 40 & 50 & 60 & 70 & 80 & 90 & 100 & 110 & 120 & 130 & 140 & 150 & 160 & 170 & 180 & 190 & 200 & 210\end{array}$

$\%$ EXCESS AIR 
COMPARISON OF COMBUSTION AIR REQUIREMENTS AND USABLE HEAT PRODUCED BASED ON STACK LOSS

Base Case 1 USGPH 140,000 BTUH Nominal Input Stoichiometric $15.2 \% \mathrm{Co}_{2}$

\begin{tabular}{|c|c|c|c|c|c|}
\hline $\mathrm{CO}_{2}$ & CFM Air & \% Excess Air & $250^{\circ} \mathrm{F}$ Stack & $350^{\circ} \mathrm{F}$ & $550^{\circ} \mathrm{F}$ \\
\hline 14 & 24.25 & $5-7$ & 123,550 & 120,400 & 114,100 \\
\hline 13 & 25.82 & $12-15$ & 123,200 & 119,700 & 113,050 \\
\hline 12 & 28.07 & 25 & 122,500 & 119,000 & 111,650 \\
\hline 11 & 30.65 & 35 & 121,800 & 118,300 & 110,250 \\
\hline 10 & 33.37 & 50 & 121,100 & 116,900 & 108,150 \\
\hline \multicolumn{6}{|c|}{.75 USGPH 105,000 BTUH Nominal Input } \\
\hline 14 & 18.18 & $5-7$ & 92,660 & 90,300 & 85,575 \\
\hline 13 & 19.36 & $12-15$ & 92,400 & 89,513 & 84,778 \\
\hline 12 & 21.05 & 25 & 91,875 & 89,250 & 83,738 \\
\hline 11 & 22.98 & 35 & 91,350 & 88,200 & 82,688 \\
\hline 10 & 25.02 & 50 & 90,825 & 87,675 & 81,113 \\
\hline \multicolumn{6}{|c|}{.60 USGPH 84,000 BTUH Nominal Input } \\
\hline 14 & 14.55 & $5-7$ & 74,130 & 72,240 & 68.460 \\
\hline 13 & 15.49 & $12-15$ & 73,920 & 71,610 & 67.830 \\
\hline 12 & 16.84 & 25 & 73,500 & 71,400 & 66.990 \\
\hline 11 & 18.39 & 35 & 73,080 & 70,560 & 66,150 \\
\hline 10 & 20.02 & 50 & 72,660 & 70,140 & 64,890 \\
\hline \multicolumn{6}{|c|}{.50 USGPH 70,000 BTUH Nominal Input } \\
\hline 14 & 12.13 & $5-7$ & 61,775 & 60,200 & 57,050 \\
\hline 13 & 12.91 & $12-15$ & 61,600 & 59,675 & 56,525 \\
\hline 12 & 14.03 & 25 & 61,250 & 59,500 & 55,825 \\
\hline 11 & 15.32 & 35 & 60,900 & 58,800 & 55,125 \\
\hline 10 & 16.68 & 50 & 60,550 & 58,450 & 54,075 \\
\hline
\end{tabular}


What the Shirvent MVP 100 can do for improved efficiency and reduced emissions.

1. Establish constant over fire pressure.

2. Eliminate variations in the vent system flow rate from wind, cold chimneys and variations in the burner blower pressures produced.

3. Set $\mathrm{CO}_{2}$ levels at $13 \%$ without producing unacceptable smoke numbers thus reduced emissions.

4. Reduce the gross stack temperatures to an efficient level without condensation in the vent system which would normally cause structural chimney damage.

5. Allow burner input rates that closer match the heating requirements of the residents.

6. Reduce substantial heat exchanger degradation.

Efficiency/Emissions Improvement Scenario

Existing appliance $1.00 \mathrm{USGPH} 10 \% \mathrm{Co}_{2} 550^{\circ}$ gross tack.

The excess air level is $50 \%$ the usable BTUH are 108,000 and the stack loss is $23 \%$. The volume of air for combustion 33.37 CFM.

Match the input to the heat loss.

.60 USGPH $13 \% \mathrm{Co}_{2}$ gross stack $250^{\circ}$ the excess air level is $12 \%$ the usable BTUH are 73,920 . The stack loss is $12 \%$ and the volume of air for combustion is 15.49 CFM.

\section{Result}

The total volume of flue gas emissions is reduced by $52.5 \%$ minimum.

The stack loss is reduced by $11 \%$, although the BTUH loss is reduced by 22,000 .

Existing Appliance

Gross Input was

140,000 BTUH

Stack Loss $23 \%$

$$
=32,000 \text { BTUH }
$$

New Gross Input

84,000 BTUH

Stack Loss $12 \%$

$$
=10,000 \text { BTUH }
$$


Now these calculations are one point in time for testing but the total run time must also be considered for the old system and the new system. When the old $1.00 \mathrm{GPH}$ system required a total number of operating hours to provide space heating and domestic water heating the new $60 \mathrm{GPH}$ system may require $X+200$ hours to provide the necessary energy for the system.

Example: The old 1.00 gallon per hour total annual operating hours is 1250 so the oil consumption would be 1250 US gallons.

The new 60 gallon per hour total annual operating is $1250+200=1450$ hours the consumption would now be 870 US gallons.

The fuel use reduction is $1250-870=380$ US gallons. The emission reduction in actual fact can best be stated as $380 \div 1250=30.4 \%$.

Along with the other benefits this is a substantial contribution to greenhouse gas reduction.

\section{CONCLUSION}

Designing a controlled venting system matched to the heating appliance and burner will allow increased energy utilization efficiencies and a reduction in emissions produced by numbers in excess of $49 \%$.

The resultant energy savings using a stable combustion process plus the elimination of the smoke spike on light off and the smoke spike on shut down, combining the Shirvent MVP 100 with pre purge and post purge on the oil burner, will eliminate the degradation of boiler and furnace heat exchangers, reduced service costs, reduced fuel costs. 


\section{ALTERNATE VENTING FOR FOSSIL FUEL FIRED EQUIPMENT}

\section{Burner A Scenario 1}

After 34 minutes end cone was still recording $230.8^{\circ} \mathrm{F}$; adaptor oil temperature was $125.3^{\circ} \mathrm{F}$ and the gross stack was $165^{\circ} \mathrm{F}$. The Co was 15 PPM. Burner $.6570^{\circ} \mathrm{A}$

\section{Burner A Scenario 2}

After 35 minutes end cone recording $249^{\circ} \mathrm{F}$, adapter oil temperature $126.9^{\circ} \mathrm{F}$ Co $14 \mathrm{PPM}$

Burner $.6570^{\circ} \mathrm{A}$

\section{Burner A Scenario 3}

Burner off at 20 minutes, end cone temperature $244^{\circ} \mathrm{F}$ at 24 minutes. No Co spike: nozzle adapter oil $121.5^{\circ} \mathrm{F}$ at 24 minutes@ oil pressure dropped 3 pounds pre adjusted.

Summary - Post purge reduces high Co spikes and nozzle spillage into combustion zone.

\section{Burner B Scenario 1}

After 34 minutes end cone was still recording $456^{\circ} \mathrm{F}$; adaptor oil

- temperature was $121.4^{\circ} \mathrm{F}$, Co was still

$\bar{\sigma}_{0}$ at 64 PPM. Burner .65 $80^{\circ} \mathrm{W}$

\section{Burner B Scenario 2}

After 2 hours and thirty seven minutes end cone $113^{\circ} \mathrm{F}$, nozzle oil adapter $78.6^{\circ} \mathrm{F}$ venter runs constant. Burner $.6580^{\circ} \mathrm{W}$

\section{Burner B Scenario 3}

After 30 minutes end cone $167.3^{\circ} \mathrm{F}$, adaptor oil temp $98.5^{\circ} \mathrm{F}$ Co 0 PPM

Burner $.6580^{\circ} \mathrm{A}$

Summary - Post purge on high $\mathrm{Co}_{2}$ performance eliminates roll back even with isolating damper in dual appliance operation.

\section{Burner C Scenario 1}

After 30 minutes end cone temperature $191^{\circ} \mathrm{F}$; oil in adaptor $121.7^{\circ} \mathrm{F}$ Co $4^{\circ}$ PPM. Burner $6560^{\circ}$ hollow.

\section{Burner C Scenario 2}

After 30 minutes end cone temperature $156^{\circ} \mathrm{F}$, oil in adaptor $112.1^{\circ} \mathrm{F}$ Co 0 PPM. Burner .65 $60^{\circ} \mathrm{A}$

\section{Summary of Burner C}

\section{Burner C Scenario 3}

Burner off at 26 minutes, Co spike to 121 PPM at 27 minutes, 31 minutes all clear end cone $135.3^{\circ} \mathrm{F}$, oil in adapter 109.2

Low end cone temperatures on all test runs. Protek nozzle cut off on Scenario 3 jumped Co spike over 121 PPM but 5 minute post purge cleared all residual flue product and cooled burner. Burner $\mathrm{C}$ was tested without the Protek nozzle shut off device and a $.6560^{\circ} \mathrm{W}$ nozzle. The end cone temperatures increased $200^{\circ} \mathrm{F}$ and the gross stack went up $80^{\circ} \mathrm{F}$. The Co $\mathrm{T}_{2}$ was increased but also the Co produced on run double the previous readings. The Co produced on shut down was nominal 42 PPM and the post purge cleaned the combustion zone and returned end cone temperatures to $134.8^{\circ} \mathrm{F}$ and nozzle adapter oil to $103.1^{\circ} \mathrm{F}$ 


\begin{tabular}{|c|c|c|c|c|c|c|c|c|c|c|c|c|c|c|c|c|c|c|c|c|}
\hline \multicolumn{21}{|c|}{$\begin{array}{c}\text { ALTERNATE VENTING FOR FOSSIL FUEL FIRED EQUIPMENT } \\
\text { Tests Results Burner A Three Scenarios } \\
\end{array}$} \\
\hline \multicolumn{4}{|c|}{ T. EC. End Cone Temp. } & \multicolumn{4}{|c|}{ AD Adaptor Oil Temp. } & \multicolumn{6}{|c|}{ S. Gross Stack $\quad$ D Overfire Draft } & \multicolumn{4}{|c|}{$\mathrm{Co}_{2}$ Carbon Dioxide } & \multicolumn{3}{|c|}{ Co Monoxide } \\
\hline \multicolumn{8}{|c|}{$\begin{array}{l}\text { Cold Tank } \\
\text { No Post Purge - Venter Off }\end{array}$} & \multicolumn{6}{|c|}{$\begin{array}{l}\text { Damper Closed } \\
\text { No Post Purge - Venter Const. }\end{array}$} & \multicolumn{7}{|c|}{$\begin{array}{l}\text { Pre Purge Post Purge } \\
\text { Venter Runs With Post Purge }\end{array}$} \\
\hline $\mathbf{T}$ & EC & $A D$ & $\mathbf{s}$ & $\underline{\mathbf{D}}$ & $\mathrm{CO}_{2}$ & Co & $\mathrm{T}$ & EC & $A D$ & $\underline{s}$ & $\mathrm{D}$ & $\mathrm{Co}_{2}$ & Co & $\mathbf{T}$ & EC & $A D$ & $\mathbf{s}$ & $\mathbf{D}$ & $\mathrm{CO}_{2}$ & Co \\
\hline 1 & & 804 & & & & & 1 & & 886 & 420 & +.03 & & & 1 & 3807 & 821 & & & & \\
\hline 2 & & 84.7 & & +004 & & & 2 & 5621 & 901 & & & & & $\underline{2}$ & & 849 & & & & \\
\hline 3 & & 867 & 550 & & & & 3 & & 923 & & & 12.8 & 018 & 3 & & 885 & 510 & +025 & & \\
\hline 4 & & 902 & 570 & +003 & & & 4 & & 942 & & & 127 & 019 & 4 & 697.6 & 904 & & & & \\
\hline 5 & & 91.9 & & & 119 & & 5 & 730 & 960 & 595 & & 128 & 019 & 5 & & 939 & & & 125 & 011 \\
\hline 6 & & 938 & 600 & & 120 & 004 & 6 & & 973 & & & & & 6 & & 95.5 & 590 & & & \\
\hline 7 & 8021 & 966 & & & 119 & 009 & 7 & & 386 & & & 128 & 021 & 7 & 7914 & 971 & 600 & & 123 & 011 \\
\hline 8 & & 97.9 & & & 119 & 012 & 8 & & 996 & & & & & 8 & & & & & & \\
\hline 9 & & 994 & & & & & 9 & & 1003 & 610 & & & & 9 & & 999 & & & 122 & 012 \\
\hline 10 & 830 & 98.9 & & & & & 10 & & 1009 & & & 126 & 020 & 10 & & 100.7 & & & & \\
\hline 11 & & 994 & & & 120 & 015 & 11 & & 1015 & & & & & 11 & & 1015 & 610 & & 12.4 & 012 \\
\hline 12 & & 998 & & & 120 & 017 & 12 & 842 & 1019 & & & 126 & 022 & 12 & 835 & 1025 & 610 & & 125 & 013 \\
\hline 13 & & 100.3 & & & 121 & 019 & 13 & & 1022 & & & & & 13 & & 1031 & & & & \\
\hline 14 & & 1005 & & & 12.1 & 019 & 14 & & 1028 & 610 & & 126 & 022 & 14 & 844 & 1036 & & & 125 & 013 \\
\hline 15 & & 100.9 & 615 & +035 & 121 & 020 & 15 & & 1031 & & & & & 15 & & 1041 & & & 12.3 & 014 \\
\hline 16 & & & 620 & & 122 & 021 & 16 & 851 & 1032 & & & & & 16 & & 1045 & 610 & & & \\
\hline 17 & 852 & 1013 & & & 123 & 021 & 17 & & 1042 & & & & & 17 & 848 & 1050 & & & & \\
\hline 18 & & 1016 & & & & 166 & 18 & & 1042 & & & & & 18 & & 1054 & 610 & & 124 & 014 \\
\hline 19 & & 1298 & & & & 349 & 19 & & 1043 & & & & & 19 & & 1057 & & & & \\
\hline 20 & & 1511 & & & & 356 & 20 & & 1043 & & & & & 20 & & 1060 & & & & \\
\hline 21 & & 1607 & & & & 227 & 21 & 773 & 1500 & & & & 57 & 21 & 744 & 137.1 & & & & 015 \\
\hline 22 & & 165.2 & & & & 205 & 22 & & 1589 & & & & 80 & 22 & 555 & 136.7 & & & & 012 \\
\hline 23 & & 1667 & 290 & & & & 23 & & 1618 & & & & 85 & 23 & & 1284 & & & & \\
\hline 24 & 576 & 1673 & & & & 150 & 24 & 20 & 1612 & & & & 65 & 24 & 244 & 121.5 & $240^{\circ}$ & & & \\
\hline & 17 Bur & ler Off, & enter & & & & & $\begin{array}{l}20 \mathrm{Da} \\
13 \mathrm{Wa} \\
20 \mathrm{Bu}\end{array}$ & $\begin{array}{l}\text { per Clos } \\
\text { Draw } \\
\text { er Off Ve }\end{array}$ & ter $\mathrm{R}$ & & & & & $\begin{array}{ll}13 & W \\
20 & B u\end{array}$ & $\begin{array}{l}\text { er Draw o } \\
\text { ler Oil Of }\end{array}$ & & & & \\
\hline
\end{tabular}




\begin{tabular}{|c|c|c|c|c|c|c|c|c|c|c|c|c|c|c|c|c|c|c|c|c|c|}
\hline \multicolumn{22}{|c|}{$\begin{array}{c}\text { ALTERNATE VENTING FOR FOSSIL FUEL FIRED EQUIPMENT } \\
\text { Tests Results Burner B Three Scenarios }\end{array}$} \\
\hline \multicolumn{5}{|c|}{$\begin{array}{l}\text { T. EC. End Cone Temp. AD } \\
\begin{array}{l}\text { Burner Off Venter Off } \\
\text { Tank Cold on Start }\end{array} \\
\end{array}$} & \multicolumn{3}{|c|}{ Adaptor Oil Temp. } & \multicolumn{3}{|c|}{$\begin{array}{l}\text { S. Gross Stack } \\
\text { Post Purge On } \\
\text { Tank Cold Star }\end{array}$} & \multicolumn{4}{|c|}{ D Overfire Draft } & \multicolumn{5}{|c|}{$\begin{array}{l}\mathrm{Co}_{2} \text { Carbon Dioxide CoN } \\
\begin{array}{l}\text { Pre Purge Post Purge } \\
\text { Venter Runs }\end{array}\end{array}$} & \multirow[b]{2}{*}{$\mathrm{Co}_{2}$} & \multirow[b]{2}{*}{ Co } \\
\hline$T$ & EC & $A D$ & $s$ & $D$ & $\mathrm{Co}_{2}$ & Co & $T$ & $\mathrm{EC}$ & $A D$ & $S$ & D & & $\mathrm{Co}_{2} \%$ & $\begin{array}{l}\text { Co } \\
\text { PPM } \\
\end{array}$ & $T$ & EC & $A D$ & $s$ & D & & \\
\hline 1 & 656 & 91.6 & & & & & 1 & & 918 & & & & & & 1 & & 82.7 & & & & \\
\hline 2 & 960 & 931 & & & & & 2 & & 947 & & + & & & & 2 & & 845 & & +004 & & \\
\hline 3 & 1034 & 958 & 630 & +004 & 126 & 20 & 3 & & 979 & & & & 13 & 10 & 3 & & 905 & & & 115 & 007 \\
\hline 4 & 1040 & 98.7 & & & & & 4 & 883 & 1008 & & & & 132 & 10 & 4 & & 94.7 & & & & \\
\hline 5 & 1043 & 100.8 & & & 125 & 16 & 5 & & 1035 & & & & & & 5 & & 977 & & & & \\
\hline 6 & 1033 & 1038 & & & & & 6 & 1030 & 105.9 & & & & & & 6 & 1059 & 1007 & 605 & & 11.8 & 018 \\
\hline 7 & 1029 & 1045 & & & 122 & 23 & 7 & 1063 & & 610 & & & 130 & 11 & 7 & & 103.4 & & & & \\
\hline 8 & 1018 & 105.9 & 620 & & & & 8 & 1048 & & & & & & & 8 & & 1054 & & & & \\
\hline 9 & 1010 & 1067 & & & 122 & 22 & 9 & 1045 & 1119 & & & & & & 9 & & 1072 & & & & \\
\hline 10 & 1009 & 1080 & & & & & 10 & & 1121 & & & & & & 10 & 1023 & 1085 & 603 & & 117 & 019 \\
\hline 11 & & 1090 & & & & & 1 & & 1131 & & & & & & 11 & & 110.1 & & & & \\
\hline 12 & & 109.0 & & & & & $1:$ & & 1136 & & & & & & 12 & & 1106 & & & & \\
\hline 13 & & 1095 & & & & & 13 & & & & & & & & 13 & & 1112 & & & & \\
\hline 14 & & 109.9 & & & & & 1 & 1023 & 1145 & & & & 130 & 11 & 14 & 1015 & 1115 & 598 & & 114 & \\
\hline 15 & & 1103 & & & & & 15 & & 1147 & & & & & & 15 & & 1340 & & & & 25 \\
\hline 16 & & 1107 & & & & & 16 & & 1150 & & & & & & 16 & & 1251 & & & & \\
\hline 17 & 1008 & 1117 & & & & & 17 & & 1153 & & & & & & 17 & & 1164 & & & & \\
\hline 18 & & 112.2 & & +004 & & & 18 & & 1158 & & & & & & 18 & & 1135 & & & & \\
\hline 19 & & 1136 & 625 & & 122 & 17 & 15 & 1015 & 1163 & 605 & & & 129 & 14 & 19 & & 1104 & & & & \\
\hline 20 & 1007 & 114.1 & & & & & 20 & & 1164 & & & & & & 20 & & 1096 & & & & 14 \\
\hline 21 & & 117.2 & & & & & 21 & & 1166 & & & & & & 21 & & 108.3 & & & & \\
\hline 22 & & 133.5 & & & & 157 & 22 & & 1251 & & & & & 25 & 22 & 225 & & & & & 10 \\
\hline 23 & & 138.7 & & & & 240 & 23 & & 1221 & & & & & 30 & 23 & & & & & & \\
\hline 24 & & 1606 & & & & 260 & 24 & 199 & 1131 & & & & & 16 & 24 & & & & & & \\
\hline & $20 \mathrm{~B}$ & Off, & 'enter & & & & & $22 \mathrm{O}$ & & & & & & & & $15 \mathrm{~B}$ & er of & the & $\mathrm{Da}$ & Clos & \\
\hline
\end{tabular}




\begin{tabular}{|c|c|c|c|c|c|c|c|c|c|c|c|c|c|c|c|c|c|c|c|c|}
\hline \multicolumn{21}{|c|}{$\begin{array}{c}\text { ALTERNATE VENTING FOR FOSSIL FUEL FIRED EQUIPMENT } \\
\text { Tests Results Burner C Three Scenarios }\end{array}$} \\
\hline \multirow{2}{*}{\multicolumn{5}{|c|}{$\begin{array}{l}\text { T. EC. End Cone Temp. } \\
\text { Burner Off Venter Off } \\
\text { Tank Cold on Start }\end{array}$}} & \multicolumn{3}{|c|}{ Adaptor Oil Temp. } & \multicolumn{6}{|c|}{ S. Gross Stack $\quad$ D Overfire Draft } & \multicolumn{4}{|c|}{$\mathrm{Co}_{2}$ Carbon Dioxide } & \multicolumn{3}{|c|}{ Co Monoxide } \\
\hline & & & & & \multicolumn{11}{|c|}{$\begin{array}{l}\text { Burner Off Venter On } \\
\text { Burner Activated on Water Draw }\end{array}$} & \multicolumn{5}{|c|}{$\begin{array}{l}\text { Burner Post Purge Venter On } \\
21 \text { Minute Water braw }\end{array}$} \\
\hline $\mathbf{T}$ & EC & $A D$ & $\mathbf{s}$ & D & $\mathrm{Co}_{2}$ & Co & $\mathbf{T}$ & $\mathrm{EC}$ & $A D$ & $s$ & D & $\mathrm{Co}_{2} \%$ & $\begin{array}{l}\text { Co } \\
\text { PPM }\end{array}$ & $T$ & EC & $A D$ & $\mathbf{s}$ & D & $\mathrm{CO}_{2}$ & Co \\
\hline 1 & & 79.4 & & & & & 1 & 25 & 989 & & & & & 1 & & 77.3 & & & & \\
\hline$\underline{2}$ & & 84.6 & & & & & 2 & & 1001 & 390 & +005 & 131 & 014 & 2 & 318 & 84.5 & & & & \\
\hline 3 & & 87.7 & 500 & +035 & & & 3 & & 1037 & & & 132 & 014 & 3 & & 934 & & & & \\
\hline 4 & & 90.3 & 525 & & & & 4 & & 1057 & & & & & 4 & & 99.5 & & & & \\
\hline 5 & 2986 & 923 & 535 & & & & 5 & 40 & 1080 & $520^{\circ}$ & +005 & 132 & 015 & 5 & 400 & 1020 & 500 & +005 & 128 & 013 \\
\hline 6 & 302.5 & 95.0 & 550 & & & & 6 & & 1100 & & & & & 6 & & 1062 & & & & \\
\hline 7 & & 95.5 & & & & & 7 & & 1115 & & & & & 7 & 410 & 108.2 & & & & \\
\hline 8 & & 96.8 & & & & & 8 & & 1128 & & & 132 & 017 & 8 & & 1105 & 525 & & 127 & 014 \\
\hline 9 & & 97.7 & & & & & 9 & & 1137 & & & & & 9 & 427 & 1121 & & & & \\
\hline 10 & & 99.0 & & & & & 10 & 43 & 1147 & 535 & +005 & 131 & 017 & 10 & & 1137 & & & & \\
\hline 11 & & 1003 & & & & & 11 & & 1151 & & & & & 11 & & 1152 & & & & \\
\hline 12 & 406 & 1042 & 560 & & 11.8 & 009 & 12 & & 1156 & & & & & 12 & & 1165 & 525 & & 127 & 016 \\
\hline 13 & & 1085 & & & 126 & 011 & 13 & & 1100 & & & & & 13 & 437 & 1172 & & & & \\
\hline 14 & & 109.5 & & & & & 14 & & 1168 & & & & & 14 & & 1180 & & & & \\
\hline 15 & & 1106 & 545 & & 130 & 013 & 15 & & & & & & & 15 & 441 & 1190 & & & & \\
\hline 16 & 440 & 112.0 & & & & & 16 & & & & & & & 16 & & 1197 & & & & \\
\hline 17 & & 1149 & & & 134 & 014 & 17 & 55 & 117.9 & & & 132 & 017 & 17 & 446 & 1200 & & & 126 & 018 \\
\hline 18 & & 1150 & & & 130 & 012 & 18 & & 1283 & & & & 028 & 18 & & 1206 & & & & \\
\hline 19 & 445 & 115.5 & 550 & & & & 19 & & 1367 & & & 129 & 049 & 19 & 464 & 1210 & 525 & & 132 & 019 \\
\hline 20 & & 117.0 & & & & 025 & 20 & 35 & 1388 & & & & 063 & 20 & 469 & 1229 & & & & \\
\hline 21 & & 1356 & & & & 052 & 21 & & 1379 & & & & 034 & 21 & & 1238 & & & & \\
\hline 22 & & 140.1 & & & & 102 & 22 & & 1352 & & & & 021 & 22 & 476 & 124.3 & & & & \\
\hline 23 & & 141.2 & & & & 068 & 23 & & 1330 & & & & 016 & 23 & & 124.8 & & & & \\
\hline 24 & & 139.6 & & & & 040 & 24 & & 1291 & & & & 007 & 24 & & 1251 & 530 & & & \\
\hline & $19 \mathrm{BL}$ & 1er Off & & & & & . & & Off & & & & & & $\begin{array}{ll}21 & n \\
26 & B \\
\end{array}$ & $\begin{array}{l}\text { er Draw } \\
\text { ner Off }\end{array}$ & & & & \\
\hline
\end{tabular}


FORCED DRAFT DIRECT VENT

ALUMINUM SIDING
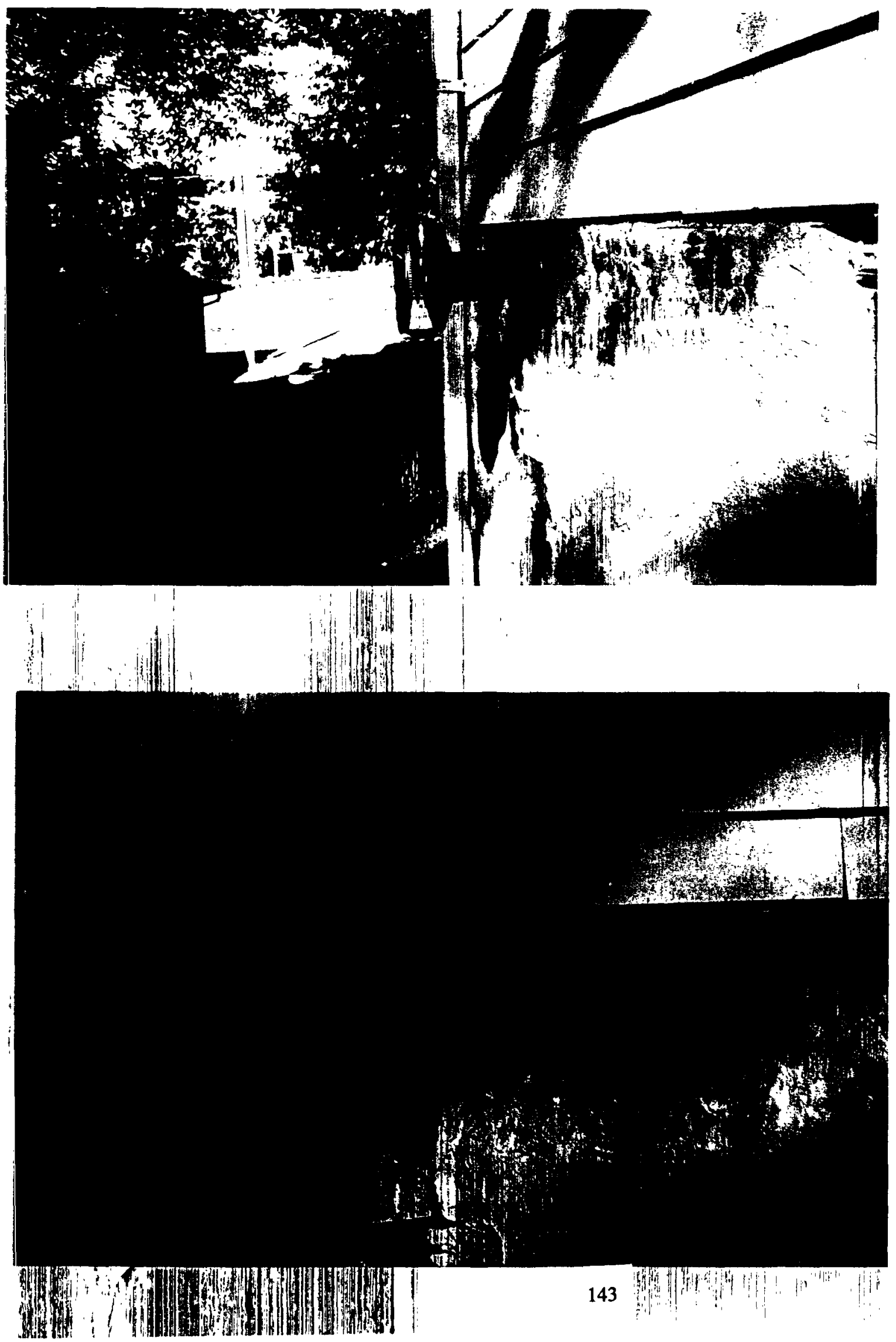

Photo \#1

Shows the terminal with adequate clearance from wall $9^{\prime \prime}$ test set up smoke ${ }^{\circ}$ to trace $\mathrm{CO}_{2} 13.1 \%$ gross stack $340^{\circ} \mathrm{F}$

Home owner stated only goes up wall when no wind.

\section{Photo \#2}

Head-on shot of terminal shows dishes designed to deflect wind so that the terminal would not stall flue gas exhaust. 


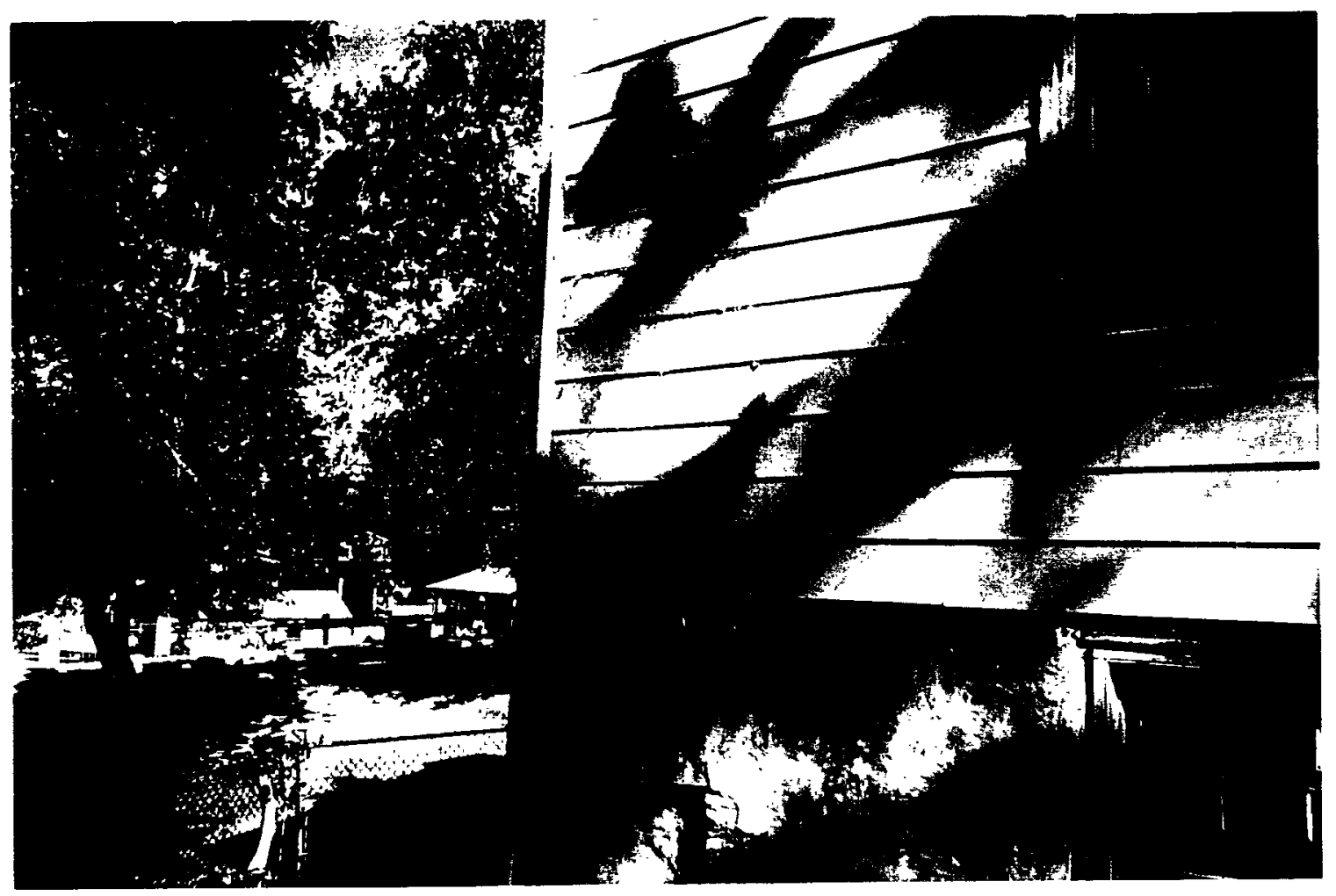

Photo \#3

Shows pattern of flue gas condensing on wall and removing finish from aluminum siding.

Photo \#4

Shows extent of pattern on wall for condensing.

Time frame 4 years 


\section{FORCED DRAFT DIRECT VENT \\ VINYL SIDING}
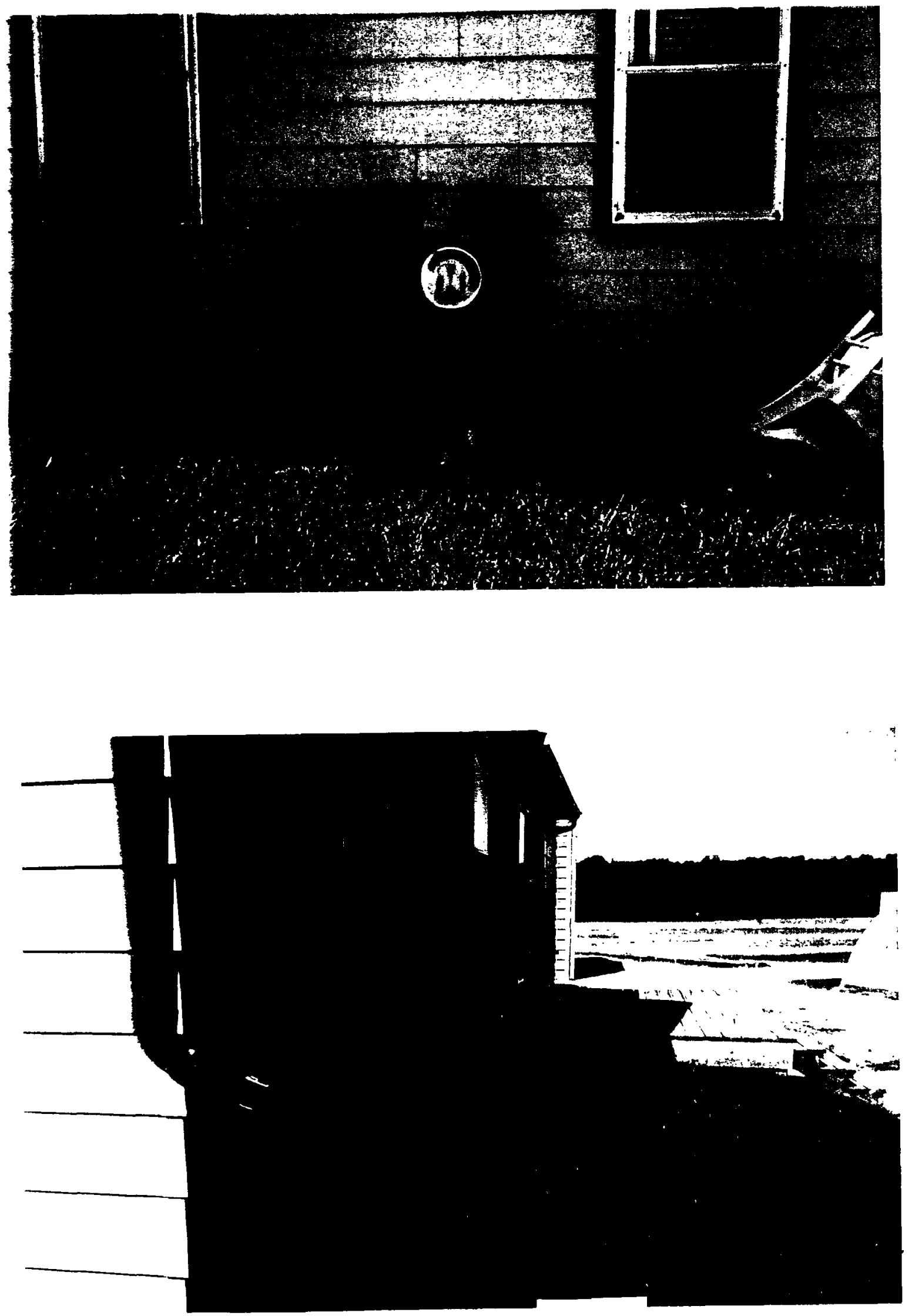

\section{Photo \#1}

Shows head-on view of riser with pattern of condensate on wall.

\section{Photo \#2}

Shows side view of north side looking west. Wind is prevailing from north west. 


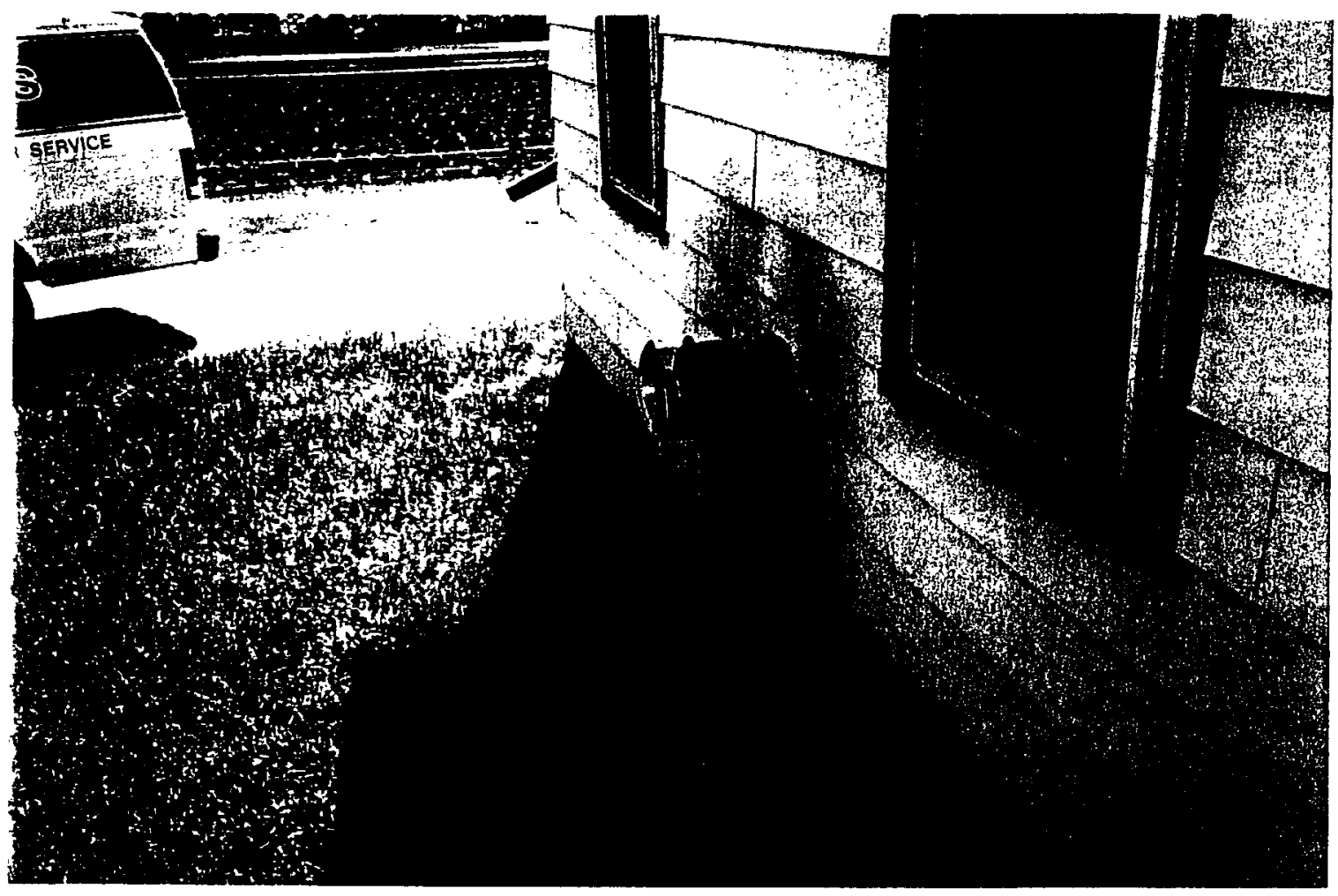

\section{Photo \#3}

View looking east. No obstructions clear flow for flue gases to be carried away except on no wind situations

Fixed storm windows

\section{Photo \#4}

Shows angle view of wall staining. Does not wipe off but has changed material This was noted with direct vent gas fireplaces on vinyl walls and on aluminum siding Brick walls did not show stain but mortar soft. 


\section{VEBTECK RESEARCH}

\section{SHIRVENT MVP 100 FIELD INSTALLATION}
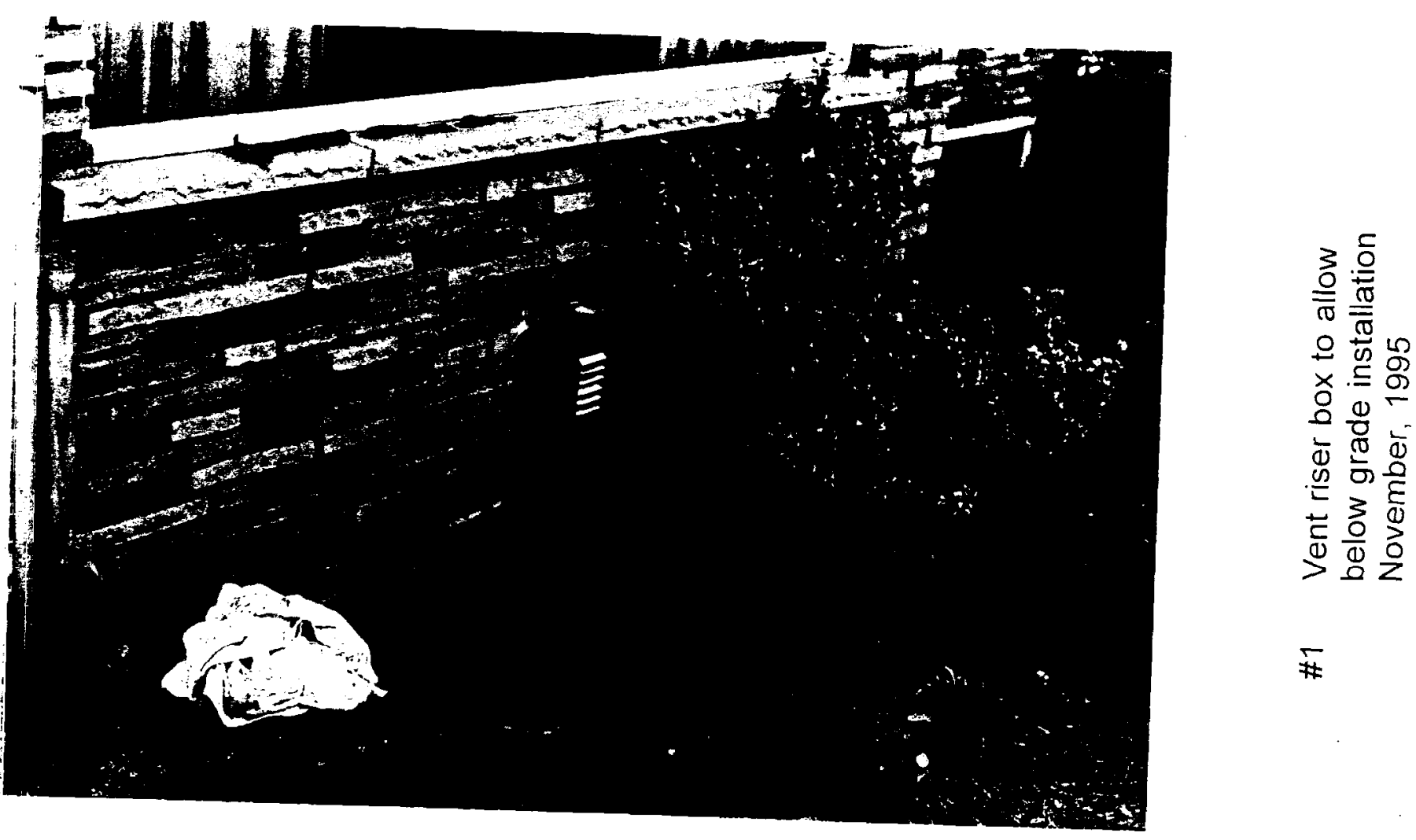


\section{VEBTECK RESEARCH}

SHIRVENT MVP 100 FIELD INSTALLATION

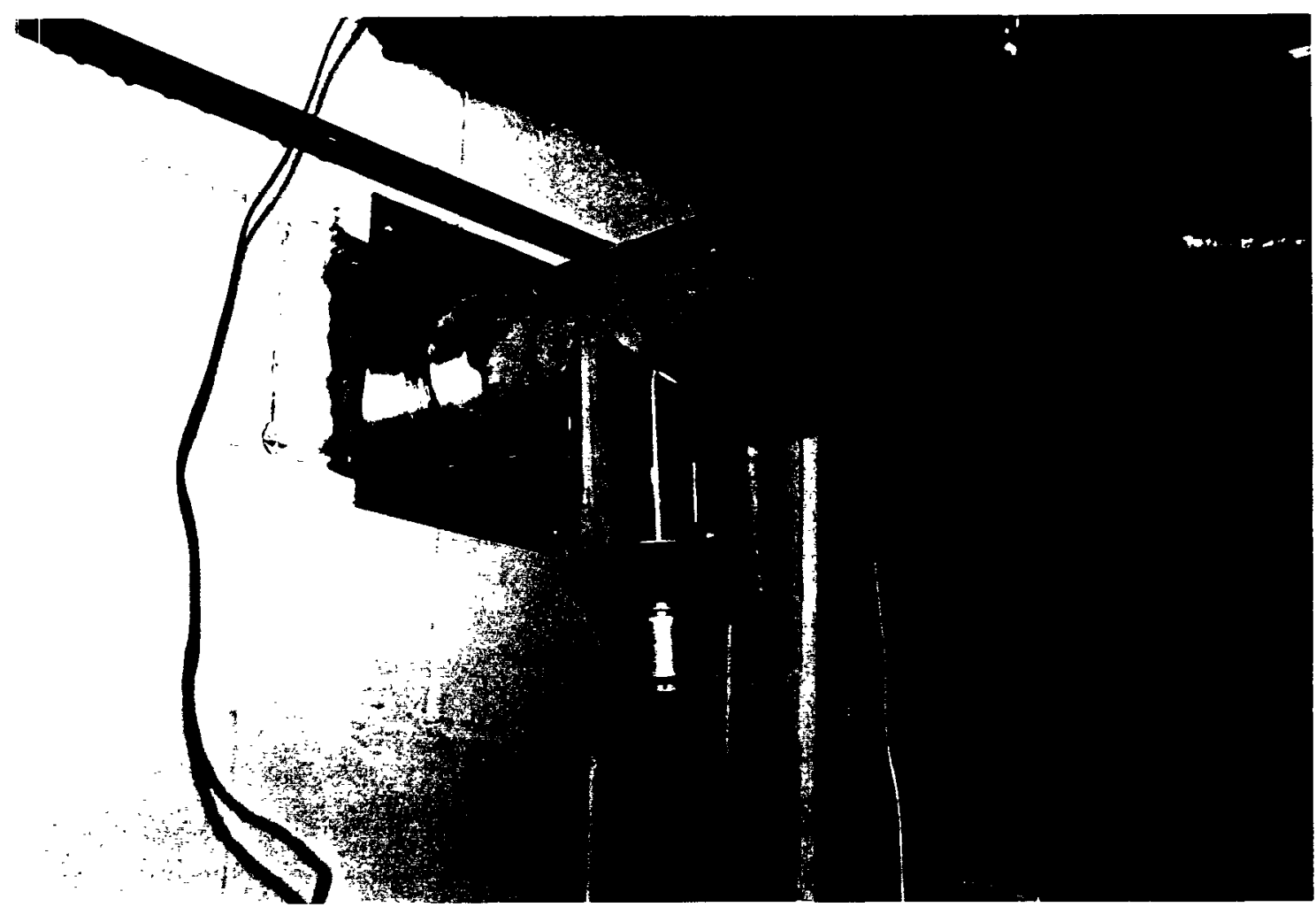

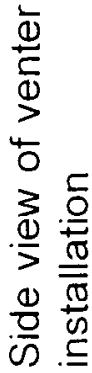

$¥$

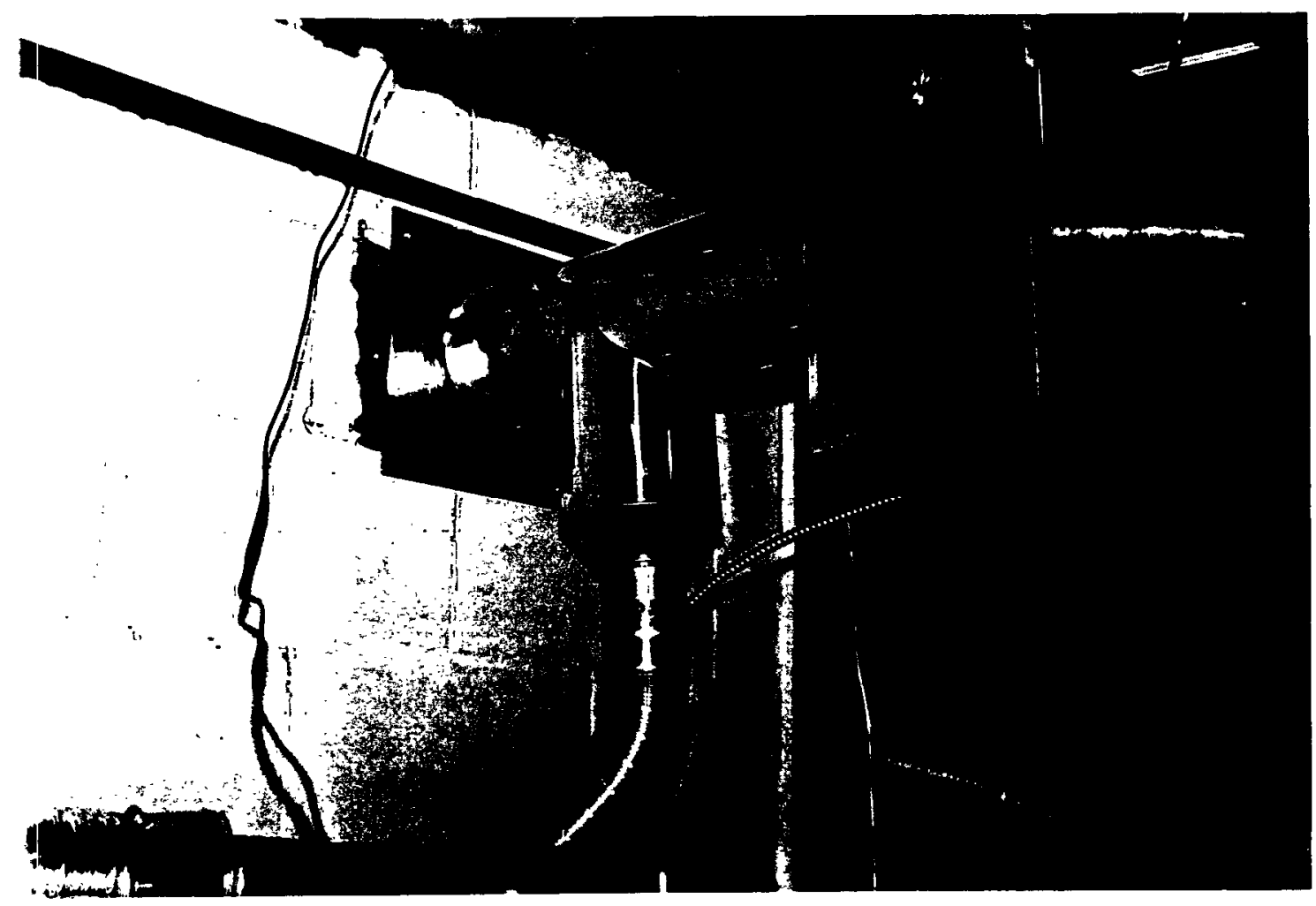

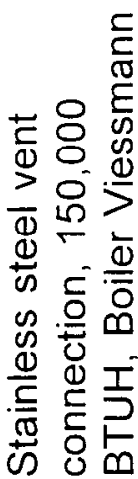

\# 


\section{VEBTECK RESEARCH}

\section{SHIRVENT MVP 100 FIELD INSTALLATION}

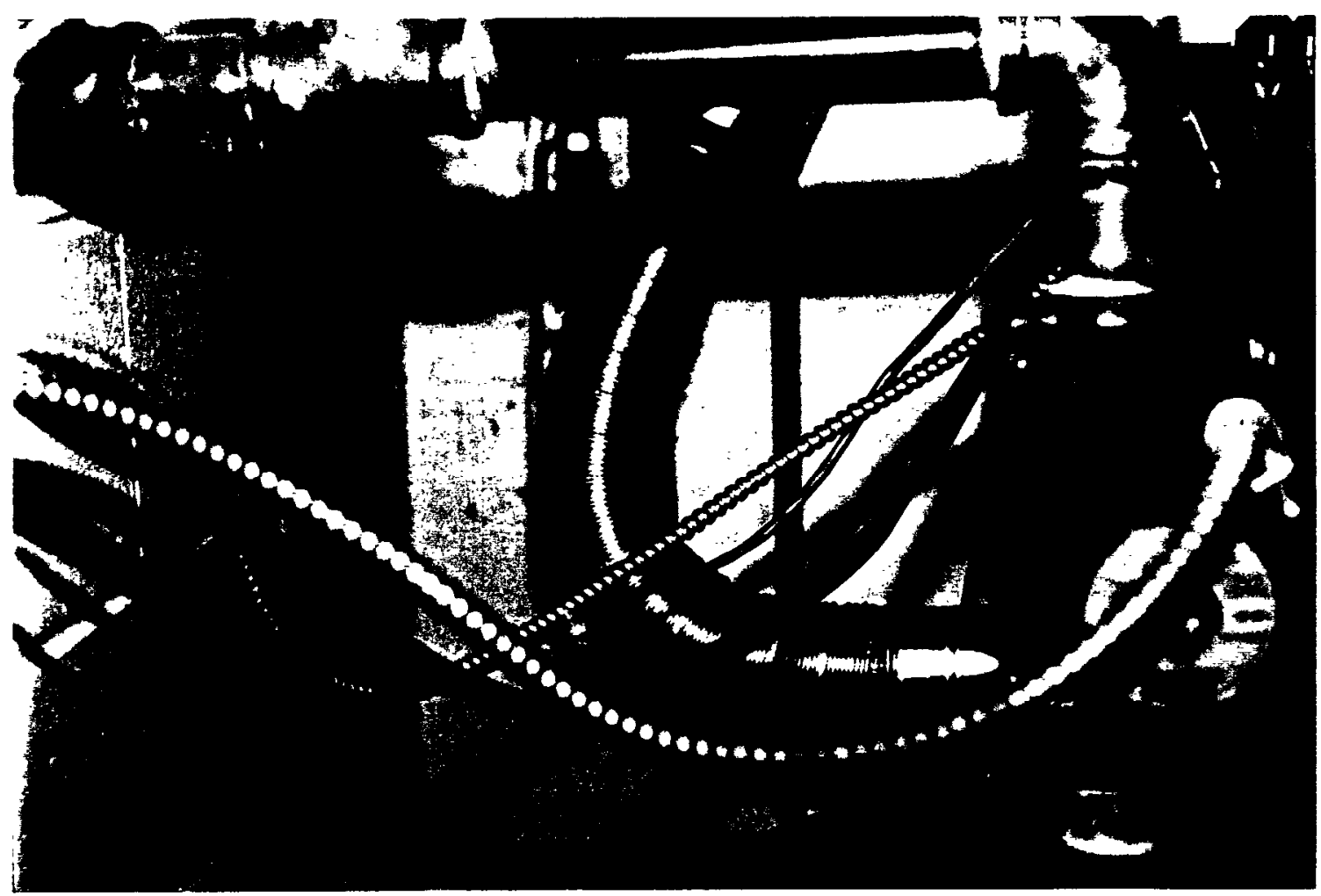

\#5 Connection on rear breech of boiler 
Paper No. 99-11

\section{Repeatability and Reproducibility error in Smoke Measurement:} Development of a new scale.

Mahesh V. Panchagnula, Design and Research Engineer, Delavan Inc., Bamberg, SC,

Gary Inman, Capital Group Consulting, Charleston, SC, and

Victor J. Turk, Director of Engineering, R.W. Beckett, Elyria, OH 


\title{
Repeatability and Reproducibility error in Smoke Measurement: Development of a new scale.
}

\author{
Mahesh V. Panchagnula ${ }^{1}$, Gary Inman ${ }^{2}$ and Victor J. Turk ${ }^{3}$
}

\begin{abstract}
Of the various parameters that are used to understand oil burner performance, smoke measurement is the most subjective and hence most prone to error. Most of the previous studies to estimate error in the measurement of smoke spanned a range of smoke number that is beyond typical operating range. Therefore, their conclusions cannot directly be used to understand the error in the lower range of operation.
\end{abstract}

The purpose of this study is to estimate the error in the range of typical measurement and help develop a methodology for measuring smoke emissions from residential oil burners using a standardized test. Towards this end, a repeatability and reproducibility study was carried out in collaboration with some OEM's. The goal of this study was to establish an upper bound on the error in smoke measurement by the current technique. The guidelines provided by ASTM in their Research Report RR D-2 -1007 were followed in the course of this inter-laboratory experiment and round-robin testing program.

A set of twenty-five smoke spots was generated on a single oil-fired warm air furnace. The total range of measurement of these smoke spots spanned typical oil burner operation range and beyond, (about zero to about 4 on the Shell-Bacharach smoke scale). The statistical study compared operator bias and the ability of the operator to read the smoke number. An optical smoke reader per the specifications given in ASTM standard D2156 was used to determine the actual smoke reading.

The study compared the capability of the operator to detect small differences of a subjective measurement. As with any measure, the error is broken down into obvious potential measurement variation such as operator, method, or inconsistency effects. This study analyzed these effects using statistical inference to determine if the probable error was greater than the unit of measurement and if a new method could provide a more precise measurement. The operators were asked to assign a value to a sample measurement using the nearest reading on the new scale. The error of the measurement was calculated using the mean and standard deviation. The measurement error was compared against the present scale and the error of the previous test method.

Comparing the mean and standard deviation showed that the probable error was within the range of a single measurement unit. The most significant error was operator bias that can be reduced by standardizing the test method. Since the unit of measurement is smaller and it is probable that the error will not exceed the measurement unit, a new standard method is proposed that will result in a more precise and accurate reading in the lower end of the smoke scale.

\footnotetext{
${ }^{1}$ Design and Research Engineer, Delavan Inc., Bamberg, SC

${ }^{2}$ Capital Group Consulting, Charleston, SC

${ }^{3}$ Director of Engineering, R.W. Beckett, Elyria, $\mathrm{OH}$
} 


\section{INTRODUCTION}

Smoke is generated from oil heat appliances as a by-product of the combustion process. It consists of particulate matter that is produced primarily from the fuel-rich regions in the combustion chamber. These regions are a result of incomplete mixing of the fuel and air.

Particulate matter, thus formed, can broadly be classified into three main groups.

1) Soot formed during the gas phase reaction of oil vapor with oxygen.

2) Heavier fractions of oil that undergo pyrolysis/combustion reaction to yield oil-coke particles.

3) Inorganic content of the fuel that is deposited as ash

The structures of the particulate matter formed by these three mechanisms are markedly different. Figures 1 and 2 illustrate the difference between oil-coke and gas phase soot. As can be observed from these two figures, gas phase soot (figure 1) consists of a number of small particles, typically about $50 \mathrm{~nm}$ in size, that are agglomerated into a long chain. Oil coke (figure 2) on the other hand, consists of large residual particles of carbon that remain from the fractional distillation of the oil, where the lighter fragments are converted into vapor.

A number of measurement techniques have been utilized in order to quantify smoke. It has been measured in terms of pounds of particulate matter produced per thousand gallons of fuel oil sprayed. Another method of quantifying smoke has been in terms of its concentration in the exhaust gas stream in terms of the weight of particulate matter per unit volume of the exhaust. A third and more accepted method of measuring smoke is to measure the grayness of a smoke spot generated by depositing the particulate matter on a white filter paper. Per ASTM Standard D2156, the filter paper has to have an optical reflectance of about $85 \%$. The smoke scale spot number is then defined as the reduction (due to smoke) in reflected incident light divided by 10 . Thus, the smoke spot number is measured by visual comparison of the generated smoke spot with a smoke scale, which consists of ten spots numbered 0 through 9 ranging in equal photometric steps from white through neutral shades of gray to black. Though this is an indirect measurement of smoke, it has been found to be very simple and efficient to use in the field.

With the advent of the flame retention head burner and other innovations, the total particulate emissions from residential oil burners have come down by a factor of 10 over the last thirty years. The smoke emissions have decreased but the technology to measure them has not undergone any significant change. There have been a couple of new innovations based on light scatter measurement techniques and particle counting techniques to characterize smoke emissions. However, these are still very complicated and definitely out of the reach of the average oil burner service technician.

This paper addresses the need for a smoke spot scale that can used to accurately measure very low levels of smoke, i.e. zero to two on the Bacharach smoke scale, that are typical of current oil burner performance. The first phase of this project was to estimate the reproducibility and repeatability error in the current system of measurement. To this end, an inter-laboratory round robin testing study was initiated. Upon completion of this study, it was found that the average error in the measurement of smoke is less than half of a single unit on the Shell-Bacharach smoke scale, especially in the low range of smoke 
measurement. In other words, though the smoke scale is marked in smoke number increments of 1 , the average human eye is capable of determining the smoke number in finer increments. We have tried to exploit this finding to develop a new scale that can deliver more reliable measurements of the smoke number.

The experimental apparatus used and procedure that was followed to generate the data is described in the next section. The results are presented and discussed in section three before we conclude with a summary.

\section{EXPERIMENTAL PROCEDURE}

A commercial warm air furnace with an oil burner was used to generate the smoke. The air setting on the burner was adjusted to achieve a desired level of smoke. A Bacharach smoke pump was then used to generate a smoke spot on a filter paper strip. Five filter paper strips, each with five smoke spots ranging in smoke number from 0 to 4 , were generated.

A couple of different smoke settings were chosen, one close to 0.3 and another close to 2.0. Multiple smoke spots were generated at these two settings and randomly distributed among the twenty-five, in order to estimate the repeatability error involved in the measurement. Care was taken that the test conditions on the warm air furnace did not change while the multiple spots were being generated, in order to minimize the variation from spot to spot. Care was also taken to minimize the effect of neighboring smoke spots influencing the operator, by having the same spot being placed next to darker and lighter smoke spots. Two smoke spots were generated by drawing clean air through the filter paper, ensuring that an exact zero reading was achieved.

These smoke strips were read by a number of operators by comparing the smoke spots to the standard Bacharach smoke scale. The operators' observations were noted as one choice from a list of nineteen options that best described the smoke spot. That list is given below.
a) Zero
b) Very light trace
k) Darker than two
c) Light trace
l) Between two and three
d) Between zero and one
m) Lighter than three
e) Lighter than one
n) Three
f) One
o) Darker than three
g) Darker than one
h) Between one and two
i) Lighter than two
p) Between three and four
q) Lighter than four
r) Four
j) Two
s) Other

The smoke spots were also read on an optical smoke reader, which provided an objective and repeatable measurement. The optical smoke reader complies with ASTM specification D-2156, Annex A1. This was applied to the entire set of twenty-five spots. The measurement was also repeated to gauge system error. It was found that the optical system was capable of measuring the smoke number within \pm 0.1 . This measurement was used as the standard to estimate operator bias. The smoke spots were read by sixteen operators from four different laboratories of major OEM's. The raw data is presented in Table 1. Each row in this table is what a single operator measured on all the twenty-five 
smoke spots. Conversely, each column indicates the measurements of all the operators with a single smoke spot. It must also be mentioned that columns 2 through 6 includes measurement data from smoke spots that were all obtained at the same burner setting. Similarly, columns 7 through 11 were also obtained at the same burner setting.

The raw data is also presented graphically in figure 3. This graph is a plot of the average operator's reading versus the smoke number read by the optical smoke meter. The average operator's reading is obtained as the average of all the readings of the different operators from a single smoke spot.

The data for one smoke spot by all the operators is presented in figure 4 . This plot shows a number of measurements on a single smoke spot. The optical smoke reader measurement is included in the plot as a dotted line. The plot also shows the average and 3 standard deviation control limits. The standard deviation was obtained from the entire data set.

\section{RESULTS AND DISCUSSION}

The overall purpose of this analysis is to determine the measurement error in smoke measurement. The measurement error has several major components. The basic component, test-retest error, has some obvious potential sources of measurement variation. This variation can be attributed to operator effects, instrument effects and dayto-day cffects.

These effects have an influence on the process measurement in two ways. They are usually referred to as "Bias effect" and "Inconsistency effect". When the average recorded readings are shifted a fixed amount, it is called a Bias effect. Variation changes due to randomness effect of readings are called Inconsistency effect.

The uncertainty in a measurement is referred to as the median uncertainty, or as the probable error. It is generally estimated to be $\pm 0.67 \mathrm{X}$ Estimated Standard Deviation. In this case, the maximum probable error over the range of measurement was found to be under 0.32 on the smoke number. In other words, the operators were able to identify the smoke number within \pm 0.3 on the Bacharach smoke scale.

The smoke scale that is currently being used as a standard in the industry uses increments of one smoke number. However, the average operator is capable of deciphering the smoke number to within about \pm 0.3 on the smoke number. This suggests that the unit of measurement on the scale is greater than what the operator is capable of reading. Therefore, we propose the development of a new scale that will utilize the operator's true measurement ability. A prototype of the new scale is given in figure 5 . This scale ranges from smoke number 0 to about 3 in increments from about 0.3 .

\section{Data Analysis}

The first stcp in this study was to use a subjective method to evaluate the operator's ability to read the smoke spot using the Bacharach scale. This was accomplished by comparing the visual subjective measurement (attribute data) with an instrument capable of reading smoke in a continuous manner (variable data). An optical smoke spot reader based on reflectivity was used for this purpose. The smoke spots were placed on the optical reader and readings obtained. This was repeated twice to ensure repeatability. The 
optical reader is capable of reading the smoke spot within \pm 0.1 of the Bacharach smoke number.

An analysis of a control chart revealed a test-retest error of about 0.48 units. The standard deviation was estimated by $\mathrm{R}-\mathrm{bar} / \mathrm{d}_{2}$ method. This indicates that the probable error is about 0.32 units $(0.67 \times 0.48)$. Therefore, the effective resolution of this measurement is chosen to be about 0.3 units.

The average Standard Deviation of the measured values is 0.48 and the average Standard Deviation of the error or the combination of Bias and Inconsistency effects is 0.258 . The true measurement system variation is therefore calculated to be,

$$
\text { The true measurement }=\sqrt{0.48^{2}-0.258^{2}}=0.405
$$

In further analysis, it was determined that some detectable shift in the average measurements had occurred with one operator. This was due to operator bias. Reducing this bias could reduce the overall measurement error.

Instrument bias was not determined since it was only used for verification and generation of test standards. This should not influence the capability to determine the trace measurement using a new smaller increment scale.

\section{SUMMARY AND CONCLUSIONS}

A round robin testing study of the smoke measurement was conducted to measure the repeatability and reproducibility error. The test consisted of having a number of operators measure smoke spots visually by comparing with the standard smoke scale. By analyzing the results of the study, it was found that the operators were capable of reading the smoke spot accurate to about \pm 0.3 units of the smoke scale. Therefore, a new scale is proposed that would range from 0 to 3 smoke numbers and increase in increments of 0.3 . Use of this new scale would result in a more accurate measurement of the smoke number.

\section{REFERENCES}

"Combustion of liquid fuel sprays", Alan Williams, Published by Butterworth \& Co. Ltd. "Standard Test Method for Smoke density in Flue Gases from Burning Distillate Fuels", ASTM specification D2156-94

"Manual on Determining Precision Data for ASTM Methods on Petroleum Products and Lubricants", ASTM Research Report No. RR D-2 1007.

"Smoke density of Flue Gases from burning Distillate Fuels", ASTM Research Report RR: D02-1325.

\section{ACKNOWLEDGEMENT}

The authors would like to thank the engineers and technicians from the combustion labs of R.W.Beckett, Burnham, Riello and Delavan for their help in gathering the data for this project in a timely manner. Special thanks are also due to Sue Clayton and Bill Fralick for the critical comments that have helped in improving the quality of this paper. 
Figure 1: Gas phase soot formed during the reaction of oil vapor with air (Combustion of liquid fuel sprays by Alan Williams, courtesy of Butterworth and Co.)

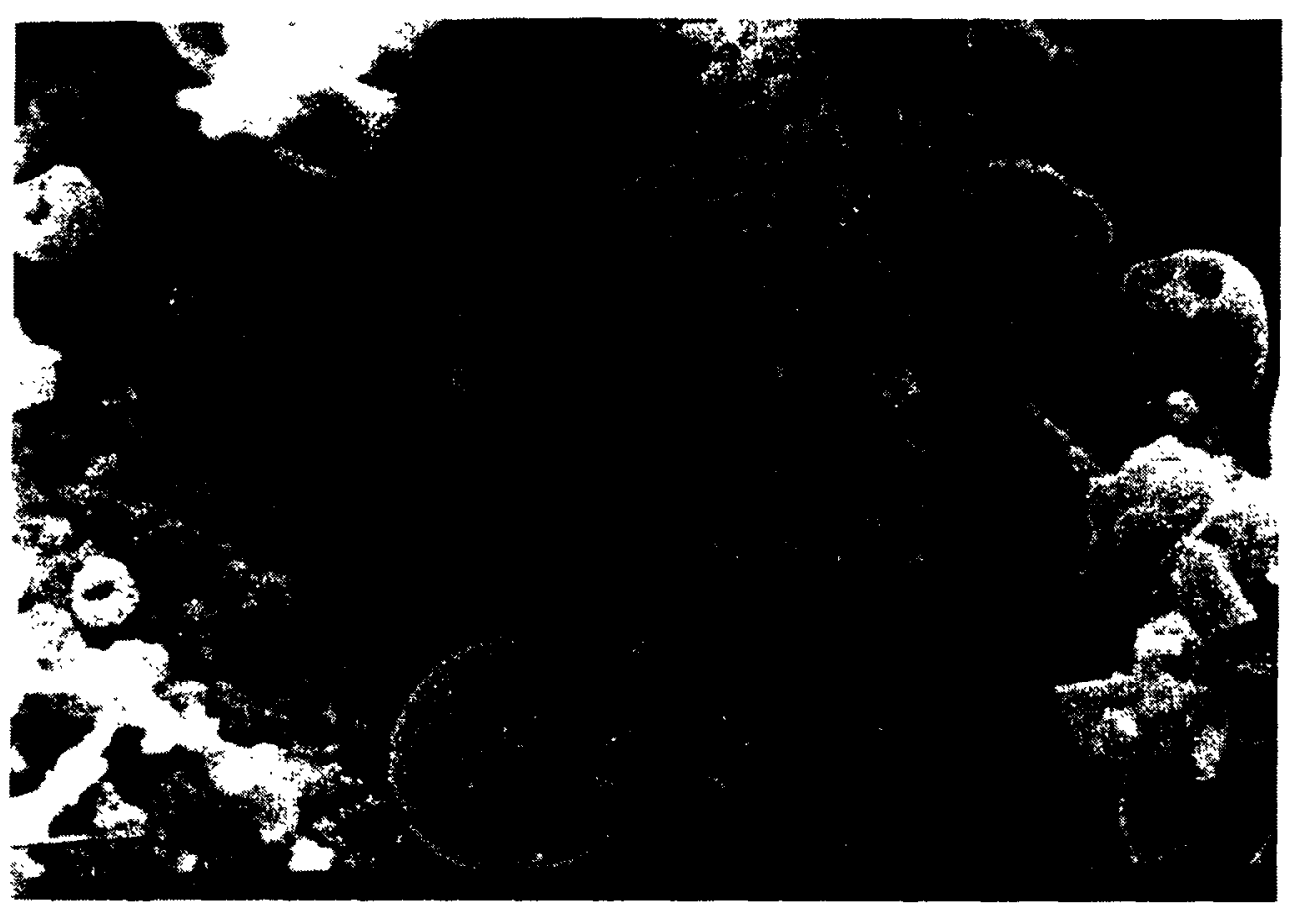

Figure 2: Oil coke formed by fractional distillation of the fuel oil droplets (Combustion of liquid fuel sprays by Alan Williams, courtesy of Butterworth and Co.) 


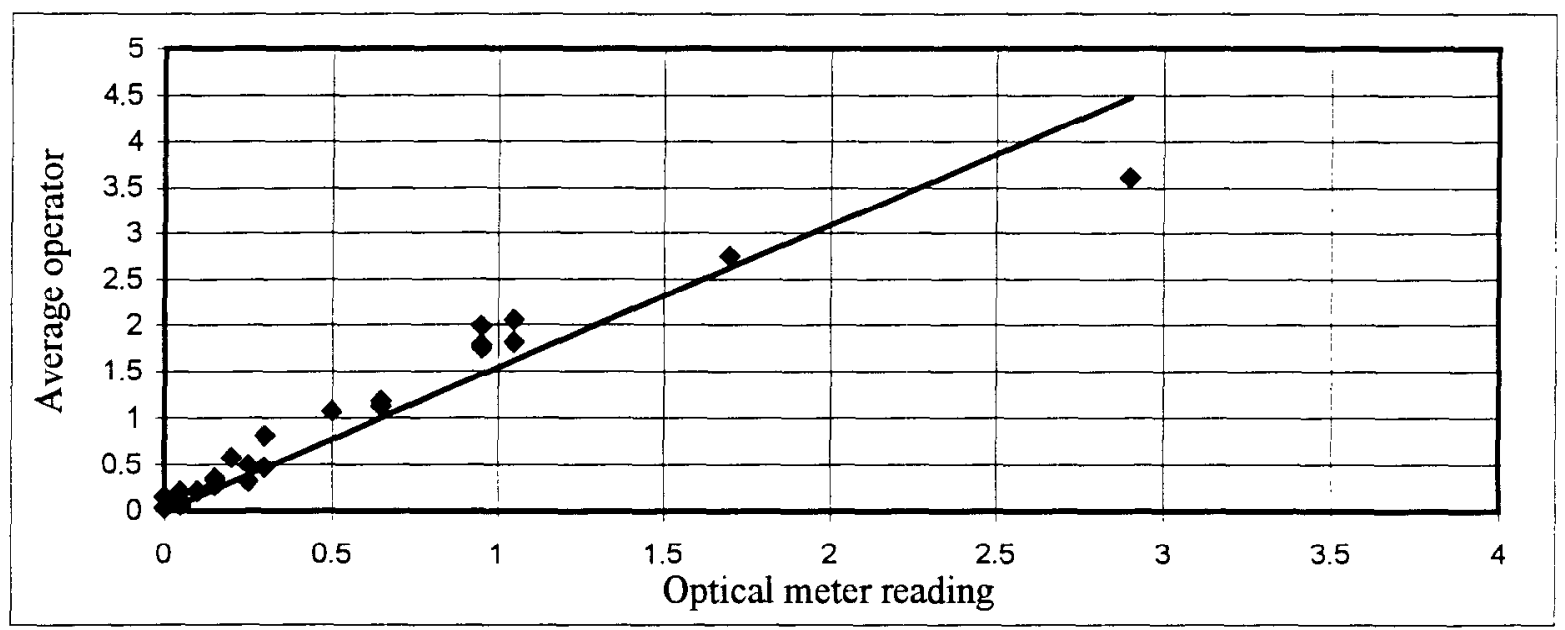

Figure 3: Raw data from the optical smoke reader versus operator's readings. The slope of the best-fit line indicates operator bias.

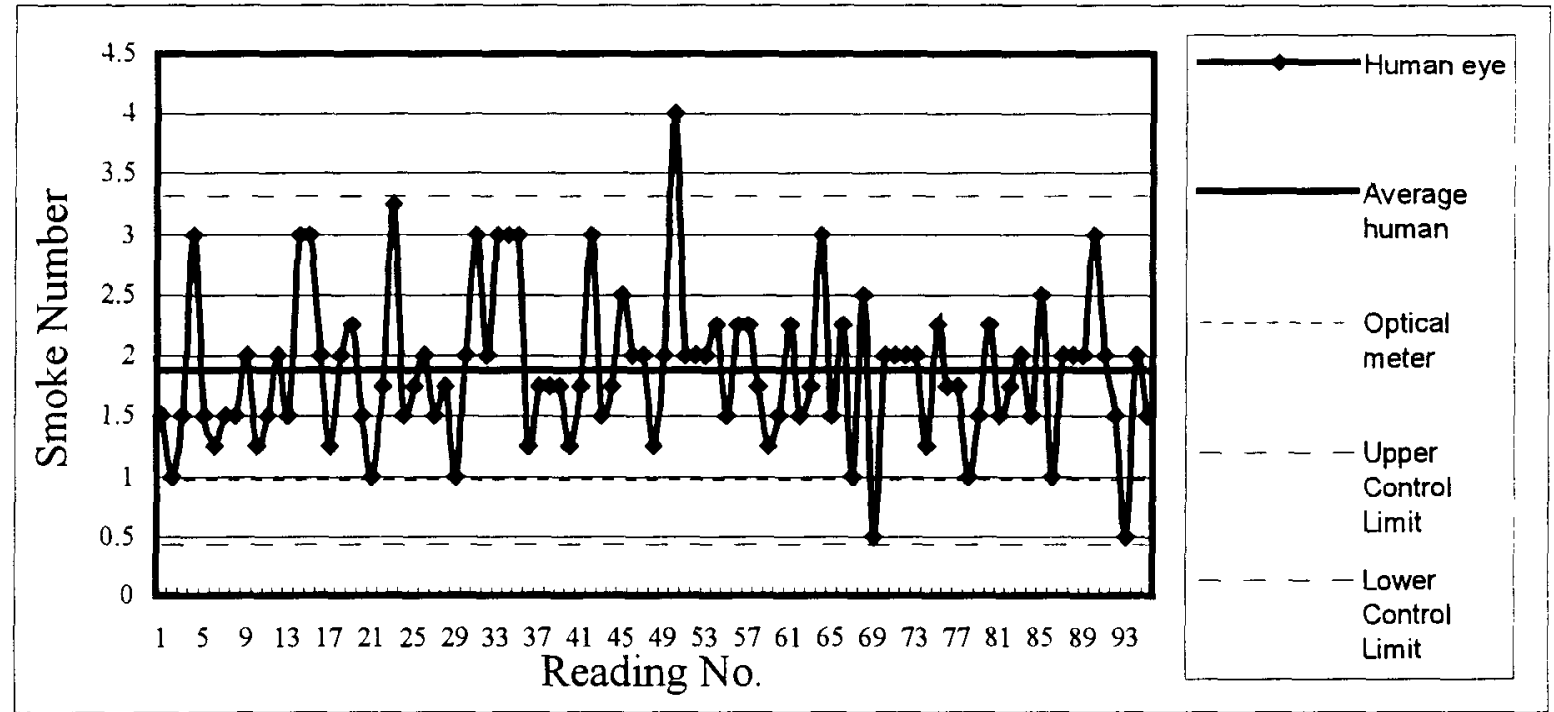

Figure 4: Control chart indicating variation from operator to operator on similar smoke spots. 


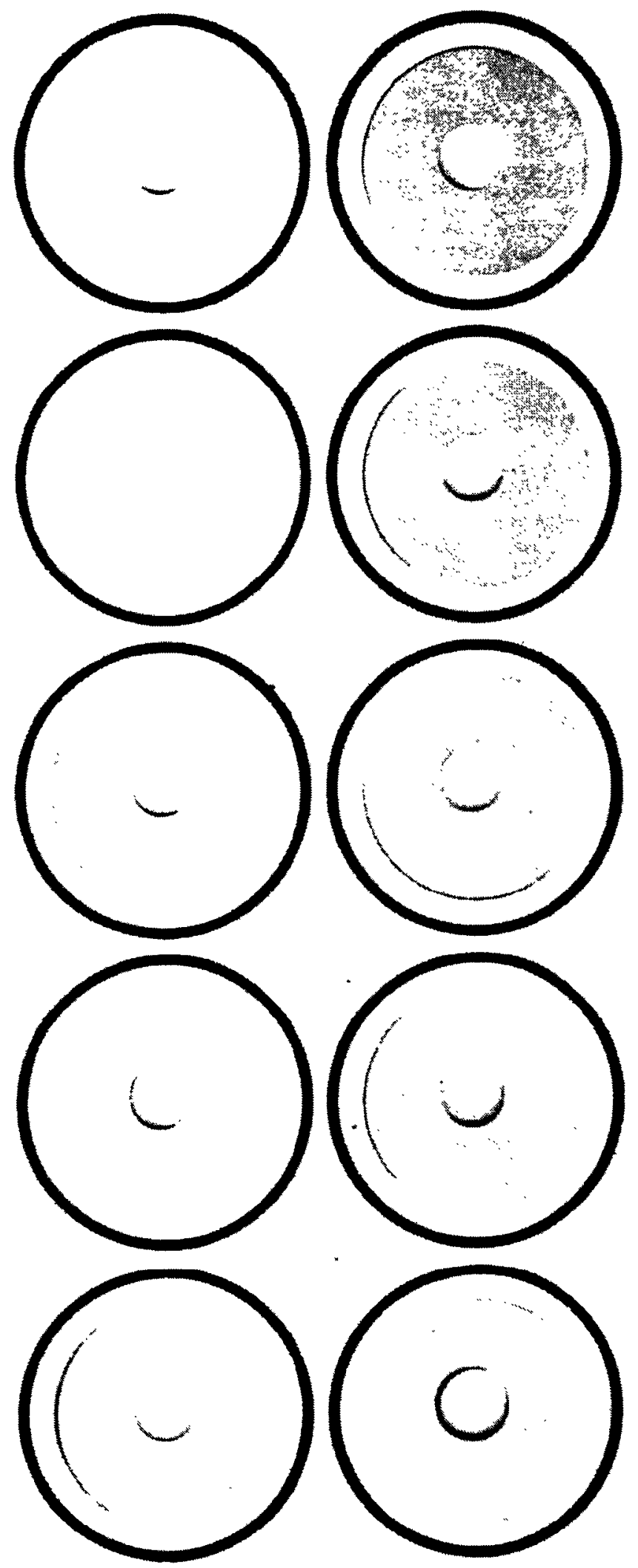

Figure 5: Smoke scale ranging from Smoke Number 0 to 3 in increments of 0.3 . 
Table 1: Raw data from the round robin smoke test.

\begin{tabular}{|c|c|c|c|c|c|c|c|c|c|c|c|c|c|c|c|c|c|c|c|c|c|c|c|c|c|}
\hline No. & $\begin{array}{r}\text { I1 } \\
\text { (1) }\end{array}$ & \begin{tabular}{r|}
12 \\
$(2)$ \\
\end{tabular} & \begin{tabular}{r|}
14 \\
(3) \\
\end{tabular} & $\begin{array}{l}\text { II1 } \\
\text { (4) }\end{array}$ & $\begin{array}{r}\text { III } \\
(5) \\
\end{array}$ & $\begin{array}{r}\text { IV3 } \\
(6) \\
\end{array}$ & \begin{tabular}{r|}
13 \\
$(7)$ \\
\end{tabular} & \begin{tabular}{r|}
$\mathbf{I 5}$ \\
$\mathbf{( 8 )}$ \\
\end{tabular} & \begin{tabular}{l|} 
II2 \\
(9)
\end{tabular} & $\begin{array}{l}\text { III1 } \\
(\mathbf{1 0})\end{array}$ & $\begin{array}{l}\text { IV4 } \\
\text { (11) }\end{array}$ & \begin{tabular}{|r|} 
II3 \\
$(12)$ \\
\end{tabular} & $\begin{array}{r}\text { II4 } \\
\text { (13) }\end{array}$ & $\begin{array}{r}\text { II5 } \\
(14)\end{array}$ & $\begin{array}{l}\text { III3 } \\
\text { (15) }\end{array}$ & \begin{tabular}{l|} 
III4 \\
$(16)$
\end{tabular} & $\begin{array}{l}\text { III5 } \\
\text { (17) }\end{array}$ & $\begin{array}{l}\text { IV1 } \\
\text { (18) }\end{array}$ & \begin{tabular}{l|} 
IV2 \\
(19)
\end{tabular} & $\begin{array}{l}\text { IV5 } \\
(20)\end{array}$ & $\begin{array}{r}\mathrm{V1} \\
(21)\end{array}$ & $\begin{array}{r}\mathrm{V} 2 \\
(22)\end{array}$ & $\begin{array}{r}\mathrm{V} 5 \\
(23)\end{array}$ & $\begin{array}{r}\text { V3 } \\
(24)\end{array}$ & $\begin{array}{r}\mathrm{V4} \\
(25)\end{array}$ \\
\hline 1 & 1 & 1.5 & 1.5 & 1.75 & \begin{tabular}{|l|}
1.75 \\
\end{tabular} & 1.75 & \begin{tabular}{|c|}
0.3 \\
\end{tabular} & 0.2 & \begin{tabular}{c|}
0.3 \\
\end{tabular} & \begin{tabular}{|c|}
0.5 \\
\end{tabular} & 0 & 0 & 0.2 & 1 & $\overline{0.3}$ & 0.2 & 0 & 3.25 & 0 & 2.5 & 1 & 0 & 0 & 0 & $\overline{0}$ \\
\hline 2 & 0.75 & 1 & 1 & 1.25 & 1.25 & 1 & 0.2 & 0.3 & 0.5 & 0.75 & 0.2 & 0.2 & 0.3 & 11 & 0.2 & 0.2 & 0 & 2.75 & 0 & 2 & 0.75 & 0 & 0 & $\overline{0}$ & 0.2 \\
\hline 3 & 1.25 & 1.5 & 1.75 & 1.75 & 1.5 & 1.5 & 0.2 & 0 & 0.5 & 0.5 & 0.3 & 0 & 0 & 0.3 & 0.2 & 0.3 & 0 & 4 & 0.2 & 2.5 & 1.25 & 0 & 0 & 0 & \\
\hline 4 & 1.75 & 3 & 3.25 & 3 & 2.25 & 2.25 & 1.25 & 1 & 1.25 & 1.75 & 0.2 & 1 & 1 & 2 & 1 & 0.3 & 0.2 & 4 & 0.3 & 3.5 & 1.25 & 0.3 & 0.3 & 0.3 & $\overline{0.3}$ \\
\hline 5 & 0.5 & 1.5 & 1.5 & 1.5 & 1.5 & 1.5 & 0.2 & 0.2 & 0.3 & 0.3 & 0.2 & 0 & 0.2 & 0.5 & 0.2 & 0 & 0 & 3 & 0 & 1.75 & 0.3 & 0 & 0 & 0 & 0 \\
\hline 6 & & 1.25 & 1.75 & 1.75 & \begin{tabular}{|l|}
1.75 \\
\end{tabular} & 1.75 & 0.3 & 0.2 & $\begin{array}{ll}0.2 \\
\end{array}$ & 0.75 & 0.2 & 0 & 0.2 & 0.75 & 0.2 & 0.2 & 0 & 3.5 & 0.5 & 2.75 & 1 & 0 & 0 & 0 & 0 \\
\hline 7 & 1 & 1.5 & 2 & 2.5 & 3 & 2 & 0.5 & 0.5 & 0.5 & 1 & 1 & 1 & 1 & 2 & 1 & 1.5 & 0.5 & 4 & 1 & 3 & 1 & 0 & 0 & 1 & 0 \\
\hline 8 & 1 & 1.5 & 1.5 & 2 & 1.5 & 1.5 & \begin{tabular}{|l|}
0.3 \\
\end{tabular} & 0.2 & 0.2 & 1 & 0.3 & 0 & 0 & 0.5 & 0.2 & 0 & 0 & 3 & 0 & 2 & 1 & 0.2 & 0 & 0 & \\
\hline 9 & 1.5 & 2 & 1.75 & 2 & 2.25 & 2.5 & 0.75 & $\begin{array}{ll}0.3 \\
\end{array}$ & 11 & 0.75 & 1 & 0.2 & 0.5 & 1.25 & 0.75 & 0 & 0 & 3 & 0 & 2.75 & 0.75 & 0.2 & 0 & 0.2 & $\overline{0.2}$ \\
\hline 10 & 0.75 & 1.25 & 1 & \begin{tabular}{|l|}
1.25 \\
\end{tabular} & 1 & 1 & 0.3 & 0.3 & 0.3 & 0.3 & 0.3 & 0.2 & 0.2 & 0.75 & 0.2 & 0.2 & 0 & 2.75 & 0 & 1.75 & 0.5 & 0 & 0 & 0 & 0 \\
\hline 11 & 0.75 & 1.5 & $\overline{2}$ & 2 & 2.5 & 2 & 0.5 & 0.3 & 0.3 & 0.75 & 0.3 & 0.2 & 0.2 & 1.25 & 0.5 & 0.2 & 0.2 & 4 & 0 & 3 & 2 & 0 & 0 & 0 & 0 \\
\hline$\overline{12}$ & 1 & 2 & 3 & 4 & 0.5 & 2 & 0.5 & 0.3 & 0.2 & 0.75 & 0.2 & 0.2 & 0.3 & 1.25 & 0.5 & 0.3 & 0.2 & 4 & 0.2 & 3 & 1.25 & 0.2 & 0.2 & 0.3 & 0.2 \\
\hline$\overline{13}$ & 1 & 1.5 & 2 & 2 & 2 & 2 & 0.5 & $\begin{array}{ll}0.3 \\
\end{array}$ & 0.5 & \begin{tabular}{|l|}
0.75 \\
\end{tabular} & 0.3 & 0.2 & 0.3 & 1.5 & 0.5 & $\begin{array}{ll}0.3 \\
\end{array}$ & 0.2 & 4 & 0.2 & 2.5 & 1 & 0 & 0 & 0 & $\overline{0}$ \\
\hline 14 & 1 & 3 & 3 & 2 & 2 & 3 & 0 & 0 & 1 & 1 & 0 & 0 & 0 & 1 & 2 & 0 & 0 & 4 & 0 & 4 & 2 & 0 & 0 & 0 & \\
\hline$\overline{15}$ & $\overline{2}$ & 3 & 3 & 2 & $\overline{2}$ & 2 & 1 & 0 & $\overline{0}$ & 1 & 0 & 0 & 1 & 2 & 1 & 0 & 0 & 4 & 0 & 3 & 1 & 0 & 0 & 0 & \\
\hline 16 & 1 & 2 & 3 & 2.25 & 2 & 1.5 & 0.3 & 0.2 & 0.2 & 0.5 & 0.5 & 0 & 0.2 & 1.75 & 0.5 & 0.3 & 1.75 & 4 & 0.2 & 3.5 & 0.75 & 0.2 & 0.2 & 0.2 & 0.2 \\
\hline 17 & 1 & \begin{tabular}{|l|}
1.25 \\
\end{tabular} & \begin{tabular}{|l|}
1.25 \\
\end{tabular} & 1.5 & 1.25 & 0.5 & 0.2 & 0.3 & 0.2 & 0.3 & 0.2 & 0.2 & 0.5 & 1 & 0.3 & 0.5 & 0.5 & 4 & 0 & 3.25 & 0.3 & 0 & 0 & 0 & \\
\hline 18 & 1.5 & 2 & 1.75 & 2.25 & 2.25 & 2 & 0.75 & 0.5 & 1 & 1.5 & 0.75 & 0.2 & 0.2 & 1.25 & 0.3 & 0.2 & 0.2 & 4 & 0 & 2.75 & 1.5 & 0.2 & 0 & 0 & $\overline{0}$ \\
\hline 19 & 1.5 & 2.25 & \begin{tabular}{|l|}
1.75 \\
\end{tabular} & 2.25 & 1.75 & 1.5 & 1 & 1 & 1 & 1.25 & 0.3 & 0.5 & 0.3 & 1.25 & 1 & 0.5 & 0.2 & 3.25 & 0.2 & 2.75 & 1.75 & 0 & 0 & 0 & \\
\hline \multicolumn{26}{|c|}{ Optical Smoke reader measurements } \\
\hline 20 & 0.6 & 1 & 0.9 & 1 & $\overline{0.9}$ & 0.9 & 0.3 & 0.2 & 0.2 & 0.3 & 0.1 & 0.1 & 0.1 & 0.6 & 0.2 & 0.1 & 0 & 2.8 & 0 & 1.6 & 0.5 & 0 & 0 & 0 & 0.1 \\
\hline 21 & 0.7 & 1.1 & 1 & 1.1 & 1 & 1 & 0.3 & 0.3 & 0.3 & 0.3 & 0.2 & 0.1 & 0.2 & 0.7 & 0.2 & 0.2 & 0.1 & 3 & 0 & 1.8 & 0.5 & 0.1 & 0 & 0.1 & $\overline{0}$ \\
\hline
\end{tabular}

Note: Row Nos. 20 and 21 are readings recorded by repeating the optical smoke spot measurements on the set of twenty-five smoke spots. This exercise helped us estimate the accuracy of the optical smoke reader. 
Paper No. 99-12

\title{
Oilheat Technology Education Needs Analysis
} Where We Are Now, And Where We Should Be Headed

\author{
Robert Hedden
}

Oil Heat Management Services, Inc.

RR 1 Box 1810

Pawlet, VT 05761 
Oilheat

Associates

Consutring, Education, Research

OHMS, INC.

\section{Bob Hedden}

RR1 Box 1810

Pawlet, VT 05761

802-325-3509 fax 802-325-3437

\title{
Oilheat Technology Education Needs Analysis, Where We Are Now, And Where We Should Be Headed
}

\author{
By Bob Hedden \\ President \\ Oilheat Associates \\ Executive Director \\ Oilheat Manufacturers Association
}

Our Industry desperately needs to better educate our people yet we seem apathetic about doing it. The purpose of this paper and my presentation is to start a dialog about the problems with Oilheat Education today, and what we can do to solve them. I hope my talk will serve to set the stage for the panel discussion to follow and a spirited Workshop Session at the end of the conference. I want to thank the dozens of people I interviewed while researching this paper. I hope I accurately portray your ideas and concerns.

All the people I interviewed agreed that when it comes to our industry's education challenges we have more questions than answers.

- Why has support for our Industry Education Programs been so weak in the last few years? What are we doing wrong? The biggest problem is we cannot find the students. What must we do to inspire people to want to learn?

- How do we educate and certify technicians in remote areas, and parts of the country where independent contractors rather than oil companies service the equipment? Over 2 million oil burners in the United States are not being serviced by Oilheat Company employees. If they are being serviced at all, it is plumbers, and air conditioning contractors who are doing the job. How do we insure that they are doing it right?

- NORA is soon to become a reality. How can we best invest the portion of the NORA money devoted to education? Who will decide how to spend it? What should we spend it on? How much of the NORA budget should be for education? How much of the education budget should be for technical education?

- How can we better link R\&D and Education? It seems that our technological advances are outrunning our education. We have so much new information, new products, and improvements on old products, but it is not getting to the front lines.

- How can we best exploit the new information sharing technology to get our message out to the front lines?

- What Industry weaknesses should Education address?

- How can we better organize our Industry Education effort? 
- At least half of the Oilheat equipment in the field is outdated, and oversized. It is not as clean burning, efficient, economical, and reliable as it could be. Our customers are not experiencing state of the art Oilheat comfort. The results are conversions to other fuels, new homes not being built with Oilheat, and a poor reputation. Is this an Education problem? If it is, what can we do about it?

- We seem to be covering basic training pretty well. The problem is with advanced and refresher training. How can we improve the quality of and participation in advanced ¿ducation?

- We have plenty of talented Educators, and some not so talented. Do we need to certify educators and develop standards for continuing education credits? Do we need to develop a curriculum of suggested study for CEU courses?

- Who should pay for technical education? The students? Oilheat companies? The manufacturers? The associations? NORA?

\section{Why Bother?}

"The rate at which organizations learn may become the only sustainable source of competitive advantage." Ray Strata. Analog Devices

In order for us to succeed we must change the widely held negative perceptions about Oilheat! The first people we must educate are ourselves. We need- Technical, Operations, Customer Relations, Marketing, Sales, and Leadership Education. Next we must educate people who influence our success- Architects, Builders, Realtors, Home Inspectors, Legislators, and Regulators.

There is no place for rule of thumb and seat of the pants guesses with the new technology. There is no margin for error. Using instruments improves efficiency, assures low smoke and soot. lowers air pollution emissions. cuts call backs, improves our image, and increases customer satisfaction. You cannot see a \#6 smoke, a 7\% CO2, or 300 degree stack temperature! The only way to be sure burners are operating properly is with instruments, yet the vast majority of technicians do not bother to use them. This leaves us very vulnerable.

Education is the ultimate marketing tool. Tom Peters maintains that "an employee whose skills are constantly upgraded provides the finest lasting source of value added. The value added through education strategy is a secret weapon. Never ending learning is part of all winner's core philosophy."

You pay for training whether you do it or not. Education doesn't cost, it pays. Learning solely from on the job experience and trial and error is a very slow and very expensive process- not only in money but also in lost customer satisfaction. Practice does not make perfect. It only makes permanent. Only perfect practice makes perfect. Formal education drastically shortens the learning curve and improves morale as well as employee retention. Studies prove that employees who have had the benefit of a formal training program have a more positive attitude toward their job, and stay with their companies longer.

Training is a knowledge based technology for improving a valuable company resource- the human resource. Your people are the only company asset capable of appreciating. All other assets depreciate over time. Only your people can learn and thus become more valuable to your company. 
Training can be your invisible edge on the competition. Your competitors can copy your methods, your advertising, your marketing, and give-aways. They cannot readily recreate working copies of the people who make up a skilled and motivated work force. Well-educated people represent an edge that lasts.

Disney World trains the street sweepers for four days. The average turn-over on that job is three months. They do all this training because they know the employee most likely to be asked unstructured questions is the street sweeper. We must educate all our people because we all get opportunities to tell the story. Our newest, lowest paid. least educated employee has the power to drive away our best customer.

Education is a large part of the solution to the challenge to improve air quality. Last year OMA developed this list of things our industry should do to decrease oil burner emissions. There is wide agreement in the industry that number five was the key task.

1. Analyze the new regulations and develop technical response and documentation

2. Investigate and evaluate benefits of low sulfur fuel oil for residential use

3. Meet with state environmental agencies and distribute technical support documents

4. Investigate European experience with emission control of home oil burners

5. Plan expanded education, training and certification programs for oil service technicians

6. Support Brookhaven National Laboratory and start other Oilheat research projects

The most specific challenge when it comes to air quality and oil burners is nitrous oxide emissions. Here again OMA's to do list prominently features education components.

- Developing a study citing all Oilheat Advantages and Oilheat's negligible impact on environment to be used to educate state environmental agencies.

- Encourage R \& D of relatively low NOX white flame burners.

- Tighten up specifications for heating oil - better fuel stability and .2\% sulfur.

- Strengthen and expand our coalition

- Continue to work to make the transition from part changing soot suckers to Oilheat Technicians.

- Launch an all out effort to replace all non-flame retention burners left in the field.

\section{Education or Training?}

I would really prefer to use the word education rather than training. Stanley Marcus once said, "You train bears, you educate people. That is because people have to understand why they should do something." It is natural for us to ask why. You can be sure your front line people will be asked why. If they do not know why they will say things like:

"I don 't know, its company policy." "I don't know, I just work here." OR "we've always done it this way." If they do not know why they will be frustrated because they are being asked to defend a policy, procedure. or price that they do not understand. Frustrated people will not render excellent service. We must educate them. We must tell them why.

We use training to teach a new motor skill. Like how to make a flair joint, or how to join two wires together. The best way to do this is the military method- see one. do one, teach one, then practice, practice, practice. The trick is to be sure it is done correctly from the start.

The greater challenge is to try to increase performance, productivity, and quality. In these cases we are trying to change behavior, which is very difficult. One day an American business executive paid a visit to a well-known Zen Master to discuss Zen's relevance to 
management. Following Japanese etiquette, the master served tea. When the executive's cup was filled the master kept pouring, and the cup overflowed into the executive's lap. The executive jumped up startled and demanded to know why the master had poured tea all over him. The master said, "Like this cup, you are too full of your own thoughts. How can I teach you Zen unless you first empty your cup?" It is very difficult to empty our cups, to give up on our old ideas, even if we want something else poured in.

Charles Dickens teaches us a very important lesson in his story, The Christmas Carol. He understood that the only way to get people to change their behavior is to get them to question their existing performance. He had to scare Scrooge nearly to death before Scrooge would change his behavior.

Can education and training change behavior? It can impart new information about how to execute a skill that can make a student's performance more effective. It can show them a better way to do something. New information can sometimes change a student's basic assumptions. It can raise their level of awareness about a problem, which could lead a student to think about what they are doing. But training cannot effect a student as long as it remains external. Students must internalize it. they must empty their cups, and allow the new information in before it can lead them to do things differently.

\section{Part Changing Soot Suckers}

The key to profitability and success is inspiring and teaching our people how to make. and why they want to make, the transition from part changing soot sucker to Oilheat Technician. The challenge is that somehow a lot more of our people have to make this transition. I have to make a confession. I am an SOB. In fact I'm worse than that, I'm a GGSOB- a great grand son of boss. I am the fourth generation in my family to work in plumbing and heating. I have been pulling a paycheck from the Oilheat Industry every year since 1963 . I was 15 when I started working part time for the family oil business. I started by helping out in the office after school and working as a plumber's helper on school vacations.

When I received my drivers license I drove an oil truck during winter vacations and did tune ups in the summer as I worked my way through college. I was a soot sucker. I had a vague idea how burners worked and I knew enough to run the vacuum and replace the nozzle. strainer, and filter. I could usually get it to run when I was finished.

The next step in my evolution was to become a part changer. I started doing no heat calls. My approach was to begin changing parts until the burner ran. I was not our star mechanic but I was a warm body willing to take night calls, besides, I was related so they really couldn't fire me.

When I graduated from college I worked full time in plumbing and heating service. At this point I did something that changed my life. I decided to learn what I was doing. My Grandfather and a couple of other local oil dealers started an Oilheat training program at the local vo-tech school. They persuaded Harry Spect, one of the best local technicians, to teach the night course. I signed up. The class went three nights a week for 24 weeks. The basic course was based on the NOFI manual and the advanced course was something Harry put together from several sources.

Harry was a great teacher. He taught us the science behind the equipment. Up to that point I was just doing what I'd seen other people do, and was learning by trial and error. Harry showed me why the stuff I was doing worked. 
You should also volunteer to be a mentor. If you really want to learn something, teach it to someone else.

\section{Some of Our Education Short Comings}

The experts I interviewed identified the following short comings.

- The equipment out in the field is obsolete. oversized, and inefficient. It is not especially clean burning.

- Enrollment for the last few years in industry Association programs is off 40 to $50 \%$ from 5 years ago. The real concern is "if we build it will they come?" Is it worth going to all the trouble to create new programs, if no one will attend them? Most associations are not trying to make a great deal of money on education, "We just want to get our bait back."

- No one was sure why enrollment is off. Could it be the warm winters of late? What about industry consolidation? The number of companies sending people to seminars is also off by $50 \%$ from the early 90 's. Is it due to a repetition of programs? Have we been to the same well too often? Are people bored with the old seminar titles and the same teachers?

- One of the problems is one of perception. Most professional educators are constantly updating and improving our seminars, but it is an evolutionary process. Should we pursue a more revolutionary approach?

- Are we the victim of a self-fulfilling prophecy? We assume it was a warm winter so they cannot afford to come to seminars, so we won't design new programs. and we won't bother to promote the old ones we offer, therefore no one bothers to attend?

There seems to be a shortage of qualified Oilheat technicians as well as drivers. Is this because we are no longer willing to invest the time and money in creating technicians and drivers? Some of the people I interviewed feel the quality of the people we are attracting has declined. The new people seem to need more basic training than the rookies of the good old days. The new consolidators. and the multi-state multi-energy companies have figured out how to deal with the shortage. They just out pay us. Service Edge is paying technicians $\$ 21$ an hour in Boston. If we are offering apprentices starting wages lower than they can make at McDonalds it is going to be hard to attract good people. To change this we have to change the way we view our service departments and our technicians. as well as our commitment to educate them. We must learn how to make money in our service departments. We need to change our technicians into energy comfort experts, to multi-fuel, and muti- discipline (plumbing heating, cooling, and electrical) experts.

To prepare this paper I also interviewed people who answer the manufacturer's tech support hot lines. They tell me the quality of technician's knowledge of basic principles they should understand is sad. The technicians are very weak. It is more likely that the homeowner who calls has read and understood the manual than the technicians. "It seems the dealers are just not training their people." "We spend all our time doing basic training over the phone." "I'm not sure who to blame. Is it management for not training or inspiring them, or is it the younger people for having no curiosity or desire to learn? They do not seem to care." "The situation is getting worse, they seem afraid to read a book. They do not want to get their hands dirty. Computers have spoiled them, they are used to pushing a button and getting an answer." Technicians are not being taught how to analyze problems. We must tell them why things work the way they do, and teach them problem solving skills. We also have to teach them how to listen and talk to customers. The industry needs an attitude adjustment. Managers must wake up. They must make training available to their 
people. We have to hire people who are interested, and educate them. Every company should hold short weekly training meetings.

I also interviewed professional Oilheat educators. Of course, they feel the need for education is great. I sensed a growing frustration over the knowledge base of the students. Even supposedly advanced programs require a great deal of basic instruction to bring the class up to speed. They all agreed there is a real need for a change in mind set. It is a struggle to get students to realize the profound differences between the old equipment and the new equipment. The old tried and true practices of setting the electrodes by eve, the Marlboro draft gauge, the bouncing saliva temperature test, and the dash board efficiency test are over. New oil burners do not make soot, but technicians often do. The new burners could go two years between tune-ups if we took five more minutes to do the job right the first time.

We need to step up our game, and the change has to start at the management level, and the cost savings side. We have to realize we invest time and money to save time and money. We could drastically cut the number of service calls, and call backs by spending more time on tune-ups and service calls. We need a philosophical change. We educators have been trying to do it at the grass roots level and it is not working. Many times we are frustrated because the wrong people are in the class room. Some of the problems we encounter are not really the fault of the front lines. They are management issues. The interest seems to be there. Technicians will accept new ideas and techniques if we tell them why, and show them how.

I am very concerned with what happened during the winter of '97-'98. It was an unusually warm year. Things were pretty quiet in most service departments. You would think this would have been a great year to really push equipment sales. and electric to oil conversions. Apparently it was not. Equipment sales for the year were down, not up. It appears to me that we can only sell new equipment when the old stuff breaks. We are not able to persuade customers to let us replace the dinosaurs that are still running.

There are at least 3 million non-flame retention burners still out in the field. There are probably another 3 million first generation retention burners still operating that are over 20 years old. This means we have over 6 million burners in the field over 20 years old. about $50 \%$ of the installed base. If an oil burner was a car. how far would it travel in a year? Let us say the average burner burns about 800 gallons a year at 1 gallon an hour. That means it runs 800 hours a year. The average car trip is driven at about 40 miles an hour. Therefore if the oil burner were a car it would travel 32,000 miles a year ( 800 hours x 40 miles per hour.) Multiply 32.000 miles a year by 20 years equals 640,000 miles. What would a 20 year old dodge dart with over 600,000 miles on the odometer look like? Would you hop in that car and drive back and forth from New York to L.A. five and one half times this winter without giving it a second thought? Your customers will. Is it any wonder the amount of emergency service required to keep burners running is increasing?

\section{How Do We Start?}

Sometimes teachers can inspire students to empty their cups and question their current performance by supplying new facts that shock or surprise, or are especially compelling. Sometimes a unique and memorable presentation, demonstration, or story can do the job. But all professional educators agree, our job is much easier if the students come to the seminar ready and eager to learn. 
One of the most exciting aspects of NORA and the compelling national Oilheat promotion it is planning to do is that it will raise young people's perception of the quality of Oilheat. This should make recruiting new people easier. In the mean time I suggest that we must work at recruiting harder than we are now. When was the last time you made a presentation at your local high school, vo-tech school, or county college about the wonders of a career in Oilheat? We cannot sit back waiting for people to come to us. We have to go out and get them. It is also time we stopped restricting our recruiting to only $49 \%$ of the population. Where is it written that women cannot fix oil burners or drive oil trucks? I have had great success recruiting, and teaching women to do these jobs, and they do them very well. By the way, customers- over half of whom are women, love to see women technicians and drivers!

In order to improve education and attitude we must understand the difference between ability and motivation. Can they do the work versus will they do the work? If they both can and will do the task, then the questions become: do they have the proper education to do the task, and do they have the proper information, time, tools and equipment to do the task properly? These are the six factors involved of success: ability, motivation, education, information, time, and tools. If there is a problem is it an education problem, or is it one of the other five?

One of our big problems is learning how we reach out to people working on burners who are not Oilheat company employees. One way to reach these people is through the national, state and local Plumbing, Heating, and Cooling Contractors associations, and the Air Conditioning Contractors of America. We need to establish relationships with these associations and invite them to work with us to improve the quality of oil burner service.

Our customers must come to see our technicians as energy experts. This requires that service technicians take on some new duties.

Inform Customers of new technology advances- Customers trust technicians. They know technicians will tell them the truth. therefore they are positioned to supply valuable advice to customers on how to get the most for their energy dollar.

Installs \& Adjusts Equipment for peak efficiency-By doing so technicians make Oilheat the safest, most reliable. efficient. cleanest. most environmentally friendly, and most comfortable heat available.

Services the equipment-we take responsibility for the operation of our customer's equipment.

Keeps track of new technology-we are perpetual students staying on the cutting edge of new technology.

Measures Combustion efficiency.

We must educate our people to perform these tasks competently.

One way to keep our people is to pay them better and differently. Pay for performance, and equity sharing are ideas we should explore. To do so we must make money in service. Part changing soot suckers must change to technicians. We have to get rid of the dinosaurs- the non-flame retention burners. We must work to improve fuel quality. We must replace tanks before they leak, convert to one pipe systems when possible, and reengineer our systems

A well-educated technician is the person best positioned to start the equipment sale process. We must teach them why they want to sell customers new equipment, motivate them to make the effort, and teach them how to start the sale. The key is we must stop peddling steel or cast iron and start selling warm fuzzies! We must promote comfort, unlimited hot water, security of supply, reliable operation, warmth, health, safety, and 
peace of mind. We must teach the technicians that customers do not live in the furnace or boiler room. They live upstairs. We must look upstairs for everything we can do to improve comfort, health, and safety. We must talk about things like high tech air cleaning, humidification, adequate return air, zoning, the advantages of isolated combustion, fast recovery water heaters, and air conditioning.

We must reevaluate one of the most over used education tools in our industry, onthe-job Training. The danger with most on-the-job training is that it is inaccurate. It is the adult version of the kid's telephone game. One kid whispers a sentence to another. They then repeat it as accurately as possible to the next kid- and so on down the line of living breathing receiver/transmitters. The fun is hearing the last kid tell the group what they heard. With on-the-job training as each person trains the next they introduce their own prejudices and preferences for how to do the task rather than returning to the refined standard. Performance drifts further from either doing the right thing or doing things right.

We must develop a learning relationship with our customers. Each customer contact is a chance to learn more about the customer and their heating system. This only works if we remember what we learn and communicate it to the people who need the information, when they need it. We must also stop tunnel vision. We have to teach our technicians to look for trouble. They must see the immediate problem only as a symptom. They must learn to ask: What is the cause? What else could go wrong? What will not last the year?

How do we inspire students to empty the cup? Some of the important components are job security, satisfaction, challenge, money, and advancement. Tell them why! Then explain. demonstrate, and encourage them to practice. Allow students to share ideas. No one is as smart as everyone. Use group problem solving exercises.

We all must be perpetual students and innovators- always looking for better ways to keep our customers safe, warm, and happy. To do so we must learn how to learn. To survive in the brave new world we need to constantly be learning. We must place a strong emphasis upon communications, collaboration, and creativity. How to learn must be part of what we learn. Some of the learning tools we have at our disposal are as follows.

- Short Weekly Meetings with our team are the most powerful and effective training vehicles.

- On-The-Job Mentoring can work if it is carefully monitored.

- Managers should learn to use interesting service calls as teaching opportunities.

- We should send supervisors with technicians on call backs and use them as a teaching opportunity.

- We should support Manufacturers' and Associations' Seminars.

- Videos can augment education.

- We are fortunate to have three fine Trade Publications. Distribute them to all your people.

- The PMAA Technician Certification Program is just starting to come into its own. It will a be a great education vehicle in the future.

- Out industry Conventions and Conferences can be good education vehicles and should be more widely supported.

Some of the new technologies being developed will enable us to achieve Distance learning through satellites, Intranet education programs, dispersed training for teams and work groups, and just-in-time desk top support tools like interactive CD-ROM's. 
The following are some principles of effective training:

- Make the training pragmatic. Be sure it has a direct relationship to the job.

- The more, and sooner people have a chance to use what they learn the better their understanding.

- Students must have a strong incentive to want to bother to learn.

- Students must be given a sense of accomplishment that stimulates retention and the desire to learn more.

- It is easier to learn something new if it is built on something already known.

- Use stories and examples to make your points and people will remember them better.

- Learning takes place by doing. Before learning can be complete a person must have the opportunity to put into practice the skills and knowledge that have been accumulated.

- Constantly encourage free expression and participation from students. Actively solicit questions and comments.

- Ask students questions to fix it in their minds. Sometimes their fellow student's answers will make a greater impression on them than your explanations.

- Adults have short attention spans that shift constantly. The average person thinks at a rate of 800 words per minute. The average person speaks at between 125 and 150 . As a result our minds tend to wander. The average sustained attention span is 8 minutes, therefore every eight minutes shift activities, move to the other side of the room, or stop and ask for questions or comments. If you are talking for more than 20 minutes introduce a content change at least every 20 minutes.

PMAA Technician Certification Update: This is part of the education solution. We will need NORA money to help fund and promote the program. The Silver Certification is doing pretty well. The shame is that the Gold program is not catching on. This is the program that can ensure our future. It emphasisizes helping customers maximize economy of operation, comfort while minimizing environmental impact, and improving reliability. It also seems that the Continuing Education Program is really not working at all yet. We are rewriting the silver book. It is now time to rewrite the gold book and extend the scope from just conservation to also include improved reliability, performance, and comfort.

One of the most exciting new education ideas we have invented is the "Seminar Kits" for do-it-yourself training. We first thought of this for the PMAA Oil Tank Coalition. The Oil Tank Seminar Kit is a loose leaf notebook that contains the overhead transparencies, speaker's notes, handouts for the students, and a short true/false test. The idea was so well received that Bob Boltz and Dave Nelsen asked me to create one titled "What Every Oilheat Technician Should Know About Carbon Monoxide" for NAOHSM and OMA. I am just finishing the third Kit for OMA and PMAA titled "The Benefits of Oilheat." These programs are all designed for Oilheat managers and instructors to use in short highly focused seminars. It is a great way for us to get education to the front lines in a quick and cost effective way.

Many of my interview subjects raised the concern about duplication of industry education efforts, as well as huge gaps in our offerings. How should PMAA, Brookhaven, NEFI, NAOHSM, OMA, our professional educators, the state, and local associations work together to improve the quality of education and direct R\&D to areas we need? Is it time for us to form an Oilheat Education Coalition? The thing that struck me during all the interviews for this talk was that we sound like Rudyard Kipling's blind men describing an elephant. Each of us has a unique take on Oilheat Education depending on our experience 
and position. The coalition could begin to build a consensus between all our varying perceptions and ideas about challenges and solutions. It could serve as a clearing house for education materials. It could coordinate our education efforts. It could raise funds for education. It could make grants for specific projects such as setting up regional training centers, writing books, doing research, developing new courses, and compiling the best and brightest of our existing programs. Let us explore how we can best create and organize this coalition. 